UNIVERSIDADE DE SÃO PAULO

FACULDADE DE ECONOMIA, ADMINISTRAÇÃO E CONTABILIDADE DEPARTAMENTO DE ECONOMIA

PROGRAMA DE DOUTORADO EM ECONOMIA DO DESENVOLVIMENTO

The Conceptual Evolution of Inflation Inertia in Brazil

A Evolução do Conceito de Inércia Inflacionária no Brasil

André Roncaglia de Carvalho Orientador: Prof. Dr. Pedro Garcia Duarte 
Prof. Dr. Marco Antonio Zago

Reitor da Universidade de São Paulo

Prof. Dr. Adalberto Américo Fischmann

Diretor da Faculdade de Economia, Administração e Contabilidade

Prof. Dr. Hélio Nogueira da Cruz Chefe do Departamento de Economia

Prof. Dr. Márcio Issao Nakane

Coordenador do Programa de Pós-Graduação em Economia 


\title{
The Conceptual Evolution of Inflation Inertia in Brazil
}

\author{
A Evolução do Conceito de Inércia Inflacionária no Brasil
}

Tese apresentada ao Programa de Pós-Graduação do Departamento de Economia da Faculdade de Economia, Administração e Contabilidade da Universidade de São Paulo, como requisito parcial para obtenção do título de Doutor em Ciências.

Orientador: Prof. Dr. Pedro Garcia Duarte

Versão Corrigida

SÃO PAULO

2015 
FICHA CATALOGRÁFICA

Elaborada pela Seção de Processamento Técnico do SBD/FEA/USP

Carvalho, André Roncaglia de.

The conceptual evolution of inflation inertia in Brazil /

André Roncaglia de Carvalho. -- São Paulo, 2015.

$239 \mathrm{p}$.

Tese (Doutorado) - Universidade de São Paulo, 2015.

Orientador: Pedro Garcia Duarte.

1. Inflação - Brasil. 2. Conflito social - Brasil. 3. Inflação inercial História -1980 - Brasil. 4. Estruturalismo. 5. Estabilização econômica. I. Universidade de São Paulo. Faculdade de Economia, Administração 
To my family, in honor of Alzira Rosa Roncaglia (in memoriam) and Joana Cajuela de Carvalho (in memoriam) 


\section{ACKNOWLEDGEMENTS}

Academic work is hardly a one-person job. Many contributions come in many forms and stem from a variety of sources. Therefore, I would like to thank my advisor Professor Pedro Garcia Duarte for his support, dedication, patience, friendship, and understanding during the writing of this thesis. It was an honor to have benefitted from his extensive knowledge and wisdom.

I am especially grateful to Professor Gilberto Tadeu Lima, whose seemingly unbounded knowledge and wisdom are coupled with a generous heart and an unbending sense of duty. His promptness in helping out whenever needed was only always matched by his patience in listening and discussing (repeatedly) the doubts and dilemmas I faced during the development of this work - truth be told, time and again, I barged in his office unannounced, just to say hello, and ended up leaving some 50 minutes later; not once did I get slightly frowned upon for disturbing his work; quite the contrary.

To Professor Renato Colistete, who constituted, along with Prof. Lima, the prospectus defence committee, I am grateful for the challenging critiques and helpful suggestions, which made a great difference in the preparation of this thesis. Prof. Colistete has an uncommon combination of a keen eye for the detail without missing the whole picture.

To Professor Jorge Soromenho I give my heartfelt gratitude for all the attention devoted to me during my studies and for his generous intellectual embrace whenever doubt befell me. As a post scriptum, I am wholeheartedly grateful to the external members of the thesis defence committee, Professors Maurício Coutinho (UNICAMP) and Marco Cavalieri (UFPR) for their attentive reading and helpful thought-provoking comments on this work.

To Professors Peter Skott and Mark Setterfield for their incredible encouragement and advice during my stay in the amazingly pleasant University of Massachusetts Amherst. To Professors Lance Taylor, Edmar Bacha and Luiz Roberto Cunha for sharing their recollections of those troubled 1980s. Maria Clara do Prado was also kind enough to provide me a great historical overview of the politics behind the Real plan, from an "insider's" perspective. I am truly grateful as well to Professors Kenneth Arrow, Maria Cristina Marcuzzo, Carlos Mallorquín and Anthony Thirwall for their prompt replies to my inquiries about Nicholas Kaldor and his early days as an economist at Cambridge. 
To my recently acquired foreign brothers, Wouter Schmit Jongbloed and Mark Kirstein for allowing me to benefit from their charisma, unending wits and overwhelming culture and, above all, their remote help through long discussions on the matter of this thesis and many others and for carefully reading pieces of this work. To Tomas Rotta, for his friendship and support during my stay in the US. To all of you I devote my undying gratitude.

To all administrative staff at the economics department at USP, and especially to Alda, Pinho and Leka, for their attention and unswerving professionalism. To Ismael, for being such a good friend throughout the last moments of this process. A special and wholehearted thanks goes out to the amazing Library staff that has always welcomed me in a most caring and helpful way, led by the gracious Margarida. Without you, none of this thesis would have come to life.

To USP and FEA for their fundamental role in my academic and personal growth. To my friends at FEA: Joelson Sampaio, André Mountian, Eliane Teixeira Guilherme Oliveira, Paula Pereda, Moisés Vassalo, Toni Ricardo, Juliana Scriptore, Lucas Chagas, Juliana Inhasz, Pedro Funari e Mauricio Matsumoto for their friendship and direct help on this work, in the form of suggestions and critiques. To my friends at FECAP: Pedro Barros, Daniel Oliveira, Jésus Lisboa, Allexandro Mori, José Carlos Domingos Silva and Nelson Cantarino, for their friendship and support which contributed, directly or indirectly, to this work.

To my family - my parents Antonio Caetano and Eliseth, my brother Eduardo, and my nephews Renan and Bernardo for putting up with all of my absences and always having a warm smile awaiting my belated arrivals to our gatherings. To my parents-in-law and in spirit, Carlos and Rosa, whose unwavering support breeds tears in my eyes whenever I think of them.

To close these acknowledgements I send my heart out to my keenest person. I bow in gratitude to my loving wife Fernanda, for her partnership, her affection in the most turbulent moments, her endless dedication and support and, above all, her patience and respect throughout this long process. Few have been so blessed as I have! 


\begin{abstract}
This work aims to contribute to the wider body of research in history of economics in Brazil by focusing on the conceptual evolution of inflation inertia. Its motivation lies in the conceptual gap that appeared, following disinflation in 1994, between the stabilization debates carried out in the 1980s and the way economists in Brazil began to describe downwardly rigid inflation patterns from the 1990s onwards. More precisely, we explore the "inertial inflation episode" as a chapter in a longer tradition of adaptations, to country-specific realities, of theoretical influences coming from the economics profession at the international level, in the late 1970s, when the inertial inflation hypothesis was brought to the fore. Our narrative reveals that this stubborn inflationary phenomenon had been previously dealt with in the debates in Latin America about growth and inflation back in the 1950s and 1960s, where a host of contributions sprung from various traditions, which were gradually synthesized by the saw-tooth model of real wages, also known as Simonsen-Pazos mechanism. We analyze the recurrent opposition between a monetarist- and a heterodox structuralist-type of thinking in their two rounds, in the 1950s and again in the 1980s. The connection between these two opposing schools is operated by the contributions by Mario Henrique Simonsen and the selfdeclared neo-structuralist economists at PUC-Rio. Based on a careful and detailed analysis of the latter's modeling strategies and conclusions, we show that, along the 1980s, these economists gradually shift towards a more ecumenical approach, inviting monetarist elements into their analyses while downplaying the relevance of the inertial component. Finally, when the 1990 s came, the rise of a macroeconomic consensus began to conceptualize "inflation inertia" as the time delay between a real or monetary shock and the response by price level changes, leaving the concept of "inflation persistence" to account for the deviations of inflation away from its equilibrium value, a view that undergirds how most Brazilian economists now understand this phenomenon. We assess how "inflation inertia" has been understood in the aftermath of the monetary reform in Brazil in 1994, by analyzing the backstage papers that circulated within the economic team in charge of the Real Plan. We conclude that there are elements of continuity between the two rounds as regards the concept of inertia, but that they are now stripped of their previous dense historical and institutional substance.
\end{abstract}




\section{RESUMO}

O presente trabalho busca contribuir para a literatura de história do pensamento econômico brasileiro, ao estudar a transformação do conceito de inércia inflacionária no Brasil desde os debates sobre estabilização na década de 1980 até o período pós-Real, mudança essa que permanece inexplicada pela literatura. Mais precisamente, o trabalho busca verificar a hipótese de que a inflação inercial não passou de um episódio de uma longa tradição de adaptações teóricas de influências oriundas de economistas estrangeiros, em especial na década de 1970, quando a hipótese de uma inflação inercial foi levantada. Nossa narrativa revela que o fenômeno da rigidez inflacionária já havia sido previamente compreendido e teorizado nos debates na América Latina, nas décadas de 1950 e 1960, quando inúmeras contribuições foram eventualmente sintentizadas no modelo de rendas contratuais sob inflação no formato de "dente-de-serra", ou o assim chamado mecanismo Simonsen-Pazos. A narrativa adota a controvérsia entre monetaristas e estruturalistas em seus dois momentos como eixo da análise, para mostrar como o desaparecimento dessa oposição coincide com a emergência do consenso macroeconômico em escala internacional. Baseando-se em uma análise cuidadosa e detalhada das contribuições dos economistas neo-estruturalistas da PUCRio e da onipresente influência de Simonsen como um sintetizador das contenciosas escolas, o trabalho apresenta evidências documentais de uma transformação estruturalista da segunda geração. Ao longo dos anos 1980, esses economistas gradualmente convergiram para uma abordagem mais ecumênica com relação aos monetaristas, reduzindo a importância do componente inercial da inflação e ampliando a relevância de aspectos usualmente associados à ortodoxia econômica. Finalmente, no período pós-Real, passa a predominar no país um conceito de inércia inflacionária que constrasta com a visão anterior dos economistas atuando no referido plano de estabilização. Esse novo conceito está associado à emergência da "nova síntese neoclássica", na qual a inércia é compreendida como o atraso na resposta dos níveis de preço a choques monetários ou reais, enquanto o conceito de persistência inflacionária representa desvios duradouros da inflação com relação ao seu nível de equilíbrio. Para compreender se essa mudança pode ser considerada uma ruptura com relação ao passado, analisam-se os artigos que circularam nos bastidores do Plano Real dentro da equipe econômica. Nosso trabalho conclui que há elementos de continuidade entre os dois momentos no que se refere ao conceito de inércia, os quais aparecem agora com uma representação analítica desprovida da substância histórica e institucional que o conceito outrora abarcava. 


\section{Table of Contents}

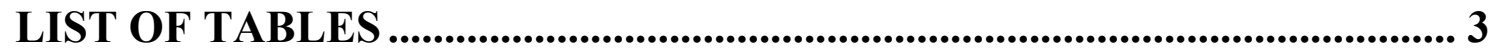

LIST OF FIGURES ...................................................................................... 5

Introduction ....................................................................................................... 7

Chapter 1 - Creeping inflation and indexation: historical aspects of inflation inertia ................................................................................................ 15

1.2 The changing perception about the significance of inflation.............................15

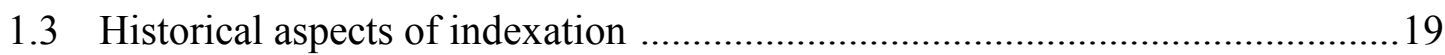

1.4 The meanings of "inflation inertia" in economics ...........................................25

1.5 Inflation Inertia in Brazil: where do we stand?............................................... 34

Chapter 2 - Anticipations of the inertial inflation concept............................. 39

2.1 Income distribution models of inflation in the Post-war period ..........................39

2.2 The Latin American Structuralism: Structural Rigidity and Inflation.................43

2.3 The First Round of the Monetarist-Structuralist Controversy …........................46

2.3.1 Nicholas Kaldor's interpretation of the Chilean inflation ......................................49

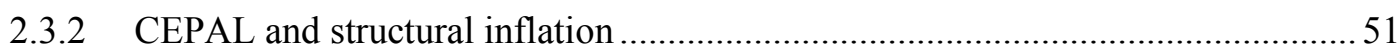

2.3.3 Furtado's view of inflation: institutional and technological inertia....................... 54

2.4 The Furtado-Kaldor-Pazos Mechanism ..............................................................57

2.4.1 The discursive representation of the saw-tooth pattern of real wages ...................59

2.4.2 The origins of the general mechanics of the saw-tooth diagram ............................65

Chapter 3 - The rise of mechanical models of inflation ............................... 73

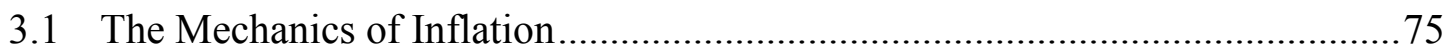

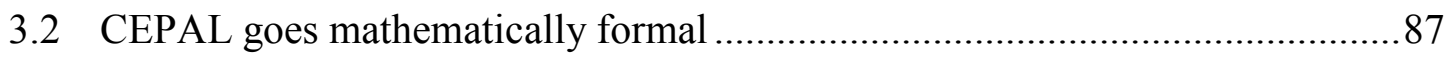

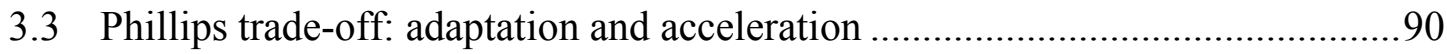

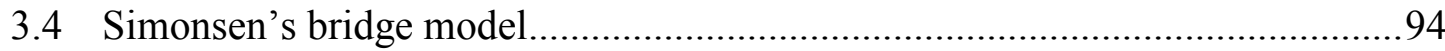

3.4.1 Georgescu-Roegen and the "structural inflation lock" .......................................... 99

Chapter 4 - The Monetarist-Keynesian controversy ................................ 103

4.1 The North American Influence .................................................................... 105

4.1.1 Development economics: structural change, growth and distribution.................. 105

4.1.2 Sticky prices, staggered contracts and indexation ............................................. 108

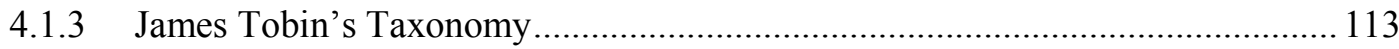

4.2 The mathematical development of the saw-tooth model of real wages............117

4.2.1 Formalization gone full-throttle: PUC-Rio.................................................... 118 
Chapter 5 - The Inertial Inflation Paradigm ........................................................ 127

5.1 The Second Round of the Monetarist-Structuralist Controversy.......................130

5.2 The first moments of Neo-Structuralist inflation models in Brazil ...................133

5.2.1 Reinventing tradition: the neo-structuralist school at PUC-Rio ............................ 134

5.2.1 The "Theory of Consistent Indexation"............................................................ 138

5.2.2 Inflation as a Social Impasse: André Lara Resende's inconsistency gap ............. 142

5.2.3 Conflict and Wage Indexation Regimes: Persio Arida's synthetic model............ 144

5.3 The eclipse of conflict-driven models of inertial inflation .................................149

5.3.1 Wage Setting and Mark-up Behaviors: a basic framework ................................. 150

5.3.2 The binding neutrality condition ..................................................................... 156

Chapter 6 - The dilution of the inertial inflation paradigm ........................... 159

6.1 The ecumenical turn: inertial inflation as a special case ...................................160

6.1.1 Edmar Bacha and the growing of the fiscal dimension ...................................... 162

6.1.2 André Lara Resende and the taxonomy of inflation............................................ 165

6.1.3 Gustavo Franco's microfoundations to inertial inflation and thereafter............... 167

6.1.1 The transition from inertial inflation to hyperinflation........................................ 171

6.1.4 Persio Arida's eclectic statement of the inertial inflation paradigm......................175

6.2 Simonsen's final synthesis: bridging silos....................................................... 180

6.3 The structuralist transformation cycle: external constraints, gradualism, fiscal

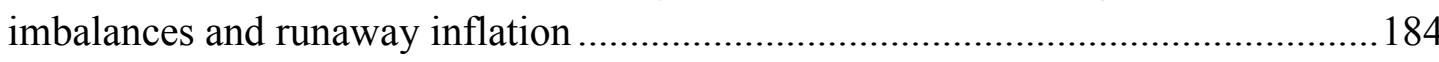

Chapter 7 - Inflation inertia in post-Real Plan Brazil: a synthesis ............. 189

7.1 The immediate post-Real Plan and the persistence of indexation: analysis of the economic team's backstage papers ........................................................................ 190

7.2 Inflation Inertia and Inflation Targeting in post-disinflation Brazil ..................198

Concluding Remarks ..................................................................................................... 203

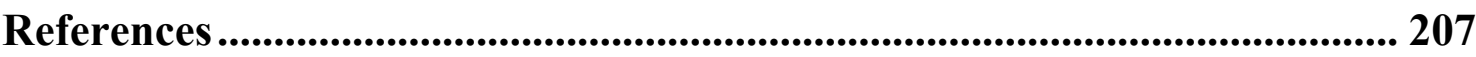




\section{LIST OF TABLES}

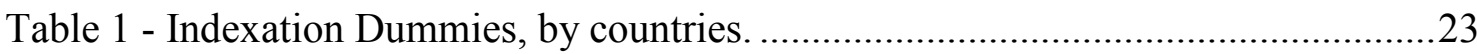

Table 2 - Inflation Targeting Regime Performance - 1999-2013. ................................37

Table 3 - List of backstage papers written by the economists in Real Plan. ................ 192 


\section{LIST OF FIGURES}

Figure 1 - Summary of Countries' Experience with Indexation until 1974_..................21

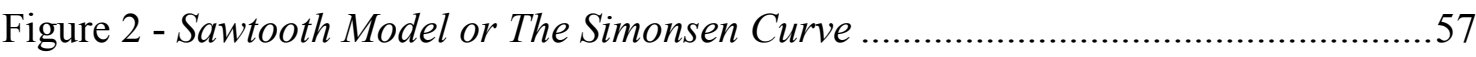

Figure 3 - Kaldor's Real Wage “Zig-Zag” diagram......................................................59

Figure 4 - Real Minimum Wage for Brazil: July 1950 - December 1960......................62

Figure 5 - Sawtooth pattern of real wages in Chile between April 1962-March1963. ...64

Figure 6 - Non-optimal and Optimal inventory policy ..............................................6 66

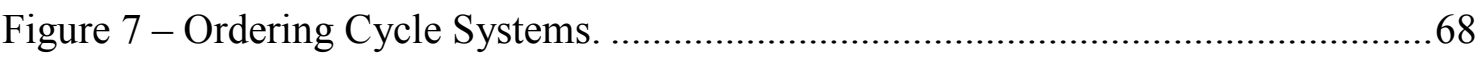

Figure 8 - Bent Hansen's Dynamic Chart of Macroeconomic Impacts on Wages..........84

Figure 9 - Thomas Humphrey's Inflationary Transmission Mechanism.......................91

Figure 10 - Sawtooth-shape of the Real Minimum Wages.........................................95

Figure 11- The saw-tooth diagrams and regressive income distribution. ..................... 100

Figure 12 - The saw-tooth diagrams of real wages ................................................. 100

Figure 13- The saw-tooth diagrams and income distribution in a growing economy...101

Figure 14 - The saw-tooth diagrams of real wages through time.................................119

Figure 15 - The saw-tooth diagram of real wages: illustrative purposes ...................... 120

Figure 16 - The saw-tooth diagram of real wages: lack of synchronism ......................121

Figure 17 - The saw-tooth diagram of real wages: systems of wage indexations......... 121

Figure 18 - Real Minimum Wage : Jan 1950 - Dec 2012 ........................................... 124

Figure 19 - Real minimum wage and inflation in BraziL ......................................... 125 


\section{Introduction}

In August 1994, a monetary reform was enacted in Brazil, as part of the Real plan, a stabilization attempt that achieved a sharp disinflation. From 1980 up to that year, Brazil had four different currencies, five price and wage freezes, nine stabilization plans, eleven price indexes to measure inflation, sixteen different wage policies, twenty-one proposals for external debt payment and fifty-four changes in price policy. Accumulated inflation in the fifteen-year period hit an impressive figure of 30.000.000.000 \% (see Franco 2005). In contrast, in the two decades since disinflation until the end 2014, Brazil has endured around $375 \%$ accumulated inflation, as read by the Headline Consumer Price Index (IPCAIBGE), a proximate yearly average of $8 \%$. Although this average seems high for developed countries' standard (1-2\% per year on average for OECD countries, for the same period, according to the World Bank Database), it pales in comparison with Brazilian inflation rates preceding disinflation.

The existence of inflationary persistence in Brazil is a reality up to this day and it is not a new phenomenon. Economy-wide inflationary upsurges date far back to the first years of the country's republican history, which started in 1889. But it wasn't until the postwar period that it became a national concern of the first order, when prices escalated amid a rapid process of structural transformations in the economy and its institutions. From the 1950 s until the late 1970 s, a State-fostered industrialization process was set in motion, and was accompanied by persistently high inflation, recurring balance of payments imbalances, secular structural public deficits and trending concentration of wealth, among other issues (see Furtado [1962] 1965). Any advances achieved in per capita income were not matched, however, by any enduring success in price stability at the macroeconomic level. The resistance of inflation to conventional measures of "financial policies" raised yet more stringent concerns about the potentially negative effects of such policies upon rates of economic growth and, as consequence, upon economic development (see Kalecki 1954b and Baer \& Kerstenetzky 1964).

In the mid-1960s, policymakers faced daunting obstacles - political and social - in breaking the inflationary thrust that led to stubbornly persistent price rises. Gradualism appeared as though it could dilute the costs of disinflation along a lengthier time path into the future. As a response, the economic institutions had to adapt to society's seemingly uncorrectable inflationary proclivities. Debt contracts, public utilities prices and wages 
became liable to automatic escalation with respect to some composite price or cost of living index (see Simonsen 1964). As a result, inflation would feed back on itself through various channels within the price structure, enhancing the burden born out by those unprotected by indexation. The ensuing persistence of rising prices thus prompted not only the dissemination of inflation-correcting automatic adjustment clauses to wide variety of contracts (formal indexation), but also the gradual spillover of this practice to the behavior of economic agents (informal indexation). Hence it became a phenomenon deeply embedded in the country's institutional fabric, as well as its social and political mindset.

In the 1980s, following the debt crisis in Latin America, inflation patterns escalated in alternated hikes mediated by short periods of stable inflation. The basal level of inflation became highly sensitive to abrupt changes in relative prices - e.g. a sharp devaluation of the exchange rate. Inflation rates drifted upwards in stepwise fashion, as the price system fully embodied in its memory any adverse shock picked up along the way. In specialized circles, such a phenomenon was contemporarily termed "inertial inflation", that is, Brazilian inflation could be largely explained by its past values. Its difference with respect to other inflationary experiences was believed to rest on the country's complex system of indexation. Despite heated controversy, many Brazilian policymakers and academic economists gradually yielded to the assumption that inflation had pronounced inertial properties, once it was noted that the government's budget was balanced and the external accounts endured no abrasive hardships (see Serrano 1986). Not only had inflation become persistent; it had inoculated inflationary trends into agents' expectations: it had risen to a social norm (see Bresser Pereira \& Nakano 1984).

Under conditions of close-to-full inertia, econometric exercises at the time argued that conventional demand-related policy instruments left inflation unscathed, at the cost of economic recession and of enticing social unrest (see Serrano 2010). Thus, according to this view, doing away with inflation required dismantling the backward- and forwardlooking index-linking behavior of economic agents. This rather unorthodox bite was not new; it echoed the stabilization debates of the 1950s - in which anti-inflation measures threatened to curb economic growth - stabilization was seen to require alternative therapies to the conventional "orthodox" measures of monetary stringency and fiscal austerity. 
The shock-propagating properties of index-linking practices became subject to great controversy from the mid-1970s ${ }^{1}$ onwards, particularly when the shocks stemmed from unanticipated government anti-inflationary policies with adverse distributional effects. Between 1986 and 1994, Brazilian policymakers launched a stream of stabilization attempts that hinged on the premise that the self-generating inflation was due to the existence of formal and informal indexation. Specificities aside, each and every plan was singularly crafted to deal with this specific mechanism which was understood to render inflation downwardly rigid.

It was not until August 1994, when the Real Plan was enacted, that Brazil finally achieved a successful and sustained disinflation. But the plan officially allowed for the indexation of contracts in specific markets, such as in public and private bond markets and for State-controlled prices of privatized public utilities companies, amongst others (see Carvalho 2014). It seemed to overlook the previously noted historical precedent that, in the face of a non-zero inflation rate, inflation-unprotected income-receivers are likely to adopt some type of indexation. And, should indexation spread out, it would most likely restore automatically adjusting behavior to past inflation, which would enhance the inertial component of inflation, especially under systematic recurrence of pressures arising from relative price dynamics. ${ }^{2}$

All the above notwithstanding, economic debates following the Real plan downplayed the relevance of the preexisting institutional conditions to "inertial inflation", i.e. indexing practices (see Bacha 1998a \& 2003). Keeping inflation rates below some arbitrary threshold level should prevent it from building in to agent's expectations and contracts. By breaking the inflationary memory, distributive conflicts were to migrate from uncoordinated price- and wage-setting behavior to the political realm of negotiations upon the use of government revenues. Within the confines of fiscal policy, competing claims of various economic groups could be made compatible with each other and consistent with macroeconomic stability, as envisaged by Franco (1995). However, from our standpoint in early 2015, such prospects have been betrayed by post-disinflation developments, for indexation has disseminated widely across the Brazilian macroeconomic price structure. To

\footnotetext{
${ }^{1}$ See, for instance, Friedman (1974), Giersch (1974), Page \& Trollope (1974), Gray (1976), Fischer (1977) and Tobin (1980a) - as well as references therein - for the discussions at the international level. Simonsen (1970b), Kafka (1974) and Fishlow (1974) are good references for the Brazilian case.

${ }^{2}$ Nonetheless, previous indexing practices persisted and are prominent in Government-regulated and services sectors in general.
} 
mention a few examples, Government-managed, regulated or supervised prices have to this day explicit indexing clauses in contracts with public utilities private companies, accounting for around $28 \%$ of Headline Consumer Price Index (IPCA-IBGE), reflecting their importance in daily expenditures of households in the income bracket from one to forty minimum wages. Moreover, in 2010, the minimum wage was set by the Congress and has recently been tied past inflation and two-year-lagged GDP growth, while prices of services clearly follow some type backward-looking behavior (see Braga 2011, p. 18-21). So, if the above reasoning is correct, the survival of index-linking practices within Brazilian institutional frame is likely to expand the inflationary memory built into the price system, thereby turning the latter more susceptible to real supply shocks that shake relative prices off their balance.

In what follows, we intend to show not only that this stubborn inflationary phenomenon had been previously characterized as having "inertial properties", in the debates in Latin America about growth and inflation and the discussions in the developed countries concerning the full-employment/inflation dilemma, both going back to the $1950 \mathrm{~s}$ and 1960s. We then tackle the question of how "inflation inertia" has been understood in the aftermath of the monetary reform in Brazil in 1994. Following disinflation, a conceptual gap settles in between the stabilization debates carried out in the 1980s and the way economists in Brazil began to describe downwardly rigid inflation patterns from the 1990s onwards. The former dispute was polarized between a monetarist and a heterodox structuralist-type of thinking. This latter approach focused distributional conflict dynamics that hinged on historically-oriented institutional underpinnings to explain why inflation rates tended to incorporate the effects of real shocks into their trend component. The 1990s witnessed, in their turn, the rise of a macroeconomic consensus that conceptualized "inflation inertia" as the time delay between a real or monetary shock and the response by price level changes, leaving the concept of "inflation persistence" to account for the deviations of inflation away from its equilibrium value.

This work thus aims to contribute to the wider body of research in the intellectual history of the economics discipline in Brazil. More precisely, we purport to analyze whether or not the "inertial inflation episode" was a chapter in a longer tradition of adaptations, to country-specific realities, of theoretical influences coming from the economics profession at the international level, in the late 1970s, when the inertial inflation hypothesis was brought to the fore. According to such a view, the 
internationalization of the discipline seems to have had a one-way effect on Brazilian economic thought. Hence, once the Brazilian institutional specificity - i.e. widespread indexation - was thoroughly removed, there would be no hurdles in abiding by an interpretation of inflation inertia, such as the one found the mainstream of the profession at the international level in late1990s.

Following this introduction to the problem, chapter one presents a brief overview of the postwar "eclipse of the goal of zero inflation". According to Leeson (1997), following the end of the World War II, the economics profession underwent a gradual change in general opinions towards inflation, according to which the maintenance of a stable price level loses primacy as a policy goal until the late 1970s. Hence the notion of an "ongoing inflation" received widespread attention by economists, and its causes were thoroughly analyzed. Still in the same chapter, we briefly survey the concepts of inertia and persistence as captured by a stream of contributions that runs from the interwar economic debates to present-day mainstream macroeconomic theory and some theoretical and methodological issues related to both phenomena. We close the chapter with a brief statement on how the mainstream economists in Brazil perceive inflation inertia nowadays.

The subsequent narrative is organized by the recurring controversy between monetarist and structuralist theorists, which begins in the 1950s and resurfaces in the early 1980s, in two rounds. In each moment of the debate, we try to keep track of the concept of inflation inertia, if and how it was altered in form and/or substance, due to a host of determinants arising from theoretical innovations of economic thinking as well as from the real-world economic events. Chapter two starts with an overview of the forerunners of the inertial inflation concept, to be found in contributions by a diverse group of authors, such as Nicholas Kaldor, Celso Furtado and Juan Noyola Vasquez. We underline the early studies of the behavior of real incomes under steady inflation offered by Celso Furtado, Nicholas Kaldor and Felipe Pazos. In line with mechanical portraits of inflation, we conclude the chapter with a reflection on Kaldor's (1957c , 1957d) seminal contributions to the stabilization debates in the 1950s, when the saw-tooth pattern of real wages was first conceived, as Vera (2013a) has recently claimed. Expanding on this author's paper, we contextualize Kaldor's input within the emerging operations research program, where mechanical models of inventory management held striking similarities to the visual representations of real incomes under sustained inflationary conditions. We aim to find 
'bits and pieces' of what later came to constitute the theoretical - and mathematical account of the self-replicating pattern of inflation.

Chapter three covers the rise in the mechanical models of inflation, summarizing the main lines of development in theoretical appraisals of inflationary processes. We delve rather briefly - and selectively - into the contributions by a host of theoreticians concerned with depicting economics with process analysis and mathematical tools of systems of difference equations. These will prove quite influential in later developments of the inertial inflation concept. We assess the effects of this expanding mathematical drive upon the Latin American quarters of economics profession, by a close reading of Julio Olivera's and M.H. Simonsen's formalization attempts. Both will be recurrent references in the debates of the 1980s. We close this chapter with a brief account of Nicholas Georgescu-Roegen's criticism of Simonsen (1964), owing not only to the unexpected appearance of the later widely known ecological economist but also to his creative extension of the saw-tooth model of real wages to a growing economy.

Chapter four completes the analysis of predecessors, by weaving the threads of two influential fields: the neo-structuralist models of growth and distribution and NeoKeynesian models of inflation. The former highlights the influence of Hollis Chenery and Lance Taylor, whereas the latter deals with the advances made by Arthur Okun, Robert Gordon and, particularly, by James Tobin. We stress some methodological aspects regarding modeling formats and the conceptualization of inflation inertia, which will inform an important part of the contributions by the economists at PUC-Rio. These latter's mathematical formalizations of the decades-old saw-tooth model of real wages closes the part.

Chapter five accounts for the fifteen-year period that precedes the Real plan and frame it against the second round of the monetarist-structuralist controversy. In this contentious environment, our narrative reveals the conscious aim of "reinventing" the structuralist tradition in Brazil by the economists at PUC-Rio. One of the outcomes of this reinvention is the build-up of the "inertial inflation paradigm". According to the latter, inflation has a dominant inertial component that renders it immune to changes in aggregate demand and is neutral in distributional terms. The relevance attributed to this notion will gradually change along the 1980 s. To the effect, an outline of their early contributions to this second moment of the controversy will provide a benchmark against which we will contrast their later writings. We point out the internal puzzles to the inertial inflation 
paradigm and combine the latter with the theory's policy performance, once it is embodied by the sequence of stabilization attempts from 1986 to 1994. We argue that the difficulties faced by these economists once they had become policymakers account for an important part of this change. We then move to unravel the gradual move these economists entail towards a more balanced view of inflation, reconsidering the relevance of budget deficits and monetary control to achieve a successful disinflation.

Chapter six thus portrays the second-generation structuralist transformation problem, whereby the neo-structuralist economists at PUC-Rio take a turn toward a more ecumenical approach to inflation inertia. We claim that this shift facilitated the later convergence of the concept of inflation inertia with the one entertained in the mainstream macroeconomics in the 1990s. In that regard, Simonsen's contribution is a crucial bridge between these two moments. We do not claim that Simonsen has a substantial historical significance in promoting the transition. Rather, his work offers an analytical connection, which allows us to make sense of the profound changes the economics profession in Brazil was undergoing in this period.

Chapter seven covers the reactions by policymakers responsible for the Real plan in the immediate aftermath of disinflation. A series of backstage papers are analyzed in order to infer how they addressed the problems of a residual indexation and, consequently, how they framed inflation inertia in this period. We highlight then the "missing gap" between this discussion and the concept of inflation inertia that was later to be adopted by inflationtargeting theories of monetary policy in the post-1999 period in Brazil. At last, some concluding remarks close this work trying to wrap up the discussion we pursued, weaving all the parts together. 


\section{Chapter 1 - Creeping inflation and indexation: historical aspects of inflation inertia}

Economists in the post-World War II period have singled out the existence of an inflationary bias to economies, both developed and underdeveloped. In a discussion promoted in the year 1949 by the Review of Economics and Statistics, Seymour Harris (1949, p. 200) opened up his contribution to the series with the following statement:

Inflation is a worldwide phenomenon: in countries ravaged by war, and in those largely untouched; in countries blessed (?) by overemployment and in those suffering from unemployment; in countries favored by an excess of imports and those "injured" by an excess of exports; in countries with budgetary surpluses and those with large deficits; in countries largely tethered to the principles of free enterprise and those relying on the planned economy and controls.

William Brian Reddaway (1997, p. 32-33) has dwelled with the more than apparent changing significance of the inflationary phenomenon in this period. He supports this claim with some simple empirical evidence on a handful of developed countries, in which the consumer price index have at least doubled in each one of them between 1962 and 1992 Germany had a $184 \%$ increase, whereas Italy faced a $1300 \%$ increase.

There are many perceptions and opinions regarding the underlying causes of this extensive upward bias in price level historical data in the postwar period. Is this tendency a "natural" property of the capitalist system or is it simply bad government running bad policies? Or yet, is it a tolerable outcome or a morally reproachable evil? It is the profession's general change of mind and heart regarding this question that this chapter is about. How did this inflationary bias come to be accepted within the economics profession? In what follows, we will paint with a rather broad brush this changing significance of inflation both in academic undertakings and in devising macroeconomic policy priorities.

\subsection{The changing perception about the significance of inflation ${ }^{3}$}

As early as 1936, Keynes ([1936] 1964, p. 307] had already sustained an inflationary bias in economic trends, which owed much to the endogeneity of the money supply to the structural and institutional forces responsible for growth and innovation. Following the end

\footnotetext{
${ }^{3}$ This section follows closely the approach set out by Leeson (1997) and Reddaway (1997).
} 
of the World War II, Leeson (1997) has identified a gradual eclipse of the goal of zero inflation, as "employment" rose to the status of a primary policy goal, relegating "price stability" to a second tier. The author also claims that, between 1953 and 1959, the fact that inflation had become persistent in industrial countries reinforced this understanding. In turn, this prompted a reaction to these inflation-tolerant views during President Eisenhower's term, when economists at the Joint Economic Committee recommended price stability be restored as the federal government's primary policy aim, preferring high unemployment (a $6 \%$ rate seemed compatible with stability) to the unquestionable inflationary pressures. It was commonly held that creeping inflation (of 2-3\% annual rate) would harm economic performance and would almost naturally degenerate into hyperinflation.

This general stand was not confined to the United States. Kaldor's memorandum to the Radcliffe Committee in the UK contained a section entitled "The Dangers of a Regime of Stable Prices", in which he claimed that the low dynamism of the British economy should be countered by "doping" the economy with inflation. He also ascribed to "valuejudgements and social preferences" the priority conferred to price stability or economic growth, and stated that "I would regard the sort of inflation we have been having, of the order of 3 to 4 percent a year, as a considerably lesser evil than economic stagnation or mass unemployment or instability in production"; in fact, he would sustain, "if we want to escape from economic stagnation, we must reconcile ourselves to rising prices" (Radcliffe et al. 1960,715-17 quoted in Leeson, 1997, p. 455, n. 11).

In academia, Paul Samuelson echoed this altered sentiment toward inflation, concluding in the first edition of his textbook that: "if price increases could be held down to say less than 5 per cent per year, such a mild steady inflation need not cause too much concern" (Samuelson, quoted in Leeson, 1997 p. 455). This idea would be repeated in a paper, he co-authored with Robert Solow (Samuelson \& Solow 1960, p. 192), where both authors claimed that 4 or 5 percent inflation would be the necessary cost of enjoying high rates of employment and economic growth. The trade-off interpretation of the Phillips Curve was a simple way to quantify, in terms of rates of unemployment, the cost of a stable price level. It also suggested, implicitly, that as long as rates of inflation were predictable and tolerably meager, low levels of unemployment would be maintained. In 1973, Samuelson would advise the Joint Economic Committee that, at 6 percent, inflation would 
not be disastrous, if everything was adjusted to that end. ${ }^{4}$

In Brazil, the notorious economist Eugênio Gudin (1965, p. 166) exposed some concerns over state-regulated prices and the ensuing downward rigidity they impose on the price level, thus engendering a systematically observed "gentle rise in the price level". Gudin asserted that "entrepreneurs have a preference for a moderate rise in prices, which entices them to do business"; workers would be satisfied in accepting some real wage decrease by slowly rising prices than a reduction in nominal wages, as Keynes had already claimed in The General Theory.

Gudin refers to Sumner Slichter, a famous Harvard professor at that time for his defense of the maintenance of a "creeping inflation" - ranging around a $2 \%$ constant yearly rate - directed at mitigating the harmful effects of union pressure for higher wages, usually above the rate allowed by the increases in productivity. ${ }^{5}$ Yet, Gudin believes this selffeeding pattern of inflation to be more spontaneous than the simple and conscious definition of policy guidelines would have us believe, for there is no "automatic force acting in favor of the restoration of equilibrium", once the inflationary process is triggered. The process tends to expand automatically, holding some similarity with a cumulative process à la Wicksell. As such, "in an inflationary regime, output production can only resume, at the same level, if the available amount of credits rise progressively", which implies logically and immediately the setting of an escalating price-wage-price spiral (Gudin 1965, p. 183).

Dispute was further inflamed in the early 1970s in the United States, when fastgrowing public spending outpaced federal revenues, under the demands of the Vietnam War, and large public deficits led to negative results in the external accounts. This twindeficit conjuncture led to Richard Nixon's devaluation of the dollar in 1971 and, given the 1973 oil-shock, subsequent abolition of the gold-dollar standard in 1973. The perception of

\footnotetext{
${ }^{4}$ For more details, see Leeson (1997, p. 456). In addition, subscribing to with this view, James Tobin (a key character in our narrative) was also a particularly notorious campaigning academic for the employment-bias within the Phillips curve trade-off, that an economy could live with inflation, but could hardly afford stagnation (Tobin \& Ross 1971, p. 24). Finally, Leeson provides a general take on the economics profession landscape: "In this way, the advocacy of zero inflation became transformed, in the 1950s, from an axiom or eternal truth to the position of a "group" whose views were "unacceptable"; and in the 1960s, to a distinctly old-fashioned-sounding minority. Even the Natural-Rate Expectations Augmented Phillips curve (N-REAP) model contained, at least prior to Friedman's Nobel Lecture (1977), the assumption that in the long run the performance of the economy, and hence the rate of unemployment, was neutral with respect to the rate of inflation - a suggestion that would have been regarded as outrageous by economists prior to the episode described in this article." (Leeson 1997, p. 454).

${ }^{5}$ On Sumner Slichter, see Leeson (1997).
} 
an "inflation explosion" started to disseminate within the profession and was supported not only by the Friedman-Phelps accelerating version of the Phillips curve at the theoretical level (see Backhouse and Boianovsky 2013, chapter 2); moreover, it spawned a massive research agenda on the empirics of inflation dynamics aimed at testing the vast array of hypotheses competing for the explanation of the troubling inflation rate hikes.

To that effect, it suffices to show that in the 1960s only two fairly encompassing surveys on inflation theories were carried out (Bronfenbrenner \& Holzman 1963; Brechling 1968), whilst a watershed of surveys and books entirely focused on inflation took over the profession in the 1970s. To keep our bibliographical references within bounds, we have been able to count at least six wide-ranging surveys along the mid-1970s (Laidler \& Parkin 1975; Gordon 1976; Humphrey 1976; Frisch 1977; Harberger 1978 and Tobin 1980), as well as several books on the same topic of controversies and advances in inflation theories and their empirical support. ${ }^{6}$

The eclipse of the zero-inflation goal did not imply the complete withdrawal of inflation concerns from the policy agenda, although it was clearly played down. Two points should have become quite clear by now: inflation was in the postwar years an empirically observable reality and economists (see Reddaway 1997), in general, have found better ways to live with it than to unbendingly keep it from happening on pain of higher unemployment and lower growth rates. The end result was the transformation of the concept of price stability to a non-zero positive rate of inflation. ${ }^{7}$

In this context, questions addressing the distributional effects of inflation were

\footnotetext{
${ }^{6}$ To cite a couple of books (see references therein for further literature), Hagger (1977) deploys an extensive survey up to 1976 and Okun \& Perry (1978) compile the papers presented and discussed in a Conference held in Washington D.C. in the spring of 1978.

${ }^{7}$ The creeping inflation that lasted a quarter of a century past the World War II prompted a change of feelings within the profession against the ongoing policy regime. Moderate commentators claimed, by 1971, that inflation was being greatly exaggerated as a menace (Gordon 1971; Tobin \& Ross 1971). Soon, however, the price hikes in the first half of the decade would challenge such stands. The balance of perceptions began to tilt towards the monetarist side of the controversy (Modigliani 1977). Even some sympathetic to Keynesian claims laid stress on the costs in terms of monetary authority's credibility of seeking "the mirage" of a steady inflation, that is, a "target of stability in the first derivative of the value of the dollar rather than in its level" (see Okun 1973; 1975 and references therein). Furthermore, developed countries were then said to be undergoing a chronic inflationary problem (Okun \& Perry 1978) due a worldwide phenomenon of an "explosive inflation" (Haberler 1974). To drive the point home, Leeson (1997, p. 482-483) reminds us that, in the 1960s, many warnings in this regard were issued in rather gloomy images; for instance, the view that a "Faustian pact" with the "inflation dragon", as Lerner (1967, p. 3) once put it, would engender the "Latin Americanisation of the world", whereby a "cost inflation at a high rate has produced a 'general crisis of capitalism' and the stability of Communist prices shines like a good deed in a naughty world; yet economic theory has nothing to say" (Wiles 1973, p. 377-379).
} 
bound to arise. In the absence of any credible indication that prices will stop rising, economic agents set out to find ways protect the purchasing power of their incomes and the real value of their asset holdings. Mechanisms such as sliding scales, escalator clauses, index-linked bonds and assets, indexation, monetary correction of contracts were all byproducts of the process of degeneration of unit-of-account property of money. We turn to this adaptation device to a continuous inflation in the next section.

\subsection{Historical aspects of indexation ${ }^{8}$}

There is quite a long history to the perception of indexation as a mechanism to cope with fluctuation in prices and the uncertainty associated with ideas going back to the early eighteenth century (see Giersch, 1974, p. 4, footnote 5). ${ }^{9}$ Hanes (2010) makes a compelling narrative of the early days of this idea in the United States and guides us through its origins. The notion of a "sliding scale" was, however, applied to sectional negotiations between workers and employers and was mostly concentrated in mining and metals industries. Moreover, it did not refer to aggregate consumer price indexes, but to a given set of sector prices. It had two purposes: one was to set a binding minimum level to wage rates, no matter what happened to prices; the other was similar to a profit-sharing mechanism, by tying wages to product prices alone or to the margin between product prices of prices of non-labor raw materials. ${ }^{10}$ Working it out in reality proved quite troublesome, for several price-related informational problems are bound to arise. Employers had to open accounting books in order to reveal sales prices and strategies, a necessity with which few enjoyed complying. The question of which prices would be adequate, if those of a general

\footnotetext{
${ }^{8}$ This section draws extensively on Friedman (1974, p. 46-58), Giersch (1974) and Vianna (1984).

9 Interest in escalator clauses arose long before its use became widespread. In 1707, William Fleetwood developed the first notion of pegging the wage rate of Cambridge faculty to an index that mirrored the evolution of cost of living, so as to discipline wage demands. One century later, John Wheatley, an English writer on money suggested something similar but did not received much attention. In 1886, even the likes of Alfred Marshall could not help but being enthusiastic in his recommendation of adjustment clauses (McNellis 1986). It could strike one as odd that index-links should be even raised in a century of widespread deflation, as the $19^{\text {th }}$ century is usually portrayed in the literature. However, if we consider that during a long process of falling prices wages tend to tag along, albeit with a lag, one can devise that indexation clauses may, in this context, act as stabilizers of the distribution of income, guaranteeing that wages are paired down to falling prices. In fact, in the turn of the twentieth-century, a professor J.E.C. Munro, a contemporaneous commentator, had proclaimed the mechanism itself, to be "the greatest discovery in the distribution of wealth since Ricardo's enunciation of the law of rent" (Munro quotes in Hanes, 2010, p. 49).

${ }^{10}$ Product-price indexation conditions wages on the value of labor in the unionized sector, and is affected by industry-specific shocks, which then tends to stabilize profit whilst raising wages to higher base level.
} 
price list or the open-market prices that embodied discounts, was largely under the prerogative of the employer, and thus entailed protracted dispute during negotiations. ${ }^{11}$

By 1925, Irving Fisher had gained notoriety for his studies on price index technology. He was known for not only favoring the "tabular standard" (the label given to widespread indexation at the time) but actually came to terms with a manufacturing company that he assisted in founding to issue a purchasing power security. Fisher argued that the terms under which the bond was issued led to its failure, due to the unfamiliarity of the market with the new asset (see McNelis 1986). However, the indexing of Fisher's bond was peculiar in that a $10 \%$ change in the price level was required before the indexing provision became effective.

When prices accelerated in many countries in the $1960 \mathrm{~s}$ the debate on the alternatives to attenuate the harmful effects of changing inflation was vigorously revived. ${ }^{12}$ Along the 1970s, controversy grew hotter and a more clear-cut division was noted between those who focused on the benefits of indexation and those of the opinion that such arrangements left the economic system more vulnerable to shocks and surges of inflation. Page and Trollope (1974) compiled the institutional diversity of indexing schemes and provided a summary in the Figure 1 below.

\footnotetext{
${ }^{11}$ For more details on the growing of wage-indexed contracts in the United States, see Gabarino (1962).

12 But this problem of rising prices was dealt with before that time. See Vianna (1984, p. 45-48) for a historical account going back to the nineteenth century.
} 


\begin{tabular}{|c|c|c|c|c|c|c|c|c|c|}
\hline & \multirow{2}{*}{ Wages } & \multicolumn{2}{|c|}{ Social security benefits } & \multicolumn{5}{|c|}{ Investments } & \multirow{2}{*}{ Taxes } \\
\hline & & Pensions & $\begin{array}{l}\text { Other } \\
\text { transfers }\end{array}$ & $\begin{array}{c}\text { Government } \\
\text { bonds }\end{array}$ & $\begin{array}{l}\text { Private } \\
\text { bonds }\end{array}$ & Mortgages & $\begin{array}{l}\text { Other } \\
\text { loans }\end{array}$ & Rents & \\
\hline $\begin{array}{l}\text { Argentina } \\
\text { Australia } \\
\text { Austria } \\
\text { Belgium } \\
\text { Brazil } \\
\text { Canada } \\
\text { Chile } \\
\text { Colombia } \\
\text { Denmark } \\
\text { Finland } \\
\text { France } \\
\text { Iceland } \\
\text { Irish } \\
\text { Republic } \\
\text { Israel } \\
\text { Italy } \\
\text { Netherlands } \\
\text { New } \\
\text { Zealand } \\
\text { Norway } \\
\text { Sweden } \\
\text { United } \\
\text { Kingdom } \\
\text { United } \\
\text { States }\end{array}$ & $\begin{array}{l}1921-53 \\
\overline{1} \\
1948- \\
1964- \\
1972- \\
1960 s \\
\\
1945- \\
1945-67 \\
1948-58\end{array}$ & $\begin{array}{l}1955- \\
1965- \\
1952 \\
1923- \\
1957- \\
1948-\end{array}$ & $\begin{array}{l}\text { late 50s } \\
1973- \\
1923- \\
1956-67\end{array}$ & $\begin{array}{l}1945-67 \\
1952-58 \\
1973- \\
1955 \\
\\
1948-\end{array}$ & $\begin{array}{l}1974 \\
1973- \\
1925\end{array}$ & $\begin{array}{r}1972- \\
-\end{array}$ & $1952-67$ & $\begin{array}{l}1964- \\
1952-67\end{array}$ & $\begin{array}{l}1946- \\
1974-\end{array}$ \\
\hline
\end{tabular}

Figure 1 - Summary of Countries' Experience with Indexation until 1974. Source: Page and Troloppe (1974, p. 47).

Fischer (1981a, p. 24-25) builds on the above survey and other sources and gives a illustrative portrait of indexation up to 1981. Amongst the 40 countries that constitute the sample, only France ${ }^{13}$, Brazil and Israel account for indexation in all of the aspects considered, namely: wages, taxes, social security, investment and government bonds. Fischer's data is summarized in Table 1 below. According to this composition of the economy, $35 \%$ of the countries have over one-half of their economies indexed to some measure of inflation. Almost half of the countries (43\%) use some sort of wage indexation scheme and roughly two-thirds of the sample $(68 \%)$ tie its financial bonds to inflation indexes.

In addition, on the institutional and structural aspects, Sachs (1979, p. 316) shows that a major change in institutions of wage bargaining, which had led to an autonomous increase of real wages ahead of productivity is many developed countries between 1969 and 1973.

\footnotetext{
${ }^{13}$ See the Economic Survey published by OECD (1984, p. 19-21) for more details on the indexation framework in France.
} 
Table 1 - Indexation Dummies, by countries

\begin{tabular}{|c|c|c|c|c|c|c|c|}
\hline Country & Wages & Taxes & $\begin{array}{c}\text { Social } \\
\text { Security }\end{array}$ & Investment & $\begin{array}{c}\text { Government } \\
\text { Bonds }\end{array}$ & Total & $\begin{array}{l}\text { \% Indexed } \\
\text { Sectors }\end{array}$ \\
\hline Argentina & 0 & 1 & 1 & 1 & 1 & 4 & $80 \%$ \\
\hline Australia & 1 & 0 & 0 & 0 & 0 & 1 & $20 \%$ \\
\hline Austria & 1 & 1 & 1 & 0 & 0 & 3 & $60 \%$ \\
\hline Belgium & 1 & 0 & 1 & 0 & 0 & 2 & $40 \%$ \\
\hline Bolivia & 0 & 0 & 1 & 0 & 0 & 1 & $20 \%$ \\
\hline Brazil & 1 & 1 & 1 & 1 & 1 & 5 & $100 \%$ \\
\hline Canada & 1 & 1 & 1 & 0 & 0 & 3 & $60 \%$ \\
\hline Chile & 0 & 1 & 1 & 0 & 0 & 2 & $40 \%$ \\
\hline Colombia & 0 & 1 & 1 & 1 & 0 & 3 & $60 \%$ \\
\hline Denmark & 1 & 1 & 1 & 1 & 0 & 4 & $80 \%$ \\
\hline Ecuador & 0 & 0 & 1 & 0 & 0 & 1 & $20 \%$ \\
\hline Egypt & 0 & 0 & 0 & 0 & 0 & $\mathbf{0}$ & $0 \%$ \\
\hline Finland & 1 & 0 & 1 & 1 & 0 & 3 & $60 \%$ \\
\hline France & 1 & 1 & 1 & 1 & 1 & 5 & $100 \%$ \\
\hline Germany, FR & 0 & 0 & 1 & 0 & 0 & 1 & $20 \%$ \\
\hline Greece & 0 & 0 & 0 & 0 & 0 & $\mathbf{0}$ & $0 \%$ \\
\hline Iceland & 1 & 1 & 0 & 1 & 1 & 4 & $80 \%$ \\
\hline India & 0 & 0 & 0 & 0 & 0 & $\mathbf{0}$ & $0 \%$ \\
\hline Indonesia & 0 & 0 & 0 & 0 & 0 & $\mathbf{0}$ & $0 \%$ \\
\hline Ireland & 1 & 0 & 1 & 0 & 0 & 2 & $40 \%$ \\
\hline Israel & 1 & 1 & 1 & 1 & 1 & 5 & $100 \%$ \\
\hline Italy & 1 & 0 & 1 & 0 & 0 & 2 & $40 \%$ \\
\hline Japan & 0 & 0 & 1 & 0 & 0 & 1 & $20 \%$ \\
\hline South Korea & 0 & 0 & 0 & 0 & 0 & $\mathbf{0}$ & $0 \%$ \\
\hline Mexico & 0 & 0 & 0 & 0 & 0 & $\mathbf{0}$ & $0 \%$ \\
\hline Netherlands & 1 & 1 & 1 & 0 & 0 & 3 & $60 \%$ \\
\hline New Zealand & 0 & 0 & 1 & 0 & 0 & 1 & $20 \%$ \\
\hline Norway & 1 & 0 & 1 & 0 & 0 & 2 & $40 \%$ \\
\hline Philippines & 0 & 0 & 0 & 0 & 0 & $\mathbf{0}$ & $0 \%$ \\
\hline Portugal & 0 & 0 & 1 & 0 & 0 & 1 & $20 \%$ \\
\hline South Africa & 0 & 0 & 0 & 0 & 0 & $\mathbf{0}$ & $0 \%$ \\
\hline Spain & 0 & 0 & 1 & 0 & 0 & 1 & $20 \%$ \\
\hline Sweden & 0 & 1 & 1 & 1 & 0 & 3 & $60 \%$ \\
\hline Switzerland & 1 & 1 & 1 & 0 & 0 & 3 & $60 \%$ \\
\hline Thailand & 0 & 0 & 0 & 0 & 0 & $\mathbf{0}$ & $0 \%$ \\
\hline Turkey & 0 & 0 & 0 & 0 & 0 & o & $0 \%$ \\
\hline United Kingdom & 1 & 0 & 1 & 1 & 0 & 3 & $60 \%$ \\
\hline USA & 1 & 0 & 1 & 0 & 0 & 2 & $40 \%$ \\
\hline Uruguay & 0 & 0 & 1 & 0 & 0 & 1 & $20 \%$ \\
\hline Venezuela & 0 & 0 & 0 & 0 & 0 & $\mathbf{0}$ & $0 \%$ \\
\hline
\end{tabular}


(Table 1 continues)

\begin{tabular}{lccccc}
\hline Country & Wages & Taxes & $\begin{array}{c}\text { Social } \\
\text { Security }\end{array}$ & Investment & $\begin{array}{c}\text { Government } \\
\text { Bonds }\end{array}$ \\
\hline Total & 17 & 13 & 27 & 10 & 5 \\
Share of Sample & $43 \%$ & $33 \%$ & $68 \%$ & $25 \%$ & $13 \%$ \\
\hline
\end{tabular}

Source: Fischer (1981a, p. 25-26; 1986, p. 208-209)

Following the 1973-1974 oil-shock, trade unions held their ground, imposing downward resistance to real wages in Europe and Japan, albeit not as much in the US. Moving on to the 1980s, McNellis $(1986,1988)$ has surveyed the different institutional arrangements regarding indexation carried out by most of the countries mentioned above. Most of them underwent a gradual de-indexing process, which did not happen to Brazil and Israel. These latter were unable to dismantle the rigid indexing structure while trapped in an escalating hike towards hyperinflation, a predicament which was only avoided by stabilization attempts launched by governments in the 1980s (successful in Israel and round failures in Brazil). Among the countries that promoted de-indexing measures, we find Chile (1982), Finland (1967) and Iceland (1983). In the three cases, inflation did not rise after indexation was suspended, although in the case of Chile rates of inflation were still far above the standard levels of developed countries.

As we have been able to see by now, indexation is a double-edged sword. It is believed by some to instill a self-feeding process in inflation dynamics (e.g. Simonsen 1970b and Fischer 1981a) whilst others praise it for its inflation-dampening effects via moderation of workers' wage claims (e.g. Friedman 1974 and Giersch 1974). In developed countries, historical records have shown that inflation precedes consumer or wholesale price indexation and disinflation antedates de-indexation (see Braun 1976). For these countries, experience has pointed out that indexing contracts under a rising inflation moderates this uprising via labor market restraints. As for developing countries, indexation is frequently understood in the literature to act merely as a propagating device of these pressures to the rest of the economy. ${ }^{14}$

To sum up, a wide variety of countries used some type - albeit with varied scopes of index-linkages of contracts while facing very different inflation trends. The available

\footnotetext{
14 Carefull and detailed discussion concerning the effects of indexation has been undertaken by Page \& Troloppe (1974, p. 51-58), Braun (1976, p. 241-261) and, once again, Fischer (1981a). We sidestep this issue in favor of the more relevant problem of how the inertial aspect of inflation was captured in Brazilian economic debates.
} 
evidence has been inconclusive as to any absolute inflation-feeding pattern of indexation among the sampled countries. This reinforces the hypothesis that indexation is but an effect of protracted deep-seated pressures impinging upon the behavior of prices. Once these pressures are acknowledged as persistent causes of price rises, the empirically observed inflationary bias can be explained; in response to this latter and to each economy's historical and institutional features, different indexing "styles" emerge. ${ }^{15}$ And once they do, these indexing styles engender country-specific channels through which the history of inflation feeds back on the inflationary environment. Institutions and structural dynamics invite themselves as immediate and obvious candidates to be accountable for such disparities in inflationary experiences and, in consequence, in the enactment of indexing clauses. We shall next turn our attention to how economics has theorized on the effects of indexation.

The complexity entailed by a variety of institutional arrangements has been conveyed in McNellis's (1986, p. 27) extended survey on the theoretical and policy-related developments in indexing schemes across a reasonable sample of international experiences. The author questions whether it is possible to define the optimal degree of indexing, a puzzle that challenged many economists in the 1970s and 1980s. Optimality is conditioned on a host of policy, institutional and structural conditions, all of which are history-sensitive categories.

The surveys on indexation we have covered so far point out that economic theory in the late 1970 s and early 1980 s focused disproportionally wage indexation to the detriment of other forms of it (see the introduction to Arida 1992). Regardless of this, indexation started to be seen as an instrument within a broader scope of stabilization tools, as we saw in the Table 1. Moreover, successful disinflation did not imply the total extinction of indexed contracts.

Contrary to what one may think, this is an expected result if we take heed of at least three aspects. First, a remarkable effect of indexation in Brazil was the distribution of income from wages to capital, in order to boost investment and growth whilst controlling inflation as it leaped up in mid-1960s (Resende 1982). Government bonds were inflationlinked so as to boost savings, which were geared to finance expansion in productive

\footnotetext{
${ }^{15}$ See Fishlow (1974) and Kafka (1974) for a detailed analysis of the Brazilian indexing style. More on this topic below.
} 
capacity. Wages were only partially and imperfectly indexed, undercompensating for the effects of inflation, thus lagging behind the consumer price index. Indexation was used as an instrument for incomes policy until mid-1970s.

Second, what seems to be most important is the extensive government-sponsored manipulation of indexing schemes, not the scope nor the degree of indexation themselves. Frequent changes in the rules of indexing affect quite adversely the behavior of the demand for index-linked bonds or the inclusion of escalator clauses not only in wage contracts but also in price setting patterns, by raising uncertainty pertaining to future inflation rates.

Third, it was the strict control over wages and the one-year time lag between adjustments that acted to decelerate price rises, not to mention that the availability of indexed bonds provided an outlet for a flight from money other than commodities, thereby damping down the second round effects of any relative price rise (Page \& Troloppe 1974, p. $45 ; 51 ; 57-58) .{ }^{16}$ The combination of the external shocks in 1979 with its severe impacts on the fiscal accounts and the shortening of intervals between wage adjustments propelled prices into an accelerating path (Resende 1982; Resende \& Lopes [1979] 1981). Next section offers a "bird's eye view" of the history of the inflationary inertia concept, aiming to depict the long-standing acquiescence by economists of this phenomenon.

\subsection{The meanings of "inflation inertia" in economics}

Inertia comes from the Latin word, iners, meaning idle, sluggish. The principle of inertia is one of the fundamental principles of classical physics. It describes the motion of objects and how they respond to external forces impinging on them. Isaac Newton defined it, in his First Law of Motion, as the tendency of an object not subject to any net external force to keep moving in a straight line at constant linear velocity. Hence, an object will continue moving at its current velocity until some force causes its speed or direction to change. In common usage the term "inertia" may refer to an object's "amount of resistance to change in velocity", or still as its "momentum" (see Fuhrer 2010).

It is not clear when it was first used as an economic description of events. The concept of inertia has a long history in economics. Use of the term dates back to the Physics-envy first moments of economists, in the likes of Pareto's and Jevons's writings in

\footnotetext{
${ }^{16}$ This alternative to flight from money will be later called "absorption effect" by Arida (1992) in his PhD Thesis and will partly account for the puzzling behavior of inflation in Brazil, which never degenerated into open hyperinflation. See more in chapters 4 and 5.
} 
the late 1800s (Mirowski 1989). However, this only meant grasping the relationship between impulses and transmission, so the underlying forces accounting for the cyclical behavior of the economy could be fettered out. The problem resided in the effects inertia generated. The principal matter had to do with price adjustment along the economic cycle (see Morgan 1991, chapter 2-4). ${ }^{17}$

In the early 1950s, Bent Hansen (1951, p. 224-227) had already alluded to the delay of price index in absorbing changes in relative prices due to low supply elasticity in certain sectors of the economy. In the same decade, the Brazilian monetarist economist Eugênio Gudin loosely mentioned the idea of price inertia as "the slow and gradual propagation of the effects of a localized rise in a given price". ${ }^{18}$ If Gudin's view is to be taken as a proxy of what was "in the air" in the early 1960s in what concerns inertia, the mainstream economic variant of the concept mirrored the principle of a body's resistance to change in its state of motion. In this case, it means the sluggish reaction of prices to a force that alters their velocity, that is, its lagged response to an exogenous shock. This understanding of inertia is aligned with the Keynesian research project of nominal rigidities that was to later characterize the New Keynesian approach, which emerged in the early 1970s and to which we will turn shortly.

\footnotetext{
${ }^{17}$ Two examples are illustrative of how this concept can be applied to various economic circumstances. First, the interplay of quantities and prices implied under-determination of economic models. For instance, the oldage quantity theory of money (QTM) required real output and velocity of circulation to remain fixed, under the assumptions that production was unaffected by the quantity of money and that velocity was stable enough to be deemed constant in theoretical terms. In the real world, as Richard Cantillon's and David Hume's accounts of the QTM goes, an increase in the quantity of money affects primarily the pace of commerce and industry and after it has reached every market in the system, prices begin to rise. Inertia is thus understood to be at work between the rise in the money stock and the belated price level response. The second application of inertia can be found in Knut Wicksell's monetary theory of the trade cycle, conveyed in his 1898 book Interest and Prices, whereby a lagging response of the banking system to a change in the natural interest rate generates a gap between the market interest rate charged on loans by the commercial banks and the rate that equilibrates available savings with demands for investment goods. The ensuing increase in the quantity of credit-money pushed demand beyond the available capacity of supply, resulting in the rise of the price level. The tardiness of banks in adjusting their interest rates is due to informational problems besetting the banking system, as also pointed out in Friedrich Hayek's Wicksellian model of Monetary Theory and the Trade Cycle. Inertia of the market interest rate is thus a fundamental cause of the non-neutrality of money in the Wicksellian sense. Once the lag in the response of market interest rate could be abbreviated, the stable pricelevel-notion of neutral money could be attained. A third illustration can be found in Dornbusch's (1976a) famous overshooting model, whereby immediate adjustment lies completely in the exchange rate and, after some lag, inflation starts increasing gradually in order to correct the real exchange rate.

${ }^{18}$ This lagged response was justified on the grounds that "sales agents do not become readily aware of the ongoing monetary developments". Consequently, "entrepreneurs only raise their prices, in general, when the inflationary wave hits them, and frequently continue to set their prices on the basis of previous nominal costs, when in fact the costs of reproduction have already been notably raised". Therefore, "the general price level of commodities and services adapt slowly to the variations on the value of currency, which has become known as price inertia". (Gudin 1965, p. 184).
} 
An alternative use of this concept arose in the debates on monetary stability in Latin America. As far as our knowledge goes, the priority in its use defers to Felipe Pazos, in his 1969 book, titled Medidas para detener la inflación crónica en América Latina. Pazos set out to explain the endogenous forces underlying the self-feeding thrust of inflation in Chile between 1962-67. The ensuing oscillating pattern of real wages found its mechanics in the periodical adjustment in nominal wages to offset the erosion of purchasing power under persistent non-zero inflation. Quoting Pazos at length:

The rise in wages and other costs, following the mechanism of alternated adjustments described above, makes inflation continue by the law of inertia, without the need to be propelled by autonomous pressures of demand, costs or of supply; (...) a considerable part of the rise in prices is generated through the internal mechanics described above; and to the rise of prices due to endogenous forces we must add the external pressures" (Pazos, 1969, p. 67 - emphasis added).

The Latin American structuralist view of inflation borrowed the concept of inertia on quite distinct grounds than that of the interwar mainstream economics at that time, represented above by Gudin and Hansen. For Pazos - and as we will see below, for many other economists -, the problem was not so much the time delay in the response of prices to a given shock, but the propagating properties of this shock upon the dynamics of the price level. Aside from these perturbations being seen as side-effects of economic development and the presence of structural rigidities, a profoundly complex distributive dynamic entailed conflicting claims over the aggregate output which, under successive cost-shift pressures, kept inflation rising in upward jumps and creeps (e.g. Simonsen 1970b, Lopes 1979, Bresser Pereira \& Nakano 1984). ${ }^{19}$

In the sections to come, we attempt to show how the view just briefly outlined came to find its international counterpart in the mainstream macroeconomics of the 1970s, under the guise of the unemployment-inflation trade-off and the numerous interpretations of the inflation dynamics it made possible. As the inflationary spurt crept up just before the eighties, this lineage of Keynesian macroeconomics went under severe criticism. The Friedman-Phelps hypothesis of a natural rate of unemployment rested on the assumption that agents formed adaptive expectations led to the view that wages had an embedded autoregressive component that explained self-generating inflation (Laidler \& Parkin 1975,

\footnotetext{
${ }^{19}$ To put in other words, the assumptions that any economic system is fraught with rigidities of all sorts and is inherently plagued by conflicts amongst social groups implied almost forcefully that inflation would most likely have a positive non-zero value.
} 
p. 748, 752-758) that was largely unstable and, under an accommodating monetary policy could lead to open hyperinflation. Likewise, Robert Lucas's rational expectations hypothesis would impart overarching change to the economics profession and, likewise, on the views economists held on the inflationary problem.

On the other hand, James Tobin (1980, p. 62-66) argued strongly against both these views of an analytically easily explosive inflation, showing that inertia could be introduced in inflationary pattern by means of a "distributed lag of past price or wage inflation rates" due to adaptive expectations and to explicit and implicit contracts, as well as patterns of emulation and catching-up behavior (informal indexation and relative wage fairness issues). The conditions for explosiveness were seen as very strong but rather rare. Economists thus tended to overlook a whole range of inflationary processes that were caught in the middle: they were stable and escalated much more slowly than the monetarist story. Hence, in what touches the problem of inflation inertia, Tobin's acclaimed Neokeynesian take on inflation inertia is somewhat aligned with the New Keynesian advances in the microfoundations of macroeconomic models.

The emerging New Keynesian literature ascribes "inertia" to price rigidities that hinder market clearing (see Mankiw \& Romer 1991a, pages 7-12). ${ }^{20}$ Low responsiveness to exogenous shocks implies the existence of nominal price rigidity resulting from nonoptimizing rational behavior. Still, inertial behavior can, at times, be an optimal response to changes in the economic environment, in the face of some cost to price adjustment. The New Keynesian approach tends to lay greater emphasis on the technical costs of carrying out price changes (Mankiw 1985). In this setting, a rational agent chooses not to adjust prices if the cost of inertia (negligible for small changes) is lower than the cost of

\footnotetext{
${ }^{20}$ The term "inertia" is also depicts the result of non-rational or near-rational behavior which imposes some nominal rigidity on the system, thereby impairing the full adjustment of prices and wages to a given exogenous shock. Akerloff and Yellen define then "near rationality" as a straightforward application of the envelope theorem. "Whenever the conditions for the applicability of the envelope theorem are met, inertial behavior starting from a fully maximizing situation turns out to be near rational. The key requisite is continuous differentiability of the pay-off objective function: marginal profits should not exhibit discontinuous jumps following small changes in the exogenous and choice variables". (Benassi et al, 1994, p. 252). One example of non-rational behavior is the consent to social customs (Akerloff 1980), in which a fairness code in wage and price setting lingers on should deviations from the fair non-optimal be not too advantageous when compared with the relative loss in reputation (Akerloff, 1969, p. 369). The systemic effects arising from near-rational behavior are analyzed within a general equilibrium framework, in which a fraction of agents respond with some delay to changes in economic conditions, whilst the remaining fraction fully maximizes. Thus "near-rationality" is a term adopted to represent economic contexts where sidestepping strict maximizing procedure does not necessarily imply foregoing relevant profit opportunities for one single agent (Akerloff \& Yellen, 1985b; Benassi at al., 1994, p. 251).
} 
adjustment itself. The literature has also encompassed "decision costs" and "implementation costs", all of which affect lag length of aggregate variable responsiveness. ${ }^{21}$ Informational problems in goods, credit and labor markets, institutional peculiarities such as long-term staggered contracts and even a passive money assumption are analyzed to underpin the observed phenomena of the effects of money on real variables.

Despite elaborate attempts to introduce price rigidity in order to generate inertia, the concept of inflation inertia has thus far fitted quite awkwardly in the analytical framework couched on the assumption of a rational optimizing representative agent. Consequently, an attempt is made at depicting some of the causes of inflation inertia, such as indexation (Gray 1976, Taylor J. 1979 and Fischer 1977) and relative price variability (Caplin \& Spulber 1987) among other traits. However, only price level inertia has been explicitly achieved, whereas the more important question of what generates the self-replicating pattern of inflation is assumed away. The degree of rigidity at the micro level implies the degree of sluggishness at the aggregate level. This result is in line with Fischer's (1977) model of wage predetermination in long-term contracts and uniform staggering of the negotiation dates. It is within this institutional set-up that lies the New Keynesian claim regarding the effectiveness of a systematic monetary policy. Due to the slow adjustment of prices, the effects of the monetary shocks on output are long lived and decrease exponentially in a movable average process. John B. Taylor's $(1979,1980)$ has set forth the baseline multi-period model of fixed prices, with uniform staggering, whereby the pricing rule follows an autoregressive behavior, while also incorporating a forward-looking element hinging on the expectations with respect to future behavior of the exogenous variables (e.g. the money supply). Hence the dynamic equations of the model are so built as to prevent the serial correlation from quickly disappearing "as soon as time elapses beyond the length of the individual price policy" (Benassi et al., 1994, p. 283).

\footnotetext{
${ }^{21}$ New Keynesian results rest on nominal rigidities and/or systematic errors in expectations. These rigidities and errors can thus find microfoundations as a reasonable 'non-rational' behavior by a fraction of the population; strategic complementarity is then a channel through which non- or near-rational choices exert a first order effect on the economy as a whole. This result is not restricted to inertial behavior; it also applies to all circumstances in which some agents violate a relevant rationality assumption (Benassi et al, 1994, p. 256). Hence the expected wider deviations of an economic framework in which a fraction of the population has backward-looking expectations when compared to the rational expectations equilibrium. Thus, "the inertial behavior of aggregate prices may be stronger and more persistent than the corresponding degree of microeconomic rigidity, so that long-lasting real effects of nominal disturbances can be sustained". (Benassi et al., 1994, p. 274).
} 
The New Keynesian literature has explored in depth the implications of different staggering structures with price rigidity. For instance, Blanchard's (1983) models consider asynchrony in price decisions within the production process, where every good being used as an input for the production of the other. Synchronization is found to be a stable equilibrium, whereas uniform staggering leads to an unstable one (Gray 1976 and Fischer 1977). Thus, if timing is endogenously derived from strict rationality assumptions, "the outcome is synchronization, unless the initial distribution is exactly uniform over time and there are no perturbations thereafter" (Benassi et al., 1994, p. 284). ${ }^{22}$

However, deriving a staggered structure of pricing decisions from maximizing principles requires adding further determinants of preferences as well as other structural and non-economic features be singled out in the model. The benefits associated with staggering are conditioned on the existence of a few large sectors in the economy (Ball \& Romer 1989a, 1989b, 1990), on the presence of institutions such as long-term contracts (Ball 1991 and Taylor J. 1979, 1980, 1981) or informational constraints to maximizing behavior (Calvo 1983 and Ball \& Cecchetti 1988). In the presence of both aggregate and firm-specific shocks with agents' imperfect information, firms gain information by resorting to long-term contracts (implicit or otherwise), by observing the prices set by others. In the latter case, each firm has the incentive to set the price shortly after other firms set theirs, and staggering can be an equilibrium outcome. (Benassi et al, 1994,p. 285).

The conclusion is that staggering seems to have no sound justifications, if timing of price decisions is dealt with explicitly. The lack of formal explanation in this framework leaves no alternative but to interpret this distribution of price decisions as a coordination failure (see Mankiw \& Romer 1991a, p. 8-9). Likewise, price rigidity amounts to a rational justification of inertial behavior, based on adjustment costs or frictional behavior in the price setting procedure, which precludes perfect flexibility (continuous optimization) and

\footnotetext{
${ }^{22}$ Aggregate behavior concerning price dynamics and the real effects of nominal changes is taken up in the presence of different cross-section distribution over time of the price changes. Two polar cases are then considered: synchronization, when all agents take their price decisions at the same time, and revise them at the same constant interval; and uniform staggering, when individual decisions are uniformly distributed over time, so that in each period a constant fraction of the total number of agents revises the price decisions (Akerloff 1969). Insofar as these assumptions about the timing of the decisions matter, there arise implications as to the dynamic persistence of the real effects of monetary changes. (Benassi et al., 1994, p. 279-280). Staggering is found to imply a smoother dynamic behavior, but price predetermination guarantees that aggregate demand affects output for a period not longer than the length of time for which each price is predetermined (Benassi et al., 1994, p. 282). In this sense, the timing of the decisions seem to be fairly immaterial in itself, for the key determinant of inertia in the aggregate price level seems to be the degree of microeconomic rigidity, which, in turn, define the horizon over which prices are set. Assumptions regarding timing of price decisions generate solely sharper or smoother behavior, but nothing more substantial.
} 
smooth market-clearing outcomes, rendering justified the short-of-optimal adoption of rules of thumb. On these non-rational behavior rests the results of infrequent and/or incomplete price adjustments (Benassi et al, 1994, p. 308).

Therefore, New Keynesian concerns with inertia are but a byproduct of investigations on the causes and system dynamics of price and wage rigidity that impedes markets from clearing. Efforts along these lines are by far more preoccupied with finding microfoundations that account for impairments to the flexible adjustment of prices than to the reasons why inflation is sustained at a higher level after a shock. That is, it is primarily focused on the speed of adjustment or response of prices than to inflation persistence in time. Nonetheless, attempts have been made to provide a clear account of the inflationary phenomenon departing from first principles of optimizing behavior.

John Taylor's (1979) model had shown that, in the presence of costs to adjustments, the price level presents inertia, that is, it only adjusts fully to a monetary shock only after sustained deviation of output from its potential value. This result owes to time-dependent fixed-price behavior in the presence of staggered contracts in price and wage setting. However, a substantial portion of price decisions as left out of this framework, such as retail firms whose price setting behavior is largely state-dependent. Caplin and Spulber (1987) provided the main contribution on these lines. Their model couches the asynchronous nature of price and wage decision on the assumption that agents adopt $(\mathrm{s}, \mathrm{S})$ pricing policies, the inventory-theoretic approach defined in Sheshinski and Weiss (1977, 1983). Price stickiness arises from fixed transaction costs at the firm level to changes in overall price level. Firms are set to respond only occasionally to inflation, when the difference between current prices and their optimal price equals a trough-value S. Statedependent price-fixity engenders the "saw-tooth" pattern devised in firms' real price behavior. The authors claim to have endogenously derived inflation from asynchronous price adjustment by firms, because a handful of firms making large price changes can generate an increase in the price level that is proportional to the magnitude of the monetary shock. In this vein, the model reinforces the result obtained by studies that connect relative price variability with inflation (e.g. Barro 1976; for a survey, see Fischer 1981b).

As we can see, the models in this lineage have trouble explaining inflation inertia. Usually a stable inflation is assumed, rather than derived. In general, causality runs from inflation to price setting in the presence of frictions and adjustments costs. This blank in New Keynesian macroeconomics will be transmitted to the emerging New Neoclassical 
Synthesis, the theory that will undergird the new consensus macroeconomics (Arestis \& Sawyer 2003).

The 1990s inaugurated an era of convergence on macroeconomics. ${ }^{23}$ The New Consensus Macroeconomics arose out of the collapse of the "Grand Neoclassical Synthesis" in the 1970s, as a result of the challenge of stabilizing prices in industrialized countries in the aftermath of the 1979 oil shock. At the time, monetary policy reflected deep divisions within the academic world. ${ }^{24}$ Inflation was commonly believed to be primarily driven by factors other than monetary policy: fiscal deficits, commodity price shocks, inflation psychology, aggressive labor unions, or monopolistically competitive firms (Goodfriend 2007). There arose a convergence to a well-defined theoretical approach to monetary theory. The New Neoclassical Synthesis (henceforth, NNS) on matters of monetary policy was born out of a cross-fertilization of New Keynesian and Real Business Cycles approaches (Clarida et al. 1999; Woodford 2003; Duarte 2011a), and is, as of this date, fully incorporated into mainstream economics and has already reached undergraduate-level textbooks (Carlin \& Soskice 2006, chapters 3-5).

The models of this more recent vintage (NNS) build on individualistic premises, whereby behavior is essentially constrained by discount rates and intertemporal utility functions of optimizing agents, such as households, government authorities and firms (see Calvo, Celasun \& Kumhof 2001). Microfoundations and rational expectations provide the methodological premises for economic behavior. ${ }^{25}$ Optimality and other equilibrium conditions for each of these groups of agents are clearly and mandatorily presented. As a result, inflation inertia in these models must be mainly ascribed to price setting

\footnotetext{
23 The foundations of growth and stabilization were summarized in the Washington Consensus, which basically proclaimed that working out institutional framework in the right direction promotes more efficient markets; that in turn leads the economy to a stable trajectory of growth. For a detailed account of the crisisbred process of reform in Latin America and the build-up of a policy consensus, see Edwards (1995).

${ }^{24}$ For historical background of the intense "disarray" in monetary theory and policy, see Toye (1987) Goodfriend (2007, p. 50).

${ }^{25}$ Goodfriend (2007, p. 58) shows that the foundations of the current consensus theory of monetary policy had already reached a degree of convergence in 1980. The assertions were basically: that prices are marked up over costs (mainly wages) and have their trends depending on expectations; that there is a natural rate of unemployment at which wage and price setters perpetuate the ongoing rate of inflation; that inflation accelerates when output is expected to exceed potential; and that inflation decelerates when output is expected to be below its potential level. (Tobin, 1980). However, the unresolved problems were crucial ones involving how to model 1) the price and wage-setting process, 2) expectations, 3) the transmission of monetary policy, and 4) real factors influencing business cycles, all in a dynamic way suitable for analyzing monetary stabilization policy. These problems were addressed one by one. For further discussion on these topics, see Goodfriend (2007, p. 58-64).
} 
assumptions of rational, forward-looking optimization, which has proven quite cumbersome so far. ${ }^{26}$ This framework thus assumes - rather than explains - steady inflation in price equations with built-in inflation and with lagged effects on itself; moreover, the impacts of monetary surprises on the real economy are thoroughly analyzed but, under the assumptions adopted, protracted inflation inertia is only poorly obtained from the model structure (Duarte 2011, p. 392-396) ${ }^{27}$.

A popular approach to introducing inflation inertia into rational expectations models is the 'hybrid' NKPC, introduced by Clarida et al. (1999) and Galí and Gertler (1999). The authors combine a rational forward-looking element with some dependence on lagged inflation. A similar role is played by index linking of contracts to past inflation in the work of Christiano et al. (2005). ${ }^{28}$ However, backward-looking expectations are perceived as a second-best theoretical premise - and can be deemed "arbitrary". The supposed lack of robust justification is attributed to the assumption that agents draw information from past occurrences, rather than learn from them in order to infer future developments based on presently available information. Nonetheless, this branch of the profession understands that backward-looking price setting behavior is quantitatively modest but nevertheless statistically significant, although it is the one that best generates inflation inertia ${ }^{29}$. Notwithstanding the results attained by this model class, they still fall short of fully explaining the behavior of steady inflation. ${ }^{30}$

\footnotetext{
${ }^{26}$ Goodfriend and King (1997) define the goal of a neutral monetary policy in NNS as follows: "The new synthesis suggests that such a monetary policy involves stabilizing the average markup of price over marginal cost. In turn, this implies a monetary policy regime of inflation targets, which vary relatively little through time. Although price stability has been long suggested as a primary objective for monetary policy, a number of major questions have arisen about its desirability in practice. We confront a range of implementation issues, including the response to commodity price shocks, the long and variable lags between monetary policy and the price level, the potential policy trade-off between price and output variability, and the use of a short-term interest rate as the policy instrument" (Goodfriend \& King 1997 , p. 232 - emphasis added).

${ }^{27}$ In addition to several seemingly ad hoc assumptions regarding informational rigidities, lagged inflation and/or full or partial indexation has to be introduced to circumvent the problem of lack of inflation inertia: "To correct this problem several attempts to introduce some kind of lagged inflation in the NKPC was made. It is common to introduce inflation indexation in the Calvo model by assuming that those firms that cannot set prices optimally index them to past inflation instead of charging the same price as the last period-and indexation here can be either full or partial" (Duarte 2011, p. 393).

${ }^{28}$ A survey of recent studies on inertia can be found in Julliard et al. (2008) and Fuhrer (2010)

${ }^{29}$ Fuhrer (2008, p. 2536) labels this process "inherited inertia", defined as inertia that arises with "the aid of lagged inflation (whether ham-fisted or 'micro-founded' from indexation or rule-of-thumb price-setters).

30 In a paper on inflation persistence in the United States and the challenges it imposes to models of optimal monetary policy, Fuhrer $(2000$, p. 79-80) acknowledges the fact that " $[\mathrm{t}]$ he predominant source of inflation
} 
As we can see, this divergence in the use of the concept of inertia in economics has a fairly long history. But foremost, these changes are of interest to us because they were contemporaneous to the formulation of the inertial inflation hypothesis. Next section briefly outlines where the Brazilian discussion on inflation stood as of the late 2000's in order to better state the puzzle we set out to untangle in the next chapters.

\subsection{Inflation Inertia in Brazil: where do we stand?}

The "vicious spiral" that Keynes (1923) had mentioned back in the day grew more institutionalized and entrenched in the fabric of the Brazilian society, as indexing practices disseminated across the economy starting in the 1960s at the outset of the military dictatorship that took over the civil government in April 1964. By the early 1980s the economy had become almost entirely dependent upon formal and informal automatic nominal adjustment of prices and contracts in accordance with past inflation rates (see Simonsen 1995). Once the propagation mechanisms had overridden the price structure, the primary causes of inflation lost priority in the debate. Owing to this institutional detail, inflation inertia was thus understood as a downward resistance of inflation rates to conventional demand-management policies. Contention shifted towards the problem of how to coordinate a controlled dismantling of the sophisticated apparatus of index-linked contracts and prices in order to restore the effectiveness of economic policy channels. Any economic team envisaging a successful stabilization was thus expected to tackle this problem upfront. After several failed attempts in late 1980s, the 1994 Real plan in fact averted a soon-to-erupt open hyperinflation but, even in its indisputable triumph, it did not

persistence in the NKPC is the lagged inflation term. The amount of persistence imparted by the lag is quite sensitive to the size of the lag" and that the recently observed decrease in US inflation persistence has little to do with enhanced credibility of the monetary policy. Furthermore, he has come to admit that: "These conclusions have other important implications for price modeling in DSGE models. They suggest that the optimizing foundations in the standard specifications are nearly unrelated to the dynamics observed in the data for inflation and real marginal cost. That is, lagged inflation is not a second-order add-on to the optimizing model; it is the model. One may motivate price-setting behavior from these optimizing foundations, but in practice, they tell us little about why inflation behaves the way it does". A few years later, Fuhrer (2008, p. 2537) worked out a Calvo-based model in which inertia was finally achieved under optimizing-behavior assumptions. This was done as follows: "at the time of reset, firms may set a path of prices, in contrast to the flat price profile assumed in more traditional Calvo implementations. In particular, in this specification, firms are restricted to choosing a fixed slope for the price path. (...) The result is that in this specification, current inflation embodies both forward-looking influences and the history of inflation rates that are embedded in previously set price paths. In this way, the authors appear to have developed a micro-founded motivation for the long sought-after inflation inertia". Even so, "ad-hockness" in the definition of the model's assumptions is not prevented, as the author readily admits. Fuhrer nonetheless finds that if "price-setters cannot reset price paths when a shock of either kind hits, then disinflations are gradual and costly (and empirically plausible), and the response to mark-up shocks is transient (and strongly counterfactual)" (p. 2540). 
manage to provide a complete resolution to the indexation problem; at most, it alleviated the symptom down to bearable proportions. ${ }^{31}$

In what follows, we intend to show that the way economists in the economic team behind the Real plan saw inflation inertia and the problem of indexation was altered - if not underemphasized - in substance and scope soon after the stabilization plan had been launched (Bogdanski, Tombini \&Werlang 2000). Indexing of exchange rate and several other prices became a veiled incomes policy that was supposed to gear the Brazilian price system onto a sustained low-inflation path. Consequently, indexing practices were allowed, for instance, in public and private bond markets and for State-controlled prices of privatized public utilities companies, such as many types of services and housing rental fees. However, living peacefully - and without tears - with constant inflation constitutes no free lunch. Its most apparent cost of a non-zero steady inflation is a higher lower bound and an upwardly flexible ceiling to inflation rates, as goes the basic argument set forth by Gray (1976) and Fischer (1977). ${ }^{32}$

The imbalances that followed disinflation measures escalated along the next four and a half years, while stabilization was yet to be secured. Recurrent fears of a currency devaluation passthrough to inflation rested on the fact that full de-indexation was - if ever attainable - much trickier than it seemed. The fixed exchange-rate nominal anchor deteriorated sharply as a sequence of crises broke out in those developing countries relying on some form of exchange-rate control. Mexico underwent the "Tequila Crisis" in 1995. Two years later, in 1997, massive capital flights erupted a large-scale financial crisis in the East Asian countries. In 1998, Russia was subdued by the same fulminant attack against its currency, and Brazil followed suit in January 1999, when a severe external crisis hit the country. Brazil's exchange rate soared and the effects were quickly passed on to inflation indices. At odds with most pessimistic prospects, this inflationary spurt did not persist long and inflation receded in the following months. It appeared as though the Brazilian price system had been extensively cleared from its self-feeding inflationary engines. Under the

\footnotetext{
${ }^{31}$ See Banco Central do Brasil (2011 and 2012), Valor Econômico (2012) Mollo \& Saad (2001) and SeguraUbiergo (2012) for different views on this problem.

${ }^{32}$ As any welfare-promoting technology - however myopic may such a notion be - it swiftly spreads across economic groups. An illustration can be found in a recent government-sponsored incomes policy, whereby minimum wages were tied to two-year-lagged output growth and one-year-lagged inflation rate. Needless to stress that the emergence of systematic institutionalized pressures on prices, such as the one just mentioned, tends to restore automatic adjusting behavior to past inflation. Once the inertial component of inflation becomes more pronounced, the economy is rendered more sensitive to supply shocks.
} 
strains of these external shocks, a new economic policy was announced a few months later, sponsored by the International Monetary Fund, under the terms of a loan provided to alleviate the severe currency crisis.

The Macroeconomic Stabilization Program (PEM, in Portuguese) consisted of fiscal austerity (enacted by the Fiscal Accountability Act, approved by the Senate in the year 2000), a floating exchange rate and an inflation-targeting regime to monetary policy. The new program placed the focus of macroeconomic management on the interest-ratebased inflation-targeting regime. ${ }^{33}$ This system has been the main focus of economic policy ever since, and has been fairly successful in maintaining price rises within the intervals stipulated by inflation targets along most of the 2000s, and has reduced inflation volatility (see Bevilacqua et al. 2007).

It is beyond doubt that this regime has been the determinant factor for the Brazilian Central Bank's growing credibility in managing monetary policy. A glimpse at the performance track of the IT regime (Table 2) reveals that both interest-rate and inflation volatilities within fiscal years have been consistently low. Price dispersion rose temporarily in 2011 and 2012 but receded in 2013. Nonetheless, when conflated with historical inflation patterns in developed countries (within the 1-3\% range), the levels of inflation targets in Brazil (4.5\% per year) are high (Barbosa-Filho, 2008, p. 193). They reveal, on one hand, that inflation is under control - especially, when contrasted against the previous four-digit rates witnessed in pre-stabilization period; on the other hand, there seems to be a downward resistance of inflation levels coupled with a systematic attraction of inflation rates to the upper limit within the target range. Both aspects raise concerns over the effectiveness of the instruments available to the monetary authority (Tombini \& Alves 2006).

Recent concerns over policy innefectiveness in the face of an inflationary revival evoke the debates on inflation inertia of the 1980s. Whereas the acuteness of the problem in the post-disinflation period is nowhere near the one suffered back then, the essence of matters are quite similar. What are the causes of the "steady" inflation ever since stabilization? Is inflation in Brazil persistent or inertial in any sense? Does indexation has

\footnotetext{
${ }^{33}$ Further details on outcomes of the inflation-targeting regime in Brazil can be found in Barbosa-Filho (2008) and Bevilacqua et al. (2007).
} 
any role to play in this regard or is it simply an effect of an inflationary environment caused by other exogenous forces?

Table 2 - Inflation Targeting Regime Performance - 1999-2013

\begin{tabular}{ccccccc}
\cline { 5 - 7 } Year & & & & \multicolumn{3}{c}{ Volatility within Year** } \\
& Target* & Inflation Rate & Deviation & Headline CPI & Interest rate & Real \\
& $\mathbf{( a )}$ & $\mathbf{( b )}$ & $\mathbf{( b - a )}$ & $\mathbf{( I P C A )}$ & (SELIC) & GDP \\
\hline 1999 & 8,00 & 8,94 & 0,94 & $5,70 \%$ & $0,61 \%$ & $0,14 \%$ \\
2000 & 6,00 & 5,97 & $\mathbf{- 0 , 0 3}$ & $22,35 \%$ & $0,28 \%$ & $0,17 \%$ \\
2001 & 4,00 & 7,67 & 3,67 & $2,75 \%$ & $0,48 \%$ & $0,15 \%$ \\
2002 & 3,50 & 12,53 & 9,03 & $2,74 \%$ & $0,40 \%$ & $0,12 \%$ \\
2003 & 4,00 & 9,30 & 5,30 & $3,25 \%$ & $0,33 \%$ & $0,07 \%$ \\
2004 & 5,50 & 7,60 & 2,10 & $1,24 \%$ & $0,42 \%$ & $0,13 \%$ \\
2005 & 4,50 & 5,69 & 1,19 & $13,67 \%$ & $0,37 \%$ & $0,13 \%$ \\
2006 & 4,50 & 3,14 & $\mathbf{- 1 , 3 6}$ & $5,25 \%$ & $0,50 \%$ & $0,14 \%$ \\
2007 & 4,50 & 4,46 & $\mathbf{- 0 , 0 4}$ & $1,70 \%$ & $0,46 \%$ & $0,14 \%$ \\
2008 & 4,50 & 5,90 & 1,40 & $1,15 \%$ & $0,32 \%$ & $0,14 \%$ \\
2009 & 4,50 & 4,31 & $\mathbf{- 0 , 1 9}$ & $1,97 \%$ & $0,33 \%$ & $0,10 \%$ \\
2010 & 4,50 & 5,91 & 1,41 & $10,54 \%$ & $0,41 \%$ & $0,15 \%$ \\
2011 & 4,50 & 6,50 & 2,00 & $1,70 \%$ & $0,31 \%$ & $0,13 \%$ \\
2012 & 4,50 & 5,84 & 1,34 & $4,94 \%$ & $0,39 \%$ & $0,16 \%$ \\
2013 & 4,50 & 5,91 & 1,41 & $7,18 \%$ & $0,38 \%$ & $0,14 \%$ \\
2014 & 4,50 & 6,00 & 1,50 & $1,13 \%$ & $0,31 \%$ & $0,11 \%$ \\
\hline Average & $\mathbf{4 , 7 5}$ & $\mathbf{6 , 6 0}$ & $\mathbf{1 , 8 5}$ & $\mathbf{5 , 4 5 \%}$ & $\mathbf{0 , 3 9 \%}$ & $\mathbf{0 , 1 3 \%}$ \\
\hline
\end{tabular}

Source: Central Bank of Brazil. (*) Targets have a tolerance fluctuation range of $\pm 2 \%$. (**) Volatility indicators denote percentage variations of the Standard Deviations of Monthly Indices within fiscal years.

In the aftermath of the stabilization plan, reasoning on the inflationary process in Brazil seemingly shifted toward a more "conventional" understanding of the inflationary process. By conventional we mean the generation of models known of as the New Neoclassical Synthesis ${ }^{34}$, as we have just seen in the preceding section. The NNS program regards inflation inertia as a given property of the system, which is embodied in a statistical regularity, namely: an autoregressive coefficient of inflation rates (Fuhrer 2008). By this

\footnotetext{
${ }^{34}$ Our goal is not to present a detailed account of the inflation-targeting framework or the more general traits of the emerging consensus on monetary policy, which can be found in Goodfriend \& King (1997; 2004). but rather to point out that its application to policy decisions may have unintended effects (Arestis \& Sawyer, 2003) when it comes to an economy with deeply-rooted conflict-infused inflationary memory, such as Brazil. For instance, Bogdanski et al. (2001) discuss its application and point out its shortcomings and the challenges the Inflation Targeting framework faces. Therefore, one cannot say such theoretical apparatus has not been naively done by monetary authorities in Brazil.
} 
token, the concept of inertia proper has become quite simply a statistical carry over between two quarters due to the introduction of lagged inflation variable into a price equation.

The above description of the inflation inertia problem stands in sharp contrast with the copious literature spawned in the early 1950s in Brazil. At this time, the problem of rigid inflation patterns was explicitly theorized with careful consideration of a broad set of historical, institutional and structural features in a dynamic analysis that tried to encompass the observed facts. In this context, "inflation inertia" was seen as the outcome of interaction among agents' aspirations and expectations - largely influenced by the social groups they were attached to -, institutions of incomes policy, bargaining power and price controls of some sort, structural shocks (e.g., currency devaluations) and the monetary and fiscal policy guidelines, to state a few. Although the models developed in the $1980 \mathrm{~s}$ in Brazil lost most of the previous historical and institutional underpinnings, they still go far beyond the NNS approach when it comes to accounting for institutional singularities, working out their implications on inflationary behavior. Hence the chief purpose of this thesis: to understand how Brazilian economists came to accept the conceptual change of "inflation inertia" from a multifaceted dynamic process into a sole statistical regularity in search of solid microfoundations. 


\section{Chapter 2 - Anticipations of the inertial inflation concept}

A spawning literature on the causes of inflationary pressures within the Brazilian tradition of economic thinking appeared in the 1950s, when the Latin American lineage of economic thought, labeled structuralists, proposed that inflation was the result of underlying structural imbalances in the economy, not of excessive monetary emission (Furtado 1954; Rangel 1963). A whole range of determinants were combined within one analytical structure, such as the market power of oligopolistic corporations, the specific inelasticity of the supply of agricultural products and the secular effective demand problem due to highly concentrated income distribution profile that marked the Brazilian economy. This stood in stark contrast with the conventional monetary quantity approach to inflation, whereby it would be always and everywhere a monetary phenomenon (Friedman 1963; Gudin 1962). Therefore, these ideas were brought to life within the so-called "structuralist-monetarist stabilization debates" that took place in the 1950s and the 1960s (Boianovsky 2012).

Our narrative begins with a selective outline of the forerunners of the non-monetary approaches to inflation and then moves to the analysis of the debate between orthodoxy and heterodoxy in the 1950s, when the Economic Commission for Latin America (ECLA, henceforth CEPAL) began its tour de force against the theoretical and policymaking influence arriving from the Northern hemisphere. The then recently established Keynesian orthodoxy on macroeconomic matters faced the opposition of the so-called monetarist counterrevolution, beginning in the early 1960s and reaching its peak-influence along the 1970s with the overall diagnosis of "stagflation" in the aftermath of Richard Nixon's devaluation of the dollar, the dissolution of the Bretton Woods policy apparatus and the 1973 oil shock. It follows through the intense reaction among the academic economists to the stabilization strategies proposed by the IMF to the debt-overburdened countries in Latin America and in other parts of the world in the aftermath of the 1982 debt crisis triggered by the Mexican default on external debt service payments in August of that year. The ensuing economic landscape provided multifaceted challenges to policy makers, which elicited an intellectual ambience highly fertile for theoretical innovation on matters of stabilization policy.

\subsection{Income distribution models of inflation in the Post-war period}

The Second World War turned inflation into an ongoing concern, due to military spending that generated excess demand, boosting price upwards. "Inflation gap" theories were a natural response to such conditions. Soon thereafter, the Korean conflagration induced 
further excessive military expenditures leading to an inflation burst. Continuous rises of the price level became an ever-present concern, even in the absence of war. In many countries, inflation posed serious economic threats. The newly crafted international monetary system of fixed exchange rates turned commercially uncompetitive those countries facing higher inflation. Balance of Payments problems gave rise to surging demands for foreign loans in a low-liquidity international financial market. Keeping inflation in line with that of other countries - namely, US inflation - was thus a way governments found of keeping their countries solvent in terms of foreign currency. This in turn required curtailing output growth, so as to keep imports and inflation controlled (see Backhouse \& Boianovsky 2013, chapter 2)

From 1945 onwards, the rise of inflation as a first hand concern produced copious theoretical material. The Great Inflation entailed a trend in economic reasoning which points to a gradual dominance of mathematical formulations and a sort of mechanical explanations of inflation. Bronfenbrenner \& Holzman (1963) provides the first widely encompassing survey on inflation theories. Following Frisch (1977), we call it the first generation appraisal of the economics of price rises. The authors are careful in stating that the difficulty in defining what it means to talk about inflation reflects the degree of confusion in the field. Albeit unstated, the authors seem (p. 639-640) to side with Turvey's (1951, p. 534) "unusually comprehensive definition", which includes cost-push in the factor markets and excess demand in output and factor markets: "the process resulting from competition in attempting to maintain total real income, total expenditure, and/or total output at a level which has become physically impossible, or attempting to increase any of them to a level which is physically impossible" (quoted in Bronfenbrenner \& Holzman 1963, p. 600). The survey is divided amongst types of approach according to the ascribed cause of inflation. First, the demand inflation (p. 600-613) comprises the postwar Keynesian inflationary gap approach and "monetarist" claims done by Friedman (p. 602), as well as the many sectoral takes on the upward bias in the price level (p. 612), where the authors fit the Latin American structuralist view of price inflexibility and the price-elasticity of output (p. 610).

Second, the supply of cost-push inflation was attributed to the $19^{\text {th }}$ century Banking School and to Keynes of the Treatise and How to Pay for the War. In this segment, several forces are lined up to explain the upward pressure on prices, such as the elasticity of demand for labor and the bargaining power of workers (the more inelastic the demand for labor for groups of laborers, the more wages can be pushed up), the factors relating to supply of labor, 
that is, the control unions have over the amount of manpower and thus on the wage negotiations, where relative wage and productivity differentials come into the decisions to bid up wages. In this instance, the degrees of militancy and inter-union rivalry are important elements of the "pushfulness" of labor unions over Management (Bronfenbrenner \& Holzman 1963, p. 618-620). The third element refers to markup pricing, which tends to facilitate the inflationary potential of cost-push pressures under conditions of stable or gently rising demand, as well as rigid prices at low levels of activity. Under oligopolistic structures, "markup pricing translates rigid wages (downward) into a price floor" (p. 621). Finally, the "profit-push" inflation reflects the presence of "administered prices", allowing firms to raise markups without any increase in costs or in demand, thereby raising prices. (p. 622).

Starting in 1948, pure cost- and mixed-inflation models started to appear in which economists assessed the features of "wage-profit-price-spiral process", which seemed a "clearly observable phenomenon" (Bronfenbrenner \& Holzman 1963, p. 623). The basic model rests on the idea that inflation results from excessive competing claims on the national output through the web of monetary arrangements that interconnect all individual and groups of income-receivers in a given society. Inflation is brought to a halt when the changes in these arrangements suit the economic objectives held by all those enthralled in the dispute for greater shares of aggregate income. This approach lends itself to the influence of sociopolitical interpretations (p. 624) for, at high levels of employment, no group can improve its real economic position without another group losing: "If, under these conditions, the distribution of income were determined in real terms, open social strife and tension would be much more common, and social cleavages would be significantly more marked than they are" (p. 626). Inflation, via money illusion, acts as a "social mollifier" by allowing various social groups to raise their money incomes (and perhaps real incomes) without cutting any other group's money income. The sociological considerations barge in monetary relationships through the "trilateral monopoly of unions, employers and monetary authorities" (p. 626). This latter is forced to choose between full employment and price stability as its primary goal. By choosing the former, the price-level determination is left to the collective bargaining and, hence, inflation serves a real socio-economic function (a safety valve) that can only be replaced by a rapid rate of economic growth, which can meet all income demands upon the available produce of society. ${ }^{35}$

\footnotetext{
${ }^{35}$ This choice between employment and stability engenders the "dilemma model" (p. 626), which denotes the practical impossibility of achieving simultaneously the twin goals of full employment and price stability, in the
} 
At last, the survey deals with the "speed, duration and extent" of inflation (Bronfenbrenner \& Holzman 1963, p. 639-652). Given their understanding of inflation as the result of conflicting excess claims on the amount produced, the speed of the process relies in "the reactions of various income and spending groups in the economy" to a demand or supply inflationary shock. If reactions and successive "reactions to reactions" are "numerous, rapid and vigorous" inflation can become explosive. The factors on which depends the wide range of possible outcomes are said to vary from nation to nation and from time to time depending on: the militancy of labor unions; commitment of authorities to full employment; climate of popular opinion regarding increases in standard of living, future price trends, etc.; marginal propensities to spend and the degree of price-elasticity of expectations, amongst other factors. (p. 640). We highlight three factors cited by the survey that will inform our later discussions, that is, the effects of lags, wage escalation and consumers' expectations. Lags are important breaks to inflation, rendering the process manageable, with particular importance to wage lags due to the time-consuming collective bargaining process and the normal time lapse between price changes and their reflection of cost-of-living indices. Wage escalation has its impact determined by the frequency of adjustment and by the percentage of the labor force covered: "If the total labor force were covered, and wages were escalated immediately and proportionately to changes in the CPI, a crucial stabilizing 'lag' would be eliminated from the wage-price system" (p. 643). Instability is enhanced if automatic adjustments according to CPI and to increases in productivity are granted. Finally, consumers' expectations of price increases may alter the time pattern of spending. These expectations are partly couched on the perceived duration of price increases ("the longer that prices continue to rise, the larger the percentage of households aware of the trend" - p. 645), but they are believed to cause and "once and for all" price rise, but not to lead to continuing inflation, unless a rising price elasticity of expectations occurs, which has been associated with the acceleration of prices during a hyperinflation fueled by a generalized "flight from cash", as in Philip Cagan's model (p. 643-646).

\footnotetext{
absence of price and wage controls. Prices may rise before full employment of labor not only because of market power, but also due to diseconomies of scale and low marginal elasticities of substitution between productive factors, as well as the fact that non-labor factors can be overemployed while unemployed labor exists. ${ }^{35}$ Related to the problem of defining the goal of policy, Reder (1948) presents the interesting "trilateral monopoly" model, whereby three groups (State, Labor Unions and Entrepreneurs) with monopoly power and no available substitutes for the services rendered by each interact in a type of strategic game, with varying compositions of relative power and coercive capabilities. Unfortunately, Reder's model, albeit analytically rich, was never extended or further elaborated.
} 
The survey ends with an analysis of the redistributive effects of inflation, which are a function of each group's abilities to foresee inflation and to adjust their economic behavior (e.g. include escalation clauses in wage contracts; invest savings in inflation-corrected bonds or common stocks etc.). The authors foresee that "inflation theory may soon reach a new synthesis around which an increasing proportion of students can find a meaningful basis of agreement" (p. 652). Although the survey has "under-stressed unintentionally the sociological, institutionalist, and structuralist literature" (p. 652), it is to this approach that we turn into in what follows.

\subsection{The Latin American Structuralism: Structural Rigidity and Inflation}

By the 1960s, the American Economic Association (AEA) considered inflation to be a contemporary economic problem, alongside employment and the resumption of economic growth. ${ }^{36}$ If it was considered a troubling matter in countries with moderate inflation, one can easily divine how worrying it was for balance-of-payment-constrained economies such as those in Latin America, facing high chronic inflation (see Backhouse and Boianovsky 2013, pp. 17-20). Therefore, the growing attention inflation received in the north finds its counterpart in the southern hemisphere, particularly in Latin America. And when Latin American economists thought about inflation, it was to their northern neighbors they looked for analytical frameworks. Until the 1950s, the dominant influence comes from various forms of the quantity theory (see Craven 1994) based on classical dichotomy reasoning that assumed the efficiency of the market mechanism as a resource-allocating device. The Keynesian revolution had questioned such type of analysis on methodological, theoretical and empirical grounds.

Skepticism regarding the resource-allocating effectiveness of the price system stems from the debates in Britain in the post-War period, when Keynes' disciples and followers were at pains with the neoclassical theory of market competition and the free market ideology that sprung from it, under the severe attack of Friedrich Hayek's Road to Serfdom. From the viewpoint of Cambridge-friendly economists, the war had changed the fundamentals of the economies around the world, imposing great rigidity onto the price system, requiring corrective measures by way of government policy. This was not, however, solely a Cambridge matter. At Oxford, Michal Kalecki and Dudley Seers were providing the theoretical basis for development policies (see Arndt 1985, p. 155). The Oxford Institute of

\footnotetext{
${ }^{36}$ For more details on the post-War economic landscape, see Backhouse and Boianovsky (2013, chapter 2).
} 
Statistics published its The Economics of Full Employment, in 1944, where they exposed the view that the regulation of the economic process by market forces ought to be "supplemented by conscious and deliberate regulation of public authorities". The waves generated by such changes in thought went, however, much farther beyond the confines of the British academia.

The appearance of a Development Theory in the early 1950s provides an interesting turning point in the making of post-War economic theory. The initial set of structural hypotheses was formulated in the 1950s by Paul Rosenstein-Rodan, Ragnar Nurkse, W. Arthur Lewis, Albert Hirschman, Walt Whitman Rostow, Hans Singer and Gunnar Myrdal, which indicates that structuralism as a general anti-market viewpoint is to be found in the post-war planning debate (Boianovsky, 2010).

The presence of large disequilibria and inflexibility of response to price incentives was an empirical truth in the Least Developed Countries (LDC) context, being frequently claimed that resources are peculiarly immobile in them. The price mechanism was viewed as a poor guide for investment decisions. The free play of market forces engendered unacceptable social costs in the form of rising national and international inequality, especially in the least developed countries. This alternative approach leaned on an understanding that phenomena taking place in underdeveloped economies would unravel differently from those observed in advanced economies. ${ }^{37}$ Such unconventional economics furnished the framework that guided activities of consultants in countries facing the challenges of industrialization by way of substitution of imports. In this regard it is, from the start, largely policy-oriented knowledge.

Although one can hardly dismiss the centrality of CEPAL to the development of the original structuralist inflation theory, CEPAL's theoretical contribution cannot be fully understood outside the broader international debate on issues of growth and distribution. And by "international" we mean both Anglo-Saxon and continental European economic thought, for before Kalecki, Kaldor and Chenery ${ }^{38}$ brought something of Keynesian flavor to the table, Swedish and French economics offered some insights into the historical, institutional and

\footnotetext{
${ }^{37}$ This seems to be the fundamental plea in Gunnar Myrdal's Economic Theory and Underdeveloped Regions, published in 1957. For further details on "political prices" and State intervention in the economy, see Myrdal (1957, p. 49).

38 We quote Arndt (1985, p. 155) at length: "Kalecki impressed Noyola; Kalecki, Kaldor and Chenery all wrote before Sunkel; and the two latter spent some time in Santiago while the structuralist theory was developed there. It cannot be said that they brought structuralism to Latin America - as we have seen, it was already in the air but there can be little doubt that they provided an important intellectual stimulus to its formulation. They constituted a direct link between the structuralist thinking that had emerged in the war and post-war years in Britain (and to a less extent in the USA) and the Latin American structuralist theories of inflation".
} 
social dimensions of inflation. Nevertheless, the scholarly visits of British and NorthAmerican economists to Latin America had the (unintended) effect of bringing the structuralist viewpoint to the fore. Such academic interactions raised enormous controversy, which ended up disseminating the rather unorthodox claims to other LDCs and also to European and North American audiences.

Various historical accounts of the "structural inflation theory" have illuminated a significant range of questions in this regard. But they either convey an excessively linear story (as in Arndt 1985) or they focus solely on highlights of the conceptual evolution of the problem of a self-sustaining inflation (as in Ramalho 2000), or dig into specific authors' contributions (as in Palma \& Marcel 1989) or yet the scope is narrowed down to a limited time span of this long-standing debate (as in Boianovsky 2012). We contribute to the literature with an assemblage of these various approaches, fleshing out the narrative structure with an emphasis on the methodological dimension of Latin American structuralist theory of inflation, with particular attention to Celso Furtado's forerunning depiction of the real income patterns under chronic inflationary conditions. ${ }^{39}$

Next section draws attention to the later post-Keynesian contribution by Nicholas Kaldor, which proved largely influential in describing the self-replicating pattern of inflation through its "vicious spiral" mechanism in subsequent decades. We believe it has informed not only the later structuralist formulations by Felipe Pazos, as it also provided the general framework that would be later picked up by the monetarism-friendly M.H. Simonsen. Following assessment of Kaldor's work, we look briefly into CEPAL's main claims on inflation theory within the controversy between structuralists and monetarists. Finally, we detail the early discursive representations of the saw-tooth model of real wages as well as

\footnotetext{
39 The contentious environment of the 1960's where monetarists and structuralists disputed primacy over stabilization policy after taking hinges on the general substance of a fertile debate on trade cycle theories up to the late 1930s and the emerging economics of growth of the post-War period, for they provide the common language and set-up of ensuing academic exchanges. The seminal Cambridge-UK formulations by J.M. Keynes ([1923] 1963; ([1936] 1964; 1940) and Michal Kalecki (1943; ([1943] 1971, chapter 12; 1954b) on the "vicious spiral" and the "inflationary effects of the rigidity of food supply", respectively, can be coupled with the historical and institutional framework of inflation set forth by François Perroux and Henri Aujac (1950), at the École des Hautes Études Sociaux in France. Additionally, James Duesenberry's (1949) dynamics of social aspirations, writing at the Harvard University in the United States and Bent Hansen's (1951) two-sector inflation gap model under the assumption of imperfect competition and his seminal description of an inflationary monetary equilibrium with a real wage "saw-tooth" pattern all come to compose a much richer narrative of the post-war theoretical accounts of inflation. However, in the interest of brevity, we sidestep the detailed history of the pre-, wartime and immediate post-war forerunners (and, perhaps, forebears) of the inertial inflation concept that conspired in unintended fashion to form a breeding ground for theoretical novelties in the following decade of the 1960s.
} 
some notes on the early history of these mechanical models, which will become quite instrumental in reasoning about inflation, in the early 1980s in Brazil.

\subsection{The First Round of the Monetarist-Structuralist Controversy}

The monetarist-structuralist debate on growth and inflation was staged in the post-War period and can be simply defined as contest between market and planning technologies for the status of best promoters of economic development. The controversy gained momentum due to theoretical and political opposition to the anti-inflationary programs in Latin America (Boianovsky 2012, pp. 277-284). ${ }^{40}$ These were sponsored by the Bretton Woods Institutions, such as the International Monetary Fund (henceforth, $\boldsymbol{I M F}$ ) and the Bank for International Development (BID), later renamed under World Bank (Hirschman 1962, p. 82). Thus the term "monetarist" referred to these specific set of policies, which usually included tighter credit constraints, cuts in public expenditures, partial wage freezes, devaluation and the repeal of various types of subsidies and direct controls.

In a nutshell, monetarists hold that inflation may only temporarily promote economic growth. It is however incompatible with it and must be stopped quickly, before it degenerates into explosive tensions, and the only effective method seems to be the curbing of excess demand through a prudent combination of monetary and fiscal policies supplemented by international financial assistance. Finally, most of the alleged low supply elasticities and bottlenecks are not autonomous or structural, but are caused by price and exchange rate distortions generated during the course of the inflationary process itself; (Campos 1962, p. 6970). In sum, based on Latin American experience, Campos alleges that bottlenecks were originally inflation-induced; even though at a later stage they may become inflation feeding.

On the other camp, the Latin American structuralist school supported a specific view of the world, by which reality is seen as irreparably inflexible, given the widespread existence

\footnotetext{
${ }^{40}$ A detailed analysis of complementary aspects of the monetarist-structuralist controversy can be found in Grunwald's analysis in Hirschman (1962, p. 108). The terms "structuralist" and "monetarist" were first used in a clear and systematic fashion by Roberto Campos - one of the orthodox-friendly contenders, alongside Eugenio Gudin - in the 1961 Conference in Rio de Janeiro on matters of monetary stabilization along the development process. The term appeared first in Hirschman (1962). Inflation had bedeviled Latin America for decades, being Chile the most conspicuous case of ineffective struggle against a chronic inflation. For more historical details on structuralism, see Arndt (1985, p. 154). On a different note, this controversy evokes a longer history than the scope we are setting up here, one that stretches back to seventeenth-century Swedes (see Kindleberger 1985 and Taylor 2004, chapter 2). Boianovsky (2012) documents that "the development of the monetary approach to the balance of payment in the 1950s proceeded independently of the later debates between monetarists and Keynesians (...). Indeed, as pointed by one of its creators, it was the Latin American experience at the time that set off discussions at the Fund that led to the monetary approach".
} 
of bottlenecks, obstacles and constraints that inhibit changes. Inelasticity of supply is taken as given, due to underdeveloped technological apparatus. Market processes left unassisted would have limited power in promoting economic progress stressed the need for State action (Little 1982, pp. 20-21) as well as a rampant skepticism is directed at the price system as an ideal resource-allocating device. ${ }^{41}$

The 1949 Manifesto put forth by Raul Prebisch sets the tone for a whole lineage of models determined to take account of the diverse economic structures to be found among Latin American economies. This diversity required specific theoretical developments and, as a result, tailored policy making. These were the general premise underlying the works of the Latin American Structuralist School, such as those of Raúl Prebisch, Celso Furtado, Ignácio Rangel, Juan Noyola Vásquez and Osvaldo Sunkel. Their writings tackled many dimensions of economic development, among which we will single out only the theories of inflation. ${ }^{42}$

However, the development of an original theory is hardly born out in a vacuum. As we said above, the international influences were crucial to stir up controversy that triggered innovation in CEPAL. Kalecki visited Mexico in 1953, as an advisor for the International Monetary Fund to attend a seminar organized by the Center for Latin American Monetary Studies (CEMLA). Kalecki presented a series of lectures, which were published one year later in El Trimestre Económico (Kalecki 1954b). The core message was that rising prices tend to appear as a side effect of a country's rapid march towards economic development. ${ }^{43} \mathrm{He}$

\footnotetext{
${ }^{41}$ Criticism of the price system as an ideal allocation device is set on three grounds. The first is the signaling component, whereby market prices would fail to mirror the economy's relative scarcities, due to the exercise of market power, the existence of externalities and economies of scale, which required state-driven development policies in order to surmount the difficulties imposed by such real world traits. The second component is the response mechanism, which claims that people in traditional societies do not respond to economic incentives, or respond perversely (backward-sloping supply curves), leading to theories of economic dualism. The third deals with the aspect of resource mobility, by which the price system would not entail the proper incentives to move resources around the economy. For instance, the irresponsiveness of investment to changes in the interest rate; the adverse effects of exchange devaluation over the balance of payments, later dubbed "elasticity pessimism"; and the limited and varied effects of wage dynamics on the distribution of labor. For more details on these general assumptions and the historical connections with theoretical developments carried out at Oxford and Cambridge-UK, see Arndt (1985, p. 151).

${ }^{42}$ A survey of early contributions can be found in Fonseca (2000) and Boianovsky (2012).

${ }^{43}$ Kalecki works out a model in which there at three economic groups sharing the proceeds of their productive efforts, namely: workers, capitalists and the small-scale farmers. In distributional terms, the power structure of production was organized to the disadvantage of labor, so that any increase in prices would most likely fuel demand for luxury goods by higher income receivers. However, only enlarged imports could supply the goods demanded by large-scale landowners, commercial and financial entrepreneurs and the like. In the meantime, the gross majority of rural population would not increase its demand for manufactured goods, which was bound to generate excess capacity in these latter industries, a tendency likely to be enhanced by higher degrees of monopoly in manufacturing - usually sown into underdeveloped countries by foreign corporations. In the limit but not necessarily as far -, the import requirements of development (e.g. capital goods and raw materials) would
} 
devised pressures entailed by an inelastic supply in agriculture under the increasing demand for foodstuffs accompanying a urbanization process, coupled with a higher degree of monopoly power by foreign corporations in underdeveloped countries.

The most distinctive about Kalecki's approach was the relevance of non-economic categories to the dynamical properties of the model. In this case, a "quasi-feudal pattern of landholding" (Danby 2005, p. 164) was central to the limited elasticity of food supply, which boosted prices upwards and reduced urban real wages. The ensuing wage-price spiral then hindered further development via a premature rise in manufacturing prime costs. Owing to these "primary" pressures, inflation is then transmitted as cost increases onto the rest of the economy, via wages trying to catch up with prices, a direct application of bottleneck inflation mechanism with a wage-based propagation effect. ${ }^{44}$ This is an invaluable anticipation of what was being nurtured inside CEPAL.

Structuralist models would eventually gain notoriety due to its originality, but also through the encouragement coming from scholars working at notorious academic institutions. Dudley Seers's papers on the matter, published in the CEPAL's Bulletin in February of 1962, and in the Oxford Economic Papers later that same year were of crucial importance. Besides those, three excellent studies by Roberto Campos, Joseph Grunwald and David Felix were published in the same year in a volume edited by Hirschman (1962), named Latin American Issues, which will provide us with an outline of the "monetarist-structuralist controversy". One year later, interest in the approach had skyrocketed, with an impressive conference on "Inflation and Growth in Latin America" being held in Rio de Janeiro, where some 80 economists attended amongst which were Arthur Lewis, Anibal Pinto, Raúl Prebisch, Juan Noyola, Osvaldo Sunkel and Celso Furtado (Baer \& Kerstenetzky, 1964; Boianovsky, 2012). The dispute between these sides of the quarrel began a few years earlier, and in a moment when the dividing line was somewhat blurry.

entail a tug-of-war with the consumption of luxury goods, triggering external imbalances that were usually corrected by inflation-feeding currency devaluations. Given the monopolistic power of industrial firms, distribution would shift to the benefit of the capitalist and landowning classes.

44 Given the institutional nature of these basic imbalances in relations of production - termed "primary inflationary pressures" (Kalecki, 1954b, p. 401) -, these non-monetary pressures are immune to neutralizing measures based on "purely financial instruments", such as control of credit and money supply.That Kalecki would use such terms is not surprising at all, once acknowledgement is made of the author's engagement in early econometric developments of time series alongside Ragnar Frisch and Jan Tibergen. This literature is fraught with mathematical modeling of "impulses and propagation mechanisms" in trying to explain the behavior of trade cycles (see Morgan 1990, chapters 2 and 3). 


\subsubsection{Nicholas Kaldor's interpretation of the Chilean inflation}

In 1956, Nicholas Kaldor was invited to spend a three-month stay in Santiago, Chile, at the Headquarters of CEPAL. He was asked by Prebisch to deliver a series of lectures on fiscal matters for development policies. Out of this sabbatical in Latin American, Kaldor provided great stimulus for the debate on inflation and growth. ${ }^{45}$ In his assessment of Chile's economic problems, Kaldor ([1956] 1959 and 1957b) noticed a low rate of gross fixed capital formation, barely sufficient to cover the annual depreciation of the capital stock. This datum stood in striking contrast with the high share of profits in Chilean's national economy, which was not accompanied by a high rate of savings. The reason for this lied in the high propensity to consume of the property-owning class, largely geared towards luxury consumption. ${ }^{46}$ Investment was thus scathed by this low propensity to save. Kaldor proposed an efficient system of taxation on purchasing power of high-income classes (and also on profits) in order to release resources to improve the country's productive structure. ${ }^{47}$ This point is essential to understand the dynamics of growth and distribution for which Kaldor is notorious, but it is instrumental to grasp his take on inflation in Chile.

Kaldor's (1957d) model asserted that a long-lived period of inflation has led different sectors in the economy to develop mechanisms to protect their incomes and assets from the erosion of inflation. This de facto indexation ${ }^{48}$ system had rendered the credit system endogenous to pressures on prices (p. 271), which are, in turn, caused by the inability of the wage-goods sector - particularly agriculture - to keep up with the growth in demand that results from rapid urbanization and the expansion of manufacturing employment, not mention workers' militancy in raising wages in accordance with productivity increases in this latter sector. The combination of bottlenecks in the primary goods-producing sector and

\footnotetext{
${ }^{45}$ There is a copious literature on this period Kaldor spent in Latin America. Given our limited scope, we refer the reader to Palma \& Marcel (1989) and Furtado's (1985) autobiography, where he comments on Kaldor's contribution and his interaction with the Cambridge-based economist.

${ }^{46}$ Kaldor estimated that roughly two-thirds of this class's gross income or three-quarters of their net income after tax was destined to consumption.

${ }^{47}$ Interesting developments surround the publication of Kaldor's papers by CEPAL. Due to the political implications of advising for an expenditure tax on property-owning classes in Latin America, Prebisch caved to political pressure of certain governments, especially Mexico, and prohibited the publication of Kaldor's paper on the expenditure tax as an official document by CEPAL. The paper was later published in El Trimestre Económico in 1957. His paper on the Chilean inflation did not face any censoring constraint and was published in 1956. For more details, see Palma \& Marcel (1989) and Furtado (1985).

${ }^{48}$ The expression is found in Palma \& Marcel (1989, p. 254). The authors claim that Kaldor implicitly assume that Kaldor had grasped the inertial component into price dynamics. This is true in hindsight, but it should be clear that Kaldor does not use the term, although a self-feeding engine to inflation is explicitly recognized in his writings.
} 
productivity-tied wage increases sets a "lower inflationary barrier" to upward pressure on wages and salaries. Rising prices of wage-goods depress real wages in manufacturing, adding a further component to wage claims in this part of the economy. Should workers attempt to channel their increased nominal incomes to wage-goods, a self-reinforcing inflation process ensues $^{49}$ (Kaldor 1957d, pp. 274 and 277).

The two-sector model highlighted the interaction between agriculture and nonagricultural sectors within a development process. Balanced growth between the agriculture and manufacturing was required in order to curtail harmful inflationary pressures. Imbalances arose from structural differences regarding the institutions governing these two sectors, namely: the absence of a "proper 'capitalist' class" in agriculture and the prevalence of "semifeudal" landholding institutions (p. 239). Instead of monetary laxity, the problem of inflation emerged from the pre-capitalist character of the agrarian property, which in turn rendered the market mechanism unable to find the equilibrium between the two sectors. Equilibrium was brought about through redistribution of real income between both sectors in favor of a very inefficient agricultural sector, whilst imposing a continuous source of inflationary impulses, which benefit mostly the property-owning class. Inflation was the result of underdeveloped institutions and structures of production infusing cost-pushes up onto prices. This is why Kaldor strongly advocated against the adoption of stringent credit and monetary policies, in situations such as these. Curtailing credit would only lead to further social loss in terms of unemployment, leaving the primary pressures of inflation untouched.

Criticism came immediately from Latin American economists at CEPAL, and referred to both scope and level of institutional detail heeded in Kaldor's analysis. ${ }^{50}$ First, the model

\footnotetext{
49 "It was the rise in food prices which caused the increase in the demand for higher wages and salaries- in order to restore real wages to the levels they had already, if only temporarily, attained-thereby raising the general level of industrial costs and prices. The inflation therefore was 'demand induced 1 as far as agricultural products were concerned; and it was 'cost induced' as far as the non-agricultural sectors were concerned... If this analysis is correct, no lasting cure of the inflationary tendencies in Chile can be found either in stricter monetary and credit policies or even in administrative reform which secured more effective taxation of the upper classes. No doubt both monetary and fiscal policy could make important contributions towards the attainment of monetary stability... But the lasting cure for inflation can only be found through a more rapid increase in food availabilities - either through a more rapid increase in the productivity of agriculture (which in turn hinges upon the reform of land tenure) or a more liberal policy for importing foodstuffs from abroad" (Kaldor 1956, pp. 274 and 277).

${ }^{50}$ Kaldor's model was highly mechanical and had the purpose to reveal some institutional barriers to the full functioning of the equilibrating properties of markets. His core argument was that for the same reason that the low propensity to save of the property-owning class in low development countries rendered shifts between wages and profits ineffective for growth and employment purposes - due to heightened propensity to consume luxury goods - the lack of price-elasticity of supply in agriculture rendered moot the redistribution of real income
} 
portrays a closed economy where the chief original or primary cause of inflation stems from the agricultural sector. It thus leaves out the pressures running in from foreign trade (the Prebisch-Singer hypothesis of deterioration of terms of trade) and its connection to the fiscal cycles (tax collection relied heavily and somewhat irrationally on exports proceeds), the structural features of the public sector, as well as the specific character of the distributional conflicts in the region. Notwithstanding critique, structuralists did not disparage Kaldor's basic claims, but aimed to complement them with structural and historical causes and how the economic system learned to accommodate such pressures turning policies centered on strict monetary and fiscal control not only ineffective but also costly in economic, social and political terms. It is at this juncture in the analytical framework that CEPAL parted with the influence coming from the north. Let us turn to these historical and institutional features in more detail.

\subsubsection{CEPAL and structural inflation}

The strategy of industrialization via import substitution pursued by many latecomers was subject to major controversy within the economics profession from 1950s up the 1980s. The overarching structural changes entailed by this type of program rendered the idea of a balanced growth path quite unappealing to economists involved in development economics. In contrast, the qualitative and quantitative effects of rapid growth on the profile of supply and demand required out-of-equilibrium analysis of the dynamics of growth, income distribution and inflation. Moreover, such a framework sought to incorporate the institutional and societal features of underdeveloped economies.

Starting from the overall terms-of-trade cycle of countries with a lowly diversified primary-export structure, the combination of export price instability, low diversification of exports and a general tendency to maintain overvalued currency are prone to generate selfreproducing scheme of periodic inflationary pressures. An increase in export prices raises tax revenues and improved the current account, leading governments to expanded public expenditure and to sustain an overvalued currency that allows for increased consumption from abroad. This internal expansion persists until a deterioration of terms of trade reverts trade surpluses - thus lowering tax collection - and trigger currency devaluation, introduced costshift inflationary pressures. Tax collection was not satisfactorily protected against inflation, due to lags in collection and to inadequate methods of adjusting the value of property for tax 
purposes. As a result, public investments were bound to become the "safety valve" under the pressure of this shrinking (or oscillating) aspect of public revenues, which were added to an already narrow system of social security and a downwardly rigid system of compensation of public servants. ${ }^{51}$

The distributional conflict dimension turns relative price changes into inflation (Sunkel 1958, p. 111). In this respect, the social structure of Latin American countries - with varying degrees, of course - is quite peculiar in that the urban middle classes are large in size and in power, which gives them a strong position to push for increases in earning beyond productivity growth, setting the pace for wage increases across the economy. This "demonstration effect" instills further inflationary bias into wage negotiations, for these latter tend to account not only for rises in food prices but also for differentials in levels of salaries and wages in both private and public sectors. ${ }^{52}$

The "basic structural factors", previously advanced by Kalecki (1954b) - when he visited Mexico in 1953 -, are seen as are the causal forces of inflation and are distinguished sharply from circumstantial, cumulative or propagation factors. Inelastic supply means roughly that supply of goods and services does not adjust sufficiently fast to meet not only a rising demand but also a change in the pattern of demand without serious price pressures. Infrastructure faces a pronounced rigidity, inducing a lack of flexibility in production. In a nutshell, bottlenecks spring from low mobility of resources. These are endemic to underdeveloped economies bedeviled by inefficient labor and capital markets, limited capacity to import and a monopolistic development in industry and in the distribution system, fostered by the small size of the domestic market. ${ }^{53}$

The "circumstantial factors" refer to non-systematic non-economic forces sprung from exogenous import price increases, political upheavals, catastrophes and irrational government interventionism; deficient public administration, lack of coordination and multiple and badly

\footnotetext{
${ }^{51}$ See Furtado (1976, p. 118-130) for a late summary of this approach, and Felix (1962) for an earlier account. A recent appraisal of the quarrel was provided by Boianovsky (2012, p. 286-294), where one can find the basic contentions.

${ }^{52}$ For further details on specific case studies where this methodology is applied, see Furtado (1970, p. 126-130).

${ }^{53}$ Additionally, the unequal distribution of income implies a certain composition of demand both domestically and for imports, which is not conducive to a high growth rate. The savings rate is exceedingly low not only because of low income levels but also due to a completely disproportionate propensity to consume of the upper income groups, whose habits are entirely out of line with those of equivalent income groups in more developed countries. At last, there is secular rigidity emanating from the instability in public revenues in the face of the rigidity of government expenditures, consisting mostly of salaries and social security contributions.
} 
employed controls. Finally, the "propagation mechanisms" relate to those furthering and aggravating the inflation problem, namely, the distributional conflict amongst social groups over national output, as Aujac (1950) had previously worked out, which in turn is bound to affect the institutional arrangement of monetary relationships. Both conflict among groups and institutional features interconnected processes in a complex history-dependent web of causation. They arise from the capacity of the various sectors of the economy to defend their real income, such as credit mechanism, automatic cost-of-living wage and salary adjustments and government deficit spending. Although they are not the root cause of inflation, they act to amplify the embedded rigidity in the structure of production.

An important aspect of inflation has to do with the impact of real forces on the value of money. The crux of the non-monetary view of inflation lies in the imperfect adjustment of prices along the chain of production. ${ }^{54}$ Imbalances in the real side cause an intrinsically monetary phenomenon in its nature. Given a finite elasticity of supply and demand for goods, any change in relative prices will encounter a downward inflexibility of monetary prices inside the actual proceedings of the capitalist organization, and will be translated into a rise in the general level of prices. An "autonomous" inflation thus emanates from pressures arising within the changing economic structure, which then triggers accommodation by monetary authorities or by the banking system; hence the passive money hypothesis (see, for instance, Sunkel 1958; Olivera, 1960, p. 626; and Furtado [1964] 1965, pp. 105-110). ${ }^{55}$

Structuralists believed this basic framework provided a powerful device to undertake historical analysis of underdeveloped economies. The stylized structuralist narrative goes as follows. During the process of development of countries' productive forces, a change in the productive structure is likely to occur which has far-reaching implications in terms of technological diffusion and factor mobility across sectors, as well as persistent alterations in the composition of demand. Under circumstances of a changing structure, mobility of factors

\footnotetext{
${ }^{54}$ Olivera (1967a) would later formalize his argument in a two-sector model (see next chapter), in which differences in elasticity of demand and supply promote sustained structural pressures over prices, termed "structural inflation". The main argument states that the Walras' law act in preventing the transmission of relative price changes to absolute prices only if the system adjusts rapidly. If the transition from one equilibrium point to another is sluggish, inflation ensues, in order to restore some consistency to the system. Chapter 3 below further analytical details.

${ }^{55}$ The monetary adjustment under such conditions is always imperfect. If it is insufficient, the level of capacity utilization will drop, whereas the excessive printing of money will generate demand-led pressure over prices. This makes money a passively adjusting variable, rather than a fully controllable exogenous one. A nonmonetary theory of inflation is thus required, in order to search "beneath the monetary surface, into the underlying region of physical flows, real prices and sectional disequilibria”. (Olivera, 1964, p. 322).
} 
and flexibility of prices are of paramount importance. For reasons of technological backwardness, ubiquitous rigidities are expected to arise within the productive structure, pressing specific prices upwards. If other prices do not decrease in response, relative prices change and most likely exert a further round of pressures upon the price structure. These forces in turn surface as cost- or demand-related forces; hence the bottleneck-related causes of inflation.

The above reasoning begs the question of how to tame these forces. Stucturalist claimed such basic pressures could only be dealt with by furthering economic development and technological change, which may render the economic structure more flexible in the medium- or long-run. Hence, the main structuralist policy-related contention is that orthodoxmonetarist monetary policy can only address propagation factors of inflation, leaving unresolved the original impediments to the smooth adjustment of the economic system. Thus, according to this view, monetarist emphasis on the functionality of money supply expansion in promoting inflation is rather irrelevant in the context of rising social tensions. As for the monetarist assertion of inflation-induced bottlenecks, structuralists buttress their case by referring to the pre-industrialization era in Latin America and to the conditions that have guided the subsequent industrialization effort. Latin American countries entered their industrialization era burdened with a domestic capitalist class of limited investment horizons and weak propensities to accumulate, and a low and regressive tax structure that hampered public capital formation. Therefore, structuralists found, on historical grounds, a causal priority of the supply rigidities, which generate chronic inflationary pressures and the monopoly pricing and social tensions which generalize these specific upward price movements, which make expansion of the money supply nearly inevitable (see Grunwald 1962). ${ }^{56}$

\subsubsection{Furtado's view of inflation: institutional and technological inertia}

Celso Furtado's version of inflation reflects and echoes the contributions set forth by Kalecki, Kaldor and the reactions by economists at CEPAL. He has contributed with a rich historical-institutional interpretation of inflation in Brazil. He describes the historical

\footnotetext{
${ }^{56}$ This is not to say that structuralists regard inflation as a viable long-run solution to Latin American growth problems; for many of the Latin American writers, it is rather seen as a manifestation of a deformed economy. Also, they accept that IMF-type stabilization programs may reduce some of the deformities in the economy. But since these latter are viewed as secondary malfunctions, such programs do not remedy the more basic imbalances that retard economic growth. On the other hand, they do act on the degree of greater efficiency, but do so at the cost of reduced employment and stagnating output, a socially untenable solution.
} 
experience of the country with the problem and turns it into a by-product of the pursuit of a differential structure of production. Interestingly, he couples his rigidity-based framework with an understanding of "inertia peculiar to institutional patterns", hereby understood as the sluggish response by the "ruling classes" in adapting the banking system and the government's fiscal structure to the demands of a development process. Furtado also finds an insufficient national supply of capitalist entrepreneurs in both manufacturing and agriculture that could slacken some of the bottlenecks that hamper the take-off stage of industrialization (Furtado [1962] 1965, p. 113-117).

An apparent ambiguity in terminology that has generated a great amount of controversy in the 1960s regarding what structuralists defined as "structural pressures". Furtado (1976, p. 124) defines them as follows: (1) the inelasticity of supply of agricultural products, (2) inadequacy of the infrastructure, (3) short-term inadequacy of labor, (4) increased financial commitments and (5) the inadequacy of fiscal systems. The first four items are readily understood as rigidity-related. Even so, as regards human resources Furtado defines the lack of entrepreneurial experience to impose some hindrance on advancements of the import-substitution effort. The fifth has to do with the frequent need to resort to external finance, which will eventually press against the availability of foreign reserves, once interest payments start to accrue to the external sector.

The fact that the fiscal and financial systems are intentionally regarded as structural factors impinging on inflation - and not, as expected, a propagation mechanism - reveals the element of "institutional inertia". These are associated with the lack of responsiveness of ruling classes to development spurts, and not to short-term fiscal policies. In fact, public deficits spring exactly from the tendency to sustain a highly inefficient and regressive tax structures with a rigid pattern of public expenditures, especially in the face of a Statedependent process of rapid industrialization. The lack of a fully developed financial system forces the government into inflationary financing of deficits via several monetary channels institutionally built to advance credit to both the State and the private sector. ${ }^{57}$

This is a straightforward understanding of inflation as the result of the State imposing its claims on the pie at the expense of other social groups, which are powerless to prevent the

\footnotetext{
${ }^{57}$ Furtado (1954, [1959] 1963, [1962] 1965) set forth a comprehensive account of Brazilian inflation. Osvaldo Sunkel (1958) followed Noyola (1956a) and provided a structuralist analysis of the Chilean inflation.
} 
expropriation of their real income by the government. ${ }^{58}$ Much later, Furtado would assert: "the State is greatest beneficiary of inflation", due to its incapability in financing its expenditures (interview to Biderman, Cozac \& Rego 1996, p. 82). This striking inflation tax argument by Furtado is thus telling of a gravely misunderstood dimension of structuralist reasoning, namely, that of fiscal and financial policies. Fiscal and credit system reforms are fiercely advocated by this school, but with a different goal in mind than that of orthodox-type of reasoning: it is not aimed at curbing inflation, which is seen as an inevitable outcome of the march towards progress. Rather, it must act to unleash the forces of structural change to promote economic development. This is perhaps why it is frequently believed that in terms of structuralist policy proposals "specifics vary and the details are distressingly vague" for structuralists are clearly "more united as critics than as programmers" (Felix 1962, p. 83).

Some final remarks are in order as regards priority in the full theoretical development of the structural inflation by the joint efforts carried out by the Mexican economist Juan Noyola Vásquez (1956a) and Chilean economist Osvaldo Sunkel (1958). Boianovsky (2012, p. 293-295) has thrown light on Furtado's thinking on the matter and on how it temporally precedes the publications by Noyola; this latter is portrayed by Craven (1994) to have undergone a transformation from a IMF-orthodox-friendly to a structuralist approach to inflation. On the other hand, Danby (2005) has rightfully claimed that Noyola's framework is much more sophisticated and detailed than that of Furtado (1954), a claim to which Furtado (1970, p. 118) himself has implicitly subscribed. Although Furtado's early take on inflation may be construed as a highly rudimentary framework for analysis - granted it was not part of his central message - it anticipates the essence of a whole lineage of later inflation models, such as Simonsen's (1964) “sociological” framework, Hicks's (1974, chapter 3) and Tobin's (1981) views of inflation dynamics based on societal groups competing for the relative income positions, as well as the distributional conflict approach set forth by Rowthorn (1977) and the second-generation structuralist models of inflation hotly debated during the 1980s hyperinflation scare in Latin America. ${ }^{59}$ But, lying between the early readings of the

\footnotetext{
58 This phraseology, as many other examples, has led Craven (1994) and others to find the influence by Aujac (1950). Note, additionally, that the concept of "conventional expectations", in the Keynesian sense, is deconstructed as "power-based coercive relations" within a given societal hierarchy. Indirectly, this notion anticipates Rowthorn's (1977) distinction between "expectation" - which is the act of speculate on future events - and "anticipation" which requires the economic agent or group to be empowered to act on these speculations.

${ }^{59}$ Celso Furtado (1954) drew on - without referring to - Henri Aujac's framework to explain how the actions of social groups put the flows of income into motion, in a struggle to enhance their relative command over the society's output surplus. Inflation was thus the end result of social struggle among social groups to shift the distribution of income towards their end. Incompatibility of aspired nominal income shares required prices to
} 
inflationary bias in developing economies and these latter is the shift in economic discourse, tipping towards mathematically mechanical models.

\subsection{The Furtado-Kaldor-Pazos Mechanism}

To the Latin American audience, the theoretical framing of this particular regularity was conveyed in the "inflation feedback model", which was developed indenpendently by Mario Henrique Simonsen (1970) and by Felipe Pazos (1972). The model is an ingeniously simple way of portraying an economy with a persistently high inflation trend. The coupling together of inflation-correcting schemes, such as index-linking of contracts and prices, and a gradual approach to anti-inflation measures, sponsored by governments in Latin America, give nominal contractual incomes a visual pattern with a resemblance to a "saw-tooth", as shown in the Figure 2 below, for the case of a constant average real wage ( $w^{\text {ave }}$, in the diagram) over time and adjustment according to the recorded inflation rate within each period.

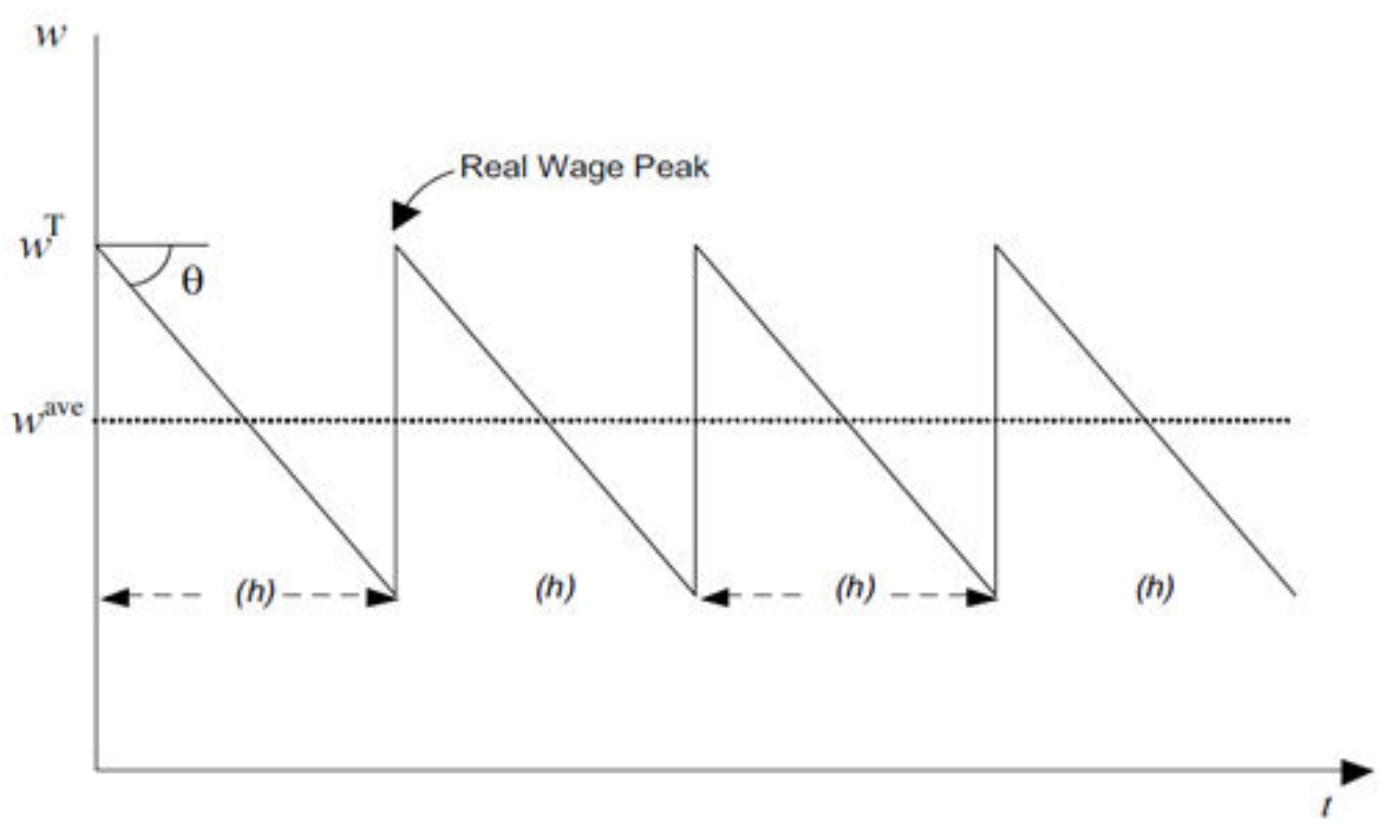

Figure 2 - Sawtooth Model or The Simonsen Curve. Source: Vera (2013a, p. 269)

rise. The most powerful groups imposed real income losses to those devoid of economic significance. In his 1962 Diagnosis of the Brazilian Crisis (published in English in the following year), Furtado ([1962]1965) spells out the entire process of inflation, ascribing the roles to each group and the reactions entailed by the social system to the impending struggle for larger pieces of the national output. In his memories, Furtado (1985, p. 120128) recollects his stay in Paris in late 1940s, where he was closely connected to François Perroux, whose approach to inflation is quoted in Aujac (1950) as inspirational of the latter's working hypothesis. It should also be pointed out that A.C.L. Day (1952), on the Economic Journal in the September edition) was one of the few reviewers of Bent Hansen's (1951) book, as well as the translator of Henri Aujac's paper in the same volume of collected essays published in the Journal International Economic Papers where one of Celso Furtado's ([1952] 1954) paper appears right after Aujac's abovementioned contribution. It is possible that Noyola may have been picked up on Aujac's working hypothesis through this channel as well. 
Vera (2013a) has recently challenged the claim regarding the authorship of the model commonly ascribed to Simonsen and Pazos - retrieving some overlooked documents that bear out Nicholas Kaldor's (1957a, 1957b, 1957c) innovative input in the early debates concerning economic theories and policies of growth, distribution and inflation in Latin America. In what follows, we take issue with this interpretation and provide further evidence of an even earlier recognition of the same pattern, in addition to Bent Hansen's en passant depiction of the process in his 1951 book (see chapter 3, section 1).

After his stay in Chile, Kaldor travelled to Brazil, in October 1956, where he attended a meeting of the International Economic Association and gave several lectures on the relationship between agriculture and industrialization in developing countries, which can be found in Kaldor (1957b). In his analysis of the connection between inflation and development, Kaldor (1957c) set up a verbal model of conflicting claims that accounted for the self-sustaining pattern of inflation. Moving away from sectional imbalances, Kaldor portrayed inflation as the result of insufficient savings while the economy is in the midst of an investment boom. Price rises thus elicit profit inflation in the early stages. Assuming that output is supply-constrained and unresponsive to shifts in demand, profits rise faster than wages, inducing increased capital accumulation and consumption of luxury goods. This typical "forced savings" argument is amended to include the need for a continued rise in money wages. In the upswing of the cycle, workers' bargaining power is enhanced and the fear of strike action leads capitalists on to grant wage increases.

In evaluating wage dynamics, Kaldor (1957c, p. 75) assumes that nominal wages are periodically adjusted to cost-of-living indicators (p. 66-67), but readily devises an asymmetry between the frequency of price adjustments and those of wages ${ }^{60}$ : "while the adjustment of prices to changes in wages is gradual, the adjustment of wages to changes in prices tend to occur periodically considering, at one stroke, the accumulated change in the cost of living relative to some previous base date" (p. 75). He then draws out a straightforward regularity from the real wage behavior in an inflationary environment: "Real wages thus fluctuate around an average set by the extremes of the level of wages immediately prior to and immediately after a particular adjustment".

Next, Kaldor describes the visual pattern of real wages when the inflation rate picks up speed: "The characteristic of the wage/price spiral is that the zig-zag becomes increasingly

\footnotetext{
${ }^{60}$ Henceforth, the translation of Kaldor's (1957b) quoted excerpts is the one published in Vera (2013a).
} 
compressed - the periods between subsequent wage adjustments tend to become successively shorter. This means, of course, a continued acceleration in the rate of increase in the general price level" (Kaldor 1957c, p. 75). This description is followed by the diagrammatic representation, in the Figure 3 below, of the process of erosion of the purchasing power of nominal wages under persistent inflation.

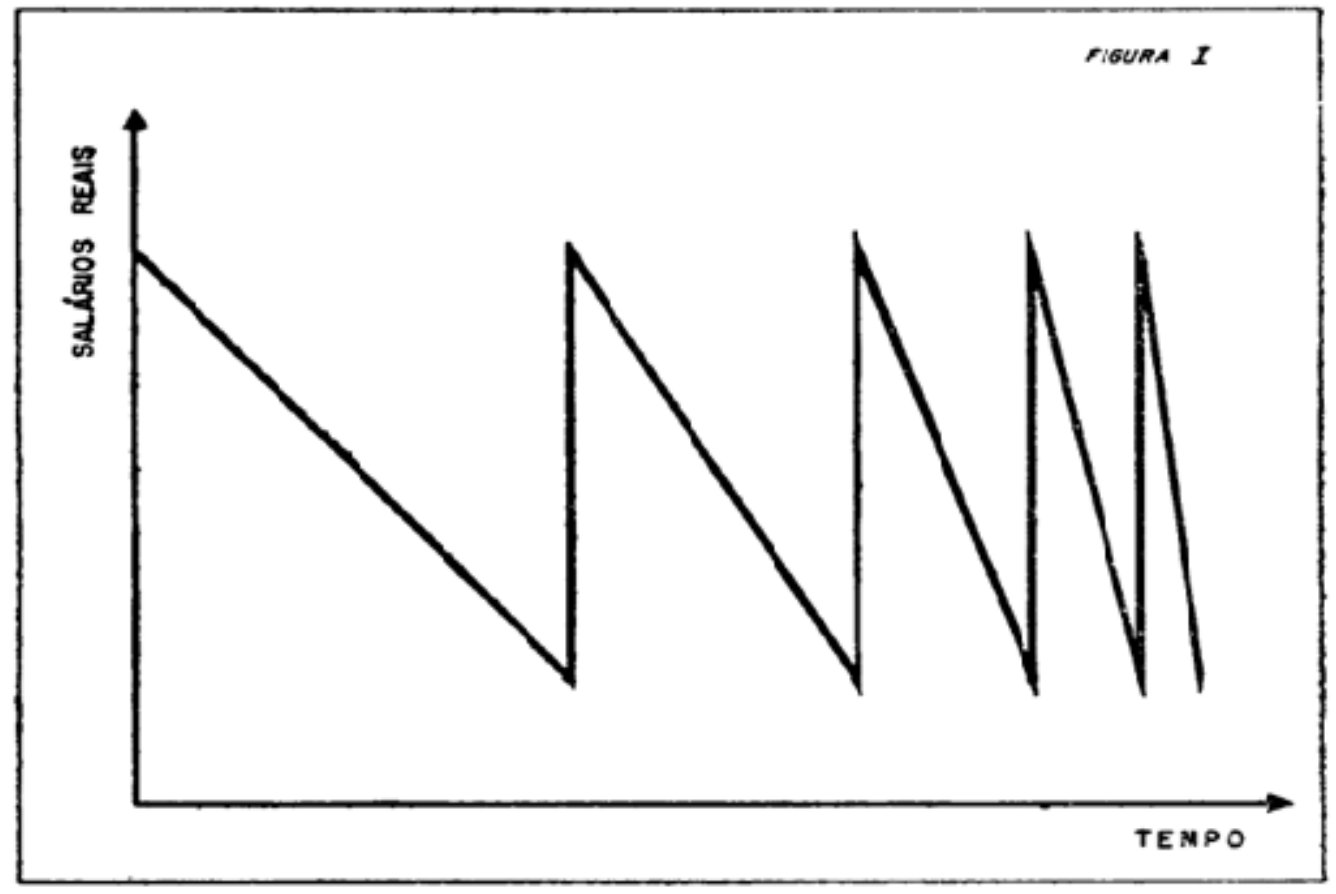

Figure 3 - Kaldor's Real Wage “Zig-Zag” diagram. Source: Kaldor (1957c, p. 68).

We agree with Vera (2013a, p. 277) in that Kaldor's relevant contribution to this debate extends beyond the mere graphic representation of the "saw-tooth model": he should also be acknowledged for having anticipated the impact of endogenous variations in contract length in the acceleration process of inflation. Vera's findings provide further insight into the dissemination of scientific knowledge while raising further questions concerning how Kaldor conceived of this idea. The author himself recalls Feiwel's (1975) reminder that scientific work does not occur in a vacuum and, by this token, no discovery is totally new. Let us explore this maxim further.

\subsubsection{The discursive representation of the saw-tooth pattern of real wages}

In his magnum opus, The Economic Growth of Brazil, Furtado ([1959] 1963, chapter $\mathrm{XXXV)} \mathrm{had} \mathrm{tackled} \mathrm{the} \mathrm{"two} \mathrm{sides} \mathrm{of} \mathrm{the} \mathrm{inflationary} \mathrm{process",} \mathrm{that} \mathrm{is,} \mathrm{"the} \mathrm{reason} \mathrm{why} \mathrm{prices}$ rise on a persistent basis" and "the effects of such rise on the economic process". Furtado touches on the problem of "historical tendency" to price level rises in the Brazilian 
economy. ${ }^{61}$ But how would such a propensity to price level increases affect the dynamics of the economy?

Furtado starts out with a dynamic equilibrium concept of neutral inflation from the distributional standpoint. A neutral inflation implies that a distributional profile is left unaffected by the rise in the price level. As a dynamic concept, it is observed along a process of adjustment, e.g. one-year-long circuit. At any point during this period, "there is bound to be a group ahead of others in the struggle for the redistribution of income". This group would benefit enormously from the stabilization of the price level at that point. Dynamically speaking, even if one could find an "average pattern of income distribution in a one-year stretch" and assuming prices stabilize around this pattern through sequential price and wage adjustments, at no single moment would all incomes be in mutual consistency.

When all groups are equipped to defend themselves and have a clear notion of the position they occupy in that moment's distributional profile of the economy, a successful stabilization becomes a troublesome task, for it is very unlikely that every group would be entirely satisfied with end result (Furtado [1959] 1963, p. 239). To this effect, any stabilization program would face insurmountable hurdles due to this staggered structure of price and wage behavior. This self-reinforcing struggle leads to the "elevation of the price level goes on displacing the system from one unstable equilibrium position to the other" with no automatic - or even existent, to that effect - countervailing process to restore the system to a stable equilibrium position (p. 239 - English in the original). ${ }^{62}$

Later, in his Diagnosis of the Brazilian Crisis ([1962] 1965, p. 101-113), Furtado amended his earlier notion with an appraisal of the unbounded excitement of distributional struggles that eventually degenerates in a inflationary spiral. As inflation becomes an inseparable part of the growth process, its positive effects upon output growth cease and "the reaction of the working masses becomes increasingly rapid, and adjustments to earnings have to be made at increasingly shorter intervals"; this implies losses to wage-earners that are

\footnotetext{
${ }^{61}$ At that point of his argument, such propensity reflected the process by which the exporting sector transferred its windfall losses to the whole of the community during the cycle troughs and periods of overproduction. This distributive imbalance impaired the workings, Furtado added, of the Gold Standard in Brazil.

${ }^{62}$ Despite Furtado's lack of emphasis on the relevance of neutral inflation, this is the first real theoretical assessment, as far as we know, of a fully indexed economy in Latin America. Although Noyola (1956a) had come to grips with something alike, as Boianovsky (2012, p. 293-294) notes, this chapter of Furtado's 1959 book is but a literal copy of an excerpt (pages 174-187) of his 1954 book on the Brazilian Economy (Furtado 1954), thereby anticipating Noyola's view on inflation as distributional struggle among income claimants and, possibly, as a neutral phenomenon from the distributive point of view.
} 
"probably greater than the gains still made from inflation by the capitalist class". This is the "sterile phase of inflation" or the pointless "game of passing the buck" (p. 107 - English in the original).

Three points are worth stressing here. First, Furtado's reasoning on neutral inflation relies on a sophisticated and abstract conflicting claims approach that glaringly resembles the analysis in Aujac (1950). Second, his narrative is surprisingly mechanical in form. ${ }^{63}$ Third, at the risk underemphasizing the historical context of his thoughts on inflation, Furtado was prescient, as early as 1954 -, of the challenged posed to disinflation measures by the lack of synchronism among the adjustment frequencies of contracts and prices, a problem that would bedevil policymakers in charge of stabilization plans in the 1980s. In light of this, Furtado di not believe "neutral inflation" to be of any significance to economists; it would be a "sterile process" in the march toward development, for it entailed absolutely no real effects on the allocation of resources (Furtado, [1959] 1963, p. 239), a conclusion that Simonsen (1970b, p. 208) would later agree with in its entirety.

If we turn to empirics, although Furtado is clearly alluding to wages at large, available data on real minimum wage in Brazil is consistent Furtado's basic dynamic framework. Figure 4 below visually depicts the distributional dynamics Furtado has in mind. However, the data evokes not the "neutral" inflation, by which the peak real wage should be lined up at the same level through time. Instead, it displays a continuously rising peak-real minimum wage in both Getúlio Vargas's (1951-54) and Juscelino Kubitschek's (1956-1961) administrations.

It is rather revealing of the intellectual landscape of those times that these saw-toothshaped wage dynamics were developed in synchrony with the full-blown adoption of government-sponsored import-substituting industrialization effort, that is, from 1951 forth; hence the idea that inflation is both cause and effect of distributional patterns along the cycle of adjustments to structural changes. It is somewhat striking that Furtado's straightforward contribution to a dynamic understanding of inflation has been so widely overlooked (as in, for instance, Palma \& Marcel 1989, p. 254), when its basic narrative is practically a verbatim reproduction of Kaldor's (1957c) scheme.

\footnotetext{
${ }^{63}$ No wonder it reflects with astounding precision the later narrative entailed by the mathematical saw-tooth model. At the risk of anticipating the later stages of our plot too soon, one cannot help but be struck by similarity in the discursive structure between Furtado's take on neutral inflation and later representations by the eocnomists at PUC-Rio, in the early 1980s (see Lopes \& Williamson [1978] 1980 and Modiano 1988 and Chapter 4 below).
} 


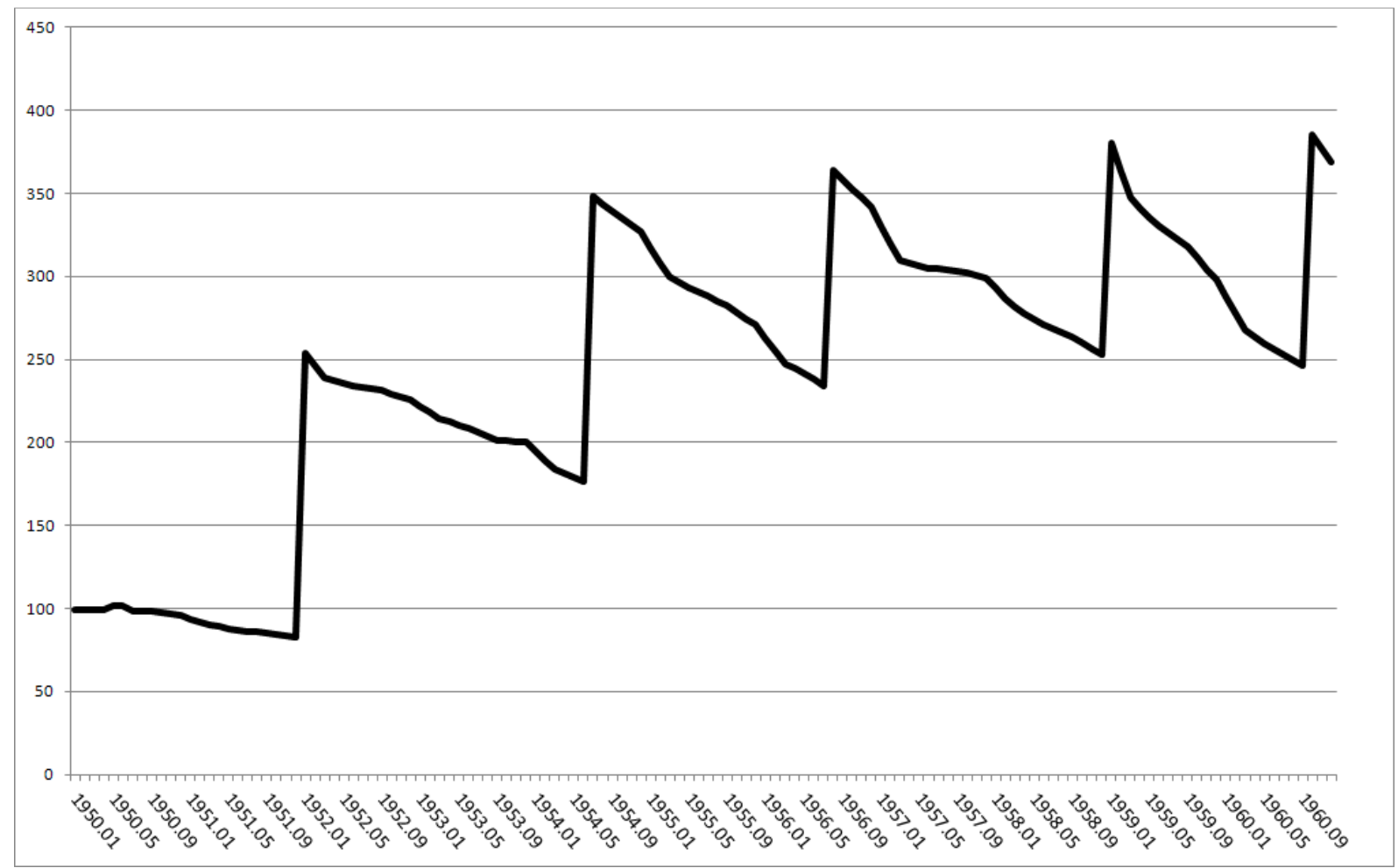

Figure 4 - Real Minimum Wage (July 1994 = 100) for Brazil: July 1950 - December 1960. Source: Institute for Applied Economic Research (IPEA - GAC12_SALMINRE12).

Almost a decade after Furtado’s (1954) published his view of inflation, Pazos's (1963) first writing on the oscillating pattern of real wages appeared in his book "Notas para un Estudio de la Espiral Inflacionaria", published by the Mexican journal El Trimestre Economico in 1963 and also in the first volume of the "Centro de Estudios Monetarios Lationamericanos" - CEMLA with the support by The International Monetary Fund and the Interamerican Bank for Development (IBD), both from Washington D.C. Pazos (1963, p. 612) presents a table with nominal and real wages within a staggered structure of wage adjustments. ${ }^{64}$ A few years later, Pazos's 1969 book, entitled Medidas para detener la inflación crónica en América Latina, brought the following diagram on Figure 5 below, in which the author showed not only the saw-tooth pattern of real wages but also the lack of synchronization among settlement dates (Sueldos y Salarios Reales, at the bottom of the picture). Real wages refer to the economy of Chile between April 1962 and March 1963.

\footnotetext{
${ }^{64}$ Although it is still quite vague in its shape, the oscillating behavior of wages is taken into account, when he states that "real wages vary throughout the year and at any moment, except for a brief interval, the wages of each group of workers is above or below its annual average. This circumstance creates serious difficulties to the application of a wage freeze that proves fair and effective at the same time" (Pazos 1969, p. 612 - Spanish in the original).
} 
Pazos delves, on Chapter 5 of the book, into the problem of wages. First he deals with the "intervals in between adjustments" and verbally states the sawtooth pattern. ${ }^{65}$

Pazos then briefly discusses the "defense mechanisms" workers develop in the countries facing chronic inflation, such as Chile, Argentina, Uruguay and Brazil. Indexation, the distribution of wage settlement dates and workers' bargaining power all come into the analysis. Morever, Pazos is careful to state the relationship among wage contract length, the distribution of settlement dates along the year and the correlation between the magnitude of the wage adjustments and the rise in cost of living since the previous settlement. ${ }^{66}$ The mechanism outlined for wages are extensible to other types of contractual incomes, such as rents and debts. This arrangement entails "an average inflation that is pushed by forces generated in the preceding twelve months"; hence the self-feeding autoregressive pattern of inflation. More than that, the very struggle among the different groups and sectors to obtain larger shares of total income is also grounded upon the inflation inherited from the previous year. (p. 66). At this juncture, Pazos (p. 67) states, for the first time, the notion of "inflation inertia" based on a staggered structure of price and wage adjustments. ${ }^{67}$

\footnotetext{
${ }^{65}$ We quote him at length: "Labor contracts in the countries under study have, by a general rule, one-year duration and its expiration dates are scattered across the following twelve months, even though they do not follow an entirely uniform distribution. At the time of renovation of each firm's contract, workers and employers convene to decide how much money will be spent for the various types of labor and, once accorded, such values are maintained constant for a year. Because at the moment of negotiation of each new contract the current wage has a lower purchasing power than it did twelve months before, and because it is expected that the new wage will lose its purchasing power in the twelve subsequent months, the employers concede a readjustment that is of a sufficient magnitude so as to be at the same time corrective and preventive. The real wage thus rises vertically at the settlement of the new contract and then lowers uninterruptedly throughout the year. (Pazos, 1969, p. 62-63 Spanish in the original).

${ }^{66}$ Altogether, they account for "a mechanism that gives average inflation many of its more peculiar and important characteristics, such as: a) its continuity; b) its compatibility with various economics situations; c) its difficulty in being curbed by policies of wage control; d) its propensity to generate real output contraction whenever demand management policies are attempted; and e) the upper bound set to its amplitude of adjustment" (Pazos, 1969, p. 65 - Spanish in the original).

${ }^{67}$ We quote Pazos at greater length: "The rise in wages and other costs, following the mechanism of alternated adjustments described above, makes inflation continue by the law of inertia, without the need to be propelled by autonomous pressures of demand, costs or of supply; and on top of this self-sustained movement of costs and prices lie the pressures generated by the variations of expenditures and tax collection by the government; of the real wage levels; of investments and private consumption, facilitated or checked by the volume of bank credit; of the harvests; of the price and value of exports; of the type of trade; etc. (...) The fact that inflation proceeds in the midst of great set of diverse movements of the national output and of the balance of payments is explained on the grounds that a considerable part of the rise in prices is generated through the internal mechanics described above; and to the rise of prices due to endogenous forces we must add the external pressures" (Pazos, 1969, p. 67 - emphasis added - Spanish in the original)
} 


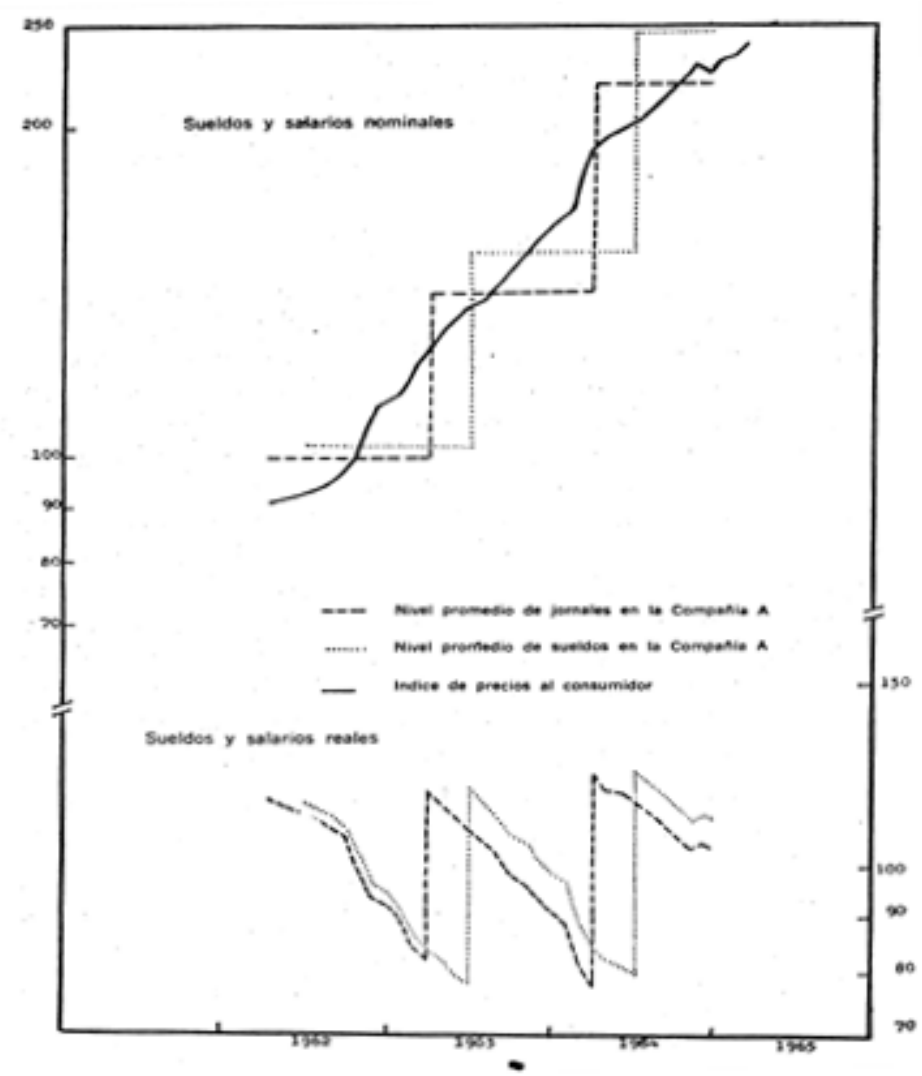

Figure 5 - Sawtooth pattern of real wages (Sueldos y Salarios Reales, at the bottom of the picture) in Chile between April 1962 and March 1963. Source: Pazos (1969, p. 62).

Finally, the shortening of wage adjustment interval narrows down the time distances among settlement dates of various groups, until it disappears completely and, when this takes hold, "the transmission of inflationary pressures through time also disappears" and the pressures are no longer passed on to the next period, but are completely dissipated within the very period in which they are generated and, thus, vanishes any connection between current and future inflation (Pazos 1969, p. 69-70).

The fact that more than one economist was able to devise this pattern in seemingly independent fashion from each other, suggests that scattered (and unsubstantiated) notions regarding the phenomenon were probably "in the air". At least a handful of authors had dwelled with this systematic and periodic pattern before the late 1970s, when some Brazilian economists at PUC-Rio put forth a systematic formalization of it (see Chapters 4 and 5 below). Some did it verbally, such as Kaldor, Furtado and Pazos, while Kaldor illustrated it graphically and, as Chapter 3 will show, Bent Hansen and Mario Henrique Simonsen approached it mathematically. We have shown above that the models of first-generation structuralist were formalized in discursive form, that is, borrowing Morgan's (2012) expression, in a "sea of words". They defended this core analytical thrust on a methodological 
basis. The contrast between this mode of reasoning and the indisputable mechanic form of the real wage pattern analyzed thus far provokes the suspicion that they shared a common cognitive procedure, at one level of abstraction higher. Next section entertains the hypothesis that this shared style of thought was borrowed - however unconsciously or unintendedly from the emerging field of operations research, from the late 1940s onwards. This detour in our narrative is important to enhance the argument made in Chapter 3, that the rise of mechanics performed a role in the later development of the inertial inflation paradigm.

\subsubsection{The origins of the general mechanics of the saw-tooth diagram}

The evidence on the connections we a trying to purport is still scant but a set of inklings points us in the direction of our general claim. ${ }^{68}$ The first is provided by one of Kaldor's biographers, who reports that

In 1945 he was seconded to the United States Strategic Bombing Survey, where he worked with a talented team of economists that included John Kenneth Galbraith (the Survey's director), Paul Baran, Edward Denison, Fritz Schumacher and Tibor Scitovsky (...). In the following year Kaldor worked briefly at the Ministry of Defence as adviser to the British Bombing Survey, and also advised the Hungarian government on postwar reconstruction (King 2009, p. 57).

The intellectual environment of the wartime was highly conducive to the fertilization of economic ideas by modeling formats borrowed from mathematics and engineering. At the time, operations research was one of the central areas of investigation in the border among social and exact sciences (see Whitin 1952 and Mirrowski 2002). ${ }^{69}$ As it so happened, this intellectual environment is likely to have influenced Kaldor in depicting the way he did the problem of real wages under chronic inflation, as just seen above. But how so? Inventory

\footnotetext{
${ }^{68}$ As we have seen previously, Kaldor had relevant contributions in an extensive list of topics in economics, mostly concerned with "real world" problems of welfare (cost-benefit) analysis, development, growth and distribution and taxation policy. He also took part in several government positions and was a renowned economic advisor on matters development policy for governments all around the world. According to J.K Galbraith's autobiography, by being such a star economist and by taking part in such high-profile dwellings, Kaldor was certainly in close contact with developments in cutting-edge economics of those times, given his conspicuous presence in Lionel Robbins's world-class seminars at the London School of Economics (LSE) and, later, holding a teaching position at Cambridge University. In what follows, we line up a few pointers regarding the academic context of Kaldor's contribution.

${ }^{69}$ Mathematicians, physicists and engineers migrated into Economics joined economists in applying linear programming techniques into this wide-encompassing area of operations research, which sought to do away with the supposed lack of rigor of the social sciences, at least from the standpoint of those hard sciences. In this sense, the Cowles Commission stationed at the University of Chicago was crucial to the developments we are about to turn to. In 1948, when the RAND Corporation becomes the main patron of Cowles, a major shift in the research agenda leads concerns toward the axiomatization of choice theory, seeking to provide the operations research quarters optimal decision rules (see Mirowski 2002, chapter 4).
} 
management policy was among the areas covered by this institutional effort (see Metzler 1941 and Arrow, Harris \& Scarf 1958, chapter 1). As it turns out, the visual pattern extracted from inventory theoretic approaches was revealed as quite influential on the economics profession of that time.

In the summer of 1950, a paper entitled Optimal Inventory Policy was presented by Kenneth Arrow, Theodore Harris and Jacob Marschak (1950) - henceforth, AHM - at the Logistics Conference organized by the RAND Corporation, in Santa Monica, California (see Arrow 2002). The article outlines a method for deriving optimal rules for inventory policy of finished goods. In the analysis of the "case of certainty", a deterministic model is presented, which establishes a constant flow of demand for goods $(x)$ that depletes the stock. When the inventory reaches a critical point, a purchase order is put forth in order to replenish the stock of goods. Time frame is set in discrete time with an $i$-th interval, given by $\theta_{i}$. Under certain conditions, the optimal policy relates to an optimal time length between purchase orders. In the authors' words: "the intervals, possibly excepting the first one, will have the same length and the same optimal highest and lowest stock levels", as shown in "Panel 1b" in Figure 6 below.

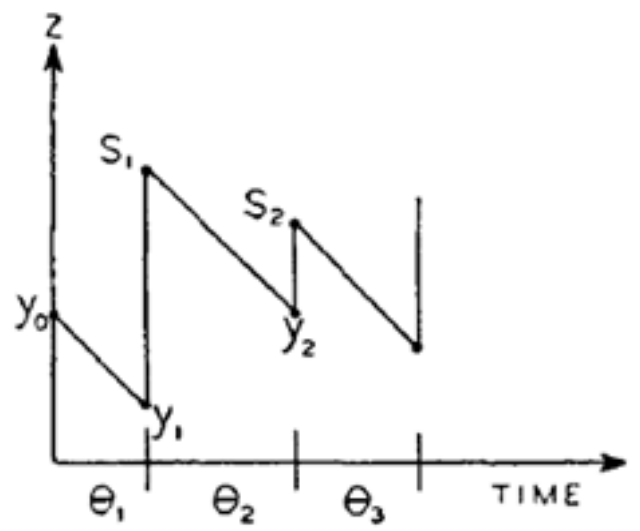

Figure la

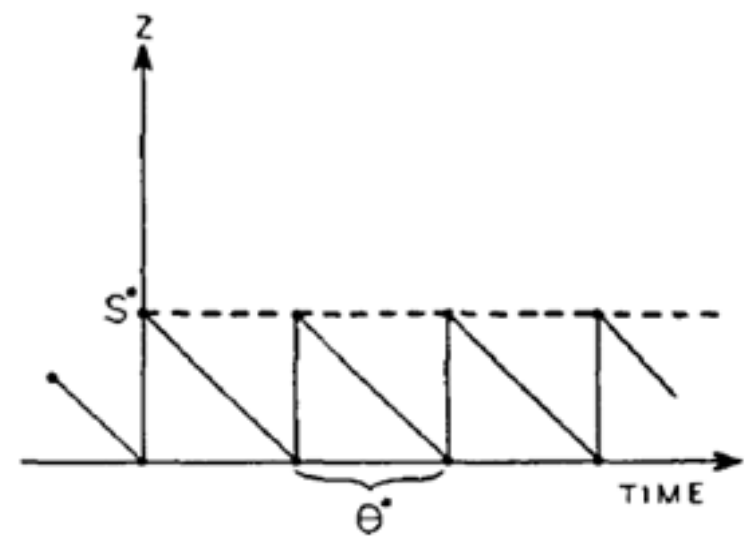

FIgURE 1b

Figure 6 - Non-optimal and Optimal inventory policy. Source: Arrow, Harris \& Marshack (1950, p. 253)

Two years later, $A H M$ 's model was translated into macroeconomics via a illustration of demand for cash balances with an interest rate opportunity cost. Baumol (1952) entitled his paper The Transactions Demand for Cash: An Inventory Theoretic Approach, in which the demand flow $(x)$ in Arrow's and his co-authors' deterministic model is replaced by the interest rate that erodes the time-value of money holdings "in a steady stream". The model thus aims at analyzing "transactions demand for cash dictated by rational behavior, which for 
our purposes means the holding of those cash balances that can do the job at minimum cost". Quoting Baumol at a yet greater length:

A stock of cash is its holder's inventory of the medium of exchange, and like an inventory of a commodity, cash is held because it can be given up at the appropriate moment, serving then as its possessor's part of the bargain in an exchange. We might consequently expect that inventory theory and monetary theory can learn from one another. This note attempts to apply one well-known result in inventory control analysis to the theory of Money (Baumol 1952, p. 545 - emphasis added).

Baumol refers, in footnote 1 (p. 545), to AHM's model and expands on the fruitfulness of the this crossbreeding between inventory theory and economics and mentions, somewhat en passant, that this had been previously done in mid-1920s by "some half dozen writers". He also makes reference to Whitin (1952), where he took the basic framework for his inventory theoretic approach. ${ }^{70}$ As has been commonly done by Baumol, his models are quite simple and provide great insight into the question under scrutiny. Suppose money demand is a function of income and of the interest rate:

$$
\left(\frac{M}{P}\right)^{d}=f(Y, i)
$$

Baumol abstracts from the precautionary and speculative motives for demanding money. The problem is drawn by an individual that makes a "steady stream" of payments ( $T$ dollars) in the course of a certain period. Cash is obtained by borrowing or withdrawing it from an investment; in both cases, there is an interest (opportunity) cost (i) per period for holding the non-interest-bearing asset. Finally, the individual is set to withdraw cash in $C$-size amounts in evenly spaced periods throughout the year, which collects a "broker's fee" ( $b$ dollars) for each time she makes a withdrawal. The value of transactions $T$ is predetermined and $i$ and $b$ are assumed constant. The total number of withdrawals will be given by (T/C) at a total broker's fee of (bT/C) over a one-year period. Additionally, since each time she withdraws $C$ she spends it in a steady stream and takes out a similar amount once it is gone,

\footnotetext{
${ }^{70}$ Baumol's (1952, p. 545) fully quoted footnote is as follows: "T. M. Whitin informs me that the result in question goes back to the middle of the 1920's when it seems to have been arrived at independently by some half dozen writers (...). Its significant implications for the economic theory of inventory, particularly for business cycle theory, seem to have gone unrecognized until recently when Dr. Whitin analyzed them in his forthcoming Inventory Control and Economic Theory (...) which, incidentally, first suggested the subject of this note to me. See also, Dr. Whitin's "Inventory Control in Theory and Practice" (elsewhere in this issue, supra, p. 502), and Kenneth J. Arrow, Theodore Harris, and Jacob Marschak, "Optimal Inventory Policy," Econometrica, Vol. 19, July 1951, especially pp. 252-255. In addition to Dr. Whitin, I am heavily indebted to Professors Chandler, Coale, Gurley, Lutz, Mr. Turvey, and Professor Viner, and to the members of the graduate seminar at Harvard University, where much of this paper was first present".
} 
her average cash holdings are given by $C / 2$ dollars. It is this latter steady stream definition of average cash balances that makes up for the sawtooth-shape of the later widely know diagrammatic representation of this model. Therefore, under these assumptions, the individual will then incur in an opportunity cost of $(\mathrm{iC} / 2)$ over the period. The total cost of using cash to meet his transactions needs, under the above circumstances is thus given by

$$
\frac{b T}{C}+\frac{i C}{2}
$$

Rationality conditions require she minimizes the cost of holding cash, which is found by deriving the total cost equation with respect to $C$, thus:

$$
\begin{gathered}
-\frac{b T}{C^{2}}+\frac{i}{2}=0 \\
C=\sqrt{\frac{2 b T}{i}}
\end{gathered}
$$

This minimization procedure was transposed almost ipsis literis from Whitin (1952, p. $505)$, where $C$ is the quantity purchased of a good that minimizes the combined ordering costs and carrying charges. Also in Whitin (1953, chapter 3), we find the same notation regarding the deterministic model of "economic purchase quantities" generating the saw-tooth pattern, as in Figure 7 below.

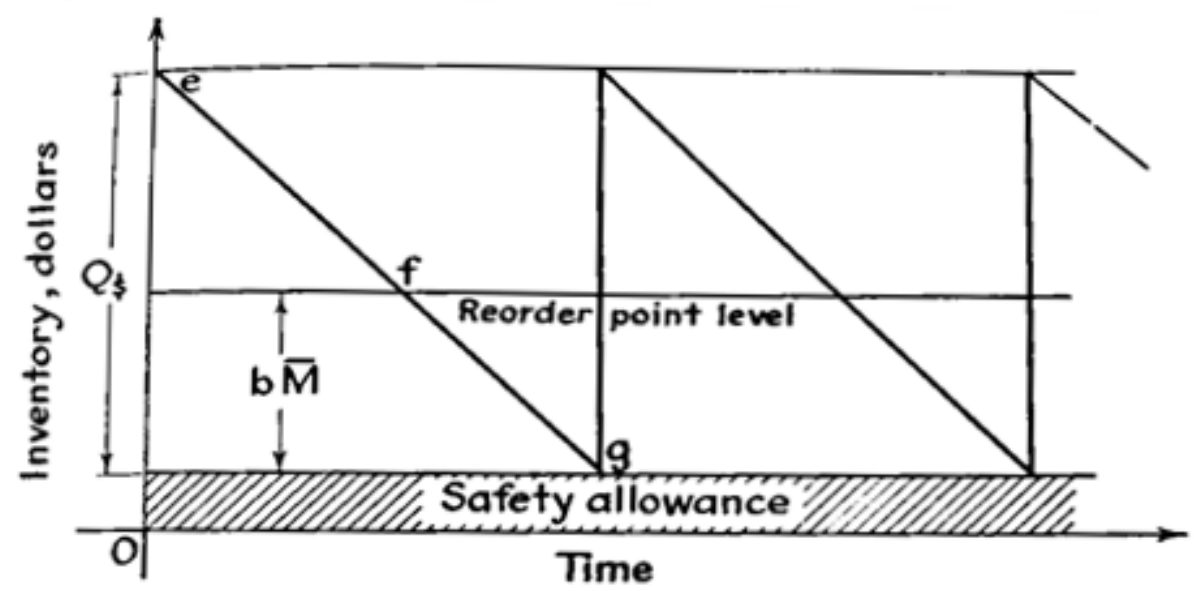

Figure 7 - Ordering Cycle Systems. Source: Whitin (1953, p. 54)

A few years later, Tobin (1956) would pursue the same avenue of analysis, in his The interest-elasticity of transactions demand for money. He mentions in the first footnote ( $\mathrm{p}$. 241) that he had not read Baumol's 1952 paper. Tobin makes no mention of the modeling 
format and its origin in the 1956 paper. Later on, in a 1961 article, he would acknowledge due credit to the borrowed inventory theory:

The theory of optimal inventory holdings, for example, shows how transactions and delivery costs must be balanced against interest and carrying costs. Applied to inventories of cash, the theory gives precision to the relation of cash holdings to the volume of nonfinancial transactions, the costs of asset exchanges, and the yields available on alternative assets. (Tobin, 1961, p. 25)

If it is beyond doubt that inventory theory was crucial to frame the ideas both authors set forth, it much less clear how the "saw-tooth pattern" came to be attached to the BaumolTobin connection, for neither the authors explicitly allude to this visual format. But once again, it is evident that inventory theory has brought a significant inspiration to economists. Just to drive the point home, we can cite some later extensions of the contributions by Baumol and Tobin, which acknowledged them as “inventory" models” (e.g., Javonovic 1982). In this same line, Romer (1986) displays the versatility of the Baumol-Tobin model by converting it into a general equilibrium framework. ${ }^{71}$ Moreover, subsequent efforts, compiled in Arrow, Karlin \& Scarf (1958), gave rise to the fruitful research program of (S,s) pricing policy models, ${ }^{72}$ of which the Allais-Baumol-Tobin ${ }^{73}$ model is but a specific application, as well as Sheshinski \& Weiss (1977 and 1983, p. 515). ${ }^{74}$

It is not heavy-handed to assume that Kaldor had come across this type of modeling strategy and manage to generate an inflation-analogue to the inventory-theoretic reasoning. ${ }^{75}$

\footnotetext{
${ }^{71}$ The purpose of Romer's paper was to highlight the inflation-induced "shoe-leather" costs of frequent trips to the bank. Interestingly, he finds that in a model with money, inflation and a positive interest rate, a "sawtooth pattern" emerges when analyzing the consumption stream (Romer 1986, p. 680).

${ }^{72}$ I thank Prof. Kenneth Arrow for pointing out to these connections in an e-mail sent to the author.

73 The introduction of Maurice Allais here honors historical accuracy for his alleged priority in deriving the mathematical basis for the optimization as it was adopted in the cash-balance theory. In a communication published in Journal of Economic Literature, at the occasion Allais was awarded the Nobel Prize, William Baumol and James Tobin recognized his early contribution as a forerunner of their own. In the authors' words: "Maurice Allais' well-deserved Nobel Prize fortuitously brought to our attention an injustice inadvertently done him, to which we were unknowing accessories. For years the literature has ascribed to us the parentage of the transactions-cost model of optimal cash balances, with its notorious square-root formula derived from inventory theory.' Recently, we found that its essence is contained in Allais' 1947 Economie et Intérêt (pp. 238-41). As Jacob Viner used to say, no matter to what source the origin of an economic proposition is ascribed, someone is sure to come up with an earlier one" (Baumol \& Tobin, 1989, p. 1160).

${ }^{74}$ In 1987, Caplin and Spulber would apply the same inventory-theoretic - (s,S)-pricing policies - format to depict the behavior of "real prices" under inflationary conditions.

${ }^{75}$ Soon before coming to Latin America, Kaldor spent a few weeks in Stanford in April 1956, where he visited Tibor Scitovsky. Kenneth Arrow had been part of Stanford's faculty since 1949, thus making it possible for Kaldor and Arrow to have met. However, in personal correspondence vie electronic mail with the author, Prof. Kenneth Arrow stated having no recollection of Kaldor's participating in any discussion on the former's
} 
Instead of wealth and cash holding, a real magnitude such as the real wage would easily suffice. The stream of cash expenditure would give way to a steady inflation and, once a critical lower bound (the lower extreme) were achieved the restoration of the previous higher bound would ensue, restarting the cycle. All of this reasoning could have easily been derived if not directly from the Baumol-Tobin apparatus, at least from an intuitive reading of Arrow, Harris and Marschak's influential 1950 model.

During his stay in Chile and then in Brazil, especially at the Getúlio Vargas Foundation, where the International Economics Association Conference was held, Nicholas Kaldor most certainly had the opportunity to exchange ideas with both Felipe Pazos and Mario Henrique Simonsen, both of whom would later be responsible for publicizing, in greater detail, Kaldor's 1956 sketch of the "saw-tooth" model. The records of the Conference were to no avail as of the writing of this thesis, but the fact that Cuban economists Felipe Pazos was one of the lecturers in the 1957 edition of the conference (see Kaldor, 1957b) suggests he may have attended Kaldor's lectures in 1956. Even if he had not been personally present at the latter, Pazos's connection with CEPAL's economist Victor Urquidi is documented in their 1956 translation of Michal Kalecki's 1954 Theory of Economic Dynamics: An essay on cyclical and long-run changes in the capitalist economy (Kalecki, 1956). Urquidi was a close participant in the first efforts to develop the Latin American structuralist theory of inflation and witnessed all the twists and turns of the early days of the new "inflation theory" (see Boianovsky, 2012; Palma \& Marcel, 1989; Furtado, 1985). Therefore, it is highly probable that Pazos had gotten word of the message conveyed by Kaldor.

As regards Simonsen, he was trained as an engineer and an economist in the late 1950s and early 1960s and became the first director of the School of Graduate Studies in Economics (EPGE) at the Getúlio Vargas Foundation, Rio de Janeiro (Biderman, Cozac \& Rego 1996, p. 189 and Boianovsky 2002, Note 1, p. 67). Kaldor visited Rio de Janeiro in October 1956, which allows for the possibility of Simonsen being present at Kaldor's lectures or being motivated by others to read the transcripts of the latter. Besides, Simonsen must have assuredly gotten in touch with inventory models in his engineering undergraduate studies.

aforementioned 1951 article - on the optimal inventory policy - nor of his time in Stanford prior to Kaldor's coming to Latin America. 
A word of caution is, perhaps, in order. Even though the timetable is consistent, this connection is, as it stands, simply a working hypothesis. The important message here alludes to one instance of how the inflation stabilization debates were affected by the overwhelming conquest of the mathematical sciences over economics in the post-War period, as documented by Mirowski (2002) and Weintraub (2002), among others. However, the saw-tooth model was not an immediately welcome contribution, for its heyday was yet to come a quarter of century later, to inform debates on anti-inflation measures in chronically inflationary economies. As the mathematical revolution slowly settled in economics, structuralist would soon rise up to the challenge of mathematically formalizing arguments. Before delving into the structuralist episode, let us turn to the broader level of the evolution of inflation models in mechanical form. 


\section{Chapter 3 - The rise of mechanical models of inflation}

The history of economics and mathematics is really a history of economics and physics, argues Mirowski (1989), in his narrative of the importation of nineteenth century rational mechanics into economic reasoning. Weintraub (1991) unravels one thread of the history of economics and mathematics as a history of economic dynamics, and Morgan (1990) unveils the econometric thread of the broader class of dynamic models. Along this continuum running from totalizing historical depiction, as in Mirowski, to the narrower scopes of Weintraub and Morgan, we add our contribution by showing that the inertial inflation hypothesis, as it stood in the 1980 s - where the focus of our narrative lies - was largely influenced by the history of mathematical dynamic macroeconomic models. ${ }^{76}$

A perusal of the few academic surveys on theories of inflation up the late 1970s reveals two moments in the debate, namely: from late 1940s up to mid-1960s the prominence of distributional conflict approach and, from 1960s up to late 1970s, a period in which prevail the mechanical reasoning of the Samuelson-Hicks type. Regardless of the method adopted to understand inflation, theories of inflation remained divided between cost-push and demandpull explanations. However, the distinction between them is far from trivial when it comes to the inflationary phenomenon proper. Sir Dennis Robertson clearly - and somewhat poetically - recognized this problem by stating that "the economic stalactite of inflated demand has met a sociological stalagmite of upthrusting claims; and when stalactite and stalagmite meet and

\footnotetext{
${ }^{76}$ The seminal mathematical formulations of dynamic systems were tied to the discussions over the dating and timing of business cycles in the late decades of the nineteenth century. Morgan (1990, chapters 1-4) describes how W. S. Jevons vexed his Sunspot theories in his Investigations in Currency and Finance, published in 1884, and H.L. Moore's Venus theory in his 1914 Economic Cycles- Their Law and Cause, both attempting to break the cyclical regularities down to a few simple econometric relationships. In the meantime, Knut Wicksell would tap the reservoir of dynamics notions with his rocking horse model, an idea that would later - in the early decades of the twentieth century - be picked up Eugen Slutsky and George Udny Yule in the 1920s, who introduce the idea of random shocks into business cycle models. In 1933, Ragnar Frisch published his Propagation Problems and Impulse Problems in Dynamic Economics, a highly influential short essay filled with the seminal notions of random impulses (or shocks) and the propagation mechanisms that sustained cyclical behavior. The simple oscillatory models of Newtonian physics were drawn in to provide a formally rich and potentially useful explanation of economic cycles. Macroeconomic dynamics proper will see the light of day with Jan Tinbergen's 1937 Model for the Dutch Economy. The Dutch model of 1936 was a complex and large model for the standards of that time. It encompassed definitional and technical equations, with causal relationships clearly defined, as well as the considerations of time trends of variables considered - using simple difference equations with lags accounted for -, instead of working with deviations from trend values. ${ }^{76}$ Alvin Hansen also applied the technique in his account of the General Theory in 1936 (Morgan 2012, p. 228). Finally, John Hicks 1939 Value and Capital and Paul Samuelson's 1947 influential Foundations of Economic Analysis constitute both the landmark in mathematical modeling in economics, especially in their unfettered use of dynamic systems and the search for stability conditions that rendered the framework suitable for scientific analysis of ergodic systems. As it happened, Samuelson prevailed and shaped the economics profession in his own mathematical image.
} 
fuse in an icy kiss (...) nobody on earth can be quite sure where the one ends and the other begins" (quoted in Bronfenbrenner \& Holzman 1963, p. 593).

It was a "breeding confusion" in debates on inflation that motivated, as per their own claim, Paul Samuelson and Robert Solow (1960) to offer the specialized economist an organizing device based on A.W. Phillips (1958) paper. The straightforward diagrammatic representation of a trade-off between inflation and unemployment rendered that divide quite obsolete in terms of economic parlance. Objectively speaking, the Phillips Curve representation set out by Samuelson and Solow (1960) defined the terms of the debate for the next two decades. The "second generation" surveys of mid-seventies were all immersed in the Phillips trade-off onslaught (Laidler \& Parkin 1975, Gordon 1976 and Frisch 1977), now with a stronger mechanical ring to it. Before its heyday in macroeconomics, though, mechanics had been a fruitful device for cogitating about inflation.

One in particular is the Keynesian-derived lineage of models in pre and postwar periods that tried to add cost-related pressures in demand inflation models in order to explain the speed and stability of inflation. Koopmans (1942), Smithies (1942), Turvey $(1949,1951)$ and Holzman (1950) are among the constructs that use "period analysis" represented by systems of differential and difference equations, revealing lagged adjustments of variables (especially in wages) and their impact on inflation dynamics. Behavioral assumptions and institutions are embedded in specific parameters within a dynamic system of difference equations. Parameters are extensively taken as fixed and the economy in most cases has a fixed maximum output with invariable composition of aggregate supply and demand (See Bronfenbrenner \& Holzman 1963, p. 603-605)

In their operational dimension, models have their stability conditions explicitly and carefully established, in order to make the model workable at least at an abstract level, so as to provide some basis for assessing the implications of policy. Its mechanical nature, as the title of the paper suggests, appears in the independence of parameters from historical time, that is, institutions are frozen in time, encapsulated as they are in unchanging parameters. These models pertain to the North American Keynesian-type much in line with the emerging mainstream of Samuelsonian economics (Morgan, 1992; Weintraub, 1999). Beyond having provided interesting insights into the underlying dynamics of price rises, both Duesenberry's (1950) and Holzman's (1950) models are illustrative of the type of mathematical models in emergence in this period. The implications of this ascending mechanical view of inflation were twofold, to say the least: first, it reinforced and crystalized the profession's wide 
acceptance of the non-zero inflation definition of price stability and, second, it spawned a new research program in macroeconomics, for both theory and empirics. The inertial inflation paradigm will emerge also against the backdrop of the ascent of inflation mechanics.

We start out, in section 3.1, with an overview of the early mechanical models of inflation, which owed its early days to Tjalling Koopmans's (1942) The Dynamics of Inflation and, in the years running up to the early 1950s, to a handful of papers dealing with the problem of inflation in dynamic settings. It was then that this format of economic reasoning and communication caught on within the economics profession; we briefly delve also, in section 3.2, into the Latin American development of this mathematical discourse in Julio Olivera's contribution. Next, in section 3.3, we turn to the modeling aspects of the Phillips curve debate and how economists embodied the notions of self-generating inflation, inertia and rigidity into mathematical reasoning and, in section 3.4, the influence it had on Mario Henrique Simonsen, the chief synthesizer of the inertial inflation hypothesis. We wrap up the chapter with an historical reappraisal of the mechanical saw-tooth model of real wages under inflationary conditions.

\subsection{The Mechanics of Inflation}

The combination of inflation and mechanics has a long history. The quantity theory approach is in itself a fairly mechanical framing of the circulation of money in any economy (see Morgan 2012, p. 23). Knut Wicksell's model of trade cycle and cumulative process is also liable to a mechanistic reading of the economy, and was in fact given such a design in the hands of Thomas Humphrey (1997). Tjalling C. Koopmans ${ }^{77}$ (1942) set forth an explicit mechanical model of inflation in his paper The Dynamics of Inflation $^{78}$, where he works out

\footnotetext{
${ }^{77}$ His academic background is somewhat telling of the new breed of economists arriving from mathematics and engineering departments that would take over the economics profession in the post-war period. Koopmans graduated from physics in the Netherlands and soon moved on to econometrics - his thesis dates from 1936 (published in 1937) and verses on the application of advanced mathematical statistics to economic data. He joined the Cowles Commission in 1944 and was its director 1948-54, where many technical novelties from mathematics and engineering were imported to economics during this period.

${ }^{78}$ Koopmans works out eight case-models to assess the dynamics and effects of inflation in a war economy subject to price controls and rationing. He deploys his model on a simple equation of income distribution of national output (p. 55): $l+e=100$, where $l$ denotes the share of income held by workers and $e$, the share appropriated by entrepreneurs. By adding the government, he reaches the following relationship: $100-l-g=e$ $-g$, where $\mathrm{e}-\mathrm{g}$ reflects the share of output available for entrepreneurs' consumption. The bottom line is that government subtracts goods from the economy and, should adjustments fail to be made, inflation will ensue. Edmar Bacha (1988) would adopt a similar model when discussing the failure of the Cruzado Plan and urging economists to find a middle ground to put an end to the second round of the monetarist-structuralist controversy. More details in chapter 6 below.
} 
an explicit mathematical formalization of an "income distribution model of inflation",79. A few years later, A.W. Phillips (1950, p. 283) dealt with Mechanical Models in Economic Dynamics. $^{80}$

Ralph Turvey (1949) claimed for a period analysis of inflation that could account for expectations concerning future developments of price behavior, which in turn hinged on the history of the system. ${ }^{81}$ Turvey entertains several difficulties relating to the asynchronous character of among individuals' own periods, which can have different lengths and be spaced out unevenly (p. 222). His "dynamic equation for the wage bill and for capitalists' expected income" (p. 223) takes the wage bill for any period $t$ as a function of wages fixed at the beginning of the period $(W)$ increased by a proportion $a$ (denoting the price elasticity of wages) of the price increase up to the preceding period $\left(P_{t-1}\right)$, or formally:

$$
W_{t}=W\left(1+a P_{t-1}\right)
$$

In May 1950, James Duesenberry publishes a paper entitled The Mechanics of Inflation. ${ }^{82}$ The main thrust of his argument, in line with Kalecki, is that mark-up behavior is an important factor in explaining some cost-related forces behind inflation. In addition, he assumes that agricultural prices are determined in competitive market - and thus constrained by supply and demand factors - and wages are determined so as to keep their real value constant, which fits the observed fact that "hourly wages have moved about in proportion to the cost of living index" (p. 114). But, Duesenberry wonders, if wages are adjusted in a semiautomatic fashion - with lags involved -, according to cost-of-living indices, what can we say

\footnotetext{
${ }^{79}$ This $\mathrm{i}$ show one of the Brazilian economists involved in the inertial inflation paradigm would later call the distributional conflict approach to inflation (see Modiano 1988).

${ }^{80}$ A.W. Phillips states: "There has been an increasing use in economic theory of mathematical models, usually in the form of difference equations, sometimes of differential equations, for investigating the implications of systems of hypotheses". Although the paper is primarily concerned with the construction of a physical analogical model (see Morgan 2012, chapter 5), the basic structure of the system is highly advanced in its mathematical formulations and already incorporated lags in variables as explanatory factors. However, little is said about prices or inflation for that matter.

${ }^{81}$ In Turvey's (1949, p. 220) words: "In order to examine the path of price through time we shall use period analysis. This may be crudely defined as the splitting of time into periods such that the events of any one period can, apart from the effects of exogenous changes, be explained with reference to the events of previous periods. It is thus a step-by-step analysis of changes through time. It is essential that the period shall be so short that all plans existing at its beginning are (as far as possible) carried out and no changes in plans are made. If the period were longer, then the events in the first part of a period could affect the events in the later part of the period, through inducing a change in plans, and the step-by-step analysis would be lost" (emphasis added).

${ }^{82} \mathrm{He}$ states at the outset: "Most of the discussion of the process of inflation has been based on the proposition that 'prices rise because there is too much money chasing too few goods'. (...) The prices are conceived of as rising by some sort of automatic process, so that no discussion of the business decisions which produce the price increase is necessary" (Duesenberry, 1950, p.111 - emphasis added).
} 
about profits and, of course, mark-up adjustment patterns? He is thus mostly concerned with the distributive effects of inflation and touches only tangentially the distributional causes of inflation. Even so, his take on the phenomenon encompasses, in somewhat prescient fashion, the modeling strategy to be pursued in later debates on inflation (in the 1970s) and the notion of a feedback process accounting for a sustained inflation trend.

Duesenberry entertained some of the hypotheses concerning cost-related pressures on prices lined up in a mathematical model formulated under the assumptions of full employment equilibrium. He works out a simple accounting framework with accompanying equations explaining the behavior of wages and mark-ups. It is, as far as our knowledge goes, the first mathematical model with the use of difference equations to explicitly describe inflation as an autoregressive process with wage and price lags. Industrial prices are to respond to a mark-up policy and agricultural prices respond to supply-demand dynamics, whereby excess demand triggers price rises according to economy-wide money wage bill. Trade unions in the industrial sector are assumed to maintain real wages constant by fully indexing nominal wages to past inflation (Duesenberry, 1950, p. 146). ${ }^{83}$

The inflation index is composed of a weighted average of industrial prices $\left(P_{I}\right)$, agricultural prices $\left(P_{A}\right)$ and a constant $\left(w_{3}\right)$ denoting fixed price movements, so that $I=$ $w_{1} P_{I}+w_{2} P_{A}+w_{3}$ and $w_{1}+w_{2}+w_{3}=1$. Wages are then modeled explicitly as an autoregressive process, namely:

$$
W_{m t}=W \cdot\left(w_{1} P_{I, t-1}+w_{2} P_{A, t-1}+w_{3}\right)
$$

Industrial prices follow a mark-up rule:

$$
P_{I}=\frac{W(1+M)}{\pi}
$$

where $\mathrm{M}$ and $\pi$ denote the mark-up rate and the productivity of labor, respectively. Analysis is carried out on a discrete timeframe, so prices of industrial and agricultural goods are denoted by the following equations, respectively:

$$
P_{I t}=\left(\frac{W_{m t}}{W}\right) \delta
$$

\footnotetext{
${ }^{83}$ In the author's own words: "The money wage rate of the industrial wage earners is fixed by trade union negotiations. The policy of the trade unions, which is always effective, is to keep the real wage rate constant in terms of a fixed weight index number" (p. 146).
} 
and

$$
P_{A t}=\frac{a\left(W_{m t} E+k\right)}{O_{A}}
$$

where $W_{m t}$ is the market-wide weighted wages, $\delta$ is a difference factor between normal prices and the ongoing industrial prices due to price control entailed by the government authorities; $a$ is the share of wages spent in agricultural goods, $E$ is the aggregate employment level, $k$ is the constant income non-wage earners devote to agricultural goods, and $O_{A}$ represents total supply of primary goods. Stability conditions are worked out and even a trend term is assumed to be in operation in the wage equation (Duesenberry, 1950, p. 147-148). Stability analysis is carried through in order to demonstrate the non-explosiveness of the system.

The second aspect worth mentioning, insofar as our narrative goes, is the seminal distributional conflict approach pursued in this 1950 paper. Duesenberry proposes that the Keynesian "inflationary gap" could be closed in various forms. Once it vanishes, inflation halts. The "expropriation of rentiers" refers to the shift of income away from fixed-income receivers - and here too, the lag between adjustments in rents is of paramount importance -, whereas governments can achieve a fiscal surplus by progressively taxing inflation-induced incomes, in a process similar to the one anticipated by Koopman (1942). He then considers that increased output can have this closing effect on the gap: if increases in income come by means of higher employment rates, only increased savings can avert inflationary pressures. On the other hand, if productivity is the way the produce is elevated, then substantial deflationary effects are to be expected.

Finally, he asserts the importance of the "wage lag" in explaining why prices rise according to a seemingly automatic process (p. 144): "If prices rise continuously while wages are raised only periodically (even though they keep up with prices in the long run), the average real value of wages is reduced" (Duesenberry 1950, p. 145 - emphasis added). ${ }^{84}$ Moreover, still in this regard, he acknowledges that "the speed of inflation will depend on the extent of the payment lags for wages and dividends" (p. 146) and - on footnote 4 on the same page - notes "that in a really great inflation, all payment lags are progressively reduced

\footnotetext{
${ }^{84}$ Duesenberry starts out with the problem of lagging wages, but extends the model to encompass rents, profits and dividends tied by contract to fixed nominal values. For instance, in the case of the wage lag, he states: "If prices rise by 12 per cent a month while wages are increased once a year by 12 per cent (I neglect the compounding), the average real value of the wage bill is reduced by 6 per cent and profits are increased correspondingly. Provided that the profits are not spent, there is always some rate of increase of prices which will reduce consumption by the amount of the excess demand. Of course, in this case, the inflation will continue indefinitely until some change in the structure (e.g., a drop in investment or government purchases) occurs". (Duesenberry, 1950, p. 145 - emphasis added).
} 
so that the pace of the inflation is progressively accelerated". But the process is not linear in its shape, for:

(...) there is an oscillation in wage earners' demand due to the fact that prices do not adjust instantaneously to wage changes. Wage earners' demand is at its height just after a wage increase. (Wage increases are heavily concentrated in the spring.) It slowly decreases as the effect of the wage increase ramifies through the system, reaching a low just before the next wage increase. All this takes place within our time period ( $p .148$ - emphasis added).

At the risk of reading too much into Duesenberry's (1950) inflation mechanics, he seems to have grasped the "zig-zag" pattern of real income under persistent inflation, which was, at least, verbally stated. To conclude, he states the partial independence of inflation from demand-related forces:

In our system, the speed of inflation is governed by the lags in wage adjustments and by the other factors which control the rate of increase of agricultural prices. The inflation need not stop when excess demand is eliminated. If the wage-price spiral has not worked itself out, when the gap is closed prices may continue to rise (Duesenberry 1950 p. 149).

Duesenberry concludes that the persistence of inflation may lead to enlarged unemployment, something that structuralists would be, time and again, accused of overlooking. Interestingly, this paper has received only a single mention in the Brazilian literature accounting for the conceptual origins of inflation inertia (Ramalho 2000). Even more striking then becomes the lack of references to this paper in subsequent writings on inflation in the 1950s in Brazil and in Latin America in general, which maybe inkling of the imperviousness of local debates to North-American theoretical developments on the matter in this period. ${ }^{85}$

At about the same time, Franklyn Holzman (1950) is responsible for the most elaborate mathematical model of inflation dynamics in the early 1950s. He works out a model to convey the phenomenon of "wage-profit-price spiral" (p. 150), on the basis of the "redistribution-of-income effect in the determination of prices and money income under inflationary conditions. He departs from the general idea that inflation is seen as the result of resistance by groups to accept reductions in their share of national output. ${ }^{86}$ Holzman

\footnotetext{
${ }^{85}$ Rather, it seems more reasonable to assume this contribution to have been simply overshadowed by Duesenberry's income theory of consumption behavior, as we have already seen in previous sections.

${ }^{86}$ Holzman's (1950) take is much in line with the methodological zeitgeist of those times: "This paper will concentrate on the wage-profit-price spiral as an example of the inflationary pressures generated by changes in
} 
separates an inflationary shock from reactions of the economy to the shocks. Inflationary shock is here defined as a relative price disturbance that increases some prices - or costs more than others and, hence, has distributive effects over real income. ${ }^{87}$ These shocks, however, can only trigger a continuing or dynamic process with the reaction entailed by different groups. It is deemed necessary that groups have power to react and turn this new distribution of income unstable. Should all the defrayed groups abide by the newly diminished shares of income, the level of money income would remain the same or even decline, depending of the propensity to consume or in the absence of further shocks.

Reactions by the various groups to the initial shock are the propagating factors, and they are aimed at recouping some part of their loss "and the continuing succession of reactions to reactions which may follow" (p. 151). Possible reactions are strikes or "pushfulness" by labor unions for higher wages; farmers may react to higher industrial prices by withholding stocks of agricultural goods in order to press prices up in the market; also, exchange rate depreciations can increase profits in the exports-producing sectors enticing workers in these latter to bid wages up, not mention that higher import prices tend to raise the domestic cost structure, given that foreign inputs are used in production. Entrepreneurs downstream in the production chain will attempt to pass these cost rises on to prices. Workers will strive for wage increases and farmers will raise the prices of agricultural goods.

Holzman's model abstracts from mobility of factors of production and from expectations, whilst assuming that money and credit behave in a "nonrestrictive" manner. The structure of the model is simple and is thus worthy of detailed attention. Let national income $\left(Y_{0}\right)$, measured in nominal terms, be distributed among wages $\left(W_{0}=\alpha Y_{0}\right)$, profits and dividends $\left(\Pi_{0}=\beta Y_{0}\right)$ and a residual $\left[R_{0}=(1-\alpha-\beta) Y_{0}\right]$ covering rents, royalties and interest receivers. Adding them up yields:

$$
Y_{t}=W_{t}+\Pi_{t}+R_{t}
$$

the distribution of income between and within all economic groups" (p. 152). The essence of the wage-profitprice spiral at full employment, he sustains, "lies in the reactions and practices of the workers (the union movement) with respect to their standard of living and to price changes, and of owners with respect to changes in demand, cost, and prices". To keep the model simple, Holzman assumes that workers react only "when their standard of living relative to that of other groups is affected" which is to say that only "if prices other than wages should rise, workers would strive for wage increases" (p. 152).

${ }^{87}$ A few examples of the type of shock Holzman is concerned with are: exchange rate depreciation, budgetary deficits, a rise in investment ahead of net savings, discontinuous price controls or subsidies, large scale dissaving, a major rise in wages due to bargaining power of labor unions etc. 
The ability of labor to push up wages to recoup income foregone by inflation is defined by $\eta=\left(\frac{W_{t}}{W_{0}} / \frac{Y_{t}}{Y_{0}}\right)$. If $\eta=1$, labor has the power to rise wages proportionally to inflation. Hence, the dynamic wage equation is given by

$$
W_{t}=W_{t-1}+\alpha \eta\left(Y_{t-1}-Y_{t-2}\right)
$$

Likewise, entrepreneurs will try to pass wage and other cost increases on to prices according to their ability to do so, measured by the parameter $\gamma$, so that profits face the dynamic behavior given by the following equation:

$$
\Pi_{t}=\Pi_{t-1}+(\gamma-1)\left(W_{t}-W_{t-1}\right)
$$

Fixed income recipients are initially assumed to have no ability to adapt to their lowering stakes within the distributive scale, so that their money incomes are deemed unchanging:

$$
R_{t}=R_{t-1}
$$

By substitution of the definitional equations into the national income relationship, we get

$$
Y_{t}=Y_{t-1}+\alpha \eta \gamma\left(Y_{t-1}-Y_{t-2}\right)
$$

Holzman finds that, under the assumptions of $\eta=\gamma=1$, redistribution of income following an inflationary shock accommodates to the disadvantage of fixed-income recipients. Moreover, he finds that, under these very conditions, the system is not explosive, but in fact approaches equilibrium after six months, assuming a $60 \%$ share of wages, $30 \%$ share of profits and $10 \%$ for fixed-income receivers. This outcome of the model is to be found in both the $\alpha$ parameter, which denotes the wage share of income, and in the value of $\eta$ (the bargaining power of workers), the echoing the notion previously mentioned by Koopmans and Turvey that the size of the effect relies on the importance of each group within the whole. Increasing the wage share implies a greater time lapse will be required to achieve a new level of equilibrium. Needless to stress that also reducing the power of labor to push for higher wages shortens the transition to a new equilibrium. Holzman then calculates the equilibrium level of money income after a shock $(x)$ as:

$$
Y_{\infty}=Y_{0}+\frac{x}{1-\alpha \eta \gamma}
$$

Stability of the system requires thus that $\alpha \eta \gamma<1$, which is not far-fetched to assume as a non-rare occurrence, since the wage share is hardly above $70 \%$ in most countries. Now, if 
firms pursue a fixed percentage profit margin over total costs - according to the definition of $\beta^{\prime}=\frac{\Pi_{0}+x}{P_{0}+x}-$, the profit equation becomes:

$$
\Pi_{t}=\frac{\beta^{\prime}}{1-\beta^{\prime}}\left(W_{t}+R_{t}\right)
$$

Holzman then finds the money income equation, rewriting it as follows:

$$
Y_{t}=Y_{t-1}+\frac{\alpha \eta}{1-\beta^{\prime}}\left(Y_{t-1}-Y_{t-2}\right)
$$

and the equilibrium level of income by:

$$
Y_{\infty}=Y_{0}+\frac{x}{1-\frac{\alpha \eta}{1-\beta^{\prime}}}
$$

Because stability now requires that $\alpha \eta+\beta^{\prime}<1$, the system becomes far less stable. This means that, should firms pursue a pricing policy by which mark-ups keep up with the index of costs, "the sum of the shares of real income which labor and ownership are implicitly trying to obtain is greater than the actual level of real income", driving up prices and money income indefinitely as long as the struggle persists. We should recall by now that the conclusions rest on many assumptions, the relaxation of which can lead to quite different results. ${ }^{88}$ Holzman $(1959,1960)$ would later set out further investigations in the cost-push and demand-pull theories of inflation, employing the same kind of technique, but with similar results.

A different take on inflation would come out of Hansen's 1951 book, titled A Study in the Theory of Inflation. ${ }^{89} \mathrm{He}$ assumes a trade economy consisting of a market for factorservices (labor-power) and a composite-commodities market. Excess monetary demand in any or both of these markets would then ensue inflationary pressures. In the compositecommodity Market, sellers of goods would find themselves free to raise their prices, under low risk of curtailing sales, whereas in factor markets, workers would secure wage increases

\footnotetext{
${ }^{88}$ For instance, Holzman admits that adjustments can be made to take into account the roles of productivity changes and expectations. Besides, many institutional features, all historically contingent, should be taken heed of: "In those countries which have labor governments (e.g., Great Britain), repressed inflation will be preferred because labor appears to suffer most from open inflation; conversely, where industry holds the balance of power, a degree of open inflation will usually be preferred. Runaway inflation is most likely to occur, ceteris paribus, in countries in which either labor or the farmers are economically and numerically strong enough to put up a struggle for their share of real income should there be open inflation, but not strong enough politically to legislate the proper controls to repress it" (Holzman, 1950, p. 157).

${ }^{89}$ See Hagger (1961) for further references.
} 
with some risk of unemployment. If these pressures are left unfettered changes in fundamental economic magnitudes, via supply and demand forces, are expected to occur. The Keynesian concept of inflationary gap is here useful in determining the size of the required reduction in demand in both sectors in situations of suppressed inflation (that is, when a disequilibrium is at place but inoperative), such as under price controls and wage sliding-scale policy ${ }^{90}$, as well as under open inflation, defined as the free reign of excess demand in both markets.

Hansen sets out to demonstrate that inflation may arise before full-employment is achieved launching a two-sector model comprised of a goods market and a factor market. Simply stated, monetary pressure of inflation exists whenever excess demand in both the commodity markets as a group and the factor-services markets as a group is non-negative during the time-period in question. Pressures are shown to arise under perfect competition and monopoly, with diagrammatic illustrations of aggregate supply and demand with a "maximum production" limit indicating the presence of some factor constraint. Hansen thus sets out to show that insufficient amount of labor-power is likely to trigger an inflationary pressure in the factor markets (the "factor gap") even in the presence of equilibrium in the commodities markets. This "factor gap" is highly suggestive of bottleneck-based inflationary pressures, as Hansen (1951, p. 89) himself has pointed out. ${ }^{91}$

When analyzing a policy of constant real wage (w/p), Hansen brings in an institutional factor of the interval in between adjustments of nominal wages, so that the above relation falls discontinuously along this interval and then is adjusted, pushing inflation up at discontinuous jumps. Since wages rise independently of supply and demand adjustment in the labor market (p. 16), a continuous "induced inflation"92 ensues, which thus press upon prices in the commodities sector, resulting in a wage-price spiral. To illustrate this process, Hansen displays a set of diagrams that represent the time path of each set of variables; among them, the "saw-tooth" pattern of real wage behavior under constant inflation, as in the Figure 8

\footnotetext{
${ }^{90}$ Nominal wages were commonly corrected for variations in cost-of-living indices in various countries. In Hansen's book, this type of policy is frequently used as example of the theory he is putting forth. See, for instance, pages 169-172. For more details on the history of wage sliding scales see Hanes (2010).

${ }^{91}$ Hagger (1961, p. 109) has taken issue with the suggestion that Hansen's model lends itself to handle situations characterized by production bottlenecks, although this possibility was never fully entertained by the author himself. Hansen (1951, p. 89) claims this to be a natural extension of the model. The problem seems to lie in the assumption that worker's expected income is equal to their realized income. However, Hansen is not fully committed to this definition. He also defines the "gap" as the difference between attempts to buy or sell and the realized purchases or sales. In this sense, should the proper assumptions be made, Hansen's model can become a bottleneck inflation model.

${ }^{92}$ Hansen uses the term "induced" in the sense of an "autonomous" or "spontaneous" factor-related costinflation (See Hansen 1951, chapters 1 \& 2).
} 
below. Hansen explores these possibilities allowing for the influence of monopoly (with a sort of mark-up pricing) and price controls on inflation dynamics. His implicit notion of an inflationary monetary equilibrium is extensively informative (perhaps even prescient?) of the challenges that inflation would later impose on economic policymakers worldwide in the 1970s.

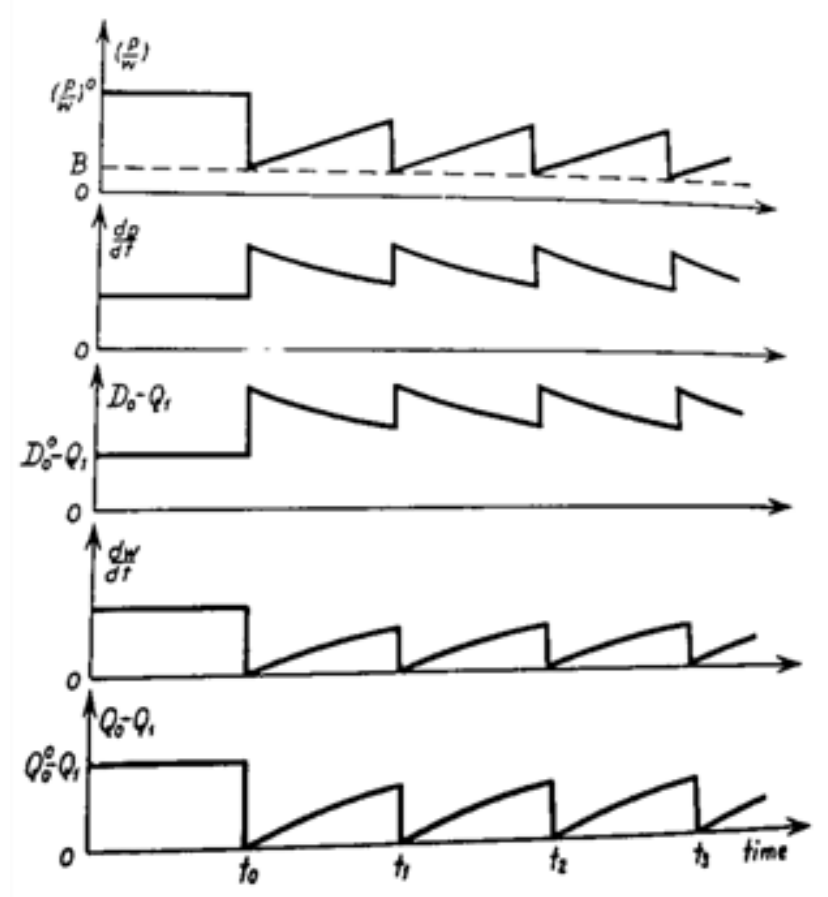

Figure 8 - Bent Hansen's Dynamic Chart of Macroeconomic Impacts of Indexed-Wages. Source: Hansen (1951, p. 170, fig. 18).

This result comes out of the "price-inertia coefficients" (p. 227), a feature present in each and every sector of the economy, which is denoted by the reciprocal of constant $k(>0)$, embedded in the price-reaction equations such as in the expression below:

$$
\frac{d p_{i}}{d t}=p_{i} \cdot k \cdot \frac{x_{i}}{q_{i}}
$$

where the time-variation of a specific price $\left(\frac{d p_{i}}{d t}\right)$ is a function of itself multiplied by the price-inertia coefficient $(k)$ and by the ratio of excess demand $\left(x_{i}\right)$ to supply of commodity $\left(q_{i}\right)$. Hansen then moves on to a "discontinuous analysis", in which "the changes of prices occur only at the beginning of each period and are such that the excess demand occurring in the preceding period determines the marking-up of the price at the beginning of the period considered" (p. 224). Calling the length of the period $\Delta t\left(=t_{2}-t_{1}\right)$, and the excess demand at $t_{1}$ by $x_{i}^{1}$, we have the corresponding discrete relation to the above equation: 


$$
\Delta p_{i}=p_{i}^{1} \cdot k \cdot \frac{x_{i}^{1}}{q_{i}^{1}} \cdot \Delta t
$$

Thus the longer the period and the greater the value of the constant $(k)$, the higher will be the variation of prices due to a lagged response of prices to excess demand. Hansen admits that, in reality, "it is not possible to reckon that $k$ - of which the reciprocal can be taken to express inertia of prices with respect to 'induced' changes - will in general be the same for all commodities and for all factors" (p. 225). The relevant price index, in the discontinuous case must have the form of

$$
\frac{\Sigma\left(\frac{1}{k_{i}}\right) \cdot p_{i}^{2}}{\Sigma\left(\frac{1}{k_{i}}\right) \cdot p_{i}^{1}}
$$

so that the weights are represented by the "price-inertia coefficients". As we can see, the fact that he was up to date with mathematical modeling (linear difference and differential equations) so dear to the emerging Samuelsonian world may have facilitated his legacy to be preserved, albeit with extensive amputations.

The relevance of Hansen's contribution has been somewhat limited to punctuated references in macroeconomic history subsequent to the 1950s - being Simkin (1952-53) and Pitchford (1957) notable exceptions. It would be out of place to try to foray into the reasons for this, but we suspect that Hansen's had too conciliatory a tone for his own good when it came to joining separate lineages of models into one analytical construct. To support this assertion we point to the rather peculiar overall "conflicting claims" vocabulary Hansen adopts. ${ }^{93}$ Concepts such as "Class struggle" and "Class warfare", capitalists and workers with different propensities to consume are all part of this parlance. Also the definition of a wageprice spiral within a general equilibrium setting, whereby quasi-equilibria populated the expected results, and moving dynamic equilibria were achieved with the aid of adaptive and forward-looking expectations. ${ }^{94}$

\footnotetext{
${ }^{93}$ See Hansen (1951, pages 17 and 246).

${ }^{94}$ Furthermore, he was later to inspire one of the threads of disequilibrium macroeconomics, namely, JeanPascal Bénassy's model of three regimes (Backhouse \& Boianovsky 2013, p. 73 and p.114-119), not mention the conflicting-claims-inspired approach to the new neoclassical synthesis carried by Carlin \& Soskice (1990 and 2006), although no credit to Hansen is acknowledged by the authors.
} 
Hansen's inflation theory would - unexpectedly, one might add - influence Juan Noyola Vasquez (1956a \& 1956b, p. 276) in his understanding of inflation (see sections below). This very fact is inkling of Hansen's impact in the profession may have been more intense than we can infer from available documentation. These questions aside, the theory Hansen puts forth cannot easily escape the criticism of being essentially a-historical and essentially mechanical in nature, although many institutional aspects are considered throughout his book and his analytical framework is frequently liable to historical comparisons. Even so, his commitment to a theory that considered explicitly the institutional features of modern capitalism should be enough to make his analysis stand out among the host of strictly mechanical frameworks of a neoclassical vintage (see Hansen, 1951, p. 239248)..$^{95}$

There are other contributions deploying the same type of mathematical reasoning, such as Holzman (1960), but a careful and detailed perusal thereof would lead us to far astray. ${ }^{96}$ The careful reading of the acknowledgement notes at the beginning footnotes of some of these papers reveal a common arena of academic exchanges, amongst which some will later be at the center of controversies pertaining to inflationary problems in the 1970 s. ${ }^{97}$ At any rate, we believe the message has been sufficiently clear: conflict inflation became a matter of mathematical (mechanical) models with the use of period analysis and systems of difference equations long before Samuelson and Solow (1960), Phelps (1967) and Friedman (1968) made their sweeping contribution to the debate on inflation. ${ }^{98}$ In the meantime, Latin

\footnotetext{
95 The following excerpt can give an illustration of our point: "They way in which spontaneous changes can eventually be avoided will not be considered here. The causal factors involved belong for the greater part to the field of politics and social psychology (the 'class struggle'), so that it is only possible to treat them economically to a minor degree. The problem is actually closely relaed to that of abolishing monopoly in all its aspects" (Hansen, 1951, p. 246). These aspects are highly influential of the results obtained in the model and are thus liable to a careful examination, although economics is, in Hansen's view, quite limited in dealing with them.

${ }^{96}$ The literature briefly perused above has several other contributions, which provide great insights into many aspects of the inflationary process in developed economies. We refer the reader to the following papers: Turvey (1951), Reder (1948), Simkin (1952) and Pitchford (1957), Smithies (1942, 1957) and references therein.

${ }^{97}$ To state a few: James Tobin, Robert Solow, William Baumol, Milton Friedman, Arthur Ross are altogether mentioned, at least once, by one of the authors in the papers.

${ }^{98}$ It is yet to be answered, in greater historical detail, how the gradual disappearance of this type of modeling from the mainstream. One reason that springs to mind is that these models may have seen rather cumbersome in a moment when the economics profession had not accommodated itself to influence of the mathematical sciences. On the other hand, granted the difference in magnitude and relevance, this approach relied heavily on simulation exercises, a practice that had yet to see its heyday in economics. A second aspect certainly had to do with the fact that these models failed to provide sound analytical basis for empirical tests, a feature in which the Phillips curve research program would have an irresistible comparative advantage for economists.
} 
American structuralists and monetarists became at least partially math-stricken by this emerging pattern of economic discourse.

\subsection{CEPAL goes mathematically formal}

Latin American Structuralists claimed that supply rigidities generated chronic inflationary pressures, whereas the monopoly pricing and social tensions acted to generalize these specific upward price movements. Hence, a finite elasticity of supply and demand for goods implies that any change in relative prices will encounter a downward inflexibility of monetary prices. Inside the actual proceedings of the capitalist organization, this shortage of supply will be translated into a rise in the general level of prices. These non-monetary pressures then compel authorities into monetary accommodation. Expansion of the money supply becomes nearly inevitable, once the social costs entailed by recession-feeding monetary shortages are acknowledged.

These basic tenets of the structural inflation theory were mathematical worked out by Olivera (1960), who entailed a search for inflationary pressures "beneath the monetary surface, into the underlying region of physical flows, real prices and sectional disequilibria" (Olivera 1964, p. 322). He also drew on previous works set forth by North-American-based scholars such as Bent Hansen (1951), Alain Enthoven (1956) and Charles Schultze (1959). Olivera inherited from Hansen and Schultze the concern with sectional bottlenecks and combined the latter with the notion of structural imbalances imposing a downward rigidity the prices in these sectors. Enthoven's analysis is crucial to show that changes in the price level and thus, on the quantity of money, require not only excess aggregate demand but also depend on the composition of demand, also know in the literature as the "Keynes-Hansen condition for inflation" (Wachter 1976, p. 18-20). Olivera (1960) ingeniously adapted Enthoven's proof to demonstrate the passivity of monetary supply under rigid prices. ${ }^{99}$

It is, in fact, true that vague notions of endogenous money, lags and expectations could be found in the works by Kalecki (1954), Duesenberry (1950), Noyola (1956), Sunkel (1958) and Pazos (1963). Nontheless, the crux of Olivera's non-monetary inflation is due to the imperfect adjustment of prices along the chain of production. He formalized his argument in a two-sector model, in which differences in elasticity of demand and supply promote sustained structural pressures over prices, termed "structural inflation" (Olivera 1967a). The main

\footnotetext{
${ }^{99}$ A review of Olivera's main contributions is provided in Vera (2013b, p. 49-51).
} 
argument states that the Walras' law act in preventing the transmission of relative price changes to absolute prices only if the system adjusts rapidly. If the transition from one equilibrium point to another is sluggish, inflation ensues, in order to restore some consistency to the system. Demand $(D)$ and supply $(Q)$ for the backward sector varies with time and with the level of relative prices $\left(P_{R}\right)$ between the prices of wage-goods $\left(P_{a}\right)$ and those of goods produced by the more advanced sector $\left(P_{b}\right)$. From an equilibrium position, given by $Q\left(P_{R}, t\right)=D\left(P_{R}, t\right)$ and differentiating totally with respect to time yields a simple definition of relative price changes: $\hat{P}_{R}=\frac{\delta-\sigma}{\epsilon+\eta}$. From this definition, it follows that relative prices depend on the excess demand $(\delta)$ over available supply $(\sigma)$ of wage goods as a proportion of the sum of the respective price elasticities of supply and demand $(\epsilon+\eta)$.

The dynamics of the model goes as follows: $\hat{P}_{R}=\hat{P}_{a, t}-\hat{P}_{b, t}=\frac{\delta-\sigma}{\epsilon+\eta}$; so that relative prices will change as a discrepancy between rates of change of prices in each sector. The labor market is assumed to have homogenous wages across sectors and varies according to some degree of lagged indexation to the wage-good price, $\widehat{w}=(1-\lambda) \widehat{P}_{a, t-1}$, where $0<\lambda \leq 1$ denotes the degree of flexibility of wages to variations in the cost of living, proxied by changes in prices of the wage-goods. For instance, a powerful labor force leads to a diminished flexibility of wages, which is depicted in the model by the parameter $\lambda$ assuming a value close to zero. As for the price of the progressive goods, it follows a markup-over-cost rule, the cost being defined by labor compensations: $\widehat{P}_{b, t}=(1-\gamma) \widehat{w}$, where $0<\gamma \leq 1$ represents the degree of markup flexibility due to market constraints on price rises. For instance, defensive entrepreneurs may entail a strategy of transmitting wage increases to prices, which is depicted in the model by the parameter $\gamma$ assuming a value close to zero. As can be seen, the conflict dynamics are to be found in the behavior of the parameters $\gamma$ and $\lambda$. Substituting the wage equation into the progressive good's price equation, we get $\hat{P}_{b, t}=$ $\Lambda \hat{P}_{a, t-1} ;$ where $\Lambda=(1-\gamma)(1-\lambda)$. Since $\hat{P}_{R}=\hat{P}_{a, t}-\hat{P}_{b, t}=\frac{\delta-\sigma}{\epsilon+\eta}$, then

$$
\hat{P}_{a, t}=\frac{\delta-\sigma}{\epsilon+\eta}+\hat{P}_{b, t}=\frac{\delta-\sigma}{\epsilon+\eta}+\Lambda \hat{P}_{a, t-1}
$$

Now, if we apply a one-time lag on the definition above we get $\widehat{P}_{a, t-1}=\frac{\delta-\sigma}{\epsilon+\eta}+\widehat{P}_{b, t-1}$; thus, $\hat{P}_{b, t}=\Lambda \frac{\delta-\sigma}{\epsilon+\eta}+\Lambda \hat{P}_{b, t-1}$. Long-run sectional equilibrium rate of inflation is attained for $\hat{P}_{a, t}=\widehat{P}_{a, t-1}$ and $\hat{P}_{b, t}=\hat{P}_{b, t-1}$, so that the equilibrium trajectories of prices are given by 


$$
\hat{P}_{b}=\left(\frac{\Lambda}{1-\Lambda}\right) \frac{\delta-\sigma}{\epsilon+\eta}
$$

and

$$
\hat{P}_{a}=\left(\frac{1}{1-\Lambda}\right) \frac{\delta-\sigma}{\epsilon+\eta}
$$

The right-hand side of both equations in (1) is composed of, first, the "structural inflation multiplier" and, second, of "the structural inflation multiplicand" or the autonomous component of inflation. The multiplier depends on the degree of flexibility of both markups and wages: the greater their flexibility (a high value of $\Lambda$ ), the lower is the multiplier. The "multiplicand" is in turn determined by the relative elasticities of supply and demand that dictate how amplified are the pressure on prices arising from excess demand over the supply of the non-progressive sector. From this straightforward model, a few cases can be outlined. Two extreme cases are those of an absolute inflexibility of wages and markups $(\Lambda=0)$ and the counterpart perfect flexibility of markups $(\Lambda=1)$. The former implies a constant structural inflation rate proportional to the tightness of the productive bottleneck $\left(\hat{P}_{a}=\frac{\delta-\sigma}{\epsilon+\eta} ; \hat{P}_{b}=0\right)$, whereas the former implies an explosive process leading to a hyperinflation $\left(\widehat{P}_{b}=\widehat{P}_{a}=+\infty\right)$. The intermediate case $(0<\Lambda<1)$ is of much interest, for it depicts the high and chronic inflationary process the previously upset Latin American economies for decades. Such nonmonetary pressures are common, Olivera argues, along a process of structural change, such as the one Latin America had been undergoing since the immediate post-War period. ${ }^{100}$

Olivera's mechanical model does in fact account for the bargaining power of both workers and firms in the market place synthesized in the value of parameter $\Lambda$. In terms of

\footnotetext{
${ }^{100}$ Therefore, whilst abandoning a primitive production structure (prone to balanced or unbalanced stagnation or decline) and moving toward a more advanced stage of development, a country is expected to experience a transition process mediated by some speed of economic growth; along with the latter comes the warranted mobility of factors and, thus, relative prices variations. As we have come to conclude from the foregoing discussion, changes in relative prices prompt a rise of the price level. The magnified effects of both the multiplier and the multiplicand of structural inflation are, once again, due to the sluggish factor movements that render the structure of supply rigid. That is why the conversion into a fully industrial economy is bound to combine a scant measure of factor mobility with an almost complete downward inflexibility of money prices. A note of caution: before the reader jumps to the conclusion that Olivera is an inflation-friendly economist, we should note that he readily admits that such "traits" regarding inflexibility of prices and immobility of factors are not only difficult to observe in reality, but constitute forces hard to countervail. Moreover, developing economies present the propensity to endure demand-pull inflation due to systematic public deficits and/or by investing more than available savings permit. Olivera then warns that distinguishing between "structural inflation" and "structural proneness to inflation" matters a great deal. The far-reaching implication from the standpoint of policy is that genuine structural inflation may be easily mistaken with a "wave of sheer demand-pull inflation", to which the former contributes only with its magnifying effects.
} 
conflict models of inflation, this is a most relevant feature. Nonetheless, at least three shortcomings must be singled out when it comes to explaining inflation inertia. First, the autoregressive component is entirely dependent on the price level of the wage goods. This time-dependency is assumed rather than explained without any further elaboration. Secondly, the latter assumption leads to a somewhat limiting result: once the agricultural problem is resolved, inflation would lose its memory component and, hence, the price level would depend entirely on the relative price variation and supply-demand discrepancies, which cannot explain the self-sustaining thrust of inflation on a systematic basis, unless it is simply assumed that both relative prices stability and demand and supply equality are seldom obtained. A mechanism for rekindling wage or price pressures on inflation rates is left missing, but will be given attention in the decades after Olivera's seminal contribution [see Cardoso ([1980] 1981a) and Gallardo \& Mansilla (2007) and references therein].

Finally, the third refers to Olivera's assumption as regards the causality running from the downward stickiness of fix-prices to the monetary regime that is set to accommodate price increases. Heymann \& Leijonhufvud (1995, p. 30) have pointed out that models of this lineage "raise the question whether the downward rigidity of prices is some sort of behavioural constant or a learned response to monetary accommodation", in line with Campos's (1962) notion of “inflation-induced bottlenecks" (see section 2.3).

Interestingly, this lineage of structural inflation models would find its North American (e.g. Baumol 1967) and Scandinavian (e.g. Aukrust-EFO model) counterparts in the same decade and thenceforth (see Frisch 1977, pp. 1304-1309). We sidestep priority issues here, only to unearth the more important web of intellectual outcomes pertaining to the inflationary phenomenon, whose mechanistic aspect began to gradually flourish in the 1960s. Next, we delve briefly into the monetarist analogue of this process, for it will inform one of Brazil's most celebrated economists: Mario Henrique Simonsen.

\subsection{Phillips trade-off: adaptation and acceleration}

As the discipline became more mathematically formalized, economic models started to growingly resemble autonomous objects - veritable tools - of reasoning, which did not depend nor were conditioned by the theories they were meant to represent (Morgan \& Morrison 1999). The mathematics simply reflects, however, a mechanistic view of economics that was not at all new by the 1950s. It's been present in economics ever since Adam Smith's gravitational market model and in Edgeworth's and Jevons' physical metaphors. In the post- 
war period, this communicational feature is emboldened in economics and, fueled by the mathematical thrust the discipline gains from the hard sciences, it becomes a standard method of thinking and probing with economic problems. Humphrey's (1975) summary of the causes of inflationary persistence is illustrative of the spirit of those times, in the Figure 9 below.

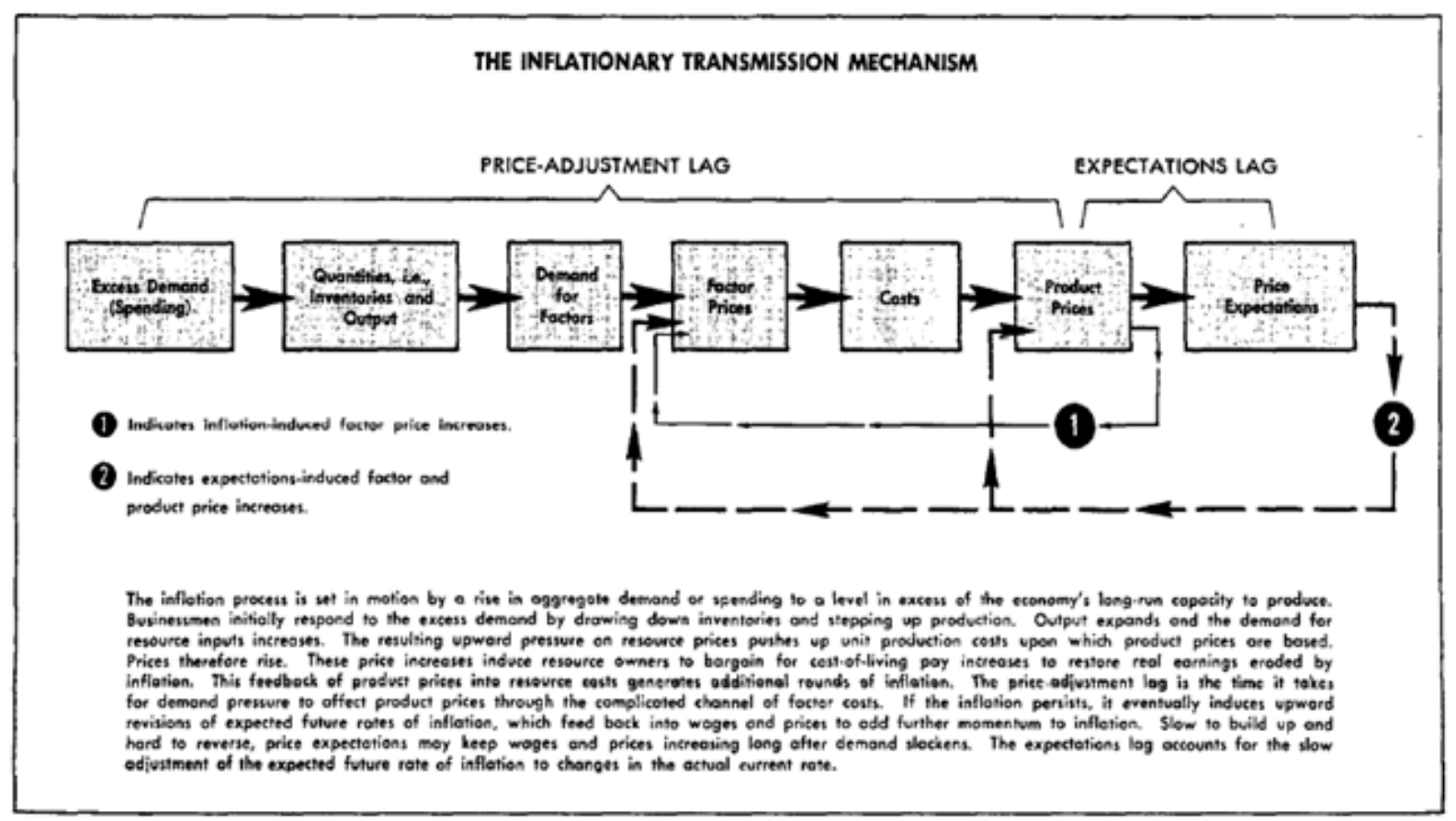

Figure 9 - Thomas Humphrey's Inflationary Transmission Mechanism. Source: Humphrey (1975, p. 5). ${ }^{101}$

The Phillips trade-off controversy of the 1960s indicates this new form of thinking and talking about macroeconomics and, particularly, about the dynamics of employment and inflation. Samuelson and Solow (1960) reframed the dichotomy between cost-push and demand-pull inflation theories in terms of the trade-off between price inflation and unemployment level (Forder 2010). Out of this came the simple diagram of a downwardsloping curve with a continuum of policy options for the short-run. Lipsey (1960) furthered

\footnotetext{
101 The footnote of the image brings the following subtitles: "The inflation process is set in motion by a rise in aggregate demand or spending to a level in excess of the economy's long-run capacity to produce. Businessmen initially respond to the excess demand by drawing down inventories and stepping up production. Output expands and the demand for resource inputs increases. The resulting upward pressure on resource prices pushes up unit production costs upon which product prices are bared. Prices therefore rise. There price increases induce resource owners to bargain for cost-of-living pay increaser to restore real earnings eroded by inflation. This feedback of product prices into resource costs generates additional rounds of inflation. The price-adjustment log is the time it takes for demand pressure to affect product prices through the complicated channel of factor costs. If the inflation persists, it eventually induces upward revisions of expected future rates of inflation, which feed back into wages and prices to add further momentum to inflation. Slow to build up and hard to reverse, price expectations may keep wages and prices increasing long after demand has slackened. The expectations lag accounts for the slow adjustment of the expected future rate of inflation to changes in the actual current rate".
} 
the mathematical underpinnings of Phillips's original relationship between the rate of change of money wages and the level of unemployment, as follows:

$$
\dot{W}=\alpha+\beta U^{\gamma}
$$

or yet

$$
\log (\dot{W}-\alpha)=\log \beta+\gamma \log U
$$

where $\dot{W} \equiv \frac{W_{t+1}-W_{t-1}}{2 W_{t}}$ denotes the rate of change of money wage rates, and $U$ the level of unemployment. The paper is written as an all-out attempt to find the best-fitted functional form estimation for the Phillips relationship. The underlying model is, though, one of excess demand inflation based on the excess demand for labor over the supply of workers as a proportion of this latter. What is most revealing about Lipsey's paper is the new problem of finding a suitable theory for this empirical regularity, as Tobin (1970) claimed ten years later.

Still in the mechanics of inflation and unemployment, Edmund Phelps (1967) proposed the acceleration of inflation rates in a long-lived inflationary environment, based on agents' adaptation to an ongoing inflation. He summarized his view as follows:

$$
\frac{d}{d t}\left(\frac{\dot{p}}{p}\right)^{e}=a\left[\frac{\dot{p}}{p}-\left(\frac{\dot{p}}{p}\right)^{e}\right]
$$

where $\dot{p}$ is the time-rate of change of the price level $(p)$, so that $\left(\frac{\dot{p}}{p}\right)$ reflected the inflation rate and superscripts " $e$ " denote expected values of the variables. Inflation rates are defined as a function of utilization rates $(f(y))$ - taken as the ration of employment to the labor supply and neglecting rising marginal costs - and of expected inflation $(-x)$; formally: $\frac{\dot{p}}{p}=f(y)-x$. The end result is a Quasi-Phillips curve relationship between inflation rates and the rate of capacity utilization, taken as a proxy of the labor market tightness (p. 261-263). An equilibrium rate of utilization is set $\left(y^{*}\right)$ beyond which the rate of expected inflation rises and shifts the curve upward; hence the natural rate of unemployment.

Humphrey’s (1976) survey of inflation theories sets up a four-equation framework to encompass all the relevant aggregative inflation theories available at that time. A wage equation, a price equation, a price-expectations and a demand-pressure equations constitute 
the set of endogenous variables defined as functions of a handful of seemingly independent and pre-determined variables, such as the following ${ }^{102}$ :

1. Wage Equation:

$w=w\left[\hat{p}_{L}, \hat{p}_{L}^{e}, x_{L}, z_{L}\right]$

2. Price Equation:

$p=p\left[w_{L}, \hat{p}_{L}^{e}, x_{L}, z_{L}\right]$

3. Price-Expectations Equation: $p^{e}=p^{e}\left[\hat{p}_{L}, z_{L}\right]$

4. Demand-Pressure Equation: $\quad x=x\left[(\widehat{m}-\hat{p})_{L}, f_{L}, z_{L}\right]$

Upon this system of equations, each theory can be depicted in accordance with the set of assumptions and historical and institutional detail. The price equation is of special interest for us. It allows one to express the difference between the Phillips trade-off assertion and the accelerationist approach by Friedman and Phelps. A relationship such as $\hat{p}=a x_{L}+\phi \hat{p}^{e}$ reveals that inflation is affected by lagged values of aggregate demand $\left(x_{L}\right)$ and by the expected inflation $\left(\hat{p}^{e}\right)$. The parameters $a$ and $\phi$ refer to the degree of pass-through from independent to dependent variables. The difference between the two approaches lies in the value of $\phi$. If it is less than 1, then a trade-off exists between prices and employment exist, due to the incomplete adjustment of prices to expected inflation. Equilibrium thus requires $\hat{p}=\left[\frac{a}{1-\phi}\right] x_{L}$, which implies that reducing demand leads to lower inflation. On the other hand, if we assume $\phi=1$, we get a fully adjusting price equation to expected inflation, generating thus the accelerationist take on inflation: $\hat{p}-\hat{p}^{e}=a x_{L}$. Should agents fully adapt to expected inflation, then $p=p^{e}$, and any demand expanding or contracting policy is no longer viable. If a lag is introduced in the price equation, so that adaptive expectations become crisply defined, we can then write: $\hat{p}-\hat{p}_{-1}=\Delta \hat{p}=a x$, the essence of the accelerationist model.

This section had the purpose of briefly outlining the inclination towards mathematical mechanical models in the mainstream monetarist quarters. It suffices to show that this tradition has been gaining momentum ever since the immediate post-war period and was further emboldened in the decades following. Above all, we meant to simply illustrate the

\footnotetext{
${ }^{102}$ Variables are defined as follows: $w$ is the percentage rate of change of nominal wages; $p$ is the percentage rate of change of prices, i.e., the inflation rate; $p^{e}$ is the expected future rate of change of prices, i.e., the anticipated rate of inflation; and $x$ is the level of excess demand, no distinction being made between labor and product markets. The variables $m$ and $(m-p)$ are the percentage rates of change of the nominal and real (pricedeflated) money stocks, respectively, and $f$ is the fiscal policy variable represented by the size of the government's budgetary deficit. The variable $z$ is the vector of cost-push forces including such factors as tradeunion militancy, monopoly power, and the political commitment to the goal of full employment and the consequent removal of the fear of unemployment as a factor constraining wage demands. The subscript $L$ represents time lags denoting that the dependent variables may be influenced by lagged as well as contemporaneous values of the independent variables.
} 
intellectual landscape in which a very important character in our narrative will contribute to the Brazilian debates on inflation and growth: Mario Henrique Simonsen. His rather eclectic approach will provide the basic framework for the second round of disputes between structuralists and monetarists and, for that much, we shall look into his writings with some detail.

\subsection{Simonsen's bridge model}

Mário Henrique Simonsen (1970) was the first to implement a formal feedback model of inflation in Brazil. As we have seen, Olivera (1967a) had already delineated a simple inflation model with wage-indexation feeding into relative price changes that ultimately affected the rate of inflation. It is worthy of note that at the time inflation was seen as an aspect of development-related issues, such as relative price changes, social aspirations, competing claims by income groups and distributive aspects of economic growth. Still, the analysis of Simonsen's writings is highly representative of the mainstream standard of theoretical discourse at that period, although it absorbs by proximity the development-laden vocabulary of the Latin American economic debate. Simonsen synthesizes form and content in such a masterful way as to create an analytical framework for the subsequent exchanges among economists on inflation in Brazil.

As regard the inflationary problem in Brazil, Simonsen (1964) initially presented an eclectic account of the causes of inflation, with an entire chapter devoted to the "sociopolitical causes of inflation", by which he meant the distributional conflict dimension of chronic inflations. In the context of a rapidly State-led industrializing process, government sought to alleviate the dissatisfaction of different social groups by dividing the national output in parts that add up to more than the whole output. He mentions "the revolution increasing aspirations" that contaminates the psychological attitude of economic agents in underdeveloped economies. In this setting, a low-income population that abruptly widens its "consumption horizons", through the "incidence of conspicuous consumption", tends to claim improvement in living patterns in a much faster pace than the one allowed by productivity growth. ${ }^{103}$ Simonsen is critical of the government's weakness in obtaining "distributively

\footnotetext{
${ }^{103}$ In this early work, the analysis is embedded on the conflict theory terminology of the time. In what concerns the aspiration gap, later formulated by Rowthorn (1977), we are told that "Everyone is honestly convinced that their wage is unfair and insufficient. This conviction is transmitted to the political orbit and the government decides to increase the share of national output held by a few, without reducing the share perceived by others. As the shares promised to each social group are expressed in nominal terms, inflation restores the logical
} 
compatible decisions", thereby fueling the "popular insensitivity to the causes of inflation", reinforcing a "philosophy of distributional incompatibility", by way of "ignorance or strategy". (p. 16). In a regime of chronic inflation, Simonsen added, the real incomes undergo an oscillatory behavior that is virtually consistent at the aggregate level, for when some groups obtain their peak real income, others are at their "valley" real income, others are midway, given the unsynchronized structure of income adjustments, later known as the "sawtooth model" of nominal incomes under inflation, a characterization of which Simonsen shows on page 18 of his first work on inflation, as in Figure 10 below.
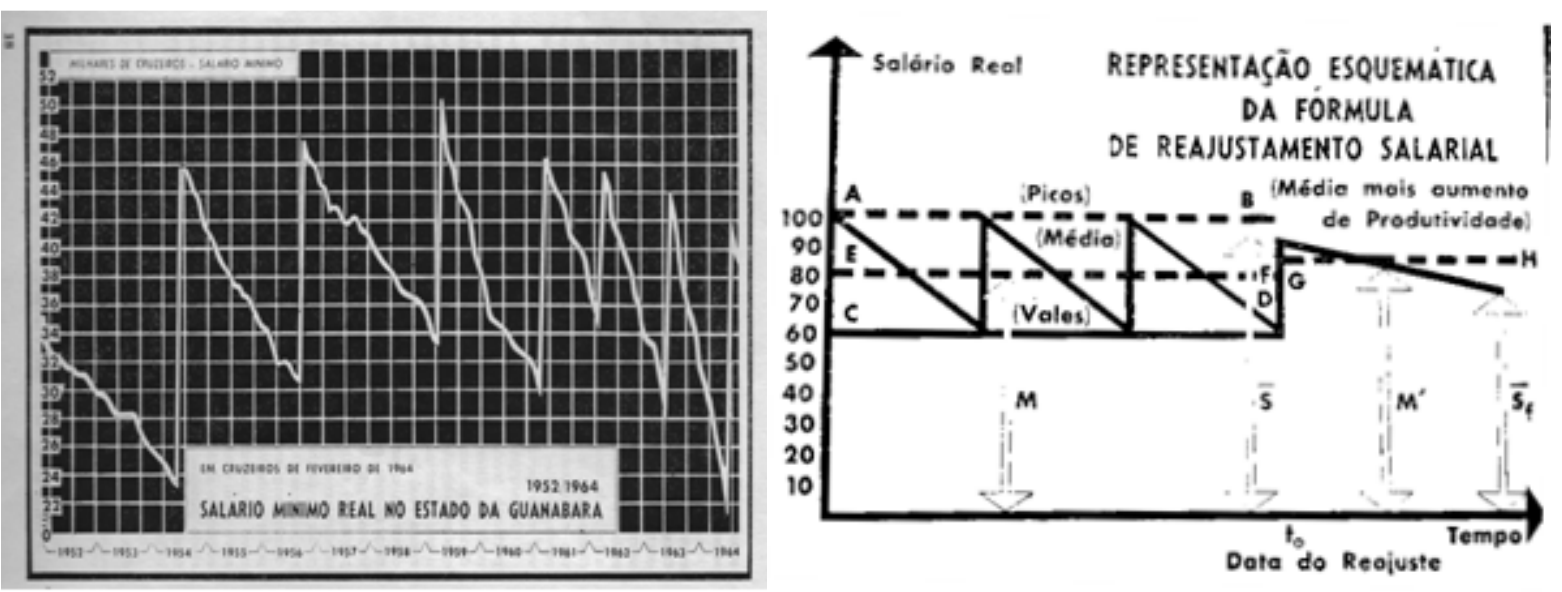

Figure 10 - Sawtooth-shape of the Real Minimum Wage in the State of Guanabara between 1952 and 1964 (Left panel) and Schematics of Real Wage(*) behavior (y-axis) through time (x-axis) (right panel). Source: Simonsen (1964, p. 18 and 92, respectively).

(*)Title of the diagram reads: "Schematic Representation of the Wage Adjustment Formula" and below it, in between parentheses, it reads "Average plus increase in productivity". The image represents the peak real wage (Picos) at level $A$, the average real wage (Média) at level E and the trough real wages (Vales) at level C.

The adjustment cycles tend to overlap and produce a movement free of oscillations. In aggregate terms, argues Simonsen, "everything appears as if individuals, instead of living purchasing power cycles, remained in the comfortable stability of average income levels". The very asynchrony among the various income peak levels may turn inflation economically viable. Were all the peak levels to be simultaneously obtained, the result would be the acceleration of price rises. It is thus the "effect of previous peak levels on the aspirations and expectations that explain the difficulties faced by monetary stabilization". ${ }^{104}$ Simonsen (1964)

consistency of the system: rising prices act to shrink the real share of each social group, in such a way as to adjust the sum of the parts to the dimensions of the whole. As the cycle repeats itself, inflation becomes chronic. And, as the system shortens its period of reaction to the compression of distributional shares through the rise in prices, inflation accelerates" (Simonsen, 1964, p. 15).

104 However, the outcome of such dynamics is a "psychological byproduct" by which the previous peak purchasing power becomes a "benchmark for income claims" that only a few are willing to let go of. A kind of mystic is created around these "previous peak levels" and a conviction is established which states that they 
hence ascribes the central cause of such difficulties to the socio-political background, namely, "the incapacity of economic policy to confront the political problem of distributional compatibility”. (p. 20). From abstract theory he would tag along the chains of neoclassical reasoning, moving closer, in successive approximations, to Brazilian reality, as Wicksell once suggested. But it would be a mistake to construe Simonsen's neoclassical inclination as inkling of untrammeled allegiance to any type of orthodox reasoning. This can be better understood in his analysis of monetarism.

The 1960s watched Milton Friedman's monetarist counter-revolution to Keynesianism primacy, which revived the quantity theory of money as the orthodoxy of monetary theory. After a thorough analysis of the limitations faced by the quantity theory in explaining inflation in Brazil, in a later work, Simonsen (1970b) found it more adequate to illustrate his claim by means of a model of feedback inflation ${ }^{105}$, as follows:

$$
\hat{p}=a \hat{p}_{t-1}+b g_{t}+c_{t}
$$

where $c_{t}$ denotes the autonomous component of inflation - or the "cost-push factor", or even the "supply shock component" - which reflects institutional changes such as minimum wage readjustments, tax increases or public utilities prices, as well as accidental events, such as bad crops or energy price rises. The parameter $a$ is the feedback coefficient, that is, the passthrough inflation from the previous period to the present, and has values within the range $0 \leq$ $a \leq 1$, except for the hyperinflationary periods, when its value may exceed unit. At last, $g_{t}$ represents the excess demand component; there is a growth rate of output that provokes no inflationary pressure, given by $y_{n}$, so that $g_{t}=\hat{y}_{t}-\hat{y}_{n}$; being $\mathrm{y}_{t}$ the effective rate of growth of output at a given period t. ${ }^{106}$ By assuming the absence of adaptive expectations or

represent the minimum distributional justice people should aspire to. (p. 19). He highlights the "mystique of acquired rights" concerning real wage levels. For further details on social tensions and stabilization policies, see Simonsen (1964, p. 87 - Portuguese in the original).

${ }^{105}$ Simonsen's model can be seen as a formalization of the feedback inflation already present in Sunkel (1958) and a local contribution to the international literature on inflation that had already incorporated the selfreplicating pattern of chronic inflations. Earlier attempts at formalizing the inherent momentum of inflation had been successfully accomplished by Julio Olivera (1964, 1967a), but are not acknowledged by Simonsen in any of his works.

106 There has been a short-lived dispute over the question of which side of the structuralist-monetarist contest should one place Simonsen's contribution. Whereas his policy conclusions are by all means inclined to the orthodox quadrant, his theoretical framework adopts the syntax and the semantics typical of structuralism. This resemblance led Lopes (1979) to characterize his inflation-feedback model as a neo-structuralist representation of CEPAL's structural inflationary pressures and propagation mechanisms, with a structuralist specification of the link between the rate of growth of aggregate demand and inflation, which rendered the long-run Phillips curve non-vertical. Barbosa (1979) would later disagree from such labeling of Simonsen's model, also drawing selectively on his writings, stating that the right specification of the aggregate demand shock in the model relates 
automatic price adjustments regulated by law (indexation) according to past inflation $(a=0)$, the model illustrates the basic interpretations of inflation, that is, the demand-pull $\left(g_{t}\right)$ and the cost-push and relative price changes $(c)$.

Reaching its steady state value requires that $\hat{p}=\hat{p}_{-1}, c_{t}=c$ and $g_{t}=0$, so that, after some algebraic manipulations, we find the equilibrium rate of inflation, given by: $\hat{p}=\frac{c}{1-a}$. This simple expression conveys two important aspects of chronic inflations: the idea that autonomous shocks have a permanent - although gradually decreasing - impact on the level of inflation rate, which depends on the lagged inflation coefficient, given by the parameter $b$. Economies facing chronic inflation develop mechanisms (such as formal indexation) to reduce its harmful effects it imposes on economic organization of households, firms, markets and government. ${ }^{107}$ Therefore, a more disseminated practice of indexation leads to a higher equilibrium rate of inflation. ${ }^{108}$ In the long run, when no demand shocks affect the economy, the inflation converges to this equilibrium rate, given the recurrence of autonomous random supply shocks. ${ }^{109}$

The crux of the question lies in the self-feeding component that gradually takes over the behavior of inflation, as the process of adjusting prices according to past inflation spreads throughout the economy. ${ }^{110}$ Before a hyperinflation, Simonsen mentions the challenges in the face of a "stability of a constant inflation", , and displays concern with "the governmentendorsed multiplication of institutional neutralizers of inflation", or indexation. The byproduct of such measures was the "establishment of an inflationary process that, as it approaches neutrality, must bring embedded in itself a high self-feeding coefficient".

to the output gap, and not a certain normal rate of demand growth. Although we do not intend to tackle this contention here, mention should be made to the context and content of reasoning in Simonsen's writings.

${ }^{107}$ For more detail on early warnings about the dangers of widespread indexation, see Simonsen (1964, p. 87).

108 As an example, if there is a $2 \%$ annual shock coming from agricultural sector and the economy faces indexation in $60 \%$ of its prices, than the equilibrium inflation rate will be $5 \%$. The value is reached by inputting the data in the formula given above: $\widehat{\boldsymbol{p}}^{*}=\mathbf{2} \% /(\mathbf{1}-\mathbf{0}, \mathbf{6})$.

109 The ad hoc character of this model is promptly recognized by Simonsen and deemed as a simple illustration of the self-feeding dynamics of inflation in an indexed economy. In his 1979 book, Simonsen would derive his model from a combination of Okun's law and the expectations-augmented Phillips Curve, within a cost-push inflation framework (Simonsen, 1970b, p. 112-130).

${ }^{110}$ Simonsen's model allows for a more varied differentiation among phases of inflation. In a later work, he criticized Friedman's theory for taking the economy too quickly from price stability to hyperinflation, leaving aside the stages comprised in between these two circumstances.

${ }^{111}$ For further detail, see Ramalho (2000). 
Simonsen is immersed in an academic arena largely influenced by the structuralist economists at CEPAL, which leads him to adopt both the terminology and the basic narrative structure in vogue at the time. Still, his writings manage to ascertain some independence regarding content. Take for instance the differences in emphasis between his inflationfeedback model and Olivera's account. The latter focuses mainly on (and analytically derives) the structural inflation multiplicand, which has to do with the changing structure of production under the import-substituting industrialization process of Latin American countries, whereas the self-feeding component receives less attention. In Simonsen's account, the structural inflation is dubbed the "autonomous component" (the " $c_{\mathrm{t}}$ " component), but is simply assumed - as a constant - rather than being derived in analytical terms. Moreover, the propagating mechanism (self-feeding component) takes center stage in the narrative.

We ascribe to this ambiguity in his framework the necessary modeling flexibility so its message can reach a wider audience. Still, even if one disagrees with this specific conclusion, the central message is that Simonsen's contribution became a cornerstone for subsequent analysis of inflation in Brazil. ${ }^{112}$ A particular feature of his writing lies in his constant effort to merge the analysis of the Brazilian case with the overall developments in the mainstream of the economics discipline. It is in these respects that he bridges the chasm between the North American and the Latin-American structuralist lineages. Chapters 5 and 6 will bring further and more specific details of his omnipresent interventions throughout the debates on inflation. In many respects, Simonsen anticipated some later important breakthroughs pertaining to inflation theory. In general, he had already set the "model-world" for those discussions in the early 1970s, namely: his early distributional conflict perspective, the self-feeding inflation model, the relevance of unsynchronized price and wage adjustments, the cautionary remarks concerning the difficulties involved in price freeze policies (later known as incomes policy, widely adopted along the 1980s in Argentina, Israel and Brazil) and, finally, his "sawtooth" diagram illustrating the effects of inflation on nominal incomes.

\footnotetext{
${ }^{112}$ The latest version of the inflation feedback model is presented in Simonsen (1995, p. 129-130) and portrays an economy under full-wage indexation, with an inflation rate at period $t$ denoted by $\boldsymbol{\pi}_{\boldsymbol{t}}$ and the capacity of the economy to pay a wage rate compatible with the underlying distributional parameters of the social structure, denoted by the variable $\boldsymbol{k}_{\boldsymbol{t}}$. The drop, maintenance or increase in this variable leads to situations of increase, stability or fall in the inflation rate, according to the following relationship: $\pi_{t}=\left(\boldsymbol{\pi}_{t-1}-\boldsymbol{k}_{t}\right) /\left(\mathbf{1}+\boldsymbol{k}_{\boldsymbol{t}}\right)$. The neutral distributional equilibrium $\left(\boldsymbol{k}_{\boldsymbol{t}}=0\right)$ allows for a constant real wage in time, so that inflation is simply fed by the previous period rate of price increases. The inflationary self-feeding mechanism is connected to capacity of the economy to pay growing wage rate, which in turn is dependent upon the institutional environment and the structure of the economy, as well as on the long-run trajectory of growth (denoted by $\boldsymbol{k}$ ). Furthermore, inflation is depicted outside the simple framework of supply and demand in competitive markets, for "there cannot be free functioning of markets under mandatory indexation" (Simonsen 1995, p. 7 - Portuguese in the original).
} 
As we have just seen, Simonsen had stumbled across this visual pattern in his 1964 book (1964, p. 92) and further stressed it on his more influential 1970 book, but did not, at that occasion, provide an explicitly formal expression of it. ${ }^{113}$ A few years after Simonsen's first analytical attempt at rationalizing the zig-zag pattern of real wages, Georgescu-Roegen (1968; 1970) would publish these two papers on "the structural inflation lock", being the second an expansion on the first version, published in 1968. ${ }^{114}$ Apart from Moraes (1990, pp. 14-17), the literature has thus far overlooked this interesting chapter in the history of the sawtooth model.

\subsubsection{Georgescu-Roegen and the "structural inflation lock"}

Both papers were published in Portuguese, in Revista Brasileira de Economia organized by the Getulio Vargas Foundation (FGV) where Simonsen held many scholarly and administrative posts, including being the editor of this journal just mentioned. He divides the economy between those fixed-income receivers and the variable income-receivers. Inflation tends to redistribute income and wealth from the former to the latter. He refers to Simonsen (1964, p. 92) and expands on it, to reveal his difference with the Brazilian author.

Georgescu-Roegen (1968, p. 12-14) draws a diagram with "semi-log scales" to reveal the impact of inflation on fixed-income earners. Simonsen (1964) assumes that at every negotiation of contracts, the recipients of fixed-income restore their peak real income level and that, by the constant inflationary corrosion of real incomes, the "normal" level coincided with the average real income throughout the period (denoted by " $R$ " in the top diagram in Figure 11 below). Thus, inflation would be neutral in the dynamic sense of income distribution, as we have seen with Furtado and Pazos in chapter 2. The pitfall in Simonsen's conclusion (diagram "a" below) is the disregard of labor productivity enhancements, bound to occur along the development process, which is depicted by the line upward-sloping I-I line on the bottom diagram " $b$ ", in Figure 11 below. Note that the w-w line is slightly positively inclined. The difference in inclination thus accounts for the income transfer from fixed income-recipients - which he identifies with workers - too variable income earners.

\footnotetext{
${ }^{113}$ Simonsen (1964, p. 92) vaguely refers to the wage formula adopted by the military government in the 1964 plan, in which he took a part. In an op-ed piece to the magazine Conjuntura Economica, Simonsen (1984) presents the basic formula. For further details, see the interviews given by Roberto Campos and Simonsen himself to Biderman, Cozac \& Rego (1996).

114 A version in English was published in Economies et Societés (Cahiers de l'I.S.M.E.A.), in the same year, under the title Structural Inflation-lock and Balanced Growth. According to Baer (1967, p. 20, n.11) the paper also appeared "in English in the Proceedings of the Cordoba Second International Congress of Economics".
} 


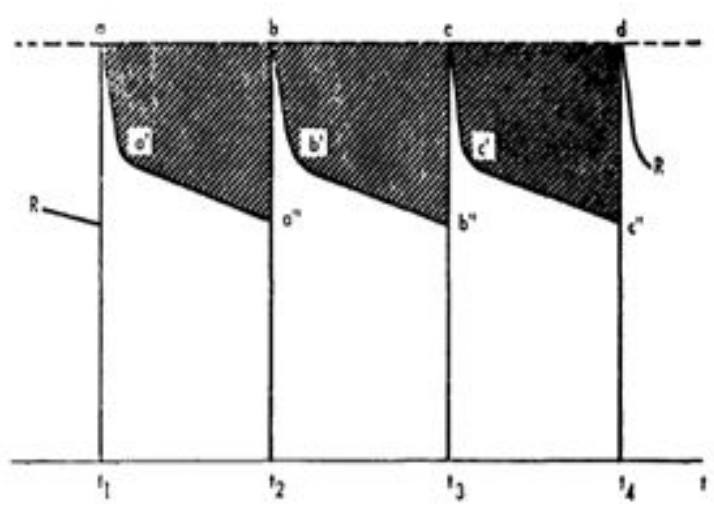

(a)

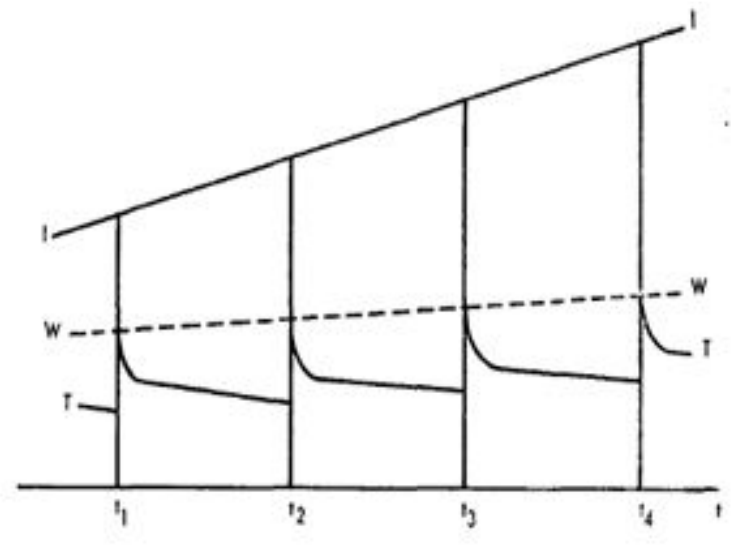

(b)

Figure 11- The saw-tooth diagrams and regressive income distribution. Source: Georgescu-Roegen (1968, p. 13)

In the 1970 extended version, Georgescu-Roegen (1970, p. 122) further explored the constant erosion of purchasing power real wages suffer under inflationary conditions, generating the visual pattern in the Figure 12 below. Again, his point is that wages tend fall out of favor as time progresses and inflation is not curbed.

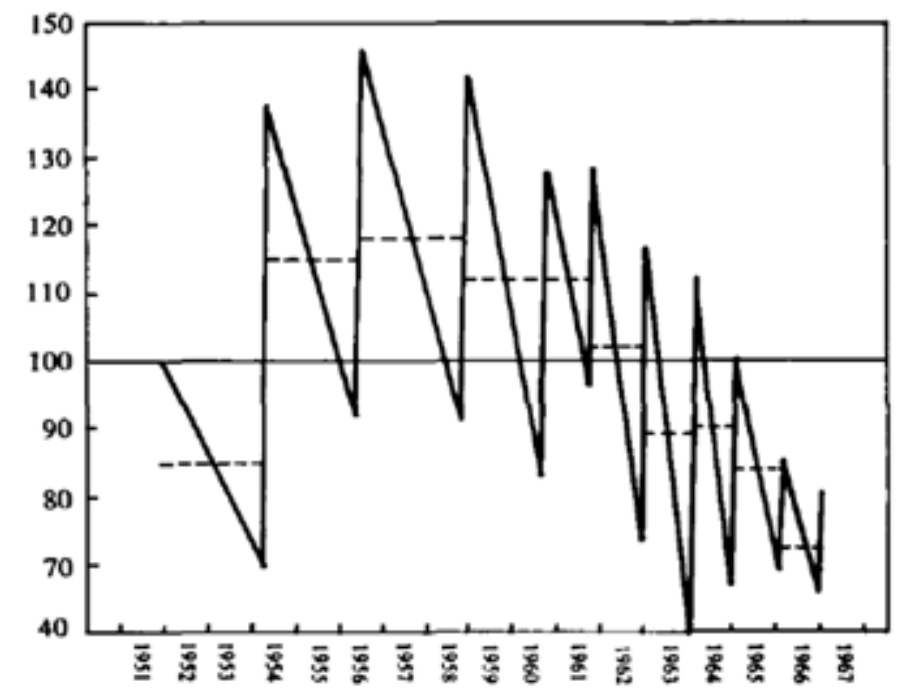

Figure 12 - The saw-tooth diagrams of real wages. Source: Georgescu-Roegen (1970, p. 121)

Next, the author extends Simonsen's (1964) diagram to posit a distribution-related visual argument in the Figure 13 below. 


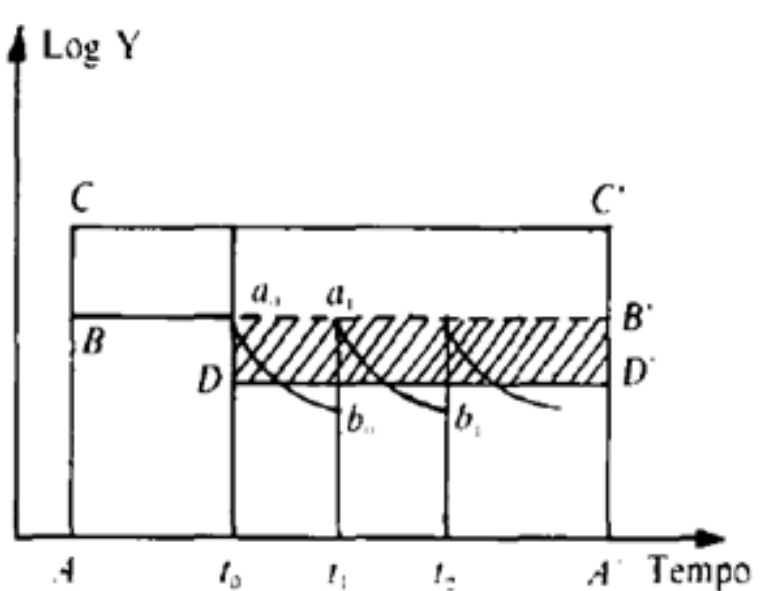

(a)

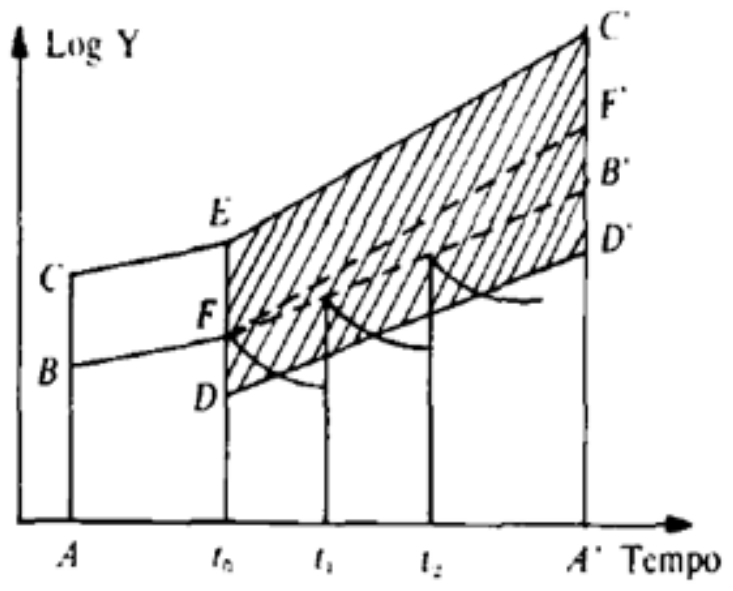

(b)

Figure 13- The saw-tooth diagrams and income distribution in a growing economy. Source: GeorgescuRoegen (1968, p. 13).

He shows that a policy that restores real income to its previous levels without correcting it for productivity gains (diagram "a") leads to concentration of wealth as variable income-receivers accrue the entire productivity gains (measured by the triangle FBF' in the diagram ' $\mathrm{b}$ "). The D-D' expresses the average real wage in a growing economy, while F-F' depicts the peak real wage level. The result is measured in welfare terms: the low-income classes fall out of favor while property-owning classes enjoy an increase in luxury consumption. From the discussion in Chapter 2, at the risk of oversimplifying this author's contribution, the argument builds on Kaldor's basic proposition of inflation as an incomedistributing process favoring property-owning classes with a high propensity to consume luxury goods. Baer (1967, p. 20, n.11) has fit this "original analysis" into the structuralist school, which seems quite adequate. ${ }^{115}$

Georgescu-Roegen has not provided an explicit mathematical formalization of the saw-tooth diagram, but it is clear the way he used it as a formal tool to reason about an inflationary environment. ${ }^{116}$ To best of our knowledge, Simonsen never replied to Georgescu-

\footnotetext{
115 For instance, Baer summarizes the point raised in the paper as follows: "The tendency of the lower income groups is to demand goods of different types of industries than the ones that were established initially. The inherited industrial structure is not flexible enough to adapt itself to new demand. Thus new industries have to be built, but old industries are threatened to have huge amounts of idle capacity. This cannot be allowed to occur. The distribution of income has to be redistributed again in favor of those groups that consume the goods of the old industrial structure. This redistribution can occur via inflation" (Baer 1967, p. 20, n. 11).
}

${ }^{116}$ Given space constraints, we strongly recommend the reading of Georgescu-Roegen's papers on inflation, for they reveal a eclectic combination of structuralism, institutionalism and political elements into a social theory of inflation. Unfortunately, his contribution has been almost entirely overlooked by the literature. 
Roegen's criticism. Further research on the context of the latter's input in the debate may prove useful to reveal how alluring was the problem of inflation and how different traditions were teamed up to bring novel readings of it. 


\section{Chapter 4 - The Monetarist-Keynesian controversy}

The overview of the academic production on matters of inflation between 1963 and 1980 reveals a growing formalization of economic models with the use of mathematical tools, whilst the problem of expectations - only tangentially touched upon previously - gained center stage of the controversy. As inflation started to soar, the problem of the original causes of creeping inflation was overtaken by the challenge of duly accounting for an accelerating inflation. Three main approaches competed for the explanation of inflation dynamics, namely: the Phillips curve, the monetarist inflation model and the Scandinavian structuralist model. ${ }^{117}$

The Phillips curve negatively relating the rate of change of money wages and the level of unemployment was further amended to incorporate adaptive expectations under the Friedman-Phelps hypothesis in order to distinguish between anticipated and unanticipated inflation. The natural rate of unemployment that came out of the contributions by the latter authors induced the new microeconomics of the Phillips curve, trying to explain the labor market features that would explain the natural rate of unemployment. Secondly, the monetarist inflation model grew out of the efforts carried out by Milton Friedman and Anna Schwartz in reviving the quantity theory of money. In a nutshell, the acceleration theorem implied that only changes in the rate of growth of the money supply would induce real effects, but that these would be temporary due to the fact that endogenous expectations would lead, by means of an error correction process, the catching up among realtive money wages and the higher inflation rate. (Laidler \& Parkin 1975, pp. 744-752)

Therefore, the dynamics of inflationary expectations were thus seen as the backbone of an accelerating inflation. John Muth and Robert Lucas added to the step-by-step adaptive expectations the idea that agents could learn from past mistakes in a way that expectations would rise as unbiased estimators of the actual inflation rate, once all available information were fully processed prior to decision making. By introducing expectations in its various modes, the very existence of either short-run or long-run Phillips curve was challenged. The combination of the concept of rational expectations with the natural rate hypothesis led to a pessimistic view of the effectiveness of economic policy (Frisch 1977, pp. 1290-1297).

Finally, the structural models of inflation were born out attempts to explain inflation in industrialized countries based on inter-sector differentials as regards productivity, prices and

\footnotetext{
117 This overview in the next paragraphs draws largely on Frisch (1977) and Laidler \& Parkin (1975) and Goodfriend \& King (1997).
} 
income elasticities of demand whilst assuming homogenous rates of growth of wages due to fairness issues or simple relative wage concerns amongst workers; all these aspects were bound to introduce several price and wage rigidities, thereby allowing for the explanation of an ongoing inflation in these countries. Among the main contributions, we can cite William Baumol's (1967) embryo cost-disease model and Julio Olivera's (1964) take on the inflationproducing oscillating pattern of relative prices along the development process of structural change; also the Scandinavian model (EFO) tying international to domestic inflations by means of a productivity-differential propagating mechanism was quite fashionable at the time. At last, the international transmission of inflation received wider attention than it did in the 1960s. Price-, demand- and liquidity-effects were articulated to bear out the rise of inflation to a worldwide first-order concern (Frisch 1977, pp. 1304-1309).

By the end of the 1970s, the New Keynesian approach emerges with the aim to provide solid micro-foundations to macroeconomics (Backhouse \& Boianovsky 2013; Mehrling 1990, p. 76). The main topics relate to costly price adjustments, staggering of wages and prices due to various time-lengths of contracts, imperfect competition and its impacts on goods markets due to (counter-)cyclical markup behavior, coordination failures, the determinants of labor and credit markets plagued by near-rational behavior, asymmetric information and institutional (or non-economic) constraints (Mankiw \& Romer, 1991a, pp. 315). ${ }^{118}$

In this chapter, we attempt to highlight several contributions along these lines, defining two threads of influence on the basic modeling strategy wherein the inertial inflation hypothesis will be spelled out in Brazil in early 1980s; to name a few: Hollis Chenery, Lance Taylor, Franco Modigliani and James Tobin, amongst others. These economists were intimately connected to mathematical reasoning, whilst keeping sight of real-world problems and puzzles to which they attempted to provide answers or explanations. Consequently, these features will find their way into the inertial inflation story, which will amount to a policyoriented mathematically shaped dynamic inflation theory. Following this introduction, the first section entertains the possible connections between the debates in the United States and Europe in the 1970s and those ongoing in Latin America, particularly in Brazil. We describe rather briefly the basic tenets of the North American Structuralist School of the late 1970s, in which the contributions by Hollis Chenery, Lance Taylor, Rudiger Dornbusch, Franco

\footnotetext{
${ }^{118}$ Given its descriptive nature, this section draws heavily on Mankiw \& Romer (1991a; 1991b) and Benassi et al.(1994).
} 
Modigliani and James Tobin are highlighted. The second section closes the chapter musing over the mathematical formalization of the sawtooth model by economists at PUC-Rio.

\subsection{The North American Influence}

The second round of "the structuralist-monetarist controversy" is deployed in the late 1970s, after the debate lost intensity from the mid-1960s on, although still remained a contentious issue in Latin American economics along the 1970s (Toye 1987, Taylor 1974, 1988 and 1989). This decade witnessed three worldwide shocks that would box in many economies, forcing their governments to resort to the International Monetary Fund for assistance. ${ }^{119}$ The IMF's stonewall orthodox strategy had changed little ever since Polak's (1957) monetary theory of the balance-of-payments, sparking the most stringent opposition to its economic policy repertoire as condition for the release of funds (see Taylor 1983).

The structuralist reaction rose up once again, but in a much different line of reasoning from those found in the early Latin American debates. They now stemmed primarily from the works of Hollis Chenery, Lance Taylor and, to a lesser extent, Rudiger Dornbusch, among others, which put forward an analytical framework based upon a formal modeling strategy with custom features for understanding the differential dynamics of underdeveloped economies.

\subsubsection{Development economics: structural change, growth and distribution}

The term "structuralist" had been associated, since the late 1950s, with the opposition to orthodox theory and policy, encompassing different styles of theory, provoked by different sets of problems, in such a way that we can account for a Latin American structuralist school (see Hirschman 1962), as well as its Anglo-Saxon and European counterparts (Canavese, 1982). Inheriting the same concerns with economic development, the neo-structuralist macroeconomics was first formalized by Hollis Chenery and further developed on the trail of Lance Taylor's (1979, 1983, 1988, 2003) efforts. ${ }^{120}$

\footnotetext{
${ }^{119}$ The academic economics profession became, in the post-World War II period, an increasingly theoretical and - and even more - abstract mathematically-driven enterprise very often disconnected from the urgent needs of economic policy-making (or the real world, for that matter) - at least in its dominant Anglo-Saxon tradition. For more details on this evolution of the economics discipline, see De Vroey (2012, p. 88-90) and Weintraub (1999).

120 In such a "structuralist" representation, institutions and the functional distribution of income influence extensively the behavior of productive sectors and social groups. Formal mathematical models are designed to portray the specific "stylized facts" of underdeveloped economies. Mathematics is important at this point for allowing the connection to other economic approaches as well as adapting the format of such theoretical
} 
Hollis Chenery $(1975,1979)$ has been a leading economist in the North American structuralist tradition. His work is rife with the problems of structural changes and inter-sector dynamics of unbalanced growth and the ensuing structural incompatibilities bound to arise as the productive structure undergoes severe and deep-reaching change. ${ }^{121}$ In essence, development economics, as Chenery (1979, p. 2) saw it, should address the following problems: (1) persistent imbalances between supplies of capital and labor; (2) consequences of scale economies and limited market size; (3) dual role of external resources. Evidently, that is not all that was to it, but the idea is that these aspects were seen as crucial for developing economies undergoing rapid processes of structural change. Chenery sought to update the analytical framework in order to tackle essentially the same problems dwelled with by Latin American structuralists back in the 1950s and 1960s.

Lance Taylor followed Chenery's footsteps, starting with his Macro Models for the Developing Countries (1979) and then the tome on the Macro Models for Brazil (Taylor et al. 1980). ${ }^{122}$ General Equilibrium models were used to assess the impact of various policy proposals on distribution of income, rates of growth and inter-sector dynamics. The problem of inflation is undertaken through many angles, for instance, as a possible means to increase output expansion through the forced savings mechanism (see Bacha 1982, p. 2-3) or by a direct application of CEPAL-vintage structuralist models (see Cardoso 1981b). ${ }^{123}$ Moreover,

endeavors to the established style of presentation within the Anglo-American economic community. But other reasons seem to justify the mathematical drive of these models. At the onset of his 1979 book, Lance Taylor states: "Economists long ago learned that mathematical formulations of their problems help clear away logical and metaphysical cobwebs. There is no reason not to apply these tools to models for poor as well as rich countries". (Taylor L., 1979, p. 2) In addition, Dutt \& Jameson (1992) argues that mathematical tools help define the particular conditions under which some results are obtained. As an example, the discursive mode of analysis present in CEPAL's structure lead inevitably to uneven development between central countries and the peripheral ones, whereas the "North-South" trade models provide the possibility of such results, but not the necessity of them. Moreover, this new generation of structuralist models departs from "stylized facts" taken out of coherent system of national accounts matrices that provide a wide perspective of the economy's building blocks (Dutt \& Jameson, 1992).

${ }^{121}$ In his words: "Economic development can be viewed as a set of interrelated changes in the structure of the economy that are required for its continued growth. They involve the composition of demand, production, and flows. Taken together, these structural changes define the transformation of a traditional to a modern economic system" (Chenery 1979 p. xvi).

${ }^{122}$ This book compiles a selection of papers written with two Brazilian economists such Edmar Bacha and Eliana Cardoso, while also benefiting from indirect contributions by Francisco Lopes, Dionísio Dias Carneiro and Pedro Malan (p. xii), all of which were important economists during the formation years of the Post-Graduate Economics Department at PUC-RJ, Brazil (see Bacha 1998b).

123 The analysis focuses internal productive bottlenecks (e.g. agriculture) and balance-of-payment constraints on growth and distribution. Prices are mainly cost determined and the resource-constraint-related mechanism permitting economic growth and structural change is ascribed to forced savings transferring income away from low-saving income classes to profit-accruing ones, in order to finance aggregate investment. This latter follows "neo-Keynesian" assumptions, whereby decisions to accumulate capital are determined by expectations, 
Taylor's influence on the writings of Brazilian economists has been recognized among those that would later be placed at the department of economics at PUC-RJ (Lopes 1979, Resende [1979] 1981, Cardoso 1979, Bacha 1982, Arida 1982b and Franco 1986) ${ }^{124}$, a research center largely influential in policymaking circles from mid-1980s onwards (see Chapter 5 below).

Far into the 1980s, these models will underpin the harsh neglect directed at the IMF's conditionality agreements by these Brazilian economists in the protracted aftermath of the 1979 supply shocks. Taylor's growth and distribution - appearing mostly as "gap models" were largely influential in these Brazilian economists' thought both in what regarded the relevance of policy (amid the monetarist-infused radical pessimism toward policy activism of the late 1970s) and the structuralist methodological standpoint, which encompassed a distributional approach to economics in light of early post-Keynesian models in Kaleckian, Kaldorian and Pasinettian lines (see, for instance, Taylor \& Bacha 1976, as well as Bacha 1994). Among them, we single out Edmar Bacha, who was, at the time, one of most prolific scholar in PUC-RJ with the highest exposure to international journals (Loureiro 2009) and will prove an important academic partner to Taylor from mid-1970s on, sharing the goal of promoting the structuralist - now deemed neo-structuralist - class of economic models. Edmar Bacha would later become one of the leading economists in the Brazilian 1994 stabilization plan.

Much more historical material must be raised as regards Lance Taylor's contribution to the Brazilian quarters of economics profession. ${ }^{125}$ But the available documentation indicates, in this vein, that Taylor was quite influential in the early moments of the 1980s, when stabilization debates in Latin America attracted attention from the international academia (see more details in the next chapter). Besides his intellectual cooperation and academic leadership in the years prior to the assemblage of the PUC-RJ economics department, Taylor's influence is at least twofold: he leveled harsh criticism at the policies imposed by the International Monetary Fund and the World Bank on developing countries,

nonmarket considerations and, to some extent, the interest rate. It is income distribution that shifts resources around and thereby determines the long-run trajectory and structural composition of the economy. The analytical drive is directed at promoting more egalitarian policies and is couched on institutions- and class-based categories that incorporates issues of economic power and coercion when considering how specific groups maintain the real value of their payments flows as prices change (Taylor et al. 1980, pp. 3-15).

${ }^{124}$ Lance Taylor is mentioned as an influential economists by all of the economists later in charge of the Real plan in their interviews to Biderman, Cozac \& Rego (1996) and Mantega and Rego (1999).

${ }^{125}$ See Dutt \& Jameson (1992), Dutt \& Ros (2003) and Ros (2000) for a review of structuralist economics and the far-reaching contributions set forth by Lance Taylor. 
whilst also providing institutional and academic support to the young Brazilian economists studying abroad, co-authoring papers, organizing books and publicizing development-related models. Taylor also took part as a co-supervisor of Gustavo Franco's (1986) thesis on the theoretical aspects of hyperinflations ${ }^{126}$ and was of an encouraging nature in favor of Persio Arida's (1992) thesis. ${ }^{127}$

Taylor's engagement in promoting scholars was matched by Rudiger Dornbusch's intellectual enthusiasm (e.g. Dornbusch 1980) for stabilization in open economies, a subject that was quite alluring to Latin American economists in those days. Dornbusch was, in his turn, very influential in Brazilian economists' works at PUC-RJ, especially those by Franco (1986) and, later, Arida (1992) to mention only the most direct ones. Given the rather conspicuous presence of this branch of the international academic economics in later writings, we postpone a more detailed analysis of their theoretical contributions to the next chapter.

A second line of analytical inspiration to the inertial inflation explanations came from a parallel controversy in the North American academia concerning the problems of inflation and unemployment. There is solid reason to believe - and we purport to provide evidence on this - that the basic analytical framework informing Brazilian stabilization policy debates were borrowed from earlier developments by the "non-monetarist" economists in the second half of the 1970s, such as Gordon (1976), Okun (1975) and Modigliani (1977). In what follows, we describe the formal contributions by Stanley Fischer, Rudiger Dornbusch, Robert Gordon and Franco Modigliani and the informal taxonomy put forth by James Tobin (1981). We shed light on the striking similarity between the frameworks carried through in both academic loci, a resemblance that is provided a causal connection on historical grounds, i.e. running from the North-American debates to the Brazilian contentious forum.

\subsubsection{Sticky prices, staggered contracts and indexation}

Schematically, three statements can sum up the Keynesian-Monetarist controversy in the 1970s: (1) monetary changes are the dominant cause of changes in nominal income to the

\footnotetext{
${ }^{126}$ These post-graduate faculties were still engaged in the Keynesian Neoclassical Synthesis of the 1950s, at arms against the monetarist Chicago school. It would take us to far from our objectives to provide sufficient evidence on the idea that this polarization in American economic theory found its way into the debates of monetary stabilization in Brazil. Still, the stringent denial of the plausibility of the monetarist framework by the Brazilian policymakers that attended the above-mentioned schools provides evidence on that matter.

${ }^{127}$ Lance Taylor's conversation with the author at $41^{\text {st }}$ Meeting of the Brazilian National Economic Association in Foz do Iguaçu, Brazil, 2013.
} 
detriment of temporary and minor influence of fiscal changes; (2) the natural rate hypothesis is valid; and (3) wages and prices are relatively flexible, so that the short-run Phillips curve is relatively steep (Gordon 1976, p. 18). Assertions (1) and (2) constitute the essential message of monetarism, whereas the latter's investment in empirical research on the short-run dynamics of wage and price behavior (3) proved less abundant. It is exactly in this segment of the dispute that Keynesians will provide most of their contributions, that is, the causes of wage and price rigidity, in sharp contrast with the implicit assumption held by monetarists of a fully flexible price and wage system. ${ }^{128}$

The empirical evidence points to the presence of "moderate lags in the response of prices to change in wages, but long lags in the response of wages to prices"; hence, the mitigated and lagged effects of aggregate demand on price behavior. Also, data indicate that persistent effects on unemployment arise out of monetary surprises and that autoregressive behavior is provides a good fit for variations in real variables, as in Gordon (1976, p. 28-29). The main problem at hand consists, then, of proving out of logic necessity that sluggish behavior can be made compatible with rational expectations or some acceptable notion of rationality.

The New Keynesian claim regarding the effectiveness of a systematic monetary policy rests upon the general result of sluggish adjustment of prices and wages (Phelps \& Taylor 1977). Due to the slow adjustment of prices, the effects of the monetary shocks on output are long lived and decrease exponentially in the pass-through coefficient, as in John Taylor's $(1979,1980)$ model of fixed prices for the next two periods, with uniform staggering. The autoregressive structure is present in both dynamic equations that prevents the serial

\footnotetext{
128 The eclipse of conflict-based inflation theories follow the perception that excessive attention had been previously devoted to the labor unions' militancy in explaining the upward trend in prices, as we saw in preceding chapters. It also reflects the highly mechanical tone of the literature emerging in the footsteps of Samuelson's systems of simultaneous equations with the expectations-augmentation motivated by the seminal hypotheses on adaptive and rational expectations. The rise of monetarism in its counter-revolution against the Patinkin-like Keynesian thinking (Mehrling 1990) is contemporaneous with the fall out of favor, inside the economics profession, of conflict models of inflation. Robert Gordon (1976) covered the theoretical developments in the theory of inflation and unemployment carried out from 1963 until 1976, with particular attention paid to the North-American quarters of the economics profession. He shows that controversy shifted from the identification of the sources of inflation - whether it was caused by demand-pull or cost-push forces to the empirical validation of the natural rate of unemployment hypothesis and the analytical criticism of this claim. Mediating between these two moments is the ascent of the Friedman-Phelps-Sargent monetarist school and its blatant refusal of the cost-push explanation on grounds that, despite the source of upward pressure on prices, the monetary authorities must validate an expanding money supply. Therefore, the causality running from money to prices stands on solid empirical and analytical grounds and any attempt to introduce other factors, especially those of a "cost-push variety" shall represent a desperate resort to "amateur sociology and politics" which plays "no part whatsoever in the problem" (Johnson 1972 quoted in Gordon 1976, p. 20).
} 
correlation from disappearing as soon as time elapses beyond the length of the individual price policy. A strong linkage is thereby set between price decisions over time; each price is set relative to the other prices, and this causes shocks to be passed from one price to another, a mechanism called "price multiplier". This result is different from that obtained with price predetermination, for in this case, the effect of a shock rises for one period and then decreases toward zero; the serial persistence is hump-shaped, reaching a peak only with a lag, the latter corresponding to the horizon of the individual pricing policy.

However, this model, by construct, only allows for price inertia, that is, the delayed response of prices to an unanticipated monetary shock. The chief conclusion in this literature is that the degree of rigidity at the micro level implies the degree of sluggishness at the aggregate level. In a similar vein, Gray's (1976) and Fischer's (1977) famous models of wage predetermination in long-term contracts and uniform staggering of the negotiation dates has spawned a rich thread of wage indexing models. But they are concerned with the macroeconomic stability under a widely indexed economic setting, which means that they assess the impact on both output and price levels, but not the impact of shocks on inflation proper.

Alternatively, Gordon (1975) had anticipated that an "indexing recession" can be avoided by a monetary accommodation of higher prices that would most certainly stoke up inflation rates, the speed of which would then rely on the lag of the indexing formula between the change in prices and the correction of wages. The model he built is a two-sector economy (farm and nonfarm goods) with flexible expectations formations regarding wages and prices. The consumer price index is given by a weighted average between farm $\left(P_{t}^{F}\right)$ and nonfarm $\left(P_{t}^{N}\right)$ prices:

$$
P_{t}^{c}=k P_{t}^{N}+(1-k) P_{t}^{F}
$$

Nonfarm price inflation is defined as

$$
\hat{p}_{t}^{N}=\widehat{w}_{t}+c \hat{q}_{t-1}^{N}
$$

in which $\hat{q}_{t-1}^{N}$ reflect the lagged growth rate of demand for nonfarm goods. Wages are indexed to the inflation rate in previous period $\left(\hat{p}_{t-1}^{c}\right)$ and lagged excess demand pressures $\left(Z_{t-1}\right)$, as in:

$$
w_{t}=p_{t-1}^{c}+j Z_{t-1}
$$


and should expectations behave adaptively, expected nonfarm prices are extrapolated from the actual level of the previous period by a distributed lag of past inflation rates up to ten periods, where $P_{t}^{N}$ denotes nonfarm prices:

$$
P_{t+1}^{N^{*}}=P_{t}^{N}\left(1+\sum_{i=1}^{10} u_{i} P_{t-i}^{N}\right)
$$

In his concluding remarks, Gordon (1975, pp. 201-202) stated:

(...) the analysis of this paper raises serious questions about the merits of the full indexation of wage contracts, which would shorten the lag in the adjustment of wages to changes in external prices and would thus inhibit the decline in the real wage required by an external supply shock. If policymakers attempt to stabilize nominal income in a wage-indexed economy, any external shock will destabilize both prices and output more than it would in an unindexed economy. Any attempt to accommodate the higher prices by raising nominal income under indexing will impose on the economy a substantially higher inflation rate for the duration of the external supply reduction.

Modigliani \& Padoa-Schioppa (1977) took a different route by assessing the $100 \%$ wage-indexed Italian economy. Their model accounts for the inflationary impacts of the shortening of wage adjustment intervals. The economy is modeled as follows:

$$
P=m\left(\frac{W S}{a}\right) t
$$

and

$$
m=m(Q), m^{\prime} \geq 0 ; Q \leq Q^{o}
$$

where $\mathrm{P}$ is the price level, $\mathrm{m}$ is a function of real output $\mathrm{Q}$, constrained by a full employment level of output $Q^{o} ; s$ and $t$ are rates of contributions to social security and of indirect taxes on consumption, respectively, whereas $\mathrm{W}$ is hourly money wages and $a$ is productivity. In sum, prices are a function of a mark-up over labor cost, inclusive of taxes and corrected for productivity. Nominal hourly wages are given the following form of indexation to a onequarter lagged price level:

$$
W=\mu P_{-1}
$$

which represents the sliding scale we have gone over in preceding chapters. Substitution and some rearrangements yield the price and, then, the annual inflation $(\dot{p})$ equations:

$$
P=g\left[m(Q) A \mu P_{-1}\right]+(1-g) P_{-1}
$$

and 


$$
\hat{\mathrm{p}}=n g\{m(Q) A \mu-1\}
$$

where $A=\frac{s t}{\pi}$, and $\mathrm{n}$ reflects the number of adjustments within a one year period. Thus, the authors have imposed on inflation equation a dependency on the frequency of adjustments. Monetary and fiscal policies are thus endogenous to this institutional scheme. The parameter $A$ incorporates cost-push forces stemming from tax increases and mitigation via productivity enhancements as well as for the degree of indexation $(\mu)$, so that any change in parameters is expected to have a persistent effect on inflation rates.

On a historical note, Franco Modigliani gave a series of four lectures from $3^{\text {rd }}$ to $7^{\text {th }}$ October 1977 at the Bocconi University in Milan as part of the Rafaelle Matiioli Lectures. In the second address, he went over the problem of inflation with its ensuing social costs and stabilization challenges. He mentioned the Italian case - the subject of the 1977 paper with Padoa-Schioppa - as a special circumstance, in which the typical Keynesian "momentum inflation" category did not apply (see chapter 1 above). The overly militant labor unions entailed a hike in real wages above the level required to hold full employment and balance of payment equilibrium mutually consistent. External balance could thus only be achieved short of full employment. And any attempt to expand demand would lead to generate deficit in foreign accounts. The resulting devaluation of the domestic currency would push up prices, which in turn triggered wage escalator clauses, reinforcing the upward move in prices. Once real wages were restored to the above-equilibrium level, any room for gains in trade from the devalued currency would vanish. He concluded his brief take on the Italian inflation by stating that:

It is apparent that this Italian-style inflation differs in one fundamental respect from the momentum inflation described earlier. In both types of inflation, unemployment can be relied upon in order to produce a gradual reduction in inflation. However, in the case of "momentum inflation", the cure so achieved should be "permanent" - once inflation has abated it should be possible to return gradually to full employment without rekindling inflation. In the Italian case of excessive real wages, on the other hand, unemployment must be relied upon not only to bring down inflation, but also to keep it low. The inflationary spiral would tend to start again if employment was moved back toward the full employment level. (Modigliani [1977] 1986, p. 46)

In Modigliani and Padoa-Schioppa (1977) a host of cost-push forces and propagating mechanisms acted together to sustain inflation. The frequency of adjustments of wages played a central role in the determination of disinflation costs with the reinforcement and tightening 
of external constraints upon the macroeconomic stability ${ }^{129}$. Italian inflation thus did not lend itself completely - or easily, for that matter - to general Keynesian explanations of momentum inflation; this story will repeat itself in the years following the 1979 shocks, with the eruption of severe inflation-fueling external crises all around the globe, with special drastic outcomes in Latin America, to which we turn in the next chapter.

The preceding narrative revealed that controversy on inflationary inertia and stabilization policies had been ongoing for almost a decade prior to Latin American contentions on the matter. We pointed out the mechanical features of models had already outstripped institutional forces within the narrative. The search for optimal policy rules - of which Friedman (1968) and Phelps (1967) are seminal examples - became the internal thrust of theoretical developments on the subject of inflation and unemployment. Another set of developments consisted of econometric estimations of best-fit reduced form equations aiming to verify the existence of short- and long-run Phillips trade-offs. This empirical pursuit accounts for the second line of influence running from the North American academic economics to the Brazilian stabilization debates. Finally, next section covers one last inspirational push towards the inertial inflation hypothesis. James Tobin epitomized the North American analogue to Simonsen's gap-bridging contribution in Brazilian quarters; therefore, a brief highlight of Tobin's specific input is of utmost relevance.

\subsubsection{James Tobin's Taxonomy}

Events culminating in the 1973 OPEC-driven oil price rise generated a worldwide inflationary bulge; this in turn set the ground for an orthodox reaction against the Keynesian-inherited policies governments led all along the post-War period (Harberger, 1978). The classic divergence reemerged with strength, eliciting a revival of academic and policy-oriented debates. As we have seen above, the long-lived inflations in Latin America and the worries about an inflationary bias in developed economies in the post-war period provided the motivation for furthering analytical and empirical developments on matters of inflation and stabilization.

In a very lucid article, James Tobin picks up on some ideas he had tackled on a more general basis a few months earlier. ${ }^{130}$ He then develops a taxonomy for the diagnostics for

\footnotetext{
${ }^{129}$ See Arida's (1992) first essay for an application of this mechanism to the Brazilian case.

${ }^{130}$ Tobin (1980) extensively recollects what the "last ten years" had taught economists about stabilization policy. The term "inflation inertia" is cited twice. As former President of the American Economic Association, Tobin
} 
inflation that may very well be the 1980s inflation-centered analogue of Prebisch's 1949 Manifesto. The passive money hypothesis is recast under new terminology and the monetarist plea is quickly dismissed on such terms. ${ }^{131}$ Tobin is most direct and succinct in his classification of the three main types inflation, namely: inertial inflation, specific price inflation and conflict inflation.

By inertial inflation Tobin means "the self-replicating pattern of wage and price inflation", which "once it is built into the system in a consistent manner it continues very much on its own" (Tobin, 1981, p. 23). ${ }^{132}$ In such an inertial setting, some prices feed into economy-wide price indexes, and then propagate onto other prices and wages, thereby eliciting the "stubbornness of built-in patterns of wage and price inflation" (p. 24). ${ }^{133}$ However, there exists a viable equilibrium path of real outcomes, on which the rate of inflation offers no threat to economic and political equilibrium. As long as the economy has adapted its conventions, institutions - in which we may include monetary and fiscal accommodative policies - and expectations - especially in regard to relative prices -, inflation poses no distortion to the economic process. ${ }^{134}$ Finally, Tobin comes to the diagnosis "that

was in a rather privileged position within the profession when he stated that " $[\mathrm{t}] \mathrm{he}$ inertia of inflation in the absence of nonaccommodative policies is the big issue" (p. 44). And also, "[t]o discuss the roots of that inertia and the sources of nonmonetary pressures for accommodation - administered prices, contracts, collective bargaining, distributive conflict, supply shocks, OPEC - is not to commit any vulgar errors or to violate any of the identities stipulated" in the quantity equation framework. And on the matter of monetary policy, he once again recalls inertia, by saying: "For short-run stabilization, the important point is that, given the persistence and inertia of inflationary trends and expectations, the central bank can and does alter real rates of interest by measures that change the nominal rate". And in a prescient statement of what would later in that decade become the basic framework for monetary policy, he states: "The notion that intertemporal substitutions in production and consumption are so perfect as to maintain constant real interest rates is one of the more bizarre propositions of this wild decade" (Tobin, 1980, p. 45).

${ }^{131}$ For more on non-accommodative policy costs see Tobin (1981, pp. 20-23).

${ }^{132}$ The conflict terminology is abundant in Tobin's plea against orthodox policy. For instance, see Tobin (1981, p.24).

${ }^{133}$ In a modern economy, Tobin proceeds, most wages and prices are administered, negotiated and decided periodically by identifiable individuals. There is, obviously, no economy-wide bargain or price decision-making process within impersonal competitive auction markets. There is also no concerted process of decision. Thus, if the economy is viewed as a $\mathrm{n}+1$-person game (to account for the "disciplinarian" government), with $\mathrm{n}$ private groups playing mainly against each other, interested in their relative position to other groups, the threat must be a "mutual promise of all major interested groups to de-escalate together, forswearing the temptation to gain relative position from the restraint of other groups. In this respect income policies or social compact go hand-inhand with announcements of plans to diminish the rate of growth of aggregate nominal spending. Countries with traditions and institutions of economy-wide wage bargaining with government participation, may be better positioned to conjoin monetary disinflation and incomes policies than those like the United States with decentralizes collective bargaining and price setting" (Tobin, 1981, p. 26-27).

${ }^{134}$ The memory built in the system is also addressed by Tobin: "If the slate could be wiped clean of the patterns of behavior and expectation that keep the inflation going, the economy could go on its merry way with lower inflation or even with stable prices. Unlike the monetarists, the diagnosticians of inertial inflation do not think it 
inflation is the symptom of deep-rooted social an economic contradiction and conflict". (p. 28). In such a framework, there is no equilibrium path.

The major economic groups are claiming pieces of pie that together exceed the whole pie. Inflation is the way that their claims, so far as they are expressed in nominal terms, are temporarily reconciled. But it will continue an indeed accelerate so long as the basic conflicts of real claims and real power continue (Tobin 1981, p. 28).

Furthermore, if players cannot agree to divide a growing pie, how will they concur with each other when dividing a smaller one? Moreover, Tobin draws attention to the aspiration gap that Rowthorn (1977) so explicitly modeled a few years before. That is, an orthodox policy restricting demand would curb rates of growth of potential output, of real wages and of real returns on capital investment; but, Tobin adds, it does not imply necessarily holding down the "standards of real income progress to which employed workers are accustomed or the profit rates that managers and shareowners expect" (p. 28). In this sense, economic downturn may stir up further conflict through the widening of the aspiration gap, thus fueling inflation upward. ${ }^{135}$

The conflict approach, as presented by Tobin, points to the fact that policy must look to how it suits the underlying societal demands the economic dimension is required to fulfill. ${ }^{136}$ Inflation could easily then fit in a development-centered analytical framework, and not be treated as an independent symptom of transitory imbalances of smoothly adjusting auction markets, correctable by exogenous policymaking. Inflation should be framed as the

is easy to wipe the slate clean. That is why they favor incomes policies rather than restrictive macropolicies unassisted" (Tobin, 1981, p. 27).

${ }^{135}$ Tobin is also preoccupied with labor insecurity that comes with contractionary policies: "The hope is that the exclusion of more and more people from the game weakens the more assertive groups. The fear is that the shrinking of the pie just makes the insiders more intransigent and protectionist. Reasoning by competitive logic does not help us in this syndicalist world". (p. 28). Vera (2005) has recently formulated a model seeking to demonstrate this very result in a post-Keynesian setting. Furthermore, In such a scenario, relative price shocks may be the source of serious and lasting conflict, not simply a transitory hike of inflation rates that quickly diminishes. Because of that, indexing wages by cost-of-living measures can be dangerous, especially if they account for prices that represent unavoidable costs to the whole society. "Somebody has to pay OPEC for oil, and not everyone can have incomes wages, or social benefits insured against such risks" (p. 29). This last point echoes a common proposal at the time as to differentiate between core inflation and overall inflation (Okun, 1981). That requires the exclusion of supply shocks from indexes, such as Simonsen (1983) and Bacha \& Lopes (1983) would later defend along the same lines.

${ }^{136}$ In a grand finale, Tobin makes the sensitive metaphor that would be very often reminded in Brazil:"The distinction I tried to make between inertial inflation and conflict inflation invites a metaphor. Consider a stadium where everyone stands up to see the spectacle. They can all see equally well if everyone sits down. The problem is to get people to sit down; but that is the only problem. A more serious situation occurs when there are not enough places in the stadium, and no way to agree on taking turns" (Tobin, 1981, p. 29). 
result of a complex interaction between monetary and fiscal institutions and the underlying socioeconomic structure.

Surprisingly, Tobin's input to the discussion has been greatly downplayed in historical accounts of the inertial inflation episode in Brazil. ${ }^{137}$ Not only was he the first economist to clearly state the concept of an "inertial inflation" - an understanding we share with Purvis (1982) and Lipsey (1981) ${ }^{138}$ - as his writings are filled with the conflict-based understanding of inflation, a few years before the "inertial inflation" concept was appropriated by Bresser Pereira and Nakano (1984). ${ }^{139}$ Tobin's missing chapter is important for it reflects the zeitgeist at the onset of the troubled 1980s, a period in which "disarray" overtook economics.. ${ }^{140}$ Moreover, Tobin's input echoes a general perception of "neo-Keynesian" economists about this self-sustaining feature of inflation - also dubbed "inflation norm" by George Perry (1980) and Charles Schultze (1981) and Okun (1981), or “core inflation" by Eckstein (1982) and Blinder (1982a, 1982b). In this vein, the basic mechanisms of the inertial inflation model's dynamics had already been set out, as depicted above, both by early mechanical models of

\footnotetext{
${ }^{137}$ The unsurprising exception is Bacha (1988) who had institutional connections to the Yale economics faculty, where he acquired a PhD title in economics in the early 1970s (Bacha 1998). More recently, Bresser Pereira (2010) and Serrano (2010) also acknowledge Tobin's contribution, albeit with less emphasis than we lay on it here.
}

138 A JSTOR search conducted on February $24^{\text {th }} 2015$ confirmed that this specific term was first adopted by Tobin in his 1980 and 1981 papers. The search yielded 122 references to the term between 1980 (the oldest) and 2014 (the latest). In the 1980s, various economists alluded to Tobin's contributions to the subject while also discussing the problem of "inertial inflation" proper, amongst whom we can cite Lipsey (1981), Blinder (1982a, 1982b), Nordhaus, Houthakker and Sachs (1980) and Solow (1986).

${ }^{139}$ For the sake of historical accuracy, a paper written by Richard Slitor, in 1978, a propos of tax-based incomes policy had a sub-section titled "Inertial Inflation" (Slitor, 1978, p. 70), a few lines after discussing briefly the phenomenon as an extension of J.M. Keynes's take on inflation. It reads: "Keynes himself recognized that for various reasons increasing output would be reflected in rising wages and prices, a tendency which would be accelerated to a point of "semi-inflation" (...) Whether this tendency is viewed in terms of the nonhomogeneity of the labor supply, bottlenecks, the rising pressure of demand on scarce factors, labor union response to improving labor markets (...) or other terms, it has an important implication for expansionist policy: wage and price rises begin to materialize almost from the beginning of an expansion initiative and to some degree counterproduce the general rise in money income and purchasing power. (...) It can easily become, as our experience demonstrates, a spiralling inertial process that goes beyond the wage and price increases consistent with the rationing of scarce resources in the face of excess aggregate demand. Expectations of inflation become built into the system and further aggravate the responses of wages to prices and of prices to wages. If the economy gets sufficiently sensitized to the whole inflationary process" (...) (p. 69 - emphasis added). Next page brings a full definition of the "inertial inflation" process as an outcome of dissatisfied economic groups with their relative real income: "Competing private interest groups understandably jockey for position in the unfolding inertial process. None wants to sacrifice its position as the price for halting the vicious cycle. Monetary and fiscal policy are compelled to be more restrictive or less expansionary than otherwise in order to prevent aggravating the spiral and, in an uncertain and novel situation, to give some conservative credence to traditional modes of treatment which punish if they do not cure by applying the remedy of weak aggregate demand and deflationary pressures on the labor market. But the inertial process is not necessarily one of stable inflation" (p. 70 - emphasis added).

${ }^{140}$ For a historical context of the late 1970s, see Modigliani (1977) and Goodfriend \& King (1997). 
inflation in the 1950s vintage, as well as by Franco Modigliani and James Tobin. These latter economists had been important references for the young Brazilian economists while they had their PhD studied abroad at Yale, MIT and Harvard, particularly. ${ }^{141}$

Our effort up to this point has consisted in shaping up the argument that the inertial inflation hypothesis drew on a diversified heritage of contributions in the post-war period, namely: in terms of geographical location of contributions, but also, as regards substance, distributional conflict models, sociological and historical appraisals, institutional and structural models and, finally, in formal terms, verbal and mathematically formal assessments of the self-sustaining pattern of inflation. One should hardly be surprised that so many different approaches had something to say about inflation inertia. The various lineages that ran up to meet the inertial inflation phenomenon were able, in their own time, to fetter out one specific pattern: the saw-tooth-shape of real wages under inflationary conditions. This oscillating behavior of real incomes in an indexed setting has become a powerful organizing device not only to understand the sides of the contention but also to unearth what they had in common.

Chapters 5 through 7 unravel the history that descended from the contributions set forth by the forerunners of the inertial inflation paradigm. This latter development amounted to a Brazilian-specific outgrowth of the broader concept of inflation inertia. But before we get to that, next section covers the mathematical development of this analytical mechanism pursued by the Brazilian economists at PUC-Rio, such as Francisco Lopes, Edmar Bacha and Eduardo Modiano. As was the case with Simonsen's feedback model of inflation, this analytical device offered an "object of reason with" (Morgan \& Morrison 1999) about the diagnostics and therapeutics of chronic inflations.

\subsection{The mathematical development of the saw-tooth model of real wages}

The idea that any fixed nominal value has its real value eroded by inflation reaches at least as far back as Irving Fisher's The Purchasing Power of Money. The core mechanism of the inflation-related saw-tooth model is, hence, in no way new. Crucial to its early development in discursive form was the empirical reality of high and chronic inflation. It is

\footnotetext{
141 In the late 1970s, the economics departments in these schools were enthralled in a dispute with the Monetarism-II (Gordon 1976) of the New Classical economics. Keynesian mainstream economics was under attack, as recognized Stanley Fischer (1986, p. ix) in the preface to his 1986 tour de force on Indexing, Inflation and Economic Policy, as well as by Tobin (1980) and Modigliani ([1977] 1986, chapter 1). Therefore, a hypothesis to be verified refers to the existence of some kind of transference of such feuds to the Brazilian debates, even if only tangentially.
} 
perhaps for this reason that such an analytical pattern was conceived and developed in Latin America. As we have seen in the section above, a similar application was found to the same visual pattern in Europe and North America in a different context and with a different subject. Its application to real wages in inflationary conditions became quite famous in Brazilian debates in early 1980s, for its visual communicability and a fair level of practicality in generating various results and even in designing policy proposals (see, for instance, Lopes 1986 and Modiano 1988).

\subsubsection{Formalization gone full-throttle: PUC-Rio}

In 1976, Francisco Lopes published his first attempt at mathematical formalization of the "inflation neutrality" phenomenon in Revista Brasileira de Economia (also published in Lopes 1986, chapter 4), wherein a sawtooth diagram displays the zigzag pattern of real incomes when their nominal values were adjusted in fixed intervals. An environment with a constant inflation renders real incomes fully flexible, while their average values remain stable at the same level. Peak real incomes $\left(r_{i t}\right)$ is a function of peak nominal income $\left(R_{i}^{\prime}\right)$, which is eroded by inflation $f\left(\hat{p}_{t}\right)$, or:

$$
r_{i t}=\frac{R_{i t}^{\prime}}{f\left(\hat{p}_{t}\right)} ; f^{\prime}>0
$$

Inflation is thereby neutralized in its distributional effects if the average real incomes of all productive factors $r_{i}^{\prime}$ (e.g., two workers, or profits and wages) are consistent with each other and they remain stationary at levels compatible with the level of capacity utilization that would be observed under price stability, its neutral values $r_{i}^{n}$ (Lopes 1986, p. 25-26). Hence, we find

$$
r_{i t}^{\prime}=r_{i t}^{n}
$$

Neutrality is then bounded by the following condition:

$$
r_{i t}=r_{i t}^{n}
$$

Admitting the existence of two productive factors $a$ and $b$, we find the identity between factors' shares $\left(a_{y}\right.$ and $\left.b_{y}\right)$ and the available income:

$$
r_{a t} a+r_{b t} b=\frac{R_{a t}^{\prime}}{f\left(\hat{p}_{t}\right)} a_{y}+\frac{R_{b t}^{\prime}}{f\left(\hat{p}_{t}\right)} b_{y}=1
$$

This basic framework allows Lopes to envisage several behavioral developments, as agents jockey to maintain or increase their share of the pie. Neutrality is then achieved when 
these individuals or income-receivers adjust their desired real income levels to coincide with the average real income level (see Figure 14 below).

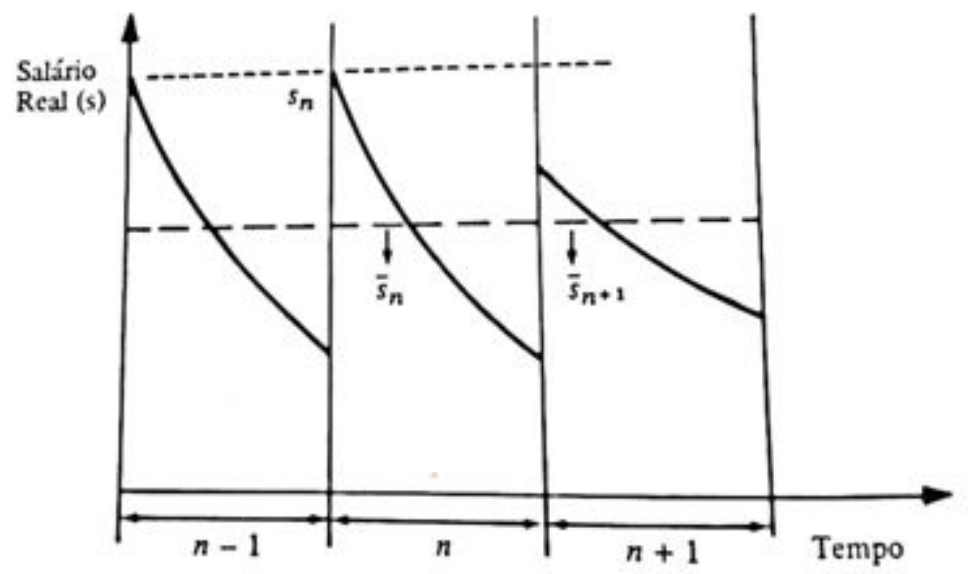

Figure 14 - The saw-tooth diagrams of real wages through time. Source: Lopes (1986, p. 48)

By 1978, Lopes had already come across a simple way to express what could explain inflation. He wrote a paper with John Williamson (Lopes \& Williamson [1978] 1980) where they derive the mathematical conditions for a "consistent indexation" (further details in Chapter 5). Basically, they find that the downward rigidity of the peak level perpetuates inflation. If real incomes were adjusted falling short of the desired peak real incomes levels, inflation would decelerate and the same real wage could be attained but with a lower inflation rate. "The operational mechanics of the system of consistent indexation" can be viewed by means of an example of fixed-interval adjustments of nominal wages, so that real wage dynamics $\left(w_{t}\right)$ behave as follows:

$$
\bar{w}_{t}=f\left(\hat{p}_{t}\right) \cdot w_{t} ; f^{\prime}<0
$$

where $\bar{w}_{t}$ denotes the average real wage and $p_{t}$ is the inflation rate observed between adjustments. Due to the specifics of the wage indexation law in Brazil, $f\left(\hat{p}_{t}\right)=\frac{1}{1+0,5 \hat{p}_{t}}$ (see Simonsen 1970b). However, when wages are settled the inflation rate that will erode its real value is not yet known, so that the relevant variable workers take heed of is expected rate of inflation for the period following negotiations, so that

$$
\bar{w}_{t+1}^{e}=f\left(\hat{p}_{t+1}^{e}\right) \cdot w_{t+1} ; f^{\prime}<0
$$

Then, the economic policy problem is to find the value of $p_{t+1}^{e}$ that will maintain the average real wage constant through time, or:

$$
f\left(\hat{p}_{t+1}^{e}\right) \cdot w_{t+1}=\bar{w}_{t+1}^{e}=\bar{w}_{t}=f\left(\hat{p}_{t}\right) \cdot w_{t}
$$


Any attempt to curtail inflation must then involve a partial indexation $(a<1)$ of wages, which comes immediately after considering that $w_{t}=W_{t} / p_{t}$ and rearranging the above equation:

$$
\frac{w_{t+1}}{w_{t}}=a \frac{p_{t+1}}{p_{t}}
$$

where $a=\frac{f\left(\hat{p}_{t}\right)}{f\left(\hat{p}_{t+1}^{e}\right)}$. Soon thereafter, Lopes co-authored another work with André Lara Resende, making extensive use of the diagram (see Figure 15 below), but now in order to undergird an empirical analysis of the causes of the then recent acceleration of inflation in Brazil (Resende \& Lopes [1979] 1981).
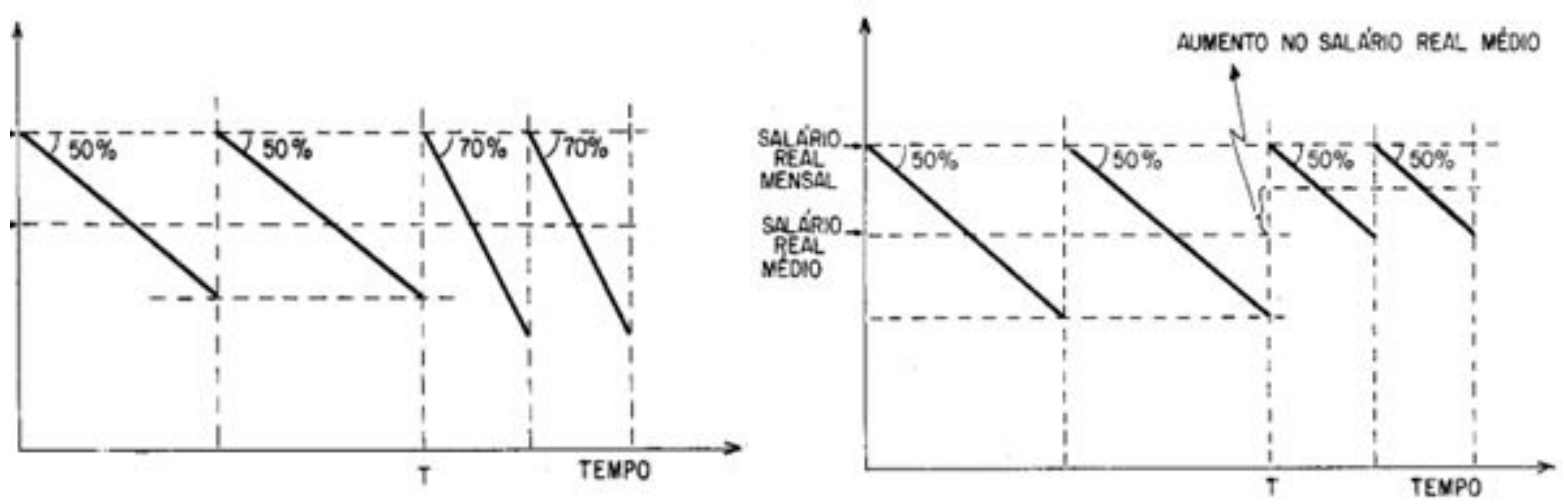

Figure 15 - The saw-tooth diagram of real wages: illustrative purposes (*). Source: Resende $\&$ Lopes ([1979] 1981, p. 610).

(*) On top of the left-hand panel, it reads: "Increase in Average Real Wage".

Or yet the diagram could depict the long-known problem of lack of synchronism amongst wage and price readjustments in a staggered adjustment setting (Figure 16 and Figure 17). It proved to be quite practical to illustrate both the coordination problem that generated inflation and the alternatives to achieve a neutral solution (see Lopes 1986, chapter 18 for the illustration of the inertial inflation case).

The sawtooth model gradually became a cornerstone of non-monetary inflation theories, which, at this time, was confused with a (neo-)structuralist approach. Its theoretical relevance is up to date a matter of controversy. ${ }^{142}$ Regardless of this contention, Taylor (1983)

\footnotetext{
142 Francisco Lopes (1979) has credited Simonsen (1970b) for "inventing" the first scheme along these lines, but has confessed some disappointment in commentators specialized in the Brazilian economy, who have treated this advance as a mere technical curiosity, instead of a relevant contribution to economic theory (see Lopes \& Williamson [1978] 1980, p. 70). Se Paulani (1997) for more details on the numerous opinions regarding the relevance (or not) of these Brazilian advances as inflation theories.
} 
comments, on an historical note, that "loss of real purchasing power of fixed money wages in the face of inflation is an old Latin American notion", and that diagrams such as the "sawtooth shaped" one "have been around the continent for decades" (p. 214, n. 3), what we can only assume to be a reference to Kaldor $(1957 \mathrm{c})$.

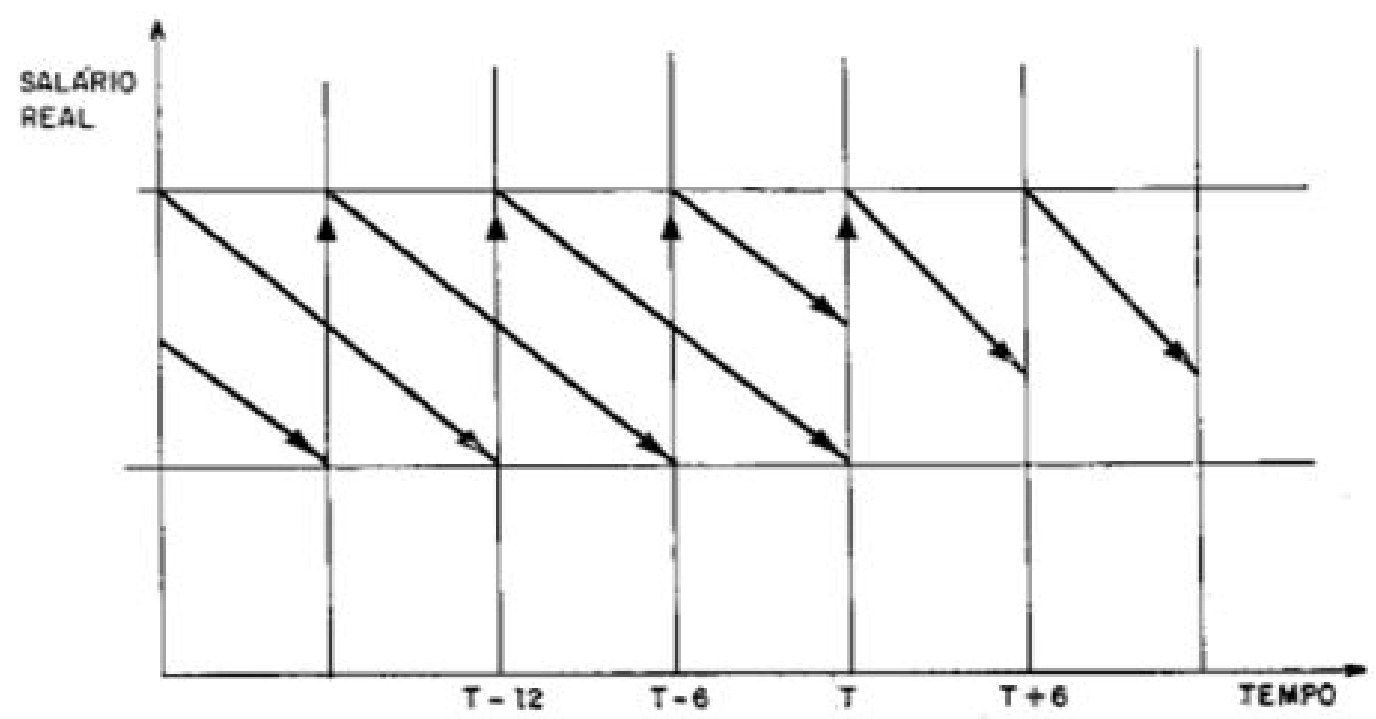

Figure 16 - The saw-tooth diagram of real wages: lack of synchronism. Source: Resende \& Lopes ([1979] 1981, p. 610)

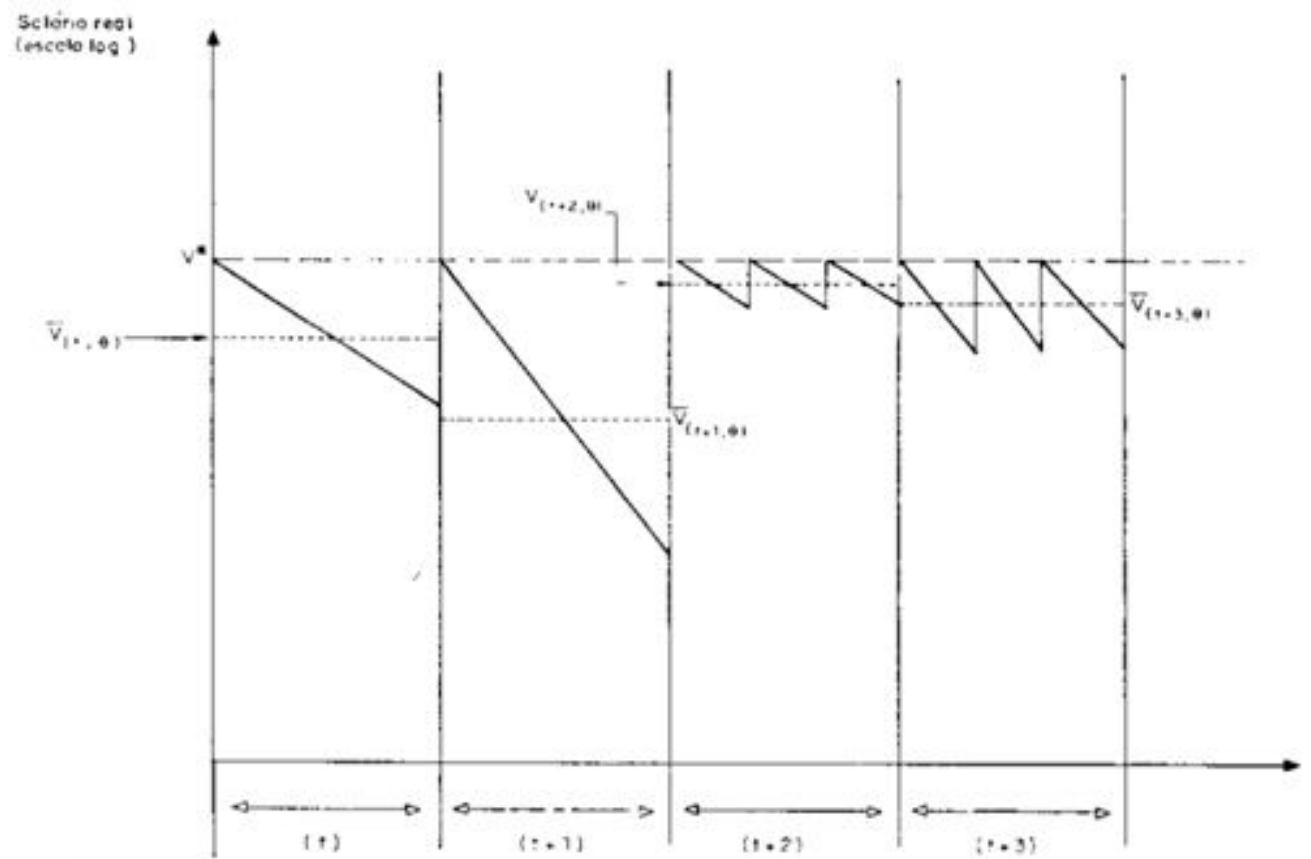

Figure 17 - The saw-tooth diagram of real wages: various systems of wage indexations. Source: Lopes (1986, p. 89). 
As regards its use, Arida (1992, p. 36-37) would later recall that this model simplifies the dynamics of nominal wages to a considerable extent. Average real wages depend on (i) exogenous base wages (beginning of period), (ii) the length of interval between wage adjustments and (iii) the rate of inflation over the indexing interval. Bacha \& Lopes (1983) provided the most rigorous mathematical formulation of the saw-tooth model, whereas Modiano (1988a) and Simonsen (1984) set forth analytical derivations of the concept of inflation inertia as a function of the ratio between peak and average wages. The formula depicts a "linear fall of the logarithm of the real wage, which amounts to assuming that the instantaneous (or monthly) rate of inflation is constant within settlement dates" (Lopes \& Bacha 1983, p. 3). In the interest of uniformity, we maintain the same notation as used above:

$$
\log \bar{w}=\frac{1}{2}\left(\log w_{0}+\log w_{0}-p\right)=\log w_{0}-0.5 p
$$

The paper is a masterly sequence of algebraic manipulations of this formula aiming at attaining the following result:

$$
\bar{w}=\frac{W}{p}=\frac{w^{*}}{(1+\bar{p})^{1-h}}
$$

where $w^{*}$ can be interpreted as the real target under price stability, $\bar{p}$ is the average inflation rate throughout the period and $h$ denotes a function of the amplifying effects of the number of wage adjustments per period of analysis $(n)$, as in $h=1-\frac{1}{2 n}$, to which the authors simply refer as "the generalizer period analysis representation of a Brazilian type wage indexation system" (p. 5). As the $h$ parameter approaches unity, the system converges to perfect indexation and, in the limit $(h=1)$, the real wage is fully sheltered from inflation (p. 6). Around one year later, Simonsen (1984, p. 102) provided yet another version of the same model, with the following formula:

$$
\bar{w}=\frac{i}{(1+i) \cdot \ln (1+i)} w^{*}
$$

He assumed that wages are adjusted twice a year at the constant rate of increase in the cost of living $(i)$ at $76 \%$ per semester. An annual inflation of $210 \%$ yields then $\bar{w}=0.764 w^{*}$, which means that, by the end of the year, average real wage will be situated $23.6 \%$ below peak levels obtained at every adjustment date. The wage legislation at the time froze the peak 
real wage at a level that, should the economy stabilize, the average real wage would jump up around $30 \%$. Rearranging the equation above, we get the "peak/average wage ratio": ${ }^{143}$

$$
\frac{w^{*}}{\bar{w}}=c
$$

where $c=\frac{(1+i) \cdot \ln (1+i)}{i}$ depicts the required rate of inflation to bring real wages into consistency with the level of wages the economy is able to afford, according to Simonsen's (1970, 1984) terms. ${ }^{144}$ It can also be construed as one instantiation of conflict inflation associated with Rowthorn's (1977) aspiration gap.

Available data for Brazil provides a rich visual illustration of the behavior of real wages; in this case, we look into the real minimum wage trend and oscillatory paths in the Figure 18 below. The incomes policy launched during the Government's Economic Program (PAEG), under the military intervention that started in 1964, was highly effective in controlling wages with a partial indexation scheme, which managed to keep the average real wage stable until 1985, when inflation-correcting mechanisms start to lag behind inflation rates and impose losses to real wages. Nonetheless, the indexing system was borderline perfect between 1964 and 1985: the significant compression in real wages and the control over workers' bargaining power in the beginning of this period managed to keep the average real wage somewhat stable, even under the strains of two oil-based supply shocks in 1973 and 1979 and of numerous changes in broad economic policy guidelines, such as the two "maxidevaluations" of the currency (1979 and 1983) and the shortening of wage indexation interval length to six-months (1979), among others.

\footnotetext{
${ }^{143}$ See Barbosa \& Simonsen (1989, chapter 1) for a discussion of the term and its anecdotic history.

${ }^{144}$ Modiano (1988a, p. 219) found yet another expression to convey a similar message as that posited by Bacha \& Lopes (1983), whereby $c=\frac{(h+1) p(1+p)^{h}}{(1+p)^{h+1}-1}$, which reveals with enhanced clarity the positive relationship between the inconsistency gap $\left(\frac{w^{*}}{\bar{w}}\right)$ and the number of adjustments throughout the year $(h)$, as well as the rate of inflation.
} 


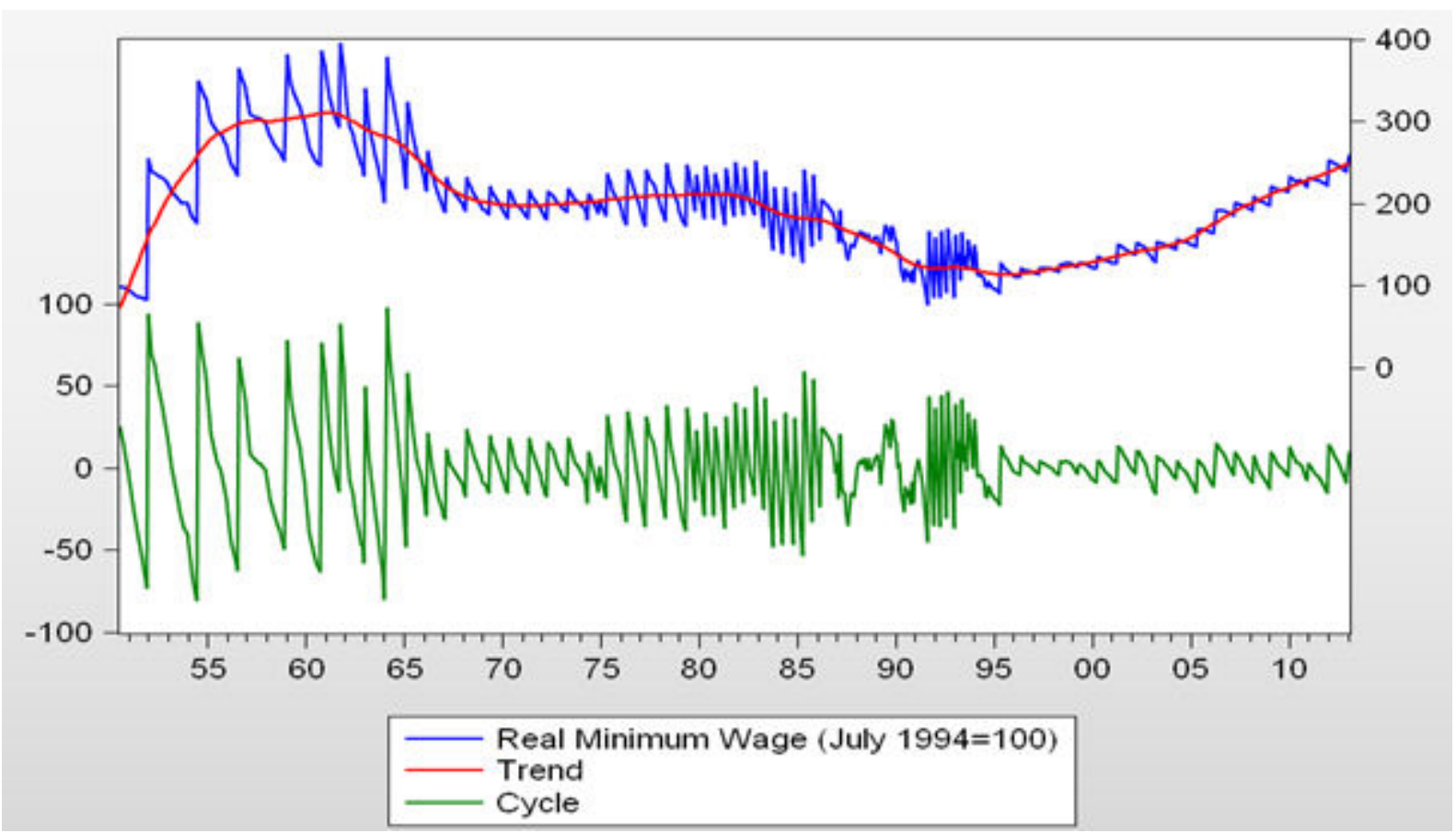

Figure 18 - Real Minimum Wage (*) (July $1994=100)$ : January 1950 - December 2012. Source: Institute for Applied Economic Research (IPEA - GAC12_SALMINRE12).

$\left({ }^{*}\right)$ Trend and cycles obtained by application of HP-Filter to the series.

As we have just seen above, the greater the gap between peak and trough real wages, the more intense are distributive conflicts likely to be. We can devise enhanced oscillatory pattern of real minimum wage along the adjustment cycle from 1975 until 1979. In September of this latter year, the minimum annual adjustment rule was trimmed down to a six-month interval between wage revisions. The immediate response of the minimum wage is easily observed in the cycle line, whereby the frequency of wage revisions generates a wider gap between peak and trough real wages. This suggests that inflation - from 1980 on - was not as stable as perceived under the inertial inflation paradigm (see Arida 1992, chapter 1). The segment comprised between 1986 and 1989 is symbolic of the how changing indexing rules so frequently can impart confusion and agony to the economic system. The problem of a repressed hyperinflation was a symptom of the messy economic environment that resulted from several heterodox shocks in just a few-years time. Consequently, the accelerating pace of uprising prices is reflected, in the graph, by the downward sloping trend in the real minimum wage until the launching of the Real plan in mid-1994, in line with the peak/average wage ratio equation.

To sum up, the saw-tooth wage model became a veritable workhorse for the inertial inflation paradigm and the discussions concerning stabilization debate. Its mathematical development is owed entirely to economists at PUC-Rio, especially the analytical effort 
Bacha \& Lopes (1983) put forth to make an axiomatic representation of it and Modiano's (1983a and 1983b) numerical translation of the "peak/average wage ratio" into a conversion rule for nominal contracts which met the neutrality condition for stabilization purposes. Evidently, Simonsen performed a crucial role by publicizing to international audiences the theoretical substance of the inflationary inertia the diagram aimed to reflect (e.g. Simonsen \& Dornbusch 1988, p. 445 in Figure 19 below). Next chapter undertakes the rise and eclipse of the inertial inflation paradigm.

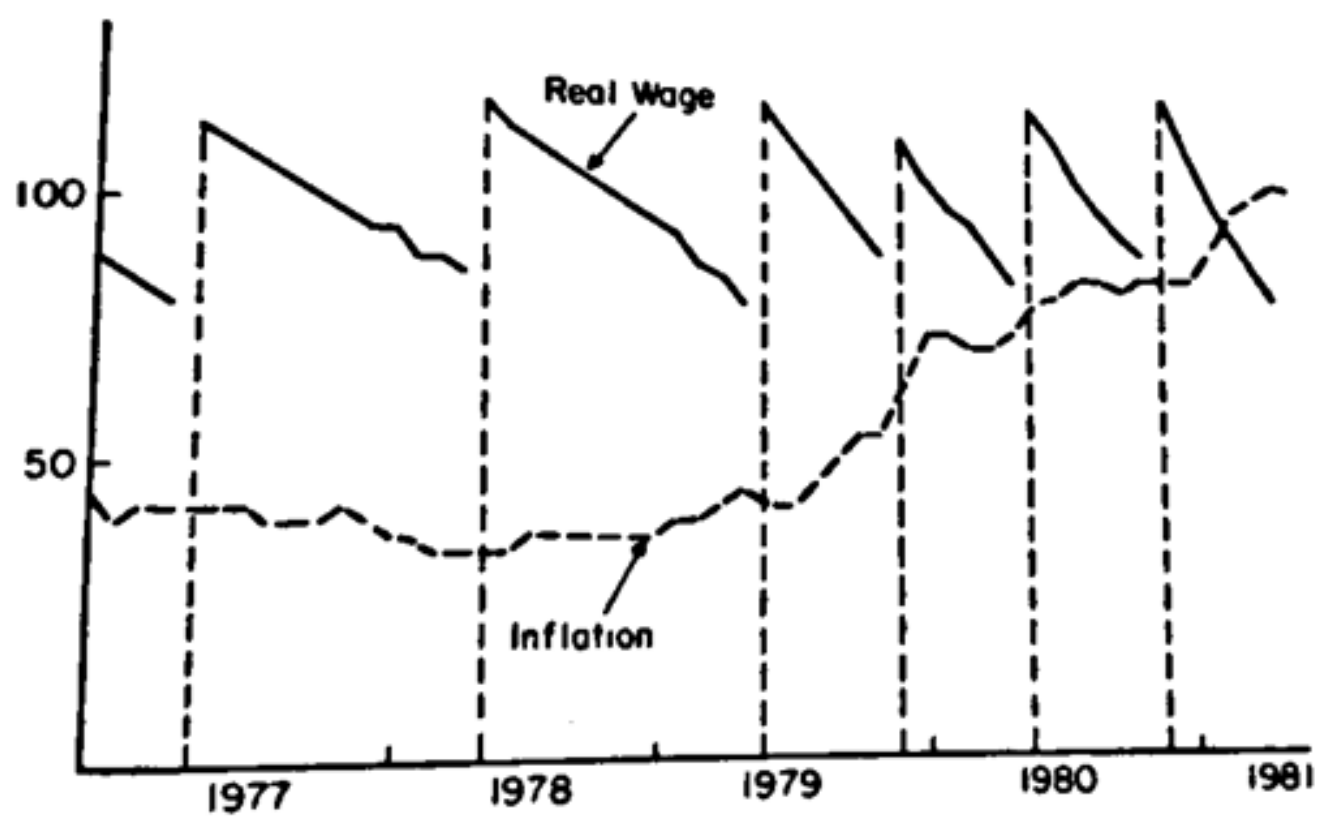

Figure 19 - Real minimum wage and inflation in Brazil (1977-1978=100 and yearly percentages for inflation). Source: Simonsen \& Dornbusch (1988, p. 445) 


\section{Chapter 5 - The Inertial Inflation Paradigm}

The preceding chapters have gone great lengths to indicate the presence of a long tradition of Latin American thinking on history- and institutions-laden economic models of inflation, contextualized by the first round of the controversy between monetarists and structuralists. Chapter 2 tried to show that the style of economic reasoning adopted by the early structuralists stressed the institutional and structural specificities of each and every economy undergoing a rapid process of development. Chapters 3 and 4 presented the parallel ascent of a mechanical mode of thought within the economics profession. These models entertained formalization in mathematical constructs, which inevitably toned down the political and institutional ring in accounts of inflation. This chapter looks into the second round of the controversy over price stabilization. The dispute is now between the monetarist orthodoxy and the somewhat hard-to-define heterodoxy in Brazil (see Bacha 1982 and Toye 1987). Serrano (1986) has surveyed five different approaches gathered behind the assumption that the Brazilian inflation had a strong inertial component.

Brazilian structuralist economists of this second moment all paid explicit homage to the seminal tradition of CEPAL, which was done by means of different methods of analysis, whether more historically driven - as in the FGV-SP contributions by Bresser Pereira and Nakano (1984) - or those mathematically formalized, such as the works by economists at PUC-Rio ${ }^{145}$ and at the University of São Paulo, such as Adroaldo Moura e Silva (1981) and João Sayad. ${ }^{146}$ Their earlier works on inflation were strongly attached to the distributional conflict approach, a common place for the competing heterodox - and, at times, even orthodox - theories of inflation in Brazil in the early 1980s. Along this decade, however, a gradual shift took place in the basic conclusions held by the economists at PUC-Rio.

A close reading of the second-generation structuralist theories of inflation points to the gradual loss of historical and social substance in the institutional and structural dimensions of analysis. Structural causes of price rises were sensitively downplayed, as the focus of theory

\footnotetext{
${ }^{145}$ The principal economists whose work we are about to address are: Eliana Cardoso, Francisco Lopes, Edmar Bacha, Persio Arida, André Lara Resende, Eduardo Modiano, Gustavo Franco and, with less emphasis, José Marcio Camargo and Dionísio Dias Carneiro.

${ }^{146}$ We also point out to the institutional-historical ring of contributions by economists at the University of Campinas (UNICAMP), such as Tavares \& Belluzzo ([1984] 1986) and Kandir (1989) among others. This lineage of models fit more comfortably, however, under the label of post-Keynesian economics of Paul Davidson with a strong emphasis on the role played by money and expectations. We refer the reader interested in this approach to Bier, Paulani \& Messenberg (1987, pp. 39-68) for further references.
} 
shifted towards the propagation mechanisms of inflation, in contrast with the early debates on the relation between economic development and inflation. From the institutional standpoint, the "Brazilian indexing-style" (Fishlow 1974) made up for the inflation-magnifying mechanism readily recognized as the chief distinction making up for the allegedly unique case of Brazilian experience with inflation - e.g., Arida \& Resende (1985) -, instead of structural and historical features emphasized by the structuralist models of the fist generation, as we have seen in Chapter 2 above.

The literature alluding to this period in the intellectual history of Brazilian economics underlines the policy-related dimension of debates on inflation inertia. The story one usually gets skips through the stage of the controversy, in which the more parsimonious academic exchanges happen, and moves too quickly to assess how these ideas have influenced policy design. The exception is Serrano (1986 and 2010), who has provided a critical interpretation of the theoretical advancements. However, he revises, only en passant, the early contributions by the scholars at PUC-Rio so he can focus on their application to stabilization policy. We attempt to contribute to the literature by assessing the analytical developments set forth by these scholars. A voluminous and dense theoretical production on the matter was published in technical volumes (such as Lopes 1979 and Bacha 1982) and also appeared on several editions of the most celebrated Brazilian academic journals at the time, such as the Revista Brasileira de Economia (FGV-IBRE), Pesquisa e Planejamento Econômico (IPEA) and Estudos Economicos (IPE-USP), all of which were published by the main economic thinktanks in Brazil. ${ }^{147}$

Our goal is to highlight the tensions that emerged within the "inertial inflation paradigm" (Arida 1992), the development of which extends from the late 1970s until the mid1990s and quickly gained notoriety in the policy circles and academia. There are internal and external forces lurking behind this change. This chapter tries to make sense of the internal inconsistencies and their importance in explaining future events. We stress two internal points of instability.

The first stemmed from the role allotted to social conflict within the inertial inflation story. The gradual displacement of this concept from a core variable to an auxiliary assumption in these models can be construed as an informative symptom of the process of

\footnotetext{
${ }^{147}$ For a more detailed historical account of the research institutes in Brazil, we refer the reader to volume organized by Szmrecsányi \& Coelho (2007).
} 
growing theoretical discomfort within the structuralist quarters. In the early moments of this approach, in the late 1970s and early 1980s, social conflict is deemed the underlying cause of the institutions of index-linking of contracts and wages and of the self-sustaining rise of prices, somewhat in line with first-generation structuralists. In the second phase, circa 1984, these "norms" become exogenously defined and conflict becomes a "jump variable" in the model, due to workers' attempt to bid up wages beyond the level compatible with macroeconomic equilibrium. Expectations become more important in the "world of the model" they set up. We sustain that the varied (and, perhaps, incompatible) nature of the theoretical influences on their reasoning, from early structuralists and neo-Keynesians, generated a tension that will be resolved with a move towards the latter school.

The second internal instability stemmed from a choice of method. The mechanical models built by the neo-structuralists (unintendedly) de-emphasized institutions and structural features, which become but denoted by specific "parameters" in these a-historic deductive models. Consequently, the second-generation models of inflation they are able to develop tended to assume - rather than explain - long-term processes of structural change and their distributional imbalances. Among those long-run aspects, we can cite the primary causes of inflation and institutional propagation mechanism, as held by the first-generation Latin American structuralists, namely: the dynamic mismatching between changes in the composition of supply and demand, technological gaps and the likely emergence of supply bottlenecks, the structural causes of balance of payments constraints, the bargaining power of various social groups and their influence upon both the policymaking process and on the qualitative features of institutions, such as tax and subsidies structures.

Chapter 6 will look into the external unstable element. It was triggered by the reevaluation the economists at PUC-Rio held on their previous writings after the resounding failure of the Cruzado Plan in 1986 - the first heterodox stabilization plan in Brazil of that time. A revision of the shortcomings in the design of the plan led these economists to gradually shift from a structuralist-type distributional conflict approach to a fiscally centered relative wages model.

The combination of these internal and external forces make up for a secondgeneration structuralist transformation problem, in reference to Craven's (1994) analysis of 
CEPAL's self-contentious first moments. ${ }^{148}$ However, at some variance with the firstgeneration problem, we sustain that this change was not a complete rupture with their previous stance on inflation theories. Rather, it showed itself more as a displacement of emphasis, bringing their assessment to a higher level of - albeit far from complete consistency with conventional readings of inflation. The structural-institutional strip-down process was thus a crucial channel acting to smooth out the transition of the concept of inflation inertia to the meaning prescribed by New Keynesian economics, as we have seen in Chapters 1 and 4. By their own properties, these a-historical, mechanical and deductive models downplayed any country-specific innovations regarding the theoretical framing of inflation, facilitating a concpectual convergence towards models developed for a different social and economic setting. ${ }^{149}$

We start with a brief summary of the second round of the controversy in section 5.1. Section 5.2 undertakes the description of the early models put forth by these economists, with attention devoted to an effort of reinventing the structuralist tradition. Section 5.3 closes the chapter by underlining some of the internal tensions to the inertial inflation paradigm.

\subsection{The Second Round of the Monetarist-Structuralist Controversy}

The second-round of the monetarist-structuralist controversy was triggered by the mid1970s. The intellectual battle between monetarist economists - such as Pastore (1969) Contador (1977), Lemgruber (1978), among others stationed at FGV-RJ - and structuralist(neo)-Keynesian economists was thus fought, at first, on the empirical turf. The main issues regarded the endogeneity of money supply in Brazil (Lemgruber 1977 and Cardoso 1979, 1918c), the effects of public deficits on the inflation via an accommodative monetary policy (e.g. Contador 1974, 1977 and Cardoso [1980] 1981a, 1983) and the effects of restrictive demand-management policies upon inflation rates by means of estimations of the Phillips

\footnotetext{
148 At that juncture, Juan Noyola Vasquez had changed from an IMF-aligned orthodox type of economics to a full structuralist position by Celso Furtado's side - and, to varying extents, by Prebisch's as well.

149 Given the varied theoretical heritages on which the inertial inflation concept is set, the question of whether there is any novelty to be ascribed to Brazilian economists is highly controversial and is addressed by Paulani (1997, pp. 177-179). With the exception of a few economists, theoretical innovation during this period is generally understood to be confined to matters of policy design. In what regards the practical significance of the inertial inflation construct, doubts have also been raised. See Bastos $(2001,2002)$ and Cunha (2001) for more details about these doubts.
} 
curve for Brazil. ${ }^{150}$ The dispute became more contentious in the early $1980 \mathrm{~s}^{151}$, for intellectual and political reasons. Let us start with the latter aspect. ${ }^{152}$

The early first half of the 1980s witnessed large-scale social and political transformations, as the military regime raised growing opposition in numerous sectors of the Brazilian society. As it so happens, economists' battling energy was harnessed towards actively trying to influence policymaking. This is the common narrative the abundant historical material on this period is prompt to show, ${ }^{153}$ that is, the stream of short articles published in newspapers raised sweeping controversy, as it suggested the need - and how - to redirect policy away from orthodox measures that, it was claimed, were ineffectively leveled against the Brazilian economy in 1980 by the Minister of Finance Antonio Delfim Netto in President Figueiredo's term, the last president of the military regime that rose to power in 1964. These measures were perceived as a severe hindrance to economic growth at the very

\footnotetext{
${ }^{150}$ Bastos \& Mello Neto (2008) provide a brief account of this empirical dispute, in Portuguese. For a survey in English of the claims made by each side, see Parkin (1991, chap. 2).

${ }^{151}$ In a nutshell, monetarists claimed that demand-based contractionary policies were effective in curbing inflation by way of much needed and unavoidable stabilization crises, whereas structuralists challenged these assertions on the grounds of the disproportional size of estimated parameters for the output gap on the price equation of the economy. Since our focus lies on the neo-structuralist side of the quarrel, we refer the reader to Barbosa (2004) for a historical account of inflation inertia as monetarism sees it.
}

152 The terms of contention can be sampled from a panel discussion organized by the Brazilian National Economic Association in the late 1970s (ANPEC, 1978, p. 153-157). The academic exchanges gravitated around the causes of inflation deceleration in that year. Lemgruber questioned the idea that inflation could be explained by the joint-efforts by groups to determine their income adjustments according to past inflation, stating that a model along such lines would imply that "inflation would be explained by its very self" (p. 154). This was the general tone of the arguments posed by those subscribing to the idea that fiscal deficits were monetized into inflation-boosting pressures, and that a Phillips curve estimated for Brazil could deliver the optimal level of unemployment necessary for a successful disinflation of the economy. Thus, the policy of a monetary restriction launched by the government in that year would amount to a simple explanation for the containment of inflation. The critics of Lemgruber's monetarist conclusions were vocal in their response. Dionísio Carneiro intervened in support of the conflict approach, claiming that it lead to a monetary policy theory of the monetary authority, somewhat echoing Reder's (1948) rationale of a "trilateral monopoly". Francisco Lopes added that the "recent deceleration" of prices had to do with other factors than monetary stringency, but to the presence of lags between shocks and price adjustments. Adroaldo de Moura Silva further challenged Lemgruber with the assertion that, despite this latter's best efforts to prove otherwise, Lemgruber (1977) had provided clear evidence that monetary policy is endogenous and that halting inflation must go beyond conventional measures and bring in incomes policies, to which Silva thought the deceleration of prices should be ascribed to. Therefore, in order to curb inflation, real income must be constant while demand is reduced. In this context, the oligopolized structure of the Brazilian economy turns any restrictive policy highly recessive, for if distributional incompatibilities are not accommodated by monetary expansion, consistency at the system level is reached by means of quantity adjustments. Both Silva and Lopes teamed up against Lemgruber's main stand and defended an open price control policy with corrections in relative prices, whenever needed in order to prevent distortions in the overall price structure of the economy.

${ }^{153}$ Sardenberg (1987) gives a vivid and detailed journalistic account of the challenges policymakers faced in the 1980s. Leitão (2012) is also a rich narrative, albeit more focused on the impacts of chronic inflation on the citizens' everyday life. 
moment the country needed a booming economy the most, that is, during a major political transition. $^{154}$

As regards economic analysis, the structuralist opposition to alleged monetarist status quo was however centered on the apparent oblivion on the part of monetarist to an "indubitable" fact (see Simonsen 1989, p.14), namely: the widespread use of indexing schemes under persistently high rates of inflation had led to a substitution of domestic currency as unit of account of contracts for other referential assets, whose values are denoted in terms of the legal tender, which comes to define the terms at which contract obligations are met (Carvalho, 1994, p. 109). In a word, indexation tends to institutionalize the price-wage spiral (Simonsen, 1995, p. 5) and imparts a mechanical drive to it (see Heymann \& Leijonhufvud 1995, p. 31)

The neo-structuralist economists involved in the controversy found it quite striking that "fundamentals" (budget and current accounts) were in place, but left inflation unscathed. This raised doubts concerning the relationship between budget deficits and inflation, as well as the level of proportionality - and the true direction of causality - between monetary aggregates and prices. For instance, Arida \& Resende (1985) were adamant in claiming the Brazilian budget deficit was close to zero and the current accounts of the balance of payments were on the positive side. And yet, inflation seemed to be stable at three-digit rates. A few months later, Gustavo Franco (1986, p. 48) published his PhD thesis amid the quarrel and, in a chapter devoted to provided analytical basis to inflationary inertia, he wrote:

It is suggested that the mechanisms responsible for inertia are not related to the workings of fiscal and monetary policy so that there would be little that the

\footnotetext{
154 An illustration of the effects of the historical moment on the way economists perceived their role in social transformation is useful at this juncture. At the onset of the 1982 financial crises triggered by the Mexican default on its foreign debt obligations, a conference was organized to debate the perspectives concerning the Brazilian economy and the latitude enjoyed by the country's economic policy in face of the severe liquidity constraint in international financial markets. The papers were collected and published in Arida (1983a). In the paper that concludes the meeting's report, Arida states with an intense critical tone that the government's orthodox policies of austerity entails the decrease in economic activity without altering the structure of the economy; "heterodoxy alters the structure in order to be able to respond to the external constraint by increasing the level of activity". In addition: "The heterodox program assumes, in fact, a reordering of political constellation of power. But this is not to be considered a flaw; it is indeed a virtue. An unfortunate fate befalls the thinking that makes economic theory a specialized technical knowledge. Economic policy is always and simultaneously economics and politics. If heterodoxy violates the ongoing power relationships, as it does, wrong are these power relations and not the heterodoxy that characterizes the measures proposed" (Arida, 1983a, p. 202-204). The general ambience of the meeting is of criticism against the $30 \%$ exchange rate devaluation coupled with restrictive measures taken by the Brazilian minister of finance, Antonio Delfim Netto, which resulted in a combination of deep recession and an increase in inflation.
} 
latter could do to arrest inflations that are largely governed by inflationary inertia. That helps to explain not only the poor record of stabilization programs centered on financial policies but also some incredible successes achieved by programs that specifically addressed the inertia problem.

The literature makes glaringly clear that stabilization policy was the end to which most theoretical efforts of this period were pointed (e.g. Bastos \& Mello Neto (2008). In this vein, it was argued that when contracts incorporate past inflation - by means of index-linkages or backward-looking behavior) - conventional anti-inflationary measures of aggregate-demand restriction become ineffective and end up exciting social unrest, once it increases unemployment and aggravates recession. ${ }^{155}$

Therefore, a mix of political discontent and theoretical rebellion fueled a yearning for institutional change and reform both in policy and in academia. As a result, it was politics that eventually teamed up seemingly irreconcilable economic approaches under the banner of heterodoxy. As we will see in Chapter 6, the economic consensus built around it was feeble. When it was challenged later on, as the economists behind it became policymakers, compromise proved to be not only partial, but also too soft. Next section sorts out how the scholars at PUC-Rio framed the concept of inflation inertia in the first moments of the neostructuralist intervention in the controversy.

\subsection{The first moments of Neo-Structuralist inflation models in Brazil}

Chapter 4 brought evidence to bear on the connection between the North-American neostructuralist constructs by Hollis Chenery and Lance Taylor and the Brazilian economists immersed in development-related studies about income distribution and growth. This section further unravels the academic byproducts of this intellectual partnership. We analyze below the core contributions by Edmar Bacha, Eliana Cardoso, Francisco Lopes, André Lara Resende, Persio Arida and Eduardo Modiano in the initial stages of the second round of monetarist-structuralist dispute that arose in the 1980s in Brazil. Our aim is not to be exhaustive but to give a clear picture of the type of reasoning these economists put forth when grasping the forces underlying chronic inflation. Two elements will stand out in what follows: the conflicting claims approach and the mathematical formalization of the saw-tooth diagram whose historical antecedents we have seen in the last section of chapter 4 .

\footnotetext{
${ }^{155}$ The conclusion is similar, in substance, to Furtado's ([1962] 1965, p. 101-113) own claims in the early 1962 , when the fear of galloping inflation entailed heightened social unrest.
} 


\subsubsection{Reinventing tradition: the neo-structuralist school at PUC-Rio}

Before he grappled with the analytical maze of stabilization policy, Persio Arida was a zealous student of methodology and the history of economics. In an influential piece he wrote for the Brazilian audience about the role of rhetoric in the advancement of economic knowledge. Developed independently from McCloskey (1983), the paper stresses the importance of "reinventing tradition" to increase the persuasive power of a new paradigm or research program (see Arida [1983] 1996). In this vein, the inertial inflation paradigm was couched on the neo-structuralist school of macroeconomics Edmar Bacha (1998b) set out to build at PUC-Rio and on the structuralist approach to the inflationary problem, as portrayed by Francisco Lopes and Eliana Cardoso. We start with the neo-structuralist macroeconomics program.

Bacha (1979) did argue in favor of an approach to inflation based on the idea of a kaleckian distributive conflict. In this and other occasions, he developed models that depicted the resolution of conflict through means of non-zero inflation rates. This theoretical lineage underlined the discussions on stabilization matters in Brazil, especially as regards the conflicting claims structure of the inertial inflation concept. It also provided a bridge with previous Latin American structuralist models, such as in Taylor (1973), Lopes \& Williamson (1980), Cardoso (1979), Bacha \& Lopes (1983). All of these attempts drew heavily on intersector models like those of Chenery (1975), Olivera (1964) and Baumol (1967) with explicitly articulated social conflicts and structural change as a driving force of events.

In the early 1980s, Edmar Bacha lectured on macroeconomic theory and economic policy based on heterodox approaches that included some Post-Keynesian and, particularly, Kaleckian models to portray the Brazilian economy, owing much to the alleged inadequacy of North-American textbooks to explain an economic structure in which the State took such a great part, as in Brazil (see Bacha 1982a, for instance). ${ }^{156}$ His 1986 book gathers many of his writings done along his stay in Yale University in the 1970s. Bacha seeks to formalize along modern analytical techniques the "generous vision of the Latin-American economy" proposed

\footnotetext{
${ }^{156}$ This is a direct outcome of his earlier studies in Yale and MIT, alongside Lance Taylor and Dionísio Dias Carneiro (see Bacha 1998b, p. 203-205). ${ }^{156}$ Bacha obtained his doctoral degree from Yale in 1968 and spent the years between 1975 and 1977 as a visiting scholar at Harvard and MIT, where he studied the dynamics of growth and distribution of income, alongside Lance Taylor, and wrote a few celebrated papers on this topic. Soon after, already back in Brazil, he would participate in the institutional construction of the Department of Economics of PUC-Rio, an important center of research in economics in the country. Many of his students would apply for $\mathrm{PhD}$ programs in the United States, focusing those of a heterodox approach, such as MIT, Yale, Stanford and Harvard.
} 
by Raúl Prebisch, Celso Furtado, Juan Noyola Vásquez and Aníbal Pinto (Bacha 1986, p. 7). These few words on Bacha's background is an important device to convey the core message of this section, that is, how development economics turned mathematical in the hands of North American Structuralist and, from there, a renewed influence found its way into Brazilian debates on stabilization. ${ }^{157}$

This general line of investigation grew out towards short- and medium-run models focussed on macroeconomic adjustments to fluctuations in the works by Francisco Lopes co-authored by John Williamson ([1978] 1980) -, André Lara Resende ([1979] 1981), Eliana Cardoso (1980a) and Persio Arida (1982). These models carry out an explicit definition of inflation as the result of a social impasse among economic groups, in their struggle to ensure themselves a desired share of aggregate income. The saw-tooth pattern of nominal incomes emerges from a whole set of non-market forces related to social and political aspects impinging on price and wage setting behavior. The interventions by Eduardo Modiano (1983b, p. 139-153) and José Márcio Camargo (1983, p.181-188) are also illustrative of the conflict approach in vogue at the time.

Take, for instance, Cardoso's (1980, p. 46) influential essay, defined by the author herself as a statement that the structuralist "theses are sufficient to generate disequilibria, which generate a permanent rise in prices, with a self-perpetuating tendency, with no automatic force emerging in order to correct it". Moreover, she stresses how central is the compatibility between the relative price and the social structures of the economy: "if relative price that holds the markets for different goods in equilibrium is incompatible with that determined by the social production relationships in industry, the outcome is a structural disequilibrium, which generates an inflationary process" ([1980] 1981a, p. 277). In an earlier version of the paper, written in Portuguese, Cardoso (1980, p. 57) is more adamant in stating that this very inflation process is "likely to perpetuate itself." This self-reinforcing feature implies the type of circularity that has, time and again, bedeviled policymakers:

It should be stressed that whatever the origin of inflation (whether high desired real wages relative to the wages compatible with market equilibrium (...) or a demand expansion (...) once the process is under way, wage and price increases follow in rapid succession, so that it becomes impossible to determine if the initial pressure was on the cost side or the demand side.

\footnotetext{
${ }^{157}$ On the connections between two moments of theoretical developments, Bacha (2003, p. 145) recalls that "the structural inflation became the inertial inflation theory", but this latter "lacked the credible monetary mechanisms" to fight it. (p. 146).
} 
Furthermore, any stabilization policy necessarily implies a lower-than-desired share in total income for at least one social group. (Cardoso [1980] 1981a, p. 279 - English in the original)

Cardoso (1979, 1980 and [1980] 1981a) purports to update the basic structuralist claims with a new modeling format. Bacha \& Lopes (1983) emphasized was the institutional "existence of a wage policy which imposes compulsory wage settlements of fixed periodicity for all registered workers" (p. 1). For these authors the role of wage indexation is to eliminate the forced savings effect, by permitting the average real wage to stay constant over time. This can be achieved if a reduction of the real wage target can be negotiated at the same time that nominal wage increases can be set lower than past inflation. There seems to be a wholly compensating effect, as the authors see it, leaving operative only the inflation tax effect, which they deem "rather small". The final conclusion on this aspect is that "a distributionally neutral increase in the intensity of wage indexation will tend to reduce the output loss resulting from a monetary deflationary shock", at the time, a widely known proposition by Milton Friedman (1974) who could only see the bright side of the indexation mechanism.

The second instance of this "reinvention of tradition" can found in Lopes's (1979) survey of inflation theories. The entire paper can be construed as a mathematical reshaping of structuralist theories of inflation. He first introduces the sides of the monetarist-structuralist controversy according to a simple formalization (he places it in a footnote), as follows. Admit an economy can be represented by a set of parameter and variable vectors in a system of equations in the following functional form:

$$
F(\hat{p}, u, \epsilon, \Delta)=0
$$

where in order of appearance, we have the inflation rate $(\dot{p})$, the level of capacity utilization $(u)$, a vector of parameters denoting the "structure of the economy" $(\epsilon)$ and a vector of policy parameters $(\Delta)$. The difference between a monetarist and a structuralist approach comes down to how one shall solve the model. In a monetarist version, the inflation rate is determined by a vector of policy parameters $(\Delta)$ and there is a finite number of structures $(\epsilon)$ consistent with the level of capacity utilization $\left(u_{0}\right)$, or:

$$
\hat{p}=h\left(\Delta, u_{0}\right) ; \quad u_{0}=g(\epsilon)
$$

The structuralist closure alternatively sustains that inflation is determined by the structure of the economy $(\epsilon)$, which has an unlimited number of configurations that are 
compatible with the level of utilization $\left(u_{0}\right)$ as long as the policy parameters are properly calibrated; formally we have:

$$
\hat{p}=h\left(\epsilon, u_{0}\right) ; \quad u_{0}=g(\epsilon, \Delta)
$$

Having parsed out the basic structure of reasoning, Lopes moves on to a careful description of the monetarist side and, next, he turns to the Latin American structuralist tradition. He restates the conclusions reached by Sunkel $(1958)$ and Olivera $(1964,1967)$ and even provides an acceleration amendment to the model to make it compatible with the monetarist view (Lopes 1979, pp. 10-14). ${ }^{158}$ Once the traditions are sorted out, Lopes builds the "neo-structuralist model" of inflation, couched upon a controversial interpretation of Simonsen's (1970) feedback model (see Chapter 3 above), whereby his demand adjustment variable is interpreted as a structuralist conclusion of an existent long-term relationship between inflation and the level of capacity utilization; this in turn makes up for a non-vertical long-run Phillips curve. ${ }^{159}$ Finally, he merges the feedback model with the early two-sector model of structural inflation (see Chapter 3 above) to provide a complete picture of the neostructuralist vintage inflation model:

$$
\hat{p}=a_{t} \hat{p}_{t-1}+b_{t} g_{t}+c_{t}
$$

where the feedback component $(a)$ can be updated to take into consideration the distributed lags, which makes the parameter a function of the acceleration of inflation:

$$
a_{t} \hat{p}_{t-1}=\phi_{1} \hat{p}_{t-1}+\phi_{2} \hat{p}_{t-2}+\cdots+\phi_{n} \hat{p}_{t-n}
$$

or

$$
a_{t}=\phi_{1}+\phi_{2}\left(\frac{\hat{p}_{t-2}}{\hat{p}_{t-1}}\right)+\cdots+\phi_{n}\left(\frac{\hat{p}_{t-n}}{\hat{p}_{t-1}}\right)
$$

as for the autonomous component, we can use Olivera's structural inflation equation, which is determined by the difference in price rises in the backward sector $\left(P_{a, t}\right)$ and the advanced one $\left(P_{b, t}\right): \hat{P}_{R}=\hat{P}_{a, t}-\hat{P}_{b, t}$. Rearranging it, according to a definition of inflation as weighed average of sectional prices, gives:

$$
\hat{p}_{t}=\beta \hat{p}_{a, t}+(1-\beta) \hat{p}_{b, t}=\beta \hat{p}_{R}+\hat{p}_{b, t}
$$

\footnotetext{
${ }^{158}$ While at it, he gives a neat formal account of Ignácio Rangel's (1963) claims, so as to unravel the most seemingly contradictory arguments by the latter author (p. 14-19).

159 The crux of Lopes's idiosyncrasy is that a monetarist version of the Phillips curve is set upon the fullemployment level with a freely adjusting price system, whereas Simonsen's specification turns the model into a growth-inflation trade-off, which suggests that demand fluctuations can affect growth in the long run.
} 
then if we assume that $c_{t}=\beta \dot{P}_{R}$ and $a_{t} \dot{p}_{t-1}+b g_{t}=\dot{P}_{b, t}$, we have the feedback model fully compatible with the early structuralist model of inflation.

Still following Arida's ([1983] 1996) piece on rhetoric, one cannot help but notice that Lopes (1979), Cardoso ([1980] 1981) and Bacha (1982) makes a compelling argument and reinvents the structuralist tradition, as a mirror of the mechanical form the economics discipline had acquired by then. The neo-structuralist economists at PUC-Rio made a veritable methodological effort to translate Latin American economic structuralism into more rigorous mathematical form. We avoid siting in any value judgment as regards this process of change. In fact, if we take Heymann \& Leijonhufvud (1995, p. 31), it seems as though the mechanical models were, to some extent, emulating the real world and the direction in which the economic profession was moving. ${ }^{160}$ In this vein, by becoming increasingly more abstracted from historical peculiarities and ever more concerned with the seemingly mechanical nature of a pure inertial inflation, these models ended up losing their previous development-laden core analytics. This strip down proved instrumental in facilitating the convergence of the concept of inertia to the one used by New Keynesian economists. We start by showing, in the next sub-sections, some details of the modeling formats and main conclusions that amounted to the "inertial inflation paradigm". Then, section 5.3 starts to make sense of the internal tensions to this heterodox construct that led to its later dilution into the more general corpus of "mainstream" inflation theories.

\subsubsection{The "Theory of Consistent Indexation"}

Francisco Lopes is an important character in our plot. Not only was he the first proponent of the heterodox shock in Brazil, he appears as most engaging in debates with orthodox economists in from the 1980s onwards. His contribution ranges from the econometric exercises aiming to show that aggregate demand fluctuations had no bearing on inflation behavior due to the extensive system of indexation to the most sophisticated analytical accounts of the saw-tooth pattern of fixed incomes under inflationary conditions. His work is central to our core message, for it reflects the diversity of theoretical lineages and modeling strategies that teamed up within his contribution. And, as a result of this plural background, paved the way to the realignment with the more abstract and institutions-free

\footnotetext{
160 The authors claim that in high inflation economies, indexing prices to an aggregate price variable, such as a CPI becomes "a likely norm" for adjustment of payments: "Thus wages and rentals may end up being revised through a more or less mechanical, backward looking procedure". In fact, Simonsen (1970b) and Bruno (1993, p. 42) both follow some "mechanics" of high inflation or some term with a similar connotation.
} 
approach of New Keynesian economics after the "pure inertial inflation paradigm" (Arida 1992, p. 34) went under water. In what follows, we take a glimpse of his consistent indexation scheme, in search of evidence to sustain our claim that an institutional and historical stripdown process was a "natural" development of the PUC-RJ contributions to the debate, a methodological proclivity much informative of subsequent moments of the inertial inflation story. ${ }^{161}$

Lopes \& Williamson ([1978] 1980) aim to show that indexation is a double-edged sword. It may reinforce inflationary pressures if introduced during a period of non-zero (high) inflation in a way that it is likely to redistribute real income, which entices defensive behavior on the part of those enduring losses. On the other hand, it is possible to design indexing schemes that have persistent deflationary effects. The paper is thus focused on the discussion of the conditions under which each of the above situations is more likely to hold. As we mentioned in chapter 4, they expand on the modeling "tradition" of Duesenberry (1950), Turvey (1951), and Olivera (1964) (see Lopes \& Williamson 1980, p. 65, n.1).

The model is formalized as follows. Nominal wage $\left(W_{t-\phi}^{\phi}\right)$ for a certain period $(\phi)$ is a function of desired real wages $(\alpha)$ and the inflation observed within the interval between adjustments $\left(P_{t-\phi}^{\phi}\right)$. Firms update the price charged for their goods after every reset of nominal wages, aiming to maintain their real mark-up factor over costs $(\tau=1+m)$, hence:

$$
P_{t-\phi}^{\phi}=P_{t+1-\phi}^{\phi}=\tau\left(W_{t-\phi}^{\phi}+a_{m} P_{t-\phi}^{\phi}\right)=\tau\left(\alpha+a_{m}\right) P_{t-\phi}^{\phi}
$$

where $a_{m}$ represents the intermediate goods input per unit of output. The price level is then set as the wage and intermediate goods price pressure, for a given mark-up in :

$$
P_{t}=\tau\left(\alpha+a_{m}\right) \bar{P}_{t}
$$

in which $\bar{P}_{t}$ denotes the average price level compounded by the sectionally-determined price level, weighted by their share of the national output $\left(\bar{X}_{t}\right)$ :

\footnotetext{
${ }^{161}$ One contribution by Lopes $(1979$, p. 33) that seems to have eluded intellectual historians is his attempt at defining a precise typology for different forms of correcting nominal values according to past inflation. At the time, the terminology used confused monetary correction and indexation. Lack of clarity also hit the notion of price controls. So, Lopes suggests we apply the term "monetary correction" to those cases in which a rule guarantees a "floor" to - or minimum rates of - adjustments in nominal value of contracts and prices. Indexation would be reserved for the application of any rule of period adjustment of a nominal value to prevent the erosion of its purchasing power by inflation. Price controls would characterize a "ceiling" or upper bound to price revisions. A "strict indexation rule" would, finally, describe the joint-application of monetary correction and price controls.
} 


$$
\bar{P}_{t}=\int_{0}^{1} \frac{X_{t-\theta}}{\bar{X}_{t}} P_{t-\theta} d \theta
$$

Stability requires $\bar{P}_{t}=P_{t}$, so that $\tau\left(\alpha+a_{m}\right)=1$. The distributively neutral outcome is given by:

$$
\tau\left(\alpha+a_{m}\right)-1=\left(1-a_{m}\right)\left[\frac{\alpha}{1-a_{m}}+\frac{(\tau-1)\left(\alpha+a_{m}\right)}{1-a_{m}}-1\right]
$$

Intutitively, the wage claims amount to $\left(\frac{\alpha}{1-a_{m}}\right)$ and the profit claims on output are reflected by $\left[\frac{(\tau-1)\left(\alpha+a_{m}\right)}{1-a_{m}}\right]$. Therefore, if $\tau\left(\alpha+a_{m}\right)>1$, claims exceed the available output. So far, this is just a restatement of Rowthorn's (1977) aspiration gap and Resende's ([1979] 1981) inconsistency gap. Any exogenous attempt to improve one group's situation at the expense of another leads to a loss by one of them, measured by:

$$
\frac{\Pi^{D}}{\Omega^{W}}=\frac{\tau\left(\alpha+a_{m}\right)\left(1-a_{m}\right)}{\alpha}-1
$$

Notation follows the one pursued in the preceding section. Wages are corrected for inflation at every $\phi$ period length: $W_{t-\phi}^{\phi}=\left(1+\hat{p}_{t, \phi}\right) W_{t-1-\phi}^{\phi}$. Thus the inflation rate $\hat{p}_{t, \phi}$ meets the following relationship:

$$
\frac{P_{t-\phi}^{\phi}}{P_{t-1-\phi}^{\phi}}-1=\hat{p}_{t, \phi}
$$

Hence, the effect of introducing indexation is to perpetuate the ongoing rate of inflation at the moment of this introduction, which is a positive circumstance if inflation is on the rise. However, this traditional type of indexing is likely to freeze inconsistent claims, thereby propagating the inconsistency to the level of the system. Consequently, inflation persists as a necessary device to make ex ante incompatible claims consistent ex post facto. Positive real shocks - such as enlarged agricultural yields or productivity advances, and even more modest government claims on available output - could decelerate the inflationary process. Conversely, a negative cost-push change would exert tremendous upward pressures, which indexation fully absorbs into the price system. In this vein, traditional indexation leads to persistent inconsistency among groups' claims at the system level.

Alternatively, one could devise a system of indexation where nominal variables could adjust so as to restore their real value in the face of price level changes, whilst not provoking 
an excess of real income claims over net available output. This consistent indexation thus requires agents to focus their aspirations on the average real wage, instead of peak real wage. Wages in a given sector are adjusted for inflation in evenly spaced intervals of one year. The actual real wage $w_{t}$ is eroded throughout the year by the registered inflation rate within the same period. Assuming a constant rate of price rises, full indexation guarantees $w_{t}=w_{t-1}$. However, once it is realized that the desired peak level is inconsistent with real profit rates at a zero inflation level, the expected average real wage $E\left(\bar{w}_{t}\right)$ could replace peak real wage in informing indexing policy, because peak real wages have to be inevitably eroded to restore consistency to the system. A consistent indexation rule would thus have the following format:

$$
\bar{w}_{t}=f\left(\hat{p}_{t}\right) \bar{w}_{t-1}
$$

in which $f\left(\hat{p}_{t}\right) \approx \frac{1}{1+0,5 \pi_{t}}$ and $f^{\prime}\left(\hat{p}_{t}\right)<0$. The authors add a diagram displaying a log-linear representation of the saw-tooth pattern within an interval of length $\phi$, as we have seen previously. Consistency will then require that the expected average real wage during the year $(\mathrm{t}+1)$ - based on a expectation of future inflation $\left(\hat{p}_{t+1}^{e}\right)$ - be equal to the actual average real wage in the year $(\mathrm{t})$ :

$$
E\left(\bar{w}_{t+1}\right)=f\left(\hat{p}_{t+1}^{e}\right) \bar{w}_{t}=f\left(\hat{p}_{t}\right) \bar{w}_{t-1}
$$

According to the above definition, we can find the formula for a consistent money wage indexation:

$$
W_{t}=\frac{f\left(\hat{p}_{t}\right)}{f\left(\hat{p}_{t+1}^{e}\right)}\left(1+\hat{p}_{t}\right) W_{t-1}
$$

When expected inflation equals past inflation $\left(\pi_{t+1}^{e}=\pi_{t-1}\right)$, the formula collapses to the traditional form. Additionally, when a deceleration of prices is expected $\left(\dot{p}_{t+1}^{e}<\dot{p}_{t-1}\right)$, wage adjustment is inferior to the rise in prices in the current period $\left(\dot{p}_{t}\right)$ (Lopes \& Williamson 1980, pp. 73-77). The authors readily admit that their story relies almost entirely on workers' behavior. To balance the scores, they qualify the consistency rule by acknowledging that discipline in profit rates warrants a policy of price controls. Should a profit-analog of the wage formula be applied to prices by some government agency, it would look somewhat like the following:

$$
T_{t}=\frac{f\left(\hat{p}_{t}\right)}{f\left(\hat{p}_{t+1}^{e}\right)}\left(1+\hat{p}_{t}\right) T_{t-1}
$$


$T_{t}$ denotes the money profit bill at time t. Once these definitions are complete, the price level can be rewritten as:

$$
P_{t}=a_{m} P_{t}+W_{t}+T_{t}
$$

Therefore, once the conditions are clearly stated, the authors conclude that a perfectly neutral distributional profile is not possible in the short run. To drive the point home, admit that the government launches an incomes policy that lowers expected inflation below current inflation. The drop in inflation would shift real income towards those sectors that had recently restored their real peak level. Other sectors would endure real losses, as they find themselves further away from the last adjustment. The lack of any compensation mechanism in the policy design to those facing real losses, it becomes clear that perfect neutrality is not compatible with a finite period of wages and price contracts, as Furtado (1954) and Simonsen (1980), among others, had also noted. In the absence of strict neutrality, a relaxed form of consistency is achievable under two conditions, namely: no redistribution from wages to profits occurs; and redistribution among sectors is of transient character.

Lopes and Williamson (1980) provided then an important contribution as regards the distributional dynamics of an inflationary economy and the nearly insurmountable obstacles facing an effective stabilization policy. It is noteworthy that the authors, in their attempt to simplify things, assumed a constant rate of inflation. Even in such "controlled" environment, the intertemporal dynamics of distributive conflicts imposes severe restrictions on the possibilities of achieving an optimal stabilization policy, allowing only for a secondbest solution that does not secure the resolution of the primary causes of the problem, namely, the inconsistent distributional profile when aspirations by economic groups are taken into account.

\subsubsection{Inflation as a Social Impasse: André Lara Resende's inconsistency gap}

Resende ([1979] 1981) deploys an analytical effort to demonstrate how distributional conflicts can sustain a non-zero inflation. In this vein, it is not surprising to find in the paper references to Aujac (1950), Kaldor (1957c, 1957d), Modigliani \& Paddoa-Schioppa (1977), Pasinetti (1962), Robinson (1956), Rowthorn (1977) and Taylor (1979), as Resende was deeply immersed in the vibrant Neo-Keynesian and Structuralist traditions of MIT/Harvard/Yale connection of the late 1970s.

Resende explicitly adopts the "inconsistency gap" (p. 133 and thenceforth) - a variant of Rowthorn's (1977) "aspiration gap" - to undergird his working concept of inflationary 
process. He also takes up on inflation expectations and evaluates the behavior of the model when an agricultural or intermediate good is inserted. ${ }^{162}$ Just like Cardoso (1980a), Resende provides a formalization of the basic structuralist conclusions regarding the primary causes of inflation which are then propagated to the rest of the economy by way of ingrained distributional antagonisms among economic groups. His model largely draws on the Keynesian Distribution and Imperfect Competition Theories, a detailed formalization of which should not arrest us here, besides its core aspects. ${ }^{163}$

The inconsistency gap is formalized as follows. Take the typical price equation composed of a mark-up over costs as $P=\tau a W$, where $\tau=1+m$ is the mark-up, $a$ is the labor input for a unit of product and $W$ is nominal wage. The negotiated profit bill is then set as $\Pi^{N}=1-\Omega^{N}$, where $\Omega^{N}$ is the negotiated real wage bill $(a W / P)$, whereas the desired profit bill is defined by $\Pi^{D}=m a\left(\frac{W}{P}\right)$. Since, by definition, $\Pi^{D}>\Pi^{N}$, we can immediately find the inconsistency gap by the following expression:

$$
\Pi^{D}+\Omega^{N}>1
$$

Should all wages be negotiated and revalued at once, firms would push up prices instantly after negotiations were settled. Inflation would soar in fast pace. The fact that wages in different categories are scattered across the calendar year prevents the price level from behaving discontinuously ([1979] 1981, p. 136). This helps to explain why the saw-tooth pattern of wages is difficult to depict when the whole of wages are taken into account, as Simonsen (1964) had previously noted. So, inflation is determined by the degree of inconsistency between wages and profits, scaled by the sensitivity of inflation to the gap $(\omega)$ :

$$
\hat{p}=\omega\left(\Pi^{D}-\Pi^{N}\right)
$$

Expectations on future values of inflation are introduced and, by choice, set equal to past inflation scores: $\hat{p}_{t}^{e}=\gamma^{W} \hat{p}_{t-1}$, where $\gamma^{W}$ is implicitly tied to workers' bargaining power. Finally, we have the full inflation equation as a result of adaptive expectations and the

\footnotetext{
162 The model we set out to show holds extensive methodological similarities with the one proposed by Silva (1981), although this latter is not mentioned in the 1981 published version. This corroborates our claim that the contributions by Robert Gordon, Arthur Okun and James Tobin had far greater impact on Brazilian thinking on inflation than the literature has come to stress thus far.

163 Resende purports to understand, at first, the behavior of mark-ups and analytically derives the positive relationship, at the normal level of capacity utilization, between the mark-up and the rate of growth of output. Moreover, oligopolistic markets render mark-up somewhat immune to cyclical fluctuations in demand, being instead determined by the firms' perception of their oligopolistic surrounding environment. A downward rigidity of mark-ups is thus explicitly introduced.
} 
inconsistency gap, in which $\bar{W}=\left(\frac{W_{t} \hat{p}_{t-1}}{1+\hat{p}_{t}^{e}}\right)$ is the desired real wage to be negotiated at the end of the period. The equilibrium rate of inflation is then found by assuming convergence of $\hat{p}_{t-1}$ to $\hat{p}_{t}$.

$$
\overline{\hat{p}}_{t}=\frac{m a \bar{W}-1}{1-m a \bar{W} \gamma^{W}}
$$

Since stability requires $m a \bar{W} \gamma^{W}<1$, in the long run, the only feasible growth rate of output is the one that closes the inconsistency gap. An increase in the bargaining power of workers or of the desired real wage generates a heightened inflation. In order to prevent saddling the economy on an explosive path, unemployment must rise (p. 142). ${ }^{164}$ Resende's ([1979] 1981) model is an important synthesis of the main contributions by the Latin and North American structuralist economics. Nevertheless, it lacks an account of the process of wage negotiations and the channels by which inflation affects the frequency of adjustments, a concern of the first order of importance in Brazil of the early 1980s and one that Persio Arida will grapple with in his paper Wage Adjustment and Inflation, published in 1982, to which we turn in the next section.

\subsubsection{Conflict and Wage Indexation Regimes: Persio Arida's synthetic model}

Arida (1982) corroborates this last statement with his wage-indexing model. He sets out to determine the conditions under which an "optimal indexing scheme" could be designed. As we have shown in chapter 4 , incomes policy had been around as a stabilization mechanism in developed economies for decades, and Arida (1982) has given an interesting contribution to the subject. The model assumes expected inflation to rely on past inflation rates and a homogeneous rate of wage adjustment across sectors and different wage brackets. The analysis addresses the choice between a fixed-period indexation and an endogenous interval arrangement for a wage-indexing policy. Inflation results from conflict between entrepreneurs and workers. Coercive power by one group on the other is limited so that workers cannot

\footnotetext{
${ }^{164}$ In the last sections of the paper, Resende introduces imported intermediate goods in the price equation to reveal that the more dependent the economy with respect to foreign productive inputs, the more sensitive inflation becomes with respect to exchange rate adjustments, thus inviting a sharp contraction of output should an international price shock (e.g. oil) hit the economy, to preclude an explosive path. At last, Resende considers the agricultural sector and reshapes Olivera's (1964) and Cardoso's (1981) models. Relative price between agricultural and industrial goods is set as a function of output growth. Excess demand over the agriculture reveals the supply rigidity typically assumed in structuralist models. His main contribution in this particular instance is to set relative prices dependent upon the real wage desired by workers, their bargaining power, and capitalists' mark-up behavior and to infuse a "memory component" in the industrial price equation with the lagged inflation term.
} 
force entrepreneurs to hold prices down, while the latter fall short of preventing full wage indexation. The root of chronic inflationary processes lies upon this social impasse (Arida 1982, pp. 311-313). The model is neatly structured as follows: entrepreneurs wish to lower workers' desired real wage $(\alpha)$ down to a level $(\beta)$ consistent with their profit-maximizing plans, so that $\beta<\alpha$. After adjustment of money wages at each negotiation date that restores the desired wage $\alpha$, entrepreneurs raise their prices in order to erode $\alpha$ down to $\beta$. This latter can be formally stated as follows:

$$
\hat{p}=\frac{2(\alpha-\beta)}{D}
$$

This equation reveals the trade-off between frequency of wage adjustments (D) and the level of inflation $(\hat{p})$. Thus, for a given periodicity of wage bargaining it is the intensity of conflict $(\alpha-\beta)$ that determines the rate of inflation. Alternatively, for a given rate of inflation, conflict will impose the maximum length for adjustment intervals (D). From the above equation we can derive the notion that the shortening of indexing intervals generates higher inflation $\left(\frac{d \hat{p}}{d D}=\frac{-2(\alpha-\beta)}{D^{2}}<0\right)$, and may set the economy on an explosive path, leading to a hyperinflation $\left(\lim _{\mathrm{D} \rightarrow 0} \hat{\mathrm{p}}=+\infty\right)$.

Conversely, we can think of a scheme wherein money wages must be adjusted for inflation once this latter accumulates a certain value $\left(\hat{p}^{T}\right)$, termed henceforth "inflation ceiling" or "inflation threshold", given by the relationship analogous to the fixed periodicity case, as follows:

$$
\hat{p}^{T}=e^{2(\alpha-\beta)}-1
$$

which is to say, once again, that the intensity of conflict dictates the level of the upper bound to inflation that brings the system into consistency. In other words, the fiercer the struggle among income claimants, the greater is the accumulated inflation required to provoke a warranted reduction in real wages. When it comes to each determinant of conflict, workers' desired real wage responds to non-market institutional and power-related factors $\left(P^{W}>0\right)$ which captures social and political aspects of militancy and workers' bargaining power -, and to the effects of unemployment on workers' morale $\left(\gamma^{W}>0\right)$; formally:

$$
\alpha=P^{W}+\gamma^{W}\left(y_{t-1}-\bar{y}\right)
$$


in which $\left(y_{t-1}-\bar{y}\right)$ denotes some variant of Okun's law, reflecting the effects of a tight labor market on the desired wage rate, given by an above-normal growth rate. On the side of entrepreneurs, their desired real wage $\beta$ contemplates the profit-maximizing condition of:

$$
\beta=\frac{a}{\tau}=P^{E}-\gamma^{E}\left(y_{t-1}-\bar{y}\right)
$$

where $a$ stands for labor productivity and $\tau$ for the mark-up rate $(1+m)$. The above relation is explained by the non-market institutional and power-related factors $\left(P^{E}>0\right)$ - which captures social and political aspects of entrepreneurs bargaining power - and by the impact of growth on entrepreneurs' profits, given by their market power $\left(\gamma^{E}>0\right)$. Inconsistent claims sustain inflation at a non-zero rate as long as $P=P^{W}-P^{E}>0$ and $\gamma=\gamma^{W}+\gamma^{E}>0$. Should the economy grow at its normal rate $\left(y_{t-1}=\bar{y}\right)$, then inflation results from irreconcilable aspirations among workers and entrepreneurs $\left(P^{W}-P^{E}\right)$; in formal terms:

$$
\hat{p}=\hat{p}^{N}+\lambda\left(y_{t-1}-\bar{y}\right)
$$

where $\hat{p}^{N}=\frac{P^{2}}{D}>0$ denotes the normal rate of inflation, that is, the prevailing rate when the economy grows at its normal rate, and $\lambda=\frac{\gamma 2}{D}>0$ reflects the magnifying effects of the periodicity of wage negotiations $(D)$ on inflation given a real shock and the sum of marketrelated bargaining power of workers and firms to push up prices to restore their desired real income levels $(\gamma)$. Arida chooses to make the permanent inflation rate depend on the degree of political and institutional struggle among workers and entrepreneurs: $\left[\hat{p}^{N^{\prime}}(P)>0\right]$. Second, he also amends the "price and wage flexibility" aspects $(\gamma)$ - stressed in Olivera's (1964, 1967a) model - with the permanent inflationary effects of changing indexation intervals $\left[\hat{p}^{N^{\prime}}(D)<0\right]$ - underlined by Lopes \& Williamson ([1978] 1980) and Resende \& Lopes ([1979] 1981) - and, finally, manages to make it consistent with the main thrust of Gray's (1976) and Fischer's (1977) argument that real shocks tend to persistently affect inflation in the presence of wage indexation $\left[\lambda^{\prime}(D)<0\right] .{ }^{165}$

\footnotetext{
165 Furthermore, the model does not rule out the importance of demand-related forces and adds a monetary aggregate demand curve, taking a monetarist constant growth rate of money $(\bar{m}): y=\bar{m}-\pi$. Arida then rewrites the inflation equation in order to incorporate the demand-side aspects: $\pi=\dot{p}^{e}-\left(y-y^{e}\right)$; being $\dot{p}^{e}=\frac{2[P+\gamma(\bar{m}-\bar{y})]}{D+\gamma 2}$ the equilibrium rate of inflation that, beyond those factors mentioned above, hinges also on the differential between the normal growth rate of output and the constant increase in the money supply; secondly, the equilibrium growth rate $y^{e}=\frac{\bar{m} D-2[P-\gamma \bar{y}]}{D+\gamma 2}$ which depends directly on the growth rate of money.
} 
Comparative dynamics have different rationales in each indexing scheme. In a fixedperiod indexation regime, a policy of monetary stringency $(\Delta \bar{m}<0)$ immediately cuts down the growth rate of output, while inflation remains unaltered at first. The rationale is that a restrictive policy generates strong-willed opposition in the short run due to higher unemployment because its effects in inflation take some time to kick in. Conversely, an expansionary monetary policy $(\Delta \bar{m}>0)$ spurs growth at first and only in the medium run does inflation rise to its new equilibrium level. This policy produces immediate political gains with higher growth and employment and only lagged effects upon inflation levels. ${ }^{166}$

On the other hand, in the regime of endogenous interval length of wage negotiations, a monetary contraction leads immediately to lower inflation scores and lengthier periods between wage adjustments. It is thus a superior policy, Arida argues, because it leaves all structural and institutional factors unaltered. Lower inflation entails greater real wage, but not a lower capacity of entrepreneurs to reduce real wage, only a longer period to achieve the desired level of real labor costs.

To conclude, Arida's (1982) model provided a rich and concise take on the dynamics of inflationary economies. More than that, the distinction pursued between indexation regimes is a masterly synthesis of the two concepts of inertia already available at the time. The notion of the time-lag between a monetary shock and the response of prices is addressed in his regime of fixed-length adjustment intervals, which closely resembles the New Keynesian stand on price and wage rigidity and the real effects of monetary shocks, however different the assumption regarding the determinants of the time elapsed between one and the other. Secondly, the proposal of a persistent non-zero rate of inflation prompted by the antagonism among economic groups is a skillful and clear illustration of the inertial inflation concept, as in Tobin's (1981) and Rowthorn's (1977) versions. In the absence of strict government control, such as wage or incomes policy, inconsistent claims are likely to impact the length of the adjustment interval, which in turn reinforces the inflationary persistence that renders the expectations of further price rises yet more rigid.

\footnotetext{
166 The model suggests that a monetary contraction coupled with a shortening of the indexation lag implies a perverse outcome of a reduction in growth rates of output and a higher inflation rate. This result is of particular interest if we heed Arida's implicit purpose, that is, to level criticism on the military government's orthodox economic policy in late 1979 and early 1980, when annual adjustments of wages were cut down to half-year intervals while a strong monetary stringency was effected, in order to reduce the trade gap so as to not default on the external debt obligations.
} 
Third, by resorting to a short- and medium-run analysis, Arida asserts that the system has no automatic triggers that promote the convergence of the equilibrium growth rate of output $\left(y^{e}\right)$ to the normal rate of growth $(\bar{y})$. While at it, he is able to frame an economy subject to a frequency of shocks on the values of the exogenous parameters in a way that the system never attains full equilibrium, a feature that concurs, to some extent, with the firstround structuralist stand on the volatility of relative prices during a process of rapid structural change, a point made by Olivera (1964), Baumol (1967), Georgescu-Roegen (1968, 1970), Chenery (1975) and Taylor L. (1979).

André Lara Resende and Persio Arida were able to concisely frame the main claims made by the structuralist school. In Arida's model, the mark-up behavior loses substance when conflated with Resende's post-Keynesian emphasis on this very issue. On the other hand, Arida underlines workers' defensive behavior in the face of rising inflation and how a full-blown monetarist policy of demand contraction is likely to backfire if the regime of wage indexation is not fully heeded. And yet, albeit quite comprehensive in its main purposes, the model falls short of providing a clear account of how wage behavior can be brought into consistency, besides the unemployment channel, with the desired profit bill aspired to by entrepreneurs. This was addressed by Lopes \& Williamson ([1978] 1980), who sought after a theory of "consistent indexation" in order to envisage ways of bringing inflation down with the use of incomes policy.

This second section of the chapter, and its subsections, aimed to show a strong structuralist and Keynesian bites to the PUC-Rio authors' analyzes, with an emphasis on the centrality allotted to the concept of distributional conflict as a driver of inflationary processes and the structural and institutional forces that complemented market-related variables in determining the behavior of economic groups. We also intended to get a glimpse of the mechanical proclivities enjoyed by these authors in shaping their theoretical constructs. Far from being a problem, this inclination simply points to a modus operandi that will prove somewhat strategic in conveying their ideas in public debates in Brazil and abroad - for one can hardly deny that empirical and mathematical prowess is a powerful rhetorical device in a competitive policy environment. On the other hand, it took a toll on the institutional and structural substance of their analyzes, sweeping the intricacies of these dimensions into unchanging reduced form parameters in the models. Next section covers the points of instability that triggered the second-generation structuralist transformation process. 


\subsection{The eclipse of conflict-driven models of inertial inflation}

Two basic puzzles beset the inertial inflation "theory" as it was stated by Lopes (1980, 1984a), Arida (1982) and Lara Resende (1979), namely: why would workers persist in bidding up nominal wages if these latter would always result in the same real wages as before? And: why, in doing so, they would link wage increases to past rates of inflation? Serrano (2010, p. 407-409) has found no "rational justification", in their models, for workers to behave in such a fashion. In fact, Lopes (1984b) argues clearly that such behavior is independent of the existence of indexation rules or overall index-linkages of contracts, or even of adaptive expectations by economic agents; a straightforward defensive behavior or outright militancy by workers could guarantee successive rounds of wage negotiation aiming at restoring peak real wage levels. According to Serrano, this unfilled blank in the specification of their models results immediately from the assumption of an exogenous fixed markup rule. In this sense, the argument goes, a very peculiar conflict model is built, in which the conflicting claims are always resolved in favor of firms and the real wage is determined by the gross profit margin and by labor productivity. In such a setting, the average real wage in endogenously determined. Variations in the nominal wages would thus have no distributive effects. Workers become powerless, entrepreneurs fully passive and inflation a sterile exercise.

In our effort to construct a narrative that accounts of the inertial inflation hypothesis, one central theme stood out, namely: the unstable conceptualization and modeling of the concept of inertial inflation. For ease of presentation, we will divide the inertia-friendly theorists in two groups, according to how they saw the conflict element in the inertial inflation framework. We start with Simonsen's $(1970,1995)$ "inflation feedback component" and the "demand management component" $\left(g_{t}=y_{t}-\bar{y}\right)$ if we extend the model to the following relation. Provided it is the first one in chronological terms, it sets out the basic form of the inertial inflation models; formally:

$$
\hat{p}=a \hat{p}_{-1}+b\left(y_{t}-\bar{y}\right)+c
$$

where $b$ denotes the sensitivity of inflation to deviations of the output level from fullemployment. In what follows, we discuss some of the hurdles economists faced regarding structure and terminology of their inflation models.

The first set of points has to do with what is to be denominated monetary correction, indexation and how these two fit into the inertial inflation framework. The parameter $c$ 
indicated the autonomous inflation, in the likes of a "jump variable" that captured effects of one-shot extra increases in nominal wages and/or supply shocks, such as agricultural price hikes, currency devaluations, changes in terms of trade, variations in indirect taxes and adjustments in prices of public utilities. The parameter $a$ denotes the "pass-through coefficient" of lagged inflation to current price increases, or the feedback component and, in this setting, reflected the degree of indexation, assumed to be lesser than unit.

This typical modeling structure is embedded in a wider category of conflict-based theoretical frameworks. We saw in chapters 2 and 3 above that such style of reasoning was in the air in mid-1960s, when Simonsen first sketched it out. Thus, inflation ensues as societal groups struggle with one another to maintain their real shares of national income. Models of distributional conflict have two general incarnations. One sustains that heterogeneous distribution of market power affects price formation and distribution of income (Ros 1988). The second is consistent with monetarist conclusions, in which conflict exerts pressure, via political process, on fiscal and monetary policies, forcing government to monetize runaway fiscal deficits (Cagan 1956 and Sargent 1982). As we will see in Chapter 6, structuralists at PUC-Rio did not abhor the monetarist assertions completely; in fact, they were much inclined to concur with the idea of a balanced budget and a disciplined monetary policy. The difference had to do with the institutional detail of indexation and how, under the specific predicament of a debt crises, IMF-fostered orthodox policies could do more harm than good. There is thus a seed of instability inside this branch of the second-round structuralists.

\subsubsection{Wage Setting and Mark-up Behaviors: a basic framework}

Following Bacha \& Lopes (1983, p. 3), we begin by defining the real average wage in an indexed economic setting, which can be formally stated as

$$
\bar{\omega}=v-(\hat{p} / t)
$$

where $\bar{\omega}$ stands for the natural log of average real wage (and is assumed to be always greater than zero), $v$ for the peak real wage, $\dot{p}$ for the inflation rate and $h$ depicts the number of within-year revision of wages ( $t=1$, for yearly revisions; and $t=4$ for quarterly wage adjustments) ${ }^{167}$. If we insert the above relationship into a simple functional distribution profile of the whole economy

\footnotetext{
${ }^{167}$ The effect of the interval between wage settlements is more clearly seen by use of the formula: $\widehat{w}=h \hat{p}+$ $(1-h) \hat{p}_{-1}$, which indicates that nominal wage growth is a weighted average of current and lagged inflation
} 


$$
y=m+\omega
$$

in which $y$ denotes the natural log of real income and $m$, real markup rate, and $\omega$ for real wages $^{168}$. If we assume $\omega=\bar{\omega}$, we find that

$$
m=y-v+(\hat{p} / t)
$$

that is, real markup decreases in response to increases in peak real wage, and responds positively and proportionally to price inflation, other variables held constant. In taking timederivatives of the $\log$ values of the variables (and assuming $n=1$, given its exogenous definition by policy) we get growth rates of each one, denoted by the "hat" sign above them:

$$
\widehat{m}=\hat{y}-\widehat{\omega}
$$

or

$$
\widehat{m}=\hat{y}-\hat{v}+\hat{p}
$$

From the above relation, we can delineate three cases. First, a real markup rate $(\widehat{m}=$ $\hat{y}$ ) growing at par with real output implies immediately that $\hat{p}=\hat{v}$. That is, changes in nominal wages have null effect on the distribution of income, and acceleration of inflation $(\hat{p})$ results entirely from attempts to raise real wage peak levels $(\hat{v}>0)$. Moreover, firms accrue every gain from economic growth. Second, $\hat{v}>\hat{p}$ would require frequent adjustments on the part of firms to restore their desired real mark-up rate. This is the stand taken by Bresser Pereira and Nakano (1984) and the PUC-Rio structuralists at their first moments in the debate (see section 5.2 above). The chief point is that incomplete power of groups over the behavior of competing groups implies that adaptation is never complete: the permanent gap separating desired and average real incomes inherently entices new rounds of dispute. Above all, desired levels of income were in no way deemed constant and could be affected by the very process of economic development. The systematically alternated attempts to achieve desired real incomes by each fraction of income claimants infused an internal thrust into inflation, keeping its rates stable at a given level if peak levels remained constant. Nominal mark-ups could vary freely and faced no determinate upper bound; also, the non-labor costs of imported inputs are

rates, with weighting being given by $h=1-\left(\frac{1}{2 t}\right)$. Thus, if wage settlements happen once a year, $t=1 \rightarrow h=$ 0.5 , hence $\widehat{w}=0.5 \hat{p}+0.5 \hat{p}_{-1}$. And, in case of a quarterly frequency of wage adjustments $(t=4 \rightarrow h=0.875)$, then $\dot{\hat{w}}=0.875 \hat{p}+0.125 \hat{p}_{-1}$. The gist is that the shorter the interval, the more sensitive will be nominal wages to ongoing inflation rates, thereby speeding up next period's inflation rate.

${ }^{168}$ We depart from $y=(1+l) \omega$ and assume that $\ln (1+l) \approx \ln (l)=m$, in which, as seen above, $m$ stands for the real mark-up over costs. 
taken into consideration, together with interest as a cost-push factor (or the Patman effect) and the inflation-rising force of changing tax rates. Conflict-based inertial inflation is thus a potentially unstable phenomenon.

Alternatively, we can see the third possible case, whereby a constant real markup rate $(\widehat{m}=0)$ implies that

$$
\hat{y}+\hat{p}=\hat{v}
$$

This relationship means that the peak real wage varies with acceleration of price increases and real output growth. Solving for a speeding-up inflation, we get

$$
\hat{p}=\hat{v}-\hat{y}
$$

which clearly holds workers income claims accountable for the increase in inflation rates. Were peak wage growth to be paired up with output growth $(\hat{v}=\hat{y})$, inflation would be held constant $(\hat{p}=0)$. Thus conflict can be destabilizing solely because wages are pushing beyond the socially agreed upon income share (which is frequently termed "underlying structure of income distribution"). Then, understanding and taming inflation requires reconciling wage demands with other groups' claims. Wage indexation is thus of paramount importance in this approach. We find such an assumption in the main contributions from the PUC-Rio school. ${ }^{169}$

Next we need to look into what this stand on wage setting behavior implies in terms of firm behavior. ${ }^{170}$ If firms seek to maintain a constant real mark-up over costs, they will adjust nominal mark-ups along the cycle of nominal wage claims. Firms are then logically understood as fully defensive decision-makers. ${ }^{171}$ But, if firms simply react to a rise in wage bidding, what triggers workers demands? Conflict can arise for a myriad of reasons. In the structuralist tradition, discrepancy between real wage and workers' targeted real wage stems from a sudden relative price change, such as a large-scale devaluation of the domestic currency or, in the case of Latin American Structuralism, high food prices. ${ }^{172}$ This aspect

\footnotetext{
${ }^{169}$ See Bacha \& Lopes (1983, p. 11), Lopes (1986, p. 50), Franco (1986, p. 13) and Modiano (1988, p. 8-20). In the 1990s, under the hot debates inside the economic team for the Real plan, Gustavo Franco would make mention of this "automatic pass-through [of cost rises], with a fixed mark-up" (Prado, 2005, p. 551). Yet more recently, Taylor (2004, p. 73) has also made the same point.

${ }^{170}$ And here, Michal Kalecki is a prominent reference of the early contributions of the PUC-RJ branch. See, for instance, Bacha (1982) and Franco (1986, p. 44).

${ }^{171}$ More recently, Taylor (2004, p. 77) has reasserted this in quite straightforward fashion: “'Conflict inflation' can be said to occur when workers' aspirations (...) are not fulfilled. The wage peak is increased less than proportionately to the real wage loss" within the interval between readjustments".

172 Take for instance the model set up by Modiano (1988, p. 95-97). Simply put, the economy could be understood within a model contemplating a single aggregate production function e only two inputs (labor and
} 
points to the question regarding the magnitude of the lagged-inflation pass-through coefficient.

To provide some support to their claims, economists at PUC-Rio marshaled empirical evidence on the assumptions of $a=1$ and $\hat{p}=\hat{p}_{-1}$; that is, indexation was believed to impose, at that time, a full-memory to the price system, generating the fully inertial component in the absence of shocks. However, the conflict dynamics was formally deemphasized in their narrative, by recognizing that incomes policy pursued by the government was the chief cause of the systematic cost-of-living wage adjustments. From this viewpoint, we could then formalize the conflicting claims component as a function of the difference between average and effective real wages as follows: $\left[c=c\left(\frac{\bar{\omega}}{\omega}\right)\right] ; c^{\prime}>0$. Conflict would thus raise the level $(c>0)$, but could not explain the inherent momentum, of inflation (given by the parameter $a$ ). ${ }^{173}$

To sum up, the principal assumptions behind the differences between the inertialist groups regard firms' mark-up behavior and workers' aspirations. This distinction reflects above all the more or less specified form assumed by "distributional conflict" in these inflation models. As we have seen, both sides share the concept of "inflationary equilibrium", in which changes in the regime of nominal wages readjustments would only stoke up prices, leaving average real wages unaffected. However, the forces driving this equilibrium have slightly distinct properties. ${ }^{174}$ Antagonism between groups collapses into an assumption about labor market institutions, bypassing the complexities of economy-wide distributional dynamics. ${ }^{175}$ Workers' aspirations are formally given an exogenous upper bound, to which

imported intermediate goods). Adjustments would face a price frontier that inversely relates real wages $(w)$ and exchange rate $(e)$, which provides the "distributional equilibrium". Formally, $\phi(w, e)=0 ; \phi_{1}^{\prime}>0$ and $\phi_{2}^{\prime}>0$. Exchange devaluations would imply reductions in real wages. Additionally, an inverse connection between inflation rates and the level of average real wages concludes the model, whereby $w_{m}=\psi(\xi, \widehat{P}) ; \psi_{2}^{\prime}>0$. Once again, conflict is but an original inflationary pressure (such as $c>0$ ), but takes no role in perpetuating inflation.

${ }^{173}$ In this situation, Simonsen (1970) has conveyed that the government swapped the arithmetic of incomes policy for the distributive conflict determinants of inflation. Workers' aspirations are not taken into consideration substantively. The best they can achieve is their ongoing relative position previously to the perturbing shock.

${ }^{174}$ Similar analysis can be found in Taylor L. (1979, 1983) and Ros (1984). For Bresser Pereira and Nakano (FGV-SP), inflation is but a symptom of the inherently conflictive character of the capitalist economic system, whereas in most of the later PUC-Rio models ${ }^{174}$, it is the staggered structure of government-sponsored wage indexation scheme. This latter modeling strategy demotes social conflict from a substantial first-order determinant of inflation to a simple shifting factor, in line with Tobin (1981).

${ }^{175}$ Ros (1988) takes up on this issue rather straightforwardly, by specifying that: "Pricing in the private sector is such as to achieve a given profit markup on current unit costs, and so the profit share of gross income is also unaffected by inflation. This assumption of markup resistance (or "real profits resistance") is a simplifying one, and is meant to dramatize a common asymmetry in capitalist and workers pricing policies, reflecting a situation 
they must rationally look up to, so as to at least maintain their relative position within the structure of claims on output. No discussion is carried out as to why this peak real wage should remain constant. In its place, the institutional detail of indexation is a recurrent theme in the models crafted on these static properties of workers' behavior. It fulfills the blanks regarding workers' rationality premises. The first involved explaining why workers bothered claiming for nominal wage increases, if their efforts are self-defeating in the inertial inflation case $(\widehat{w}-\hat{p}=0$ or $\omega=\bar{\omega})$. The second question implied providing analytical support to the notion that workers would choose to link wages to past inflation $\left(\widehat{w}=\hat{p}_{-1}\right){ }^{176}$

It is rather telling that such features would pose any trouble to these scholars. If we recall the works by George Perry (1980), Charles Schultze (1981), Arthur Okun (1981) and James Tobin (1981) on the self-sustaining thrust of inflation, they relied on conventions, norms and general institutional details, which were deemed perfectly suitable factors accounting for such a behavior. Given their academic background, it is yet more puzzling that the economists at PUC-Rio found it hard yielding to an argument based on such ad hoc assumptions points to the self-imposed requirement of conforming methodologically, in some degree, to the emergent phenomenon of the rational expectations canon. At some point, the argument goes, forward-looking indicators would have to override workers' behavior.

This requirement engendered enormous analytical trouble. An easy way to "have the cake and it eat it too" consisted in assuming several exogenous unanticipated shocks coming from government-endorsed policies such as monetary correction of public taxes and of public utilities fees, maxi-devaluations of the domestic currency, increased frequency of wage adjustments and so on. Under such circumstances, relative price changes would fool workers into "money illusion", which would trigger wage bid-ups in the subsequent period. In the absence of such shocks, however, it became rather uncomfortable to couch the self-sustaining behavior of inflation on workers' adaptive behavior.

where the balance of market power in favor of sellers in the product markets is much more pronounced than in the labour market. All this leaves the wage share and the real wage to be determined as residuals (...)". And, to reinforce the point we have just made above about assumption on the labor market, he claims: "The asymmetry is common at least in Latin American countries and models. In this respect, the latter differ from Scandinaviantype models of inflation where - due to centralized wage bargains in the labour market, strong international competition in product markets and a regime of fixed nominal exchange rate-profits, rather than wages, are the residual share".

${ }^{176}$ Serrano (2010, p. 408-410) was able to find ways out of these puzzles, by switching the value of $x=1$ to $x<1$; that is, by turning their model into a likened variant of Bresser Pereira \& Nakano (1984). 
The second solution to this rationality puzzle was found in the relative wage dynamics, a shortcoming that Arida (1982) had previously underlined without raising any alarm. A copious literature of the 1960s and 1970s had shown that discrepancies among wages in different industries could give rise to catching-up behavior of labor compensations that would create sustained cost-push pressures on inflation, rendering price indices inflexible downwards (see Laidler \& Parkin 1975). This inter-sector wage dispute solves the problem but leave open the question of how workers obtain the information concerning wage adjustments in other sectors. Besides, why should workers disregard in today's wage bid, as in backward induction, future wage adjustments claimed by workers in other sectors as a response to the disequilibrium generated by today's claim? What would prevent the explosive behavior of wage claims? The answer lies in one expression: wage indexation. Propagation mechanisms had taken over the determination of price setting behavior. Success in stabilization could only be achieved if this problem were adequately addressed. Curbing inflation then could not avoid dismantling the widely indexed price and wage structures.

However differently each camp saw it fit to classify the causes of inflation and its propagating mechanisms, the nature of policies required to deal with them were not in dispute; both sides of the structuralist camp disparaged any hope leveled at the efficacy of demand-management anti-inflationary measures. Alternatively, stabilization of prices should be achieved through an adequate management of wage policy coupled with a disciplining of mark-up rates. Conflict should be ameliorated somehow by way of a social pact. The question came down to one point: would society adhere to it in a voluntary or compulsory fashion?

Next section addresses the policy implications of the PUC-Rio approach, that is, the requirement of distributional neutrality. For now, it suffices to single out that economists in both camps frequently used the term "distributional conflict", but with different meanings. The way the former group, from PUC-Rio, took up on this concept was quite dissimilar to the legacy of CEPAL, to which Bresser Pereira and Nakano (1984) are eminent successors. Our point is that this very diversity of approaches marching under the banner of the "inertial inflation hypothesis" opened up a breach in its internal consistency. Once the model was put into practice and reality proved resistant to the policies derived from it, external consistency went under heavy fire. The fast-paced evasion of the small group of PUC-Rio economists from the inertialist camp concluded the destabilizing process of the theory it was supposed to deliver. 


\subsubsection{The binding neutrality condition}

A successful stabilization should see to three binding conditions. First, the structural distributional incompatibility had to be stabilized, which meant keeping steady the difference between negotiated and actual wages. Second, the wage indexation had to be suppressed and, third, the system's inflationary memory had to be wiped out. It should be sufficiently clear by now that these aspects are not independent from each other. For instance, transposing the distributional profile from a highly inflationary environment to one where prices rise only moderately amounts to reproducing the previous inflation-breeding distributive structure. Wiping out the inflationary memory would become, under such circumstances, almost impossible, and therefore, the same could be said of eliminating wage indexation schemes.

Following Tobin (1981), Bacha (1988), pointed out that inertia could be understood as a coordination problem inside a soccer stadium, where the crowd stands in order to watch the game, when it would better suit the spectators to sit down. However, that would only be obtained if everybody sat simultaneously. It would require the referee (meaning the government) to stop the game and threaten to proceed only after everyone has sat down. In economic terms, inflation is a result of unsynchronized behavior in price and wage adjustments. This diagnosis entailed a policy prescription that would bring all incomes to their average levels - and hence to mutual consistency -, therefore discouraging agents to try and run ahead of inflation - or, metaphorically, standing up again on the bunkers in order to get a privileged view of the game. ${ }^{177}$ This is termed the "distributional neutrality" condition for a sustainable stabilization, and it had two facets. ${ }^{178}$ The first implied achieving the conditions for distributive neutrality at the analytical level. The second was sought after at the policy level, albeit conditioned by the former, to which we now turn in more detail.

Lopes (1986, chapter 6) provided a rather didactic exposition of the "inflationary process", which is remarkably telling of the way economists at PUC-RJ pictured inflation. The starting point is the typical neo-structuralist national accounting identities, as in Taylor

\footnotetext{
${ }^{177}$ Franco (1986, p. 23) also noted that indexation cut the link between "the 'height' of the Phillips' trade-off" and the inflationary expectations, thus having to do with "problems involved in engineering coordinated wageprice restraint as part of a stabilization effort".

${ }^{178}$ Unlike Tobin's story, nothing is said about the people that could not get in to watch the game. To reinforce the argument forwarded in the previous section, the conflict story thereby told takes as given the underlying pattern of distribution of income as well as the productive capacity of the economy. By doing so, it becomes a rather different one. Conflict becomes exogenous - a shift factor - to the problem at hand: the coordination of agents' expectation within a commons problem. (Biderman et al., 1996, p. 238).
} 
(1983). After constructing both the indexed wage equation and the inflation equation, closing the model allows us to attain the inflationary equilibrium:

$$
\hat{p}=\hat{p}_{-1}+\delta \hat{n}^{*}
$$

in which $\hat{n}^{*}$ denotes the change in nominal mark-up rates and $\delta=\frac{n_{-1}^{*}}{1+n_{-1}^{*}}$; as usual, "hats" over variables indicate proportional rates of change. In this simplified version, inflation drifts are caused by variations in mark-up rates. Should firms stick to the average profit rate of the economy, the inflationary equilibrium is guaranteed. But how do wages behave in this economy? Whenever inflation exceeds expectations, firms adjust their mark-ups to maintain real profit rates. By contrast, when inflation rises, real wages are eroded and income distribution is shifted in favor of firms. To see that more clearly, we can define $\sigma=\frac{w N}{p Y}$ as the wage share, which can also be written in terms of real wage $(\omega=w / p)$ and labor productivity $(Y / N): \sigma=\omega / e$. Taking logs and then time-derivatives gives us the rate of change in the wage share: $\hat{\sigma}=\widehat{\omega}-\hat{e}$; the author also defines a target inflation rate $\left(\hat{p}^{*}\right)$ workers take into account during the bargaining process. Lopes reached the conclusion that altering the inflation target affects the distribution of income by the following relationship:

$$
\hat{\sigma}=\hat{p}^{*}-\hat{p}
$$

This result unveils the daunting difficulties involved in any stabilization plan. Whatever outcome should hold which differs from workers fully achieving the targeted inflation rate implies a change in the distributional profile of the economy. If targets are underestimated, wage share is reduced from its inflationary equilibrium point. By contrast, if policy is more effective than predicted, distribution shifts in favor of wages. In the final analysis, inflation will be curbed by use of policy instruments to suppress claims from agents facing relative income losses. How should this be achieved? We must now turn to policy design.

In the model sketched out above, as we have seen in Arida's (1982) model in section 5.2 , a monetary contraction or a policy of price controls would necessarily imply a downward adjustment of the mark-up rate. Therefore, an adequate policy of wage control should accompany such disinflation measures, in order to maintain intact the pre-stabilization distributional profile. ${ }^{179}$ Needless to say, achieving such a result in the real world would

\footnotetext{
179 The analytical limits of the model were disquietingly narrow, for they left out the solution to distributional effects across firms and across labor groups, as well as functional distribution categories. This hurdle pointed to
} 
prove much more complex than theory allowed one to grasp. Besides, a whole range of details were only seen within the scope of partial equilibrium analysis, such as exchange rate management, the conversion of tax collecting intervals and interest rates to the new state of low inflation, as well as the portfolio adjustments during the transition. Chapter 6 aims at assessing the feedback effects of the theory's policy performance.

one additional problem: the inter-sector lack of synchronism of wage and price adjustments. Eduardo Modiano (1988) proposed one way around this obstacle that consisted of gradually coordinating contract adjustments by means of a set of conversion rules that steered all contract values towards their average real values, measured in a stable unit of account in the post-disinflation period. Doing so required that no major redistributions of income and wealth were attempted. If these conditions were to hold, a disinflationary "neutral shock" could restore the patterns of income and wealth distribution prior to disinflation. Underlying this neutrality condition was the notion that a fully inertial inflation kept real incomes dynamically stable at their average levels; or, as Furtado (1954) claimed back in the 1950s, it was distributionally and dynamically neutral. 


\section{Chapter 6 - The dilution of the inertial inflation paradigm}

The previous chapter forayed into the early theoretical debates on price stabilization policy during the 1980s, which reignited the contention between structuralist and monetarist (see Toye 1987 and Taylor 1988). This time it was directed at assessing the displacement of emphasis in the diagnostics of the causes of inflation in the PUC-Rio tradition, whose focus stood in contrast with the first-generation structuralist core analysis which stressed the institutional, political and structural forces that rendered inflation an inevitable - but in no way desirable - outcome of the process of economic development. We provided evidence that these economists narrowed the crux of the problem down to their "propagation dimension", leaving unexplained the primary causes of inflation. This chapter concludes our narrative pertaining to the second-generation structuralist transformation problem.

The unraveling of the fiscal orientation assumed by the scholars reflects a longstanding ambiguity in the structuralist theoretical framework as regards the tendency to accumulate public deficits and its intimate connection with chronically rising prices. This aspect was initially relegated to a second tier in the neo-structuralist framework. The reason is clear: the inertial inflation paradigm assumed that deficits were under control, the trade balance was not exerting pressure on the exchange rate and monetary aggregates held an endogenous relationship to inflation. As attempts couched on such assumption failed to control inflation, there emerged a growing recognition of the central role of fiscal matters in both driving the inflationary spurts and curtailing chronic inflation's life support. The growing of the fiscal dimension implied the belittlement of inflation inertia's priority in their general understanding. Whether this was intended or not, these economists' views on inertia started to converge to the meaning it was given at the international level of the economics profession.

This chapter investigates two underlying forces that provided the backdrop to this narrowing down of their views on inflation. First, the failure of the real-world application of the inertial inflation paradigm (the Cruzado debacle) raised several doubts as to the adherence of the analytical framework to the economy's conditions when the plan was announced and to the subsequent developments not accounted for by the theory, namely: the theoretical assumptions regarding the passive roles played by fiscal and monetary control during stabilization shed unfavorable light on the hypothesis that Brazilian inflation was dominated by its inertial component. Second, at the regional and international level of the economics 
profession, an academic consensus was being built; it aimed at finding a common ground on the centrality of monetary and fiscal policy to a successful stabilization procedure, whilst taking heed of the heterodox proposals (see Bruno 1993, chapters 1-3). Both these aspects will provide the context to better understand the demotion of the inertial inflation paradigm to a subsidiary component in a more general theoretical setting.

The sections below substantiate the claim that the works the scholars from PUC-Rio published along the 1980s gradually evolved from a seemingly distributional conflict approach - embodied in a relative wages model of inflation - to a fiscally dominated understanding of inflation, more compatible with monetarist-type of reasoning. First section briefly narrates the revision of the "heterodox shock" policy outcome in the aftermath of Cruzado Plan's debacle. The development of the inflationary crisis provided further refinement in the understanding of the dynamics of inflation in Brazil, which may have defined the magnitude of political constraints faced by any stabilization policy in the context of an accelerating inflationary process, a dimension markedly singled out by Persio Arida, one of the group's senior policymaker, as Cunha (2006, pp. 392-393) has indicated. We marshal textual evidence of the more pluralistic stand taken by these economists, characterized by a change in both focus and emphasis concerning the fiscal element, which receives increasing importance towards the end of the 1980s and becomes central by 1994 . The second section purports to show how Simonsen's $(1989,1995)$ synthesis bridges the gap between the inertial inflation paradigm and the more general New Keynesian approach to inflationary inertia, which has become the conventional approach to the matter in the postdisinflation period in Brazil. The third section weaves together the threads of the argument posited in the preceding sections with the message conveyed in Chapter 5.

\subsection{The ecumenical turn: inertial inflation as a special case}

The unequivocal structuralist reasoning echoes in all of the PUC-Rio authors writing in the 1980s. Bacha would later recall that this period was filled with a political drive towards restoring the democratic process in Brazil (Bacha 1998b). Structuralism provided a theoretical framework much in line with such aims, although it was later found to be a failed project by some of its followers, including Bacha himself (Biderman et al., 1996, p. 236). The idea of a social pact as a credible instrument to fight inflation was quite ubiquitous among heterodox economists from various traditions and it is present not only in Modiano's and Carmargo's interventions abovementioned, but can also be found in Bacha \& Lopes (1983) and in Tobin 
(1981). Such optimism would soon be frustrated by the Cruzado plan and the subsequent stabilization attempts. ${ }^{180}$

In retrospect, the economists at PUC-Rio now commonly state that post-Cruzado period provided important lessons concerning stabilization policies and the effectiveness of the assumptions made at an earlier stage. The relevance of public deficit control and the political coalition supporting it and the need for strict control over monetary policy evoked concerns aired by Tobin (1980) some time earlier. In addition, the previously held goal of neutral effects (in distributional terms) of a stabilization effort was deemed "wishful thinking". This reflected Lara Resende's (1989) assertion that "the purpose of curbing inflation is not focused at eliminating the conflicts that underlie the social structure, but to break the inertial behavior built in inflation". Whereas the root cause of inflation lied in the distributional conflicts, at the policy level, the neo-structuralist approach failed to provide the necessary monetary tools to fight the problem (Bacha 2003, p. 146).

In this sense, we venture to say that abandoning the pure inertial inflation paradigm implied, at least to some extent, resigning the affiliation to the structuralist school. However, one should anticipate that this change of heart was not an epiphany in its own right, but the outcome of fierce and multipronged criticism leveled at the theory undergirding the failed stabilization exercises, such as in Barbosa \& Simonsen (1989). We term this episode the ecumenical turn, in reference to Boianovsky's (2012) account of Celso Furtado's alleged orthodox turn when he became Brazil's Minister of Planning to launch his Three-Year Plan in early 1963.

The Cruzado plan debacle raised enormous amount of controversy among Brazilian economists. From the side of structuralists and broadly defined heterodox economists, revisionism of the theory underpinning the plan started soon after the surprise launching of the price and wage freeze coupled with a full-blown monetary reform. The main papers were compiled in a book published in 1989, titled The recent acceleration of inflation: inertial inflation theory revisited (Rego 1988). Amongst the various contributions concerned with the drivers of inflation's growing speed, we single out Edmar Bacha's (1988) take on inertia and conflict and André Lara Resende's (1989) newfound three-stage inflation taxonomy: moderate, chronic and hyperinflation. Afterwards, in order to offer a more complete account

\footnotetext{
${ }^{180}$ A detailed account of the history of such attempts can be found, in the English language, in Bastos (2002, chapter 6).
} 
of this turn, we tackle the similar move taken by Gustavo Franco, Persio Arida and Eliana Cardoso.

\subsubsection{Edmar Bacha and the growing of the fiscal dimension}

We start with Bacha's 1988 paper on Money, Inertia and Conflict to his 1994 paper on Inertia and Fiscal Policy. This enables us to portray how the discomfort with the inertial inflation hypothesis allowed this and other scholars find a common ground with more orthodox reasoning, especially regarding the relevance of fiscal tightness and monetary stringency to the success of anti-inflation policy measures.

Bacha (1988) extracts lessons from the Cruzado Plan, the first Brazilian stabilization experiment based on the inertial inflation hypothesis. First, the plan denied importance to the control of public deficit and monetary expansion, considering them to be fully passive to an indexed economy. Such an outstanding disregard of the relevance of the inflation tax to explain the monetary expansion was compensated, in Bacha's view, by the notion that inertial inflation was a byproduct of imperfections present in price and wage setting, caused by a lack of coordination in such processes and by the existence of overlapping wage contracts. Therefore, a suppression of such imperfections by way of a widespread de-indexation policy would guarantee, by itself, "zero inflation".

The "pure inertial inflation paradigm" is first dismissed on empirical grounds. $\mathrm{He}$ singles out the irony that this hypothesis had gained political momentum and academic notoriety just as the assumptions that gave it support were being checked by reality itself. This statement suggests that inertia was not only a virtual trait of inflation, but pertained also to the theoretical understanding that tried to frame it. The empirical triumph of such an approach was based on the behavior of price indexes between 1968 and 1982, which was largely explained by the combination of external and agricultural supply shocks and changes in indexation regimes in the country. Considerable memory built in the time series are likely to have biased the empirical assessments that gave the theory support. In the early 1980s, prices escalated with increasing speed. ${ }^{181}$ Such acceleration is consistent with the excitement of

\footnotetext{
181 The incomes policy launched during the Government's Economic Program (PAEG), under the military intervention that started in 1964, was highly effective in controlling wages with a partial indexation scheme, which managed to keep the average real wage stable until 1985, when inflation-correcting mechanisms start to lag behind inflation rates and impose losses to real wages (Resende 1982). By then, the indexing system was borderline perfect.The significant compression in real wages and the control over workers' bargaining power in the beginning of this period managed to keep the average real wage somewhat stable, even under the strains of two oil-based supply shocks in 1973 and 1979 and of numerous changes in broad economic policy guidelines,
} 
distributive conflicts by the external debt crisis and the increasing labor unions militancy in augmenting the degree of indexation. All these took place in the context of political transition to democracy.

If these conjectures are right, it follows that the inertialist hypothesis had it moment of glory exactly when Brazilian inflation had lost its inertial character, in order to acquire accelerationist features, which could be explained both in monetarists terms and in conflictist terms, but not on strict inertialist ones - for they do not encompass an increasing endogenous indexation, nor the need by the government of a greater inflation tax than that generated by inflation inertia (Bacha, 1988, p. 13 - Portuguese in the original).

As a result, removing the obstacles to stabilization, Bacha added, required a consensus among all contending groups of economists. According to him, the failure of heterodox experiments underlined that inflation was no longer a matter of theoretical and empirical acuity. It had become a problem of policymaking and political support. All views were right in their own terms. And yet, they failed to see the whole story. Putting them altogether made it possible to comprehend the suitable constraints to be imposed upon the political dimension of the stabilization procedure. That inevitably led to the framing of fiscal imbalances.

The close reading of Bacha's works reveals a trajectory of change that might be easily described as an orthodox twist (Bastos \& Mello Neto, 2008). Alternatively, we propose that this is only apparent, and that a gradual change may also be viewed as a development process of previously held assumptions found in his earlier models of inflation. He had flirted with orthodox conclusions regarding the importance of fiscal aspects to understand inflation dynamics, albeit departing from strict heterodox reasoning. By the early 1980s, he had displayed a (milder) concern for fiscal dynamics and its impact on long run growth.

For instance, in a conference on the effects of 1982 Mexican crisis Bacha's (1983) intervention addressed mostly the fiscal side of the crisis. The role played by the inflation tax in financing government investments had already been emphasized in this paper, while considering alternative policies for stabilization, the author aims to debunk the orthodox stabilization plan followed by the Brazilian government under President Figueiredo administration (1979-1985), starring Delfim Netto as Finance Minister. On another occasion Lopes \& Bacha (1983) sustained that "a monetary deflationary shock will ceteris paribus 
produce (...) not just the usual temporary recession bubble (...) but also a permanent loss in the economy's growth potential" (p. 13). Alternatively, they argue, a combination of a monetary shock and a fiscal reform that increases government savings as a share of aggregate income would entail a compensation effect on growth rates, which would allow the economy to restore its pre-stabilization potential growth rate. ${ }^{182}$ As he would later note, in recollection of that period:

In the case of inflation, the fiscal matter emerged from the conception that, although government collected little inflation tax (due to the primacy of indexed money), inflation was important to eliminate the ex post (via inflationary erosion of expenses) public deficit inscribed in official budget. A credible halt of inflation, hence, demanded an elimination of ex ante budget deficit, which was obtained with the approval of a constitutional amendment that created the Emergency Social Fund and the subsequent voting of a (almost) balanced budget for 1994 (Bacha 2003, p. 149 - Portuguese in the original).

This somewhat curious outcome of an inflation-eroded public deficit was termed "reverse Olivera-Tanzi effect", for inflation acted to reduce expenditures faster than it eroded revenues. Brazil would sit on the "bad side" of a Laffer curve. Therefore, a consistent process of stabilization required more than sharp disinflation. It demanded a complete restatement of the terms by which the distributional conflicts would be expressed and negotiated. Among the various forms by which this can be accomplished, it is clear in later writings that the path chosen was to shift such conflicts to the fiscal dimension of policy by way of a sound and realistic public budgeting process, where social aspirations would be channeled according to the political forces composing the Legislative Congress (see Bacha 1998 and Franco 2005). By this token, irrespective of the original causes of inflation and its sophisticated propagation mechanisms, in the end inflationary processes funnel down to uncontrolled public finances (Bacha 1994 and Franco 1995) and adverse portfolio shifts in the post-disinflation period, as we will see below, when we go over Arida's (1992) thesis.

\footnotetext{
182 The paper has a closing with the following assertion, quoted at length below: “... the paper builds on previous work of Brazilian economists to propose a tentative outline of an alternative macroeconomic model for the study of stabilization policies in Brazil. We argue that a 'stabilization crisis' is not necessarily the main cost of an orthodox anti-inflation program: The potential output growth rate may be permanently reduced as a consequence of such policies. Barring the adoption of a wage squeeze, we suggest that a fiscal reform that increases government savings be put in effect, in order to avoid the growth reducing consequences of a monetary control program" (Bacha \& Lopes, 1983, p. 17 - underline added). One should not be struck by this emphasis on fiscal matters, for the concern with runaway fiscal deficits propelling inflation was not an exclusive orthodox plight. In fact, Keynesian economists were adamant in defending the effectiveness of fiscal policy in stabilizing an inflationary economy (see Tobin 1981).
} 
Edmar Bacha's journey is hence illustrative of this move toward a negotiated compromise with orthodox views. For one, Bacha disconnects the inertial inflation approach from conflict-based models of inflation, which reinforces our previous claim that distributional conflict was loosely defined in the PUC-Rio analytical framework. ${ }^{183}$ Secondly, he demotes the inertial inflation hypothesis from its centrality in policy debates to a more modest supporting role in the overall stabilization plot - generating counterintuitive fiscal effects, for instance. Finally, at the theoretical level, his works on inflation from 1983 until 1994 evoke - with several qualitative adjustments - the overall understanding shared by the basic New Keynesian framework put forth by Stanley Fischer's (1986) comprehensive volume on indexing, inflation and economic policy. Bacha (1998b, p. 208) himself has confessed that the reemergence of the New Keynesian school in the 1990s has allowed him to reconcile with the "mainstream" of the economics profession, after the neo-Keynesian "debacle" of the early 1980s. ${ }^{184}$

\subsubsection{André Lara Resende and the taxonomy of inflation}

In his interview to Biderman, Cozac \& Rego (1996, p. 305-310), Resende reminisces over the 1980s and goes to some length to disparage the explanatory power of the distributional conflict story: "I have come to the conclusion that the view of inflation as distributive conflict is almost tautological. Any inflation theory can be reformulated as a distributional conflict" (p. 305). "The argument is not necessarily false on its own but adds little to the understanding of the phenomenon" (p. 306). In what seems to be a reference to first-generation structuralism, he claims that one can accept "the idea that inflation has some functionality. It is a way to create forced savings" to sustain a fast-paced process of industrialization, which fits well within this framework. "But, I insist, the notion of

\footnotetext{
${ }^{183}$ Like many of the PUC-RJ economists taking part in the stabilization plans in Brazil was linked to Taylor's and Dornbusch's academic network. Given their privileged status within the Brazilian economics profession, attaining a $\mathrm{PhD}$ abroad practically implied a one-way street from theoretical speculation to policy-making. As we have seen in section 5.2, Bacha's case is particular in that his academic endeavors have always mixed empirical matters with small-scale models that provide fruitful insight into the matter of concern (Bacha \& Taylor, 1977).

${ }^{184}$ By this token, it is not striking that the PUC-RJ economists' concerns were steered away from purely theoretical achievements and towards policy-oriented efforts. At that time, the very definition of "theory" was hotly debated among various strands of economic approaches; by "theory" in strictu sensu, we mean the abstract analytical reasoning derived from first-principles $a ̀$ la Arrow-Debreu, which was brought to macroeconomics by Chicago economist Robert Lucas and colleagues in the late 1970s, with their search for microfoundations of macro theory. The scholars from PUC-RJ were situated in the opposite pole of this emerging contention, more akin to the North-American structuralist economics of Lance Taylor and Rudiger Dornbusch and the Neoclassical Synthesis Keynesian economics worked out by Don Patinkin and James Tobin.
} 
distributive conflict seems insufficient to me, almost devoid of any meaning" (p. 306). He sides, almost verbatim, with Bacha's (1988) conclusion that the persuasive power of the conflicting claims story is that it strongly appeals to the non-specialist, for its intuitive ring.

In contrast with the approach mentioned above, Resende refers to an attempt he had made while a $\mathrm{PhD}$ candidate at the MIT to generalize, in mathematical terms, the argument posited by Azariadis (1975). Resende believes to have shown that in the presence of implicit contracts, there is a rational justification (in maximization terms) for the existence of sticky wages. He then credits John B. Taylor (1979) with having proved that the presence of staggered contracts can generate inertia, even if rational expectations are assumed (Biderman, Cozac \& Rego 1996, p. 307-310). He alerts to the point that inertia in a moderate inflation differs from that of a chronic inflation, which takes us to his 1989 paper on the taxonomy of inflationary regimes.

Resende ([1989] 1994) re-labels the inflationary regimes and de-emphasizes the idea of a fully inertial inflation down to a simple recognition of an "inertial component" of inflationary processes, which tend to vary according to the level and persistence of inflation. In a moderate inflation, this component is dwarfed by the emergence of aggregate demand pressures, only to become more pronounced in a chronic inflation, whereby the public deficit and other imbalances among relative prices can, at best, attenuate or aggravate the pace of price rises, but fails to explain the level of inflation. Thus, under this regime, inflation may speed up steadily while the economy enjoys a balanced budget and explicitly positive results in the Balance of Payments (p. 16).

Curbing this autonomous process requires bridging the silos of structuralism and monetarism. Chronic inflation required breaking down the inertial component, but a more balanced view led Resende to invite orthodox elements, such as strict monetary control in the immediate post-disinflation period and the downsizing of public deficits, in order to make the latter compatible with the non-monetary sources of finance within the limits of the expansion of domestic credit. These orthodox elements would go a long way in tying expectations around a nominal anchor, a function to be fulfilled by the exchange rate, wages and other key prices (Resende [1989] 1994, p. 17-18).

In retrospect, he's evaluated this paper as a "rhetorical effort" to convince mainstream economists that the inertial component deserved more attention (Biderman, Cozac \& Rego 1996, p. 308-309). In doing so, he managed to turn the chronic inflation regime into an outgrowth of a moderate inflation wherein indexation arrangements were highly disseminated 
across the price and contract structures. Its protracted predominance over inflationary trends can very well lead out to an open hyperinflation. Resende ([1989] 1994) underlined the central role played by expectations, which a stable and widespread system of indexation tends to discipline and order. However, a deterioration of the public's trust on the substitutes of legal tender likely to arise in chronic inflations leads expectations to grow more disorganized and economic activity is bound to be hampered, reinforcing distributional conflicts that saddle the economy on an inflationary spiral (pp. 23-26). Thus, for the author, expectations provide the trigger that takes the economy from a chronic inflation situation to the explosive pattern observed in the historical episodes of hyperinflation, which raises the question: how do expectations break free from the discipline imposed by formal indexing arrangements? Unfortunately, Resende makes no clear statement on this matter.

Resende's ([1989] 1994) taxonomy can be construed as an evaluation of the status held by the inertial inflation paradigm within the broad corpus of the economics discipline, namely: an intermediate stage to the stereotypical two-stage monetarist taxonomy contemplating only moderate and hyperinflation. ${ }^{185}$ Recall that, during the stabilization debates, Resende (1985, p. 17) was adamant in stating that "heterodoxy" was characterized by " a better understanding of indexing mechanisms" but, he went on, once these latter have been superseded, "we will have an economy just like any other, with stable prices and one-digit inflation", a circumstance in which "there is no escape from orthodoxy". The key question concerning heterodox economists was, per his claim, how to de-index the economy, so as to restore the effectiveness of orthodox policy instruments. Once this was done, the inertial component would shrink to levels observed in moderate inflations and explained by implicit and staggered contracts.

\subsubsection{Gustavo Franco's microfoundations to inertial inflation and thereafter}

The same methodological turn can be found in Gustavo Franco's works. In his $\mathrm{PhD}$ thesis submitted to Harvard on the Aspects of the Economics of Hyperinflation, Franco (1986, chapter 3) proposes a theory of inflation inertia. He defines it rather loosely as "the process by which the economic system transforms past inflation into current inflation". Inertia is not necessarily connected to the determinants of inflation, and may be "related with a number of institutional factors and rigidities that are unrelated with the 'fundamentals' of the process".

\footnotetext{
${ }^{185}$ It is important to recall that Simonsen had pointed out to this omission by monetarism in his 1970 book on inflation.
} 
He attempts to "set up the inertia problem on a more general framework", which is done by developing "the notion that inflationary inertia is naturally generated by the strategic behavior of rational economic agents within an inflationary environment". He then claims that, similarly to Keynes's claims regarding labor unions, inertia "should not be seen as an ad-hoc rigidity vitiating the market mechanism but as quite an organic feature of large capitalist economies" (p. 48).

Franco makes three claims worth mentioning here, given our purposes. First, that momentum inflation should not be viewed as the result of expectations alone, as in Sargent (1982). Rather, in chronically inflationary economies, expectations are subdued by the dissemination of formal and informal mechanisms of indexation, which entail "a pattern of 'automatic' wage-price reactions to observed inflation that would change very fundamentally the nature of inflation inertia" (p. 50). Indexation is shown to be an organic feature of capitalist economies by a formalization of rational decision makers that must decide whether or not they should enter into indexed contracts based on the inflationary environment surrounding them. The strategic behavior of both firms and workers brings out not only the predicting ability enjoyed by agents, it stresses the "incentives and economic mechanisms" involved in the adoption of indexation (p. 23). These incentives rely on the uncertainty regarding future inflation and on the risks embedded in nominal contracts which embody inflation forecasts. An insurance premium is paid by workers and firms in order to adopt indexing arrangement. This premium is thus said to reflect agents' degree of risk aversion. Workers face a choice between a real wage known with certainty (indexed contracts) and a "lottery" by which they sign a nominal contract for the next period based on their inflation expectations. Firms choose between a regime with wage costs fixed in real terms (indexation) and a regime in which the real value of their wage bill depends on the extent to which inflation expectations embodied in labor contracts are mistaken. As inflation levels rise, the variability of relative prices is increased, rendering inflation forecasts less reliable. As a result, chronic disagreement between firms and labor as regards the adoption of indexation vanishes once some critical level of inflation is surpassed, so that the willingness of workers and firms to adopt indexation is consistent with each other (p. 23-25). Franco (1986, p. 28-29) formalizes firms' behavior as follows:

$$
\begin{aligned}
& \hat{p}_{t}^{F}=\hat{p}_{t} \quad \text { if } \widehat{w}_{t}=\hat{p}_{t}^{e}<\hat{p}_{t} \\
& \hat{p}_{t}^{F}=\hat{p}_{t}^{e} \quad \text { if } \widehat{w}_{t}=\hat{p}_{t}^{e}>\hat{p}_{t}
\end{aligned}
$$


where $\hat{p}^{F}$ is the price change in the goods market, $\hat{p}_{t}^{e}$ and $\hat{p}_{t}$ are the expected and actual rate of inflation, respectively, and $w_{t}$ reflect changes in wages. This rule means that whenever workers underestimate inflation, firms do not let it reflect of prices. Consequently, prices would tag along observed inflation and absorbing worker's money illusion as "a temporary improvement of their profit margins" (Franco 1986, p. 33-34). This reasoning points to the discomfort firms face in adopting indexation under low inflation. Depending on their market power, in clear evocation of Kalecki's (1943) notion of "monopoly power", firms would choose when to transmit wage increases onto costs according to the above asymmetric response rule.

Franco asserts that strategic behavior of rational agents is likely to engender the widespread use of formal and informal indexation, which in turn reinforces the inertial component of inflation. But next he finds that individuals gather in class-related groups sustain different levels of this inertial inflation outcome. This leads us to the second point. Franco finds that inertia has two dimensions: one has to do with the degree of cooperation amongst individuals and the other relies both on the average length of wage contracts and on the degree of synchronization among wage contracts negotiations. As regards the first dimension, when agents are allowed to interact with each other and take heed of this interdependence, there emerges a Nash equilibrium which is not Pareto optimum, wherein non-cooperative behavior tends to generate stronger inflation inertia than under cooperation. Franco is then led to conclude that inertia is inversely related to the degree of "social consensus", so that a large decentralized economy would be more prone to inflation inertia than "a more centralized and corporatist society with 'fewer' and 'larger' agents" (p. 54). In the second dimension, it is of paramount importance to a reasonable level of synchronization the "degree of unionization and also some more 'structural' factors directly related to union's strength, such as, for example, the presence of a large informal sector or of an overcrowded backwards agricultural sector" (p. 69). A more scattered structure of labor unions, within and among industries, is bound to conduce to heightened tensions and rivalries with respect to relative real wages than it would in the presence of large or multi-industry unions.

Finally, and upon the argument just raised above, the third point refers to his definition of a "purely inertial inflation". One interesting result that comes out of his analysis is that a certain level of price stability is compatible with several distributive equilibrium positions. By defining price stability as a non-marketable public good whose supply is beset by free-riding problems, Franco is able to make stability consistent with a long range of distributional 
profiles with endowments depending on who's paying for the public good and who is free riding. In this setting, a purely inertial inflation occurs when "relative prices/distributive shares do not need to be changed for the economy to pass from inflationary to the stable prices steady state” (p. 55), a variant of Furtado's (1954) early stand on neutral inflation (see chapter 4 above). Once the role of 'fundamentals' are assumed away, inflation results markedly from the inertial forces embedded in wage- and price-setting behaviors under the oversight of government agencies. Most of the analysis is carried out in terms of labor coalitions and of unions' "pushfulness", as well as membership issues taken up along gametheoretic lines. Only a subsidiary note adds that "the organization of business interests is equally important", and that the levels of industrial concentration matter much for coordination purposes (p. 69-70). At last, the State is seen as "a large employer and supposedly the repository of the national priorities but usually an ad-hoc manager of the distributive tensions", playing a crucial role in the coordination of economy-wide behavior. ${ }^{186}$

Our narrative benefits from Franco's work to the extent that the author painstakingly searches for a convincing set of microfoundations to inflation inertia, by couching them upon the strategic behavior of rational agents, whilst not overlooking the "social" dimension embedded in an inflationary environment and the problems that emerge by considering price stability a public good. His contribution to the understanding of inflationary processes exceeds, of course, the limited set of aspects we have highlighted here. It suffices to have shown, nevertheless, how inclined economists of PUC-Rio were towards fitting the theoretical novelties related to chronic inflations into the general canon of the economics profession. It remains to be shown if and how this choice of method led Franco away from explicitly considering power relationships, instead of simply assuming that workers and firms are fully empowered to decide whether to enter or not into indexation arrangements. Questions regarding the dynamics of bargaining power in an inflationary environment are understandably sidestepped in favor of assuming these aspects as exogenous variables. Even so, given the applied nature of his work, Franco's PhD thesis is compelling analysis of how chronic inflations can degenerate into hyperinflations and, as such, fulfills some of the analytical gaps left in Resende's (1989) taxonomy, as we pointed out above. ${ }^{187}$

\footnotetext{
${ }^{186}$ One can hardly escape making the connection between Franco's framework, couched on a variant of the commons problem, and Reder's (1948) "trilateral monopoly".

${ }^{187}$ An interesting development took hold after Franco submitted his thesis for approval at Harvard. In 1989, he republishes his thesis with a different title and a few changes (Franco 1989). For one, it stands out the removal of his heartfelt greetings to Lance Taylor's for his guidance, which proved "an invaluable source of energy and
} 


\subsubsection{The transition from inertial inflation to hyperinflation}

An important contribution to the subsequent debates on stabilization came from Bruno, DiTella, Dornbusch and Fischer (1988), in their book Inflation stabilization: the experience of Israel, Argentina, Brazil, Bolivia and Mexico. Modiano contributes to the volume with a lucid piece, trying to make sense of the Cruzado Plan and, as such, it is illustrative of the point we are trying to make here. Modiano follows the "income distribution conflict" framework we have seen in Chapter 5. His assessment of the shortcomings of the Cruzado Plan is telling of his unwavering allegiance to the idea that inflation is best understood as the outcome of ex ante inconsistency in the distribution of income (Modiano 1988 b, p. 216). We do not aim to sit in any judgments as to how historically accurate is his understanding of the plan's flaws. We are more concerned with his selection of explanatory variables accounting for the observed outcomes.

Modiano attributed the Cruzado debacle to the misperception of demand pressures built up before the plan's announcement, which imparted an accelerating component to an otherwise-viewed purely inertial inflation. Therefore, the heterodox shock was launched when inflation was moving to a new plateau and the inherent distributive conflicts were being resolved. Inflation was thus accelerating, ruling out the possibility of administering a neutral shock, at least not "before a new inertial inflation and a new income and wealth distribution was settled" (1988b, p. 223 - English in the original). In addition, the neutrality condition was violated by political commitments that push forth a $20,6 \%$ minimum wage bonus. By further igniting the heat on the demand side, the policy makers in charge of the plan infused a shift in the income distribution that violated the neutrality condition to the successful of disinflation, which jeopardized the broader goal of a sustained stabilization: "relative prices were frozen at levels that were not consistent with longer-term equilibrium and indexation was not fully abolished". Quite the contrary, the introduction of a sliding scale for wage adjustments

motivation along the way" and for instilling in him (Franco) "a lively reminder of how not to go the other way, namely to loose relevance in the name of rigor" (Franco 1986, iii). Second, as Bastos \& Mello Neto (2008) have also noticed, his new version of the analytical model that triggers hyperinflation "from outside factors" (such as massive devaluations of the currency), and not from 'fundamentals' out of place, replaces a distributional conflict model with a Phillips curve equation. Franco recalls that he was invited to publish his thesis soon after he submitted it. But the time and effort to update the bibliography that was spawned with new primary sources that appeared with the fall of the Berlin wall discouraged him from pursuing its publication (see Mantega \& Rego 1999, p. 385). It is not far-fetched to assume that the 1989 republishing reflected but an effort to update the analytical part of his thesis to the novelties in modern macroeconomics. Even so, we believe this to be a minor element in the overall narrative, and yet one more instance of the change in the economics profession at the time and their impact upon these scholar's arguments and their gradual return from theoretical rebellion. 
imparted a high-risk factor to macroeconomic stability, "as reindexation adjustments started to be triggered without a fixed periodicity" (p. 242).

Policy makers nurtured the belief that corrections of eventual imbalances inside the price structure could be made during the execution of the plan. This certainly did not help matters at all. Errors in the assessment of the economy's prior conditions led to the dissonance between theory and practice, which imposed insurmountable hurdles for policy makers to solve by use of limited fine tuning instruments. Therefore, once mistakes were acknowledged, it was left to "the scope and ability of policy-makers" to implement corrections. However, when the time for that came, "the same political constraints that helped to launch [the Cruzado Plan] on February 28, 1986, remained active, restricting the action of economic policy" (Modiano 1988b, p. 242). ${ }^{188}$

Cardoso (1988 and 1991) offers, in her turn, an account of Brazilian inflation throughout the 1980s that is most explicit in the ecumenical proclivity enjoyed by the scholars at PUC-RJ. Her comments to Modiano's (1988b) paper at the Conference we just covered above leave no doubt as to her gradual allegiance to a more balanced monetarist-structuralist approach of inflation. Already in 1988, Cardoso raises the binding problem of fiscal consolidation to heterodox programs based on price and wage freezes, a challenge made yet more difficult by the size of the public debt and the rather halfhearted effort made by policymakers in this regard:

Some [economists] among [the policymakers working on the Cruzado plan] argued that Brazilian inflation was different from that in other countries, and the budget deficit did not have a role in it; inflation was purely inertial, and all that was needed to stop it was a price freeze and some formulas to recalculate wages, rents, and future installments on existing contracts. Others denied the existence of the problem by putting numbers together that showed a zero budget deficit. (Cardoso 1988, p. 289 - English in the original)

\footnotetext{
${ }^{188}$ Modiano's account of the Cruzado debacle underlines the fact that prices were not set right before the plan was launched. By his account, imbalances in relative prices implied non-neutrality in the distribution of income, which propagated distortions to the rest of the price structure, distortions that the conversion rules were incapable of correcting. The technical difficulties in the conversion of rents and future contracts only added harm to foul, given the uncertain path of post-disinflation behavior of prices. These technical glitches eventually amounted to further distortions, as the monetary and fiscal policies were set to passive mode, owing to Arida's and Resende's (1985) claim that the decline in inflation would boost a non-inflationary demand for real money balances, as a consequence of portfolio shifts toward a stable new currency. Monetary policy was excessively lax and fiscal management fell prey to all sorts of political pressures that spurted expenditures far above the State's tax collection capacity (p. 235). Modiano's contribution can be viewed, in this sense, as upholding the early PUC-Rio approach, one that will be challenged by a colleague with a similar background.
} 
Cardoso bears data on the inflation-corrected deficit ration to GDP and finds that it amounted to $6 \%$ in 1985 , in stark contrast with the claim made by Arida \& Resende (1985) that 'fundamentals' were right at this very time. ${ }^{189}$ This does not mean that "the money-goods model of monetarism" becomes readily appropriate to the Brazilian economy. Instead, she points out that inflation in the country was not explained by monetized deficits, but by institutional features of the financial markets in Brazil and the country's growing external debt. In this regard, she finds that in Brazil, equality between inflation tax and seignoriage does not hold, for "an increase in inflation increases the inflation tax but also increases velocity and reduces seignoriage" (p. 290). The role of deficits in sustaining inflation "has to be understood in light of changing sources of financing the budget and the economy". The acceleration of inflation in Brazil from 1979 to 1985 is thus "linked to the switch from external to domestic finance and to the larger trade surpluses that pushed up interest rates and inflation" (p. 294 - English in the original).

Three years later, the author stressed her agreement with the general opinion, conveyed in Barbosa and Simonsen (1989), that the failure of the Cruzado plan had to do with "an extremely loose monetary policy coupled with a lack of fiscal austerity"; also, under the pressure of repeated price controls, the variability of inflation increased and, "the decline in tax collections and the growth of interest payments on a ballooning domestic debt have been building up a massive fiscal problem" (Cardoso 1991, p. 143 - English in the original). More than that, Cardoso's analysis was now couched on a simple model that introduces financial markets and interest rates in the "traditional (Cagan-style) model of inflationary finance with rational expectations". Moreover, she claims: "It assumes inflation inertia. This means that inflation in the current period reproduces inflation in the previous period. Inertia occurs through the existence of formal and informal indexation interacting with a staggered setting of wages, prices, and financial contracts" (p. 143 - English in the original). ${ }^{190}$

\footnotetext{
${ }^{189}$ By "fundamentals", Cardoso means the balances of government budget and external accounts. The latter had a positive value, at the time the Cruzado was launched. The same does not apply to the fiscal deficit, the point around which the controversy set in.

${ }^{190}$ The interest rate performs the role of jump variable, generating fluctuations of inflation relative to previous periods. Inflation is set to respond to deviations of real interest rate $\left(i_{t}-\pi_{t}\right)$ from full-employment real interest rate $(\rho)$ with a fully indexed economy, in the Friedman-Phelps accelerationist sense: $\pi_{t}-\pi_{t-1}=\phi \cdot\{\rho(g)-$ $\left.\left[i\left(h_{t}\right)-\pi_{t}\right]\right\}$; where $\rho$ is a function of the share of government expenditures in GDP, denoted by $g$, and the nominal interest rate $i$ depends upon the values of the ratio between real cash balances and real income $\left(h_{t}\right)$. This equation implies, according to Cardoso, "the existence of both inflation inertia and a scope for monetary policy to affect inflation" (Cardoso 1991, p. 155). The model does not depart much from Bacha's (1994) fiscal model of inflation, in the sense that it is aligned with monetarist-type models and in that it engenders two equilibrium positions, one good and stable low-inflation point and a bad, unstable high-inflation position.
} 
The core idea is that should governments attempt to halt inflation by means of price controls without the necessary fiscal effort to reduce the debt-burden on government budget, inflation is most likely to pick up once controls are lifted (p. 161). Cardoso then addresses the "recent analyses of inflation" which, according to the international literature of the time, can be divided into the fiscal view and the balance of payments view (p. 164). The former attributes the fundamental source of inflation to monetary emissions aimed at financing budget deficits, whereas the latter links inflation to exchange rate depreciation triggered by balance-of-payments crises. Cardoso's conclusion is that we started off with an exchangerate-infused inflation in early 1980s and, under the pressing demands to service interest payments on the external debt, Brazil moved to the fiscal model of deficit-monetizing primary emissions, which have "evolved into a massive fiscal problem" (p. 169-171).

Let us see why this change in perspective is simply a shift in emphasis. In an earlier paper Cardoso (1980b) concluded that the rough structuralist argument of inflation caused by relative price disequilibria fit the empirical data rather poorly. The results of her econometric exercise indicated, alternatively, that pressures of prices on fiscal deficits and monetary accommodation were, in fact, the statistically significant factors. This did not mean, however, that the structuralist theory lacked empirical support. Rather, she sustained that primary pressures acted through budget deficits and money supply expansion, which fulfilled the roles of the propagating mechanisms. As it so happens, Cardoso (1980b, p. 335) argued, this "fiscalist explanation, so-called monetarist", is entirely consistent with the structuralist stand on passive money. ${ }^{191}$ Hence, she added, structuralism approaches modern macroeconomic theory by stressing the relevance of the fiscal and monetary aspects, as well as that of wages and exchange rates in inflationary processes.

Finally, the indexation problem: Cardoso (1991) stressed that doing away with indexation is not essential to achieve inflation stabilization, because while "indexation contributes to the propagation of inflation, it also protects against the kind of volatile inflationary acceleration" that occurred in the aftermath of the Cruzado plan in 1986-87. Additionally, "[i]ndexation establishes inertia at a lower inflation rate, locking in disinflation gains", whilst also facilitating "political acceptance of a stabilization program, an attribute whose importance cannot be overestimated" (p. 172). In his comments to Cardoso's paper,

\footnotetext{
${ }^{191}$ The emphasis on fiscal matters when analyzing the causes of inflation is usually associated with the IMF's conditionality clauses, as they were imposed upon those governments constrained by the external debt crisis initiated in 1979. Fiscal austerity and monetary parsimony were viewed as hallmarks of a propensity by this institution to interfere in national sovereignty.
} 
Arida ([1991] 1992) took issue with this conclusion and, in doing so, advanced on the understanding of indexation and its relationship with inflation inertia. We take that in the next section.

For now, the sample we have taken out of Cardoso's work leaves little doubt as to the more welcoming position regarding some of the monetarist conclusions pertaining to the importance of fiscal matters, while not abandoning the opinion that inflation inertia matters. Nevertheless, inertia was relegated to a subsidiary role in her analysis, whether inflation was seen through the lenses of the fiscal view or of the balance-of-payments view.

\subsubsection{Persio Arida's eclectic statement of the inertial inflation paradigm}

The papers we have just assessed were presented in the 1986 Conference (Bruno et al. 1988), at which occasion several stabilization experiments launched in the countries were analyzed, and where Modiano and Cardoso made the contributions just seen above. A few years later, another Conference was held (Bruno et al. 1991) which aimed to update the knowledge shared in the first meeting. ${ }^{192}$

In his opening remarks to the volume that reports on the conference, Michael Bruno tackles the "quasi-stability of that [high chronic] inflation", which comes from "an inherent inertia" that is "strongly tied up with a high degree of indexation or with accommodation of the key nominal magnitudes (wages, the exchange rate, and the monetary aggregates) to the lagged movements of the price level" (p. 1). In anticipation of his 1993 book on the "therapy by consensus", Bruno readily asserts that "the origin of this process [of galloping three-digit inflation], as of its hyper brother, lies in government finances", and therefore, its cure "must perforce involve the same sharp orthodox fiscal and monetary measures", as long as "supplementary direct intervention in the nominal process" by means of incomes policies is carried through to deal with inflationary inertia (p. 1). Most of the participants at the conference also emphasized the need to observe fiscal matters, so as to balance the heterodoxearned "reputation of fiscal leniency" (see Bruno et al. 1991, p. 399). The interventions made at this meeting are highly illustrative of the emerging consensus on stabilization theory that gained momentum in early 1990s.

\footnotetext{
192 The heterodox experiment was advanced over the Israeli and Argentine economies in 1985 and in Brazil in 1986. Cunha (2006) informed us that Arida spent a few months in Israel with Michael Bruno, to observe in loco the development of the price freeze. Lopes also comments, in his interview to Mantega \& Rego (1999, p. 349), on his interaction with the economic team in charge of the Austral plan in 1985 in Argentina. It is to this international network of economists that we allude to when we talk of an emerging consensus on stabilization policy, whose synthesis can be found in Bruno (1993) and Heymann \& Leijonhufvud (1995).
} 
At this venue, Arida ([1991] 1992) commented on Cardoso's (1991) paper and set forth a distinction that had yet to be cleared up in his previous writings. At variance with Cardoso, he claimed that dismantling the indexation schemes was an essential part of a stabilization procedure. In this vein, there are two senses by which we can understand the term "de-indexation". The first sense has to do with the breaking down of the inertial mechanisms when a stabilization program is launched, that is, "deindexation means a policy act designed to change the indexing laws that prevailed before the program in order to ensure that nominal variables after the program do not reflect pre-program inflation rates" (p. 181). However, de-indexing the economy involved also providing some "after-program indexation" scheme, so that the imbalances caused by price freezes in the structure of relative prices do not propagate such distortions out to the whole economy. This is why indexation is bound to outlive stabilization plans, for indexation clauses largely facilitate the acceptance of a stabilizing program.

The demand for indexing rules is stronger the smaller the initial credibility of the program. It is also true that in any sensible stabilization program longterm government bonds are to keep indexing clauses; the same applies to longterm supply contracts depending on specific baskets of goods and services. The real issue is posed by short-term wage indexation. Residual inflation is likely to occur even when the fundamentals are right. (Arida [1991] 1992, p. 182English in the original)

Therefore, in a long-lived inflationary process, a full-blown deindexation program is not expected to do away with indexation completely; rather, it is supposed to compulsorily extend contract lengths to a minimum of one-year intervals or longer. Arida focuses on wage indexation and intervals between renegotiations of labor contracts. A shift of emphasis would soon occur when, in his $\mathrm{PhD}$ thesis, Arida (1992) provides an important contribution to the understanding of chronic inflations, of which we highlight two aspects. He neglects the possibility of achieving a distributionally neutral disinflation due to a combination of portfolio shifts expected to take place during stabilization and the post-disinflation required level of interest rates (p. 53).

He then sets forth a two-pronged taxonomy of the inflation inertia concept are construed as another instantiation of the ecumenical turn we have been addressing in this section. First, Arida takes issue with the monotonous concern with wage indexation usually found in theories of inflation. He steers attention toward asset indexation and coins the term "absorption effect" to explain why high inflations can go on for decades without degenerating into a hyperinflation. The gist is that agents seek substitutes to money legal tender in indexed 
assets, a demand for which is likely to increase as inflation speeds up. In other words, by focusing too much on the shifts between real and financial assets, economists have overlooked a crucial dimension of chronic inflations, that is, changes in the composition of financial portfolios. The changing composition of asset portfolios not only averts the process of "flight from money" that boosts the explosive behavior of prices, it in fact sheds light on why any stabilization attempt will logically fail to meet the neutrality constraint, as posited by Lopes \& Williamson ([1978] 1980). ${ }^{193}$

Secondly, he ascribes two different "senses" to the concept of "inflation inertia". "Inertia may describe a situation in which inflation remains above the level indicated by fundamentals or may describe a situation in which the response of inflation to shocks or changes is sluggish". In the first sense, "if equilibrium wages are smaller than base wages, inflation persists above the level dictated by seigniorage (...) because of backward looking indexation clauses" (Arida 1992, p. 75). This "sense of the term" justifies, Arida later tells us, the "widely held argument" that "the equilibrium steady state inflation in indexed economies may not bear a one-to-one relationship to budget deficits" (p. 211). The second sense ties the concept of inertia to "wage contract staggering" (p. 75), a view that has "led policy makers in charge of heterodox programs to the conclusion that wage indexation imparted rigidity to the inflation" (Arida 1992, p. 211). We then get a whole picture of the "pure inertial inflation paradigm" (p. 67), thence characterized by the author as follows:

Consider an ideal stabilization setting in which fundamentals are right in the sense that government deficit is zero and the current account deficit does not exceed the available supply of external savings. The inflation rate required by seigniorage is zero by hypothesis. There are no external shocks. Wages are indexed with fixed length, backward looking 100\% plus escalating clauses. Money is passive. (Arida 1992, p. 67-English in the original)

Should these conditions hold, inflation is positive if base wages exceed equilibrium wages. Moreover, the shorter the indexing lag, the higher the rate of inflation. Inflation brings wages into consistency with equilibrium in all markets. Furthermore,

\footnotetext{
${ }^{193}$ The rationale is as follows. In the aftermath of disinflation agents' perceived uncertainty involving future inflation rates is likely to sustain the demand the demand for indexed bonds. Monetary stringency is thus required to avert an excessive consumption boom. Hence the post-disinflation real rate of interest has to be higher than the pre-stabilization real interest rate. Post-disinflation equilibrium is therefore bound to be different from the pre-disinflation one; hence the violation of the principle of distributional neutrality. The warranted rise in interest rates is an increasing function of the degree of endogeneity of contract indexation to ongoing rates of inflation, which are, in turn, independent from the size of the public deficit.
} 
Central to the paradigm is the notion that, if budget is balanced, monetary correction in financial assets and wages is a veil in the sense of not altering real equilibrium. The equilibrium average real wage would not be inflation dependent. (Arida 1992, p. 67-English in the original)

When it comes to the Brazilian experience, here is his understanding:

Besides budget imbalance and the lack of non-inflationary sources of finance, Brazilian inflation reflected to a substantial extent the inertia caused by the economy-wide compulsory, backward-looking indexation in staggered contracts. The inertial component differentiated Brazilian inflation from both the low, one digit inflation rate driven by excess demand or supply shocks and the extreme rates of open hyperinflation in which the adjustment intervals of contracts are but a span while a foreign currency becomes the standard of value and a current mean of payments. Because the equilibrium inflation rate imposed by seigniorage was lower than the inflation rate dictated by inertia, incomes policy was called forth to complement tight fiscal policy in rapid disinflation (Arida 1992, p. 10 - English in the original-emphasis added).

Arida then posits his core argument, namely: the pure inertial inflation paradigm holds true in a world with no uncertainty regarding inflation rates. This result is changed in the face of inflation uncertainty because changes in inflation are likely to alter both the desired composition of financial assets between money and bonds and the desired composition of wealth between real and financial assets. While demonstrating this very result, Arida reveals the methodological turn of interest to our analysis. This turn is observed in his modeling strategy and his historical account of Brazilian experience with stabilization. First, Arida's models are shaped by the theoretical Keynesian contributions in the likes of Dornbusch (1980) and Fischer (1986), a framework in which the inertial inflation becomes but a special case in a more general setting. In his three-asset model (money, government indexed bonds and capital or equity) asset demands for equity $\left(k^{d}\right)$ is a function of wealth $(\Theta)$, inflation $(\dot{p})$, the real rate of return on capital $\left(r_{K}\right)$ and the real rate of interest paid by indexed bonds $\left(r_{b}\right)$.

$$
k^{d}=f\left(r_{K}, r_{b}, \dot{p}\right) . \Theta
$$

Central to Arida's argument is the value of $f_{\dot{p}}$ or $\left(\frac{d f}{d \dot{p}}\right)$. By assuming that inflation uncertainty is a continuous and positive function of inflation, the author defines $f_{\dot{p}}=0$ as the necessary condition for the pure inertial inflation paradigm to be true, that is, changes in inflation alter the desired portfolio composition between financial assets but not between real and financial assets (Arida 1992, p. 69-71). 
Still in the methodological dimension, the distributional conflict approach that undergirded his 1982 model is demoted within the model's hierarchy of explanatory variables. Arida relegates the conflicting claims among social groups to a second tier in the determination of a specific circumstance within this new framework, namely, that of an unstable and accelerating phenomenon. According to this newfound notion, a distributive conflict describes a situation whereby inflation can only be stable if equilibrium wages are equal to target or desired peak real wage. Moreover, conflict is set to depict the combination of a specific type of indexation arrangement - complete endogenous indexation - and a higher real wage than the economy can afford. In this setting, inflation accelerates continuously in steady state, even though the public budget is balanced (Arida 1992, p. 110-116). Conflict inflation thus becomes but an extreme instantiation of the wage-price spiral, in stark contrast to Arida's early stand on the role played by worker's and firms' bargaining power in determining the level of real wages as well as the frequency of wage and price adjustments or the indexation lag. ${ }^{194}$ He leaves no doubt in this regard when he concludes that the "wage indexation responsible for inertia is wage adjustments at given exogenous time intervals set by law" (p. 180).

Finally, his historical account of the then recent Brazilian experience relies mostly on Modiano (1988) and Cardoso (1991), whose narratives acquiesce the centrality to be ascribed to fiscal measures in place of the fully inertial inflation claim. In this vein, Arida also makes the same ecumenical pledge we have been pointing out in other scholars the PUC-Rio tradition. Quoting him once again at length:

"Heterodox and orthodox programs are not opposite. Tight fiscal and monetary policies characterize both. The difference lies in incomes policy that coordinates price setting decision making. In heterodox stabilization, price and wage controls are but complementary to the adjustment in fundamentals" (Arida 1992, p. 10 - English in the original). ${ }^{195}$

\footnotetext{
194 The author strips his model from the more political and structural aspects by assuming all of these latter affect inflation by means of the "wage gap", that is, the difference between average and desired base wages, which then has its inflationary effect magnified by indexation cost-of-living adjustment (COLA) provisions in contracts (see Arida 1992, p. 180)

195 Militant unions are thus assumed to press upon government to alter legislation on indexing intervals. By suppressing these hard-to-frame political and institutional forces, Arida's model achieves a more convenient level of tractability. This is not to imply any negative criticism on our part. Rather, it points to our early claim that mechanical models tend to affect the way economists think and, thus, adjust the choice of variables to the limits of the modeling tools available to them. Moreover, his purpose in this late model is to unveil the properties of different indexing schemes. This only reinforces another of our earlier assertions that these scholars became ever less concerned with the underlying primary causes of inflation in order to stress the persistence of propagation mechanisms.
} 


\subsection{Simonsen's final synthesis: bridging silos}

M. H. Simonsen is commonly referred to as the closest forerunner of the inertial inflation paradigm (see Barbosa 1997, Werlang 1998 and Ramalho 2003). The "self-feeding model of inflation" had managed, by 1970, to bring the contending parties in the first monetarist-structuralist controversy to a relative consensus (Boianovsky 2012, p. 290). Cabello (2014) has found, on the other hand, that Simonsen's take on inflation inertia evolved along the decades after he first envisioned the saw-tooth pattern of real wages in 1964 (see section 3.4 above). By the dawn of the 1980s, Simonsen (1983a and 1986) had formally proved that inflation inertia is bound to emerge even in models that assume agents' rational expectations. He also extended the framework of staggered contracts in the Fischer-Taylor variant to cover the Brazilian notion of inflation inertia by (see Simonsen 1985).

Simonsen (1988a) attributed the "traditional explanation" of "inflationary inertia" to the Friedman-Phelps acceleration principle, according to which inflation is interpreted vaguely as an autoregressive process, combining the natural rate of unemployment with adaptive expectations. One decade later, the Rational Expectations (RE) revolution had then dismissed adaptive expectations as an "ad-hoc" assumption, for its analytical inconsistency with optimal decision-making. Simonsen had made clear his disagreement with the LucasSargent Rational Expectations research program from the start. He bluntly criticized it for its heroic assumptions regarding agents' behavior (see Werlang 1998). The implications of assuming rational expectations on the concept of inflation inertia were, according to the author, quite limiting in scope: "Under the aegis of the new classic [sic] economics, inertial inflation can only spring from two sources: autoregressive expected rates of monetary expansion and outstanding contracts based on previous inflationary expectations" (p. 259).

Simonsen did not expand on the first source, claiming only that it can be abated by a credible monetary rule of a respectable and independent Central Bank. Nevertheless, more than closely tied to the monetarist conception, this view sits comfortably with one of his coauthor's opinion that the concept of inflation inertia is an immediate byproduct of the emerging econometric time series literature in the 1950s (Barbosa 2004). As for the second source, it generates only "temporary and dampened inertia, the so-called Fischer-Taylor inertia" (p. 259); and because the length of the non-indexed contracts is a decreasing function of the inflation rate, the transition from high to zero inflation could be indeed quite rapid. He did not seem convinced by any, which led him to conclude: "An adequate theoretical 
framework is needed to explain what causes inflationary inertia and how incomes policies can break the dependence of the inflation rate on its past behavior" (p. 259). The problem was similar to Simonsen's reluctance to accept the Friedman-Phelps acceleration principle back in his 1970 book, that is, both sources produce unstable behaviors in the presence of shocks, thereby steering the economy quite rapidly to a hyperinflation path. Instead, Simonsen was interested in finding an analytical explanation of the self-sustaining properties of high inflation for long periods of time.

Alternatively, Simonsen identified the source of inertia within a game-theoretic framework, wherein they combine inflation and price-setting behavior in a $(n+1)$-person noncooperative game - namely, $n$ private sector participants and the government $(+1)$. Agents must chose their strategies before any other participants reveal her choice. Under risk aversion, agents then tend to choose a maximin strategy, which guarantees, the authors argue, the best possible outcome in the worst conceivable scenario. The end result is that prudent playing yields price and inflation inertia, because agents take time to locate a Nash equilibrium, granted that any participant can, in the process, improve her playoff by unilaterally changing her strategy. In a repeated game setting, prudent players are likely to gradually narrow the conceivable range of other participants' strategies, which in turn steers agents toward a common Nash equilibrium, albeit with "unknown a priori speed of convergence" (Simonsen 1988a, p. 260-261). Hence the problem of distributive neutrality, which is central to the inner workings of inflation inertia, can be addressed on game-theoretic terms as follows:

Of course, the chances of hitting a Nash equilibrium through incomes policies are extremely remote. Staggered wage and price setting may be a formidable obstacle to a wage-price freeze, because it implies that there is no calendar date at which relative prices are in equilibrium. That is, before being frozen, wages and prices must be realigned. Yet, even if the synchronization problem is solved, the fact that wage and price controls yield some supply shortages should not come as a surprise. In fact, policymakers can easily detect when relative prices are visibly out of equilibrium but can never perfectly identify when the equilibrium has been reached. Even if they could and then decree a wage and price freeze, the following week they could be wrong, because equilibrium prices move up and down with shifts in demand and supply over time (Simonsen 1988a, p. 272). 
Soon after, in his contribution to the volume (Barbosa \& Simonsen 1989) that openly disparaged the Cruzado Plan ${ }^{196}$, Simonsen (1989, p. 4) moved on to rehabilitate the assumption of adaptive expectations. Short of this amendment, he claimed, inertia could not be properly explained within an equilibrium framework with optimizing agents dealing with a full information set. He combines the hypothesis of adaptive expectations with a noncooperative multiple-agent game in which individuals seek a Nash equilibrium by successive approximations. He finds that, in such a framework, rational expectations require agents to take other agents' behavior into consideration as part of the information set, instead of only heeding government policies. Therefore, if agents are not certain that others will follow the same reasoning, until the Nash equilibrium is achieved by all of the involved, they will most likely reproduce their own past behavior (in the case with indexation) - because the latter is conditioned upon the behavior of the system, which is in turn affected by the behavior of others. In this regard, Simonsen (1989, p. 50) finds a middle ground, a blend of rationality hypotheses, one he dubs "adaptive-rational expectations". 197 The combination of staggered contracts and adaptive-rational expectations transform "dampened inertia" into a specific result of the broader class of inherent inflationary inertia, i.e. the very result of agents' noncooperative backward- and forward-looking rational behavior.

Simonsen extended the view of economics as a discipline to understand - and deal with - coordination problems to encompass inflation inertia. By doing so, he explained, without mentioning, Franco's (1986, chapters $2 \& 3$ ) assumption that inflation inertia is but an "organic" property of the economic system, by using a game-theoretic framework that include rational expectations in a market-clearing set up, instead of assuming both away. In this vein, he was able to not only rationalize the persistence of inflation - by covering both New

\footnotetext{
${ }^{196}$ In its very title, the organizers claimed that the economists in charge of the plan had confused "inertia" with "inaction", in clear reference to the lack of explicit monetary and fiscal measures. Simonsen had earlier claimed that authorities typically resisted enforcing stabilization crises, through restrictive fiscal and monetary measures, in order to hold inflation, fearing the political costs of such policies; hence the allegation of inaction on the part of the economic team.

${ }^{197}$ Let us look into an example. Suppose the government announces a nominal output expansion at a rate of growth $r$, and that agents take both $R=R_{0}(1+r)^{t}$ and $P=P_{0}(1+r)^{t}$ as a moving Nash equilibrium at the rate $r$, for one period. Assuming that agents believe completely in the government's promises does not preclude the possibility that they distrust others will rise prices only as much as the rate announced by the authorities, or less. Expectations are thus adaptive as regards prices and rational as regards output (Simonsen 1989, p. 50). This outcome is, in itself, sufficient to generate inertia. If indexation is allowed, the problem is then to desert the strategy of indexing wages or prices if the others do not do the same, along the same lines as Franco (1986) suggested.
} 
Keynesian and Neo-structuralist results - and thereby make the case for the combination of orthodox and incomes policies to stabilize an inflationary economy.

Interestingly, after all, Simonsen stood his (middle) ground, yet once again, as regards the controversy between monetarists and structuralists. He finds as many shortcomings in one side as he does in the other. Besides the already mentioned assumption of passive fiscal and monetary policies, heterodox economists had, according to him, become too deeply attached to and overly enthusiastic with a flawed theoretical model, by assuming that the peak real wages desired by workers and the mark-up rate pursued by firms were immune to aggregate demand fluctuations and to the expected rate of inflation. Without explicit reference, Simonsen recalled Rowthorn's (1977) notion of "discipline by demand forces" - e.g. the unemployment rate or shortage of sales revenues -, an aspect of the conflict approach that seems to have eluded the Brazilian neo-structuralist economists in general. ${ }^{198}$ The direct analytical result is that a "real wage floor" is established without reference of a upper bound to workers' claims. On the side of monetarists, Simonsen disparage the complete disregard for the indexation-related inflation inertia "perhaps because this [wage indexation] rule was never discussed at the University of Chicago" (1989, p. 14), and how inertia exerted pressure on the monetary aggregates, rendering them partially endogenous (p. 18). ${ }^{199}$

Simonsen had systematically aimed, throughout his career, at bridging the seemingly irreconcilable intellectual silos within the controversy we analyzed thus far. This intellectual proclivity toward building a synthesis of opposed forces led him to provide, in this 1989 paper, a prototype model of an inflation-targeting scheme, based on monetary authorities' utility function within an optimizing framework. An inflation fluctuation band is thus derived from Simonsen's long-standing perception of a systematic tug-of-war between the socially desirable goal of price stability (upper bound) and the social resistance to the costs of disinflationary stability crises ${ }^{200}$ (lower bound). An "independent" ${ }^{201}$ Central Bank must then

\footnotetext{
198 This is not to say that structuralist and neo-structuralist economists overlooked demand pressures when explaining inflation. Rather, that the determination of wages in these models seems to respond predominantly to non-economic exogenous factors, such as indexation legislation and political aspects of policies. As we have seen above, Cardoso $(1980,1981)$ had already acknowledged the presence of demand pressures, albeit they were seen as resulting from structural underlying forces.

199 "If the mistake of our monetarists was overlooking the problem of inertia, the heterodox antithesis was equally wrong, to imagine inflation as purely inertial. The [monetarist à la Cagan] model makes evident that it is useless to erase the memory of inflation e then reignite it by monetary and fiscal expansion" (Simonsen 1989, p. 8).

${ }^{200}$ For further details, see section 3.4 above.
} 
control monetary aggregates to keep inflation freely oscillating within the fluctuation band without the need for intervention (Simonsen 1989, p. 15-19).

To sum up, Simonsen's views on the phenomenon of inertia grew more sophisticated, as he adapted it to the changes in the economics discipline. We forayed into his later writings about this concept, published from the late 1980s until mid-1990s, when Simonsen sadly passed away. One cannot help but marvel at his far-reaching understanding of the inflationary process and the way he managed to build such a basic framework, that both sides of the dispute became but specific emphases of his more general taxonomy. Our claim is that Simonsen $(1988 \mathrm{a}, 1989,1995)$ provided a final theoretical synthesis to the problem of inflation inertia that allowed for the smooth - and unspoken, we venture to say - conceptual transition from the 1980s explicit debates on the matter to the post-disinflation period (from 1994 onwards), when the Brazilian specificity - namely, the widespread system of indexation - was allegedly brought down to "normal" and tenable proportions (see Bacha 2003).

\subsection{The structuralist transformation cycle: external constraints, gradualism, fiscal imbalances and runaway inflation}

We are now ready to state our claim that a second-generation structuralist transformation occurred in Brazilian debates on stabilization policies, in the period ranging from the first versions of the model in the 1950s to their later format in the late $1980 \mathrm{~s}$. The original Latin American structural theory of inflation underwent a major shift in its theoretical emphasis, being gradually stripped of its more fundamental elements regarding the structure of production, and the dynamics of income distribution, conflict among social groups, patterns of structural change, technological innovation and economic growth, among others. In essence, the neo-structuralist approach drifted from a distributional conflict-friendly approach to a fiscally conditioned relative wages model of inflation, according to the taxonomy previously outlined.

This displacement in emphasis did not, however, alter the basic stand relating to the external constraint and the importance of fiscal matters (see Seers 1962 and Boianovsky 2012). The reasons for such a dislocation can be only partly ascribed to the theoretical and empirical weaknesses of the inertial inflation hypothesis that informed policy guidelines, as

\footnotetext{
${ }^{201}$ Independent goes in between quotes because Simonsen reminds the reader that a Central bank must enjoy an utility function that is proximate to society's own function, because central bankers do not have at their disposal a "Pretorian guard to guarantee their ample and unrestricted sovereignty". Updating the terms, Simonsen is really saying Central Banks must enjoy "operational autonomy".
} 
we have seen in the previous chapter, when we depicted Edmar Bacha's hesitation with the claims made by economists arguing for the "pure inertial inflation paradigm". In addition to this, we underline two other forces. First, the change in academic, economic and political landscapes of the late 1980s and early 1990s led to the formation of an international consensus towards a shared taxonomy to fight inflation among many countries that were plagued by high and persistent inflation. As a result, the inertial inflation hypothesis was relegated to a second tier in guiding the stabilization attempts, particularly in what concerned the dismantling of the inflationary memory, entrenched in the widespread system of indexation found in these countries. This demotion was accompanied by a rising concern with fiscal sustainability and post-disinflation monetary policy, factors that had been explicitly overlooked during the rapid ascent of the creed that inflation in Brazil had a purely inertial behavior. Second, Persio Arida $\mathrm{PhD}$ thesis provides an instrumental push towards turning the “inertial inflation paradigm" (Arida 1992, p. 71) a special case within the broader modern macroeconomics along Dornbusch's (1980) line, smoothing out its transition to resemble Fischer's (1986) typical New Keynesian framework, wherein indexation is largely ascribed to the existence of staggered structure of contracts renegotiated at evenly-spaced intervals.

What we set out to show is that both this more balanced approach to the problem of stabilization and the reshaping of the theory according to the canons of the general economics professional at the international level amounted to stripping the so-called "inertial inflation paradigm" from any of its most distinctive aspects. More than that, we provided evidence that this was done by some of the economists previously engaged in the defense of such paradigm, which reinforces our claim that the internal instability of the theory found its agent in the economists at PUC-Rio.

A summary of the main points made thus far is, perhaps, in order. In tracing out the history of the inertial inflation hypothesis, we have focused thus far on aspects related to its internal consistency. We saw that difficulties arose in more than one dimension. First, nomenclature and modeling styles mixed different traditions of economic thought under the same pretense of explaining inflation by system-level ex-post inconsistencies among income claimants. The fact that it adopted a common term (inertia) - albeit with a different connotation then the one found in North-American New Keynesian framework - added, however marginally, to the ongoing confusion and to the ensuing poor reception of the idea.

Second, these variegated foundations imposed confusion as to what explained the selffeeding behavior of inflation; was it indexation or the complex non-cooperative interaction 
among social groups? Or both? In the latter case, which groups, and by which mechanism was information relating to misalignments among relative income levels or prices conveyed across aforementioned groups? A third concern could be stated as: if the process was inherently dynamic, how should one guarantee that stabilization would reinforce previously accepted standards of living under stability of prices and of monetary institutions?

Fourth, one could justifiably wonder how useful were models couched on conflict dynamics informing policy design, beyond a highly didactic commonsensical illustration of the inherent dynamics of inflation. Fifth, insofar as the hypothesis of inertial inflation goes, if a stable conflict keeps inflation steady, how could conflict stability be maintained once the level of inflation is sharply reduced? That is, any deviation from this highly unstable saddle path of distributionally neutral disinflation would gear the system into an infinite variety of potential trajectories. Therefore, requirements for success were highly sensitive to the initial conditions, for any imbalance would be instantaneously transmitted to the new low-inflation equilibrium. As a consequence, the sixth factor would point to the matters of government budget equilibrium and monetary policy details. In a country so accustomed with gradualist anti-inflation policies, how should government cope with the sudden extinction of inflation tax without disrupting the social pact around low inflation?

This last aspect geared attentions to the problem of fiscal policy. Whereas it was clear that price and wage freezes were effective in plunging inflation rates, less clarity befell policy makers as regards post-disinflation restraint measures. Also, the external constraint was acknowledged as a sine qua non condition to success. The awakening to these binding constraints on any stabilization effort made the "inertial inflation" component grow ever smaller within the general framework of analysis. Balance of payments constraints and the structural proneness to public deficits moved toward center-stage, something that the old Latin American structuralism of CEPAL had come to grips with by the works of Furtado (1954, 1959), Noyola (1956a) and Sunkel (1958) (see Boianovsky 2012 for a thorough survey of contributions).

The extensive amount of intellectual energy devoted to reason about the inertial inflation paradigm has arguably enriched knowledge at the boundaries between economic policy and theory. The concepts of price inertia and inflation inertia were eventually made into organic parts of the anatomy and physiology of high inflations (see, for instance, Bruno 1993 and Heymann \& Leijonhufvud 1995). Slowly, economists' attention began to shift in the late 1980s towards Julio Olivera's (1964) long-standing warning that one should not 
confuse structural inflation with structural proneness to inflation, the latter being a historical feature in Latin America, plagued time and again by inflation-complacent populist governments (Bresser Pereira 1991b; Dornbusch \& Edwards 1989, 1990, 1992). A general displacement of Brazilian economists towards more conventional economic policy was induced by a growing perception regarding the existence of a fiscal crisis of the State, as in Bresser Pereira (1989 and 1991a). This was informed by incursions in the sociological underpinnings of populism in Latin America, the product of which inevitably led to a more liberal view of the role of the State in the economy, as in Cardoso \& Helwege (1995).

To some extent, the social insertion of the scholars engaged in this theoretical debate has something to do with the decline of this research program. As they left the academic sphere to occupy government positions and, thereafter, to consulting firms and to the financial sector (Loureiro, 2009), they fell short of attracting human resources to pursue solutions to the unresolved theoretical problems. Precisely why this was so is still an open question. Nevertheless, the decades long worth of knowledge that was built in Latin America and in the heterodox quarter of professional economics was not lost. These efforts were absorbed by the heterodox theoretical canon, such as in North American structuralist camp led by Lance Taylor (2004, chapters $2 \& 3$ ) and colleagues of a similarly critical approach (Ros 1988 and 2003, and Barbosa-Filho 2014). Further, the impact on stabilization policy theory of these latter efforts is modest, truth be told, but it is far from insignificant, for it has indeed been absorbed into the "mainstream" of the economics of stabilization (see Simonsen \& Dornbusch 1988, Bruno 1993 and Heymann \& Leijonhufvud 1995, chapters 2 \& 5).

Taken together, all these extra-scientific influences solely provide a historicalinstitutional context for the dilution of the "inertial inflation paradigm" into the broader mainstream economics. As inflation was controlled and indexation receded in several developed countries after the late 1970s "inflation bulge", to use Tobin's (1980) expression, academic attention of those inhabiting the profession's mainstream was directed elsewhere; the Great Moderation period was a fertile ground for the emergence of the New Neoclassical Synthesis (see next chapter). At this latter instance, the changing landscape engendered by the "crisis of the economics profession" (see Coats, 1993, p, 464) led to the emergence of a New Neoclassical Synthesis in the early 1990s (Goodfriend \& King, 1997), where the concept of inflation inertia will sit in quite comfortably, albeit at some variance regarding its substance and theoretical form. 
What appears to be a discontinuity in the history of Brazilian economic thought on inflation inertia in Brazil finds, in fact, a theoretical connection in M.H. Simonsen's later writings, the close reading of which has shed light - we hope - on the main elements that may compose the narrative we have unraveled hitherto. It is our claim that, by bridging seemingly incompatible silos, Simonsen allows us to build a transition - at the analytical level - from the disenchantment regarding the inertial inflation paradigm - and the ensuing emerging macroeconomic consensus on stabilization policy, described in Bruno (1993) - to the later emergence of a monetary policy consensus based on new-Keynesian theory, as claimed by Goodfriend and King (1997) and Clarida et al. (1999), on which runs the current understanding of inflationary processes. 


\section{Chapter 7 - Inflation inertia in post-Real Plan Brazil: a synthesis}

We have presented evidence of the narrowing scope of analysis adopted by the economic team responsible for the Real plan. The level of inflation had a bearing on the widespread use of myriad escalator clauses. "Exogenous" causes of inflation were of secondary importance, for they impinged on the acceleration of inflation. Amongst these cause featured the distributional conflicts ingrained in the Brazilian society. If it is assumed that stabilization plans are merely institutional devices attempting to discipline distributive conflicts by establishing a specific pattern of income distribution that minimizes society's aspiration gap, the efficacy of the distribution of wealth set out by any plan is thus crucial to its following result. The aftermath of a stabilization process is largely determined not only by the set of policy instruments designed to restrain the different groups' income claims, but also by how these groups react to such pattern of wealth distribution in the context of a changing economic structure. It is hence not surprising that indexation practices persisted after disinflation. Considering that it plays an uncertainty-mitigating role in the decision-making process, indexation is but a symptom of the price system's memory.

In the early 1990s, a clearer notion concerning the difficulties in - or even the impossibility of - fulfilling the policy goal of "distributional neutrality" allowed the economic team to reassess the stakes. The fiscal accounts and the employment rate would bear the adjustment in distribution of wealth and income, through an aggressive policy of privatization of State-owned companies aiming at reducing the potentially boosting effects over the public debt as a result of such adjustment, something Arida had claimed in his MIT thesis (Arida, 1992, p. 191). The economists at PUC-Rio eventually became government authorities and were able to connect their theoretical claims to the growing convergence of opinions on stabilization matters at the international level (see Dornbusch and Simonsen 1988 and Bruno 1993).

In 1984, as inflation accelerated to ominous proportions, the proposals to abate it first made their public appearance with the "heterodox shock" (see Lopes 1986, chapter 17) and the LARIDA proposal (see Arida \& Resende 1985). Thenceforth, a ten-year-long institutional and theoretical learning process culminated in a singular stabilization plan. The evolution of the theoretical debate on the causes of the persistence of Brazilian inflation ultimately gave way to a successful "package deal", which achieved an unquestionable success in rapidly 
deflating prices, although its incompleteness was claimed among some scholars and public authorities in its aftermath (Dornbusch \& Cline, 1997).

Following disinflation, indexing schemes persisted as part of the stabilizing effort. This meant an implicit acceptance of the inevitability of inflationary inertia, as Franco (1986, chapter 2) tried to demonstrate. Nevertheless, one could wonder if the diminished level of inflation would affect in any way the concept of inertia. In the next section, we peruse the perception of this problem by the economic advisors behind the Real plan, to understand if and how they understood the concept of inertia. We do so by delving into the backstage papers shared within the economic team in charge of the Real Plan, published by Prado (2005) as part of her detailed journalistic report of the day-to-day management of the plan. This documental analysis has not been pursued thus far in the academic literature.

\subsection{The immediate post-Real Plan and the persistence of indexation: analysis of the economic team's backstage papers}

The main purpose of the Real plan consisted of eliminating this inflationary memory by way of pegging the total array of assets and pries of the economy to a general and unified indexing scheme, the Real Value Unit (URV, in Portuguese). Complete de-indexation followed suit, which was achieved through a monetary reform that converted all contracts according to the unit of account provided by the new currency. Inflation-adjusting behavior (or clauses) was prohibited for periods shorter than twelve months. This minimum interval to indexation practices provided the grounds to neutralize the inertial component of inflation. Nonetheless, no full de-indexation could be achieved by a one-time strike on the economy without finding a dynamically stable solution to these underlying conflicts. The latter requires dealing with complex price-output macrodynamics in the context of long run development trajectory of the economy, which do not fit entirely within the scope of policy control.

Following disinflation, the ensuing institutional framework of economic policy stood on thin ice. There emerged a sensitive balance to the policy space that followed the stabilization attempt, which required readiness and flexibility from policymakers in order to live up to the challenges of a resistant inflationary memory. Keeping the ability and the advantages of first-movers in policy-making was key to sustained success. As initiatives were taken, inflation rates were acutely reduced to one-digit levels and remained so ever since, with the exception of specific circumstances associated with momentary shocks that accelerated price index increases during the second half of the 1990s and early 2000s. 
In what follows, we draw on the records of the economic team's backstage papers as they discussed the strategies to keep inflation under control. Our analysis will cut through the details of provisional measures and legal acts, so we can focus on how they understood, in the immediate aftermath of the stabilization attempt, the implications of the institutional survival of indexation schemes on inflation inertia. The documents were published over a decade after the plan was set in motion. We can find them in the annexes of Prado's (2005, p. 485-564) journalistic account of the process of arrangement for the plan and the challenges that followed up its execution.

We also resorted to Bacha's $(1998,2003)$ narrative of the plan and Lopes (see Cunha et al. 2013, p. 280-320) his recollections of the long stabilization saga in which he took part, beginning in the early 1980s until his controversial resignation from the Central Bank in 1999, scathed by the forceful currency devaluation of January $15^{\text {th }}$ of that year. Such documents have not received any academic assessment as of this date. We believe they throw some light, however dim, on the institutional inertia of economics after a long adaptation process that reduced the costs of living under chronic inflation. The Brazilian society could not help but reflexively entertain, under low inflation, the "bad recollections" regarding the previous decades-long period. Since old habits die hard, the collective inflationary memory was thus instilled in the economic institutional framework that was to be built in the aftermath of disinflation, as we have shown elsewhere (Carvalho 2014).

The papers did not appear in regular frequency, since they responded to the challenges the policy makers faced as the plan progressed (see Table 3 below). Some of them, Prado (2005, p. 485) tells us, were repeatedly conveyed, so as to reinforce some specific argument. The papers allow for a vivid inference of the diversity of views and opinions on a host of topics regarding the execution of policy. The main contenders are Persio Arida, Francisco Lopes and Gustavo Franco. The first two were already senior economists during the making of the Cruzado plan, in 1986. At the time, Franco was still pursuing his doctoral studies at Harvard, under the supervision of Jeffrey Sachs and Lance Taylor, trying to make sense of the economics of hyperinflation (Franco 1987). By 1993, Franco had already become a senior economist at the Economic Policy Department for the Brazilian Federal Government under the Itamar Franco's administration. 
Table 3 - List of backstage papers written by the economists in charge of the Real Plan

\begin{tabular}{|c|c|c|c|c|}
\hline Date & Author & Title & $\begin{array}{l}\text { Mention of } \\
\text { Indexation }\end{array}$ & $\begin{array}{l}\text { Main topics of } \\
\text { discussion }\end{array}$ \\
\hline 11 July 1994 & $\begin{array}{l}\text { Gustavo H. B. } \\
\text { Franco }\end{array}$ & The new exchange policy & No & Exchange rate policy \\
\hline 9 August 1994 & Persio Arida & $\begin{array}{l}\text { Notes on the program's } \\
\text { redesign }\end{array}$ & Yes & Exchange rate policy \\
\hline 20 August 1994 & $\begin{array}{l}\text { Gustavo H. B. } \\
\text { Franco }\end{array}$ & Directions of the Real plan & No & Exchange rate policy \\
\hline 5 November 1994 & Persio Arida & Real & Yes & De-indexation \\
\hline 20 February 1995 & $\begin{array}{l}\text { Gustavo H. B. } \\
\text { Franco }\end{array}$ & $\begin{array}{l}\text { Proposal for Exchange } \\
\text { Policy - } 1995\end{array}$ & No & Exchange rate policy \\
\hline May 1995 & Francisco Lopes & $\begin{array}{l}\text { On the definition of a } \\
\text { exchange rate regime for } \\
\text { the Real plan }\end{array}$ & Yes & $\begin{array}{l}\text { Exchange rate policy } \\
\text { and de-indexation }\end{array}$ \\
\hline May 1995 & Francisco Lopes & $\begin{array}{l}\text { Notes on the second phase } \\
\text { of de-indexation within the } \\
\text { Real plan }\end{array}$ & Yes & De-indexation \\
\hline December 1996 & Francisco Lopes & $\begin{array}{l}\text { Notes on exchange rate } \\
\text { policy at the final stage of } \\
\text { stabilization }\end{array}$ & No & Exchange rate policy \\
\hline May 1997 & Francisco Lopes & $\begin{array}{l}\text { The exchange rate problem } \\
\text { and its solution }\end{array}$ & Yes & $\begin{array}{l}\text { Exchange rate policy } \\
\text { and de-indexation }\end{array}$ \\
\hline 9 June 1997 & $\begin{array}{l}\text { Gustavo H. B. } \\
\text { Franco }\end{array}$ & $\begin{array}{l}\text { On the exchange rate } \\
\text { problem: is there any? }\end{array}$ & Yes & $\begin{array}{l}\text { Currency devaluation, } \\
\text { inflationary memory, } \\
\text { price setting behavior, } \\
\text { inflation targets, } \\
\text { credibility and } \\
\text { exchange policy }\end{array}$ \\
\hline 14 July 1997 & $\begin{array}{l}\text { José Roberto } \\
\text { Mendonça de } \\
\text { Barros }\end{array}$ & $\begin{array}{l}\text { Adjustment on the external } \\
\text { front }\end{array}$ & No & Exchange rate policy \\
\hline 11 September 1998 & Francisco Lopes & $\begin{array}{l}\text { Proposal for the immediate } \\
\text { execution of Plan B }\end{array}$ & No & Exchange rate policy \\
\hline
\end{tabular}

Source: Prado (2005, p. 485-564) - assembled by the author.

The first manifest concern regarding indexation came up in Arida's first paper of 9 August 1994 (Prado, 2005, p. 495). Shortly after the monetary reform (July 1 ${ }^{\text {st }}$ ), Arida proposes to redesign the plan due to a few inconsistencies among the policy variables. He points to the coexistence of compulsory indexing mechanisms (with a 12-month minimum interval), such as those attached to wages and defined at the policy level, and what is commonly defined in these papers as "nominalism" of the exchange rate. This latter had an upper bound tacitly defined at par with the dollar, but no lower bound. Hence, any residual 
inflation, not yet captured by inflation indices, would act to impose further overvaluation of the Brazilian currency The asymmetry was found in that the exchange rate was measured in nominal terms, whereas wages were defined in real terms. These latter were pegged to a consumer price index specifically furnished to discipline wages in the immediate postdisinflation period: the IPC-r. The end result is a further appreciation of the real exchange rate, which potentially aggravates balance of payment problems.

Arida further mentions that de-indexing the price structure of the economy changes the composition of portfolios held by firms and families, with the prominence of real assets to the detriment of financial ones. On one side, de-indexation diminishes volatility of relative prices but, on the other, is likely to boost demand and generate inflationary pressures. Wage indexation in turn acts as a costless insurance against price rises. By reducing the real wage volatility, this mechanism decreases households' promptness to overspend in the face of uncertainty; this ends up raising the saving rate and may further press down on interest rates (p. 497). He finally suggests that any compulsory indexation scheme be abolished and let the market find its own index-linking devices.

On November $5^{\text {th }} 1994$, Arida recants some of his previous stands on indexation and monetary policy matters. When the plan was being forged he contended that any indexing mechanism be banished from the legal pieces that gave the plan judicial support. He was outvoted and the plan called for a partial de-indexation. In retrospect, he admits that his radical solution would have generated numerous legal actions at the Supreme Court, as in the Argentine Austral Plan of April $1^{\text {st }}$ 1991. According to this latter, no escalator clause or index-linking mechanism of any type were permitted in any market, negotiation, contract, taxes or what have you. He then claims:

We prevented de-indexation and demanded that all indexed contracts had at least one year's length, extending in practice the periodicity of readjustments from a monthly to a yearly basis. It was as if we were trying to spin the wheel of history back to the late 1960s or early 1970s. The effects of contract lengthening are typical of "catching up inertia" [a term used by Lopes (1994)]. The stabilization program's greatest effect appears at the outset. Inflation then picks up on an upward trend and converges to a lower level than the one observed prior to stabilization only if it is possible to maintain the lengthier adjustment interval throughout the process (p. 507 - Portuguese in the original).

Contract length was an important parameter to be looked after in the aftermath of disinflation measures. In many stabilization cases in history, there has been a tendency to 
bring index-linking mechanisms back to the ordinary business life, and a few wage adjustments before the minimum legal interval had taken hold. If wage negotiations attempted to develop lead indicators for inflation beyond the official index, the plan's very cornerstone would be in danger. In addition, Arida recalls that no variation range was set up to control for wage escalation. This means that the full extent of the IPC-r would be transmitted to wages, when there came the time. The IPC-r was closely tied to the exchange rate. And given the downward nominal rigidity of wages guaranteed by law, inflationary negative shocks could not be eventually compensated by deflationary positive ones.

It is worthy of note that Gustavo Franco's interventions seldom payed any attention to the indexation problem. His entire focus is addressed to the exchange rate control. One would be mistaken to infer from this any oblivion on his part towards such a crucial matter. In order to see this, we must turn to Francisco Lopes's contentions of May 1995, concerning the options for a slow correction of the exchange rate, to which Franco reply quite vigorously.

Every stabilization plan that hinges on overvalued domestic currencies established this latter as an economy-wide nominal anchor, which goes to say that all macroeconomic prices are linked to the exchange rate. That is the role of a nominal anchor. Inflation tends to run out of control when such anchor is dispersed among several escalator mechanisms, wreaking havoc into the entire price system. Bringing all prices at the same speed around the same anchor amounts to achieve monetary stability.

As we have just seen, in the immediate post-disinflation, there were a few indexing mechanisms at work in Brazil. Nonetheless, the residual mechanisms correcting wages, rentals and taxes were pegged to consumer price indices, which were in turn only partially determined by the exchange rate (the other parcel had to do with the inflationary residual left over from before disinflation took hold). Thence, everything came down to the next measures concerning the value of domestic currency. Any slip in devaluating the currency, making it faster than the economy could absorb it in non-inflationary manner would lead to a lowering of real wages, inviting correcting measures. Inflation would thus rise again.

Lopes (p. 521-522) goes over the enormous amount of trouble a rigid judicial culture of labor-biased courts creates for a stabilization attempt. Any proposal acting to diminish the degree of index-linkage to past inflation faces counteracting measures by the Labor Relations Courts. Moreover, after 30 years of widespread indexing clauses across the price and contract structure, there was bound to emerge and to solidify a pattern of intra-sector employeremployee interaction, highly complacent with fairness issues raised by workers. At the micro 
level, this is not a problem in itself. When we think in terms of general equilibrium, though this is seemingly a "fair play" within a sector, it only shifts the brunt of stability to other sectors, to be shared between workers and firms. Unintentional non-cooperative behavior among workers and firms across sectors ensues, and there we have Hicks's (1974, chapter 3) disequilibrium dynamics all over again, with self-sustaining inflation. This is why, again, the economic team had to pay close attention to whatever irregular behavior might show up and, if it did, to try to prevent its effects from spreading out.

On a lengthy note in May 1997, Lopes (p. 538-541) presents a series of simple models with which to portray the new challenges posed by inflation under this exchange-rate nominal anchor. The first model is one of "pure inertia", whereby inflation $(p)$ is a weighted average of lagged inflation $\left(p_{-1}\right)$ and the rate of devaluation of the domestic currency $(e)$ :

$$
\hat{p}=\alpha \hat{e}+(1-\alpha) \hat{p}_{-1}
$$

being $\alpha$ a constant parameter reflecting the pass-through effect of exchange devaluations on inflation. Rearranging terms, after some manipulations, gives us

$$
\hat{p}-\hat{p}_{-1}=\frac{\alpha}{1-\alpha}(\hat{e}-\hat{p})
$$

The above relation means that a real devaluation of the currency can only be obtained at the expense of a permanently accelerating inflation. The lower the sensitivity of inflation to the exchange rate (lower $\alpha$ ), implies a lower acceleration, but nonetheless an existing one. Of course, increases in productivity $(q)$ can weigh in to press down upon inflation. Doing so implies Lopes's Model 2:

$$
\hat{p}-\hat{p}_{-1}=\frac{\alpha}{1-\alpha}(\hat{e}-\hat{p})-\frac{q}{1-\alpha}
$$

Finally, if we add the level of activity compared to the natural level $\left(y-y_{n}\right)$ we reach Model 3, namely:

$$
\hat{p}-\hat{p}_{-1}=\frac{\alpha}{1-\alpha}(\hat{e}-\hat{p})-\frac{q}{1-\alpha}+\left[\frac{c}{1-\alpha}\left(y-y_{n}\right)\right]
$$

That is, the greater the pass-through effect of exchange rate on inflation, any expansion of the economy beyond its equilibrium level will stoke up inflation, all other variables equal. It is interesting to note that Lopes does not mention whether this normal level of activity should be seen as a growth rate or a NAIRU-type variable. In any case, despite the 
assumption of a fully indexed price structure, the underlying concern was really pointed towards the exchange rate, as we have seen.

Any measure leading to the devaluation of the domestic currency would impose a trade-off between credibility of the anchor and effectiveness of the de-indexation measures. If government discretion in devaluation were to take hold, credibility would be harmed, and economic agents might start to speculate against the currency, set out to convertibility at a fixed exchange rate. Alternatively, if a fixed rule of devaluation were to be followed, people may think that the government is trying to index the exchange rate, and odds would be that restoring escalator clauses could look attractive. However, if no connection was made between the exchange rate devaluation path and the consumer price index, a forward-looking indexing scheme could be achieved, if agents looked to the exchange rate instead of price indices. Creating a path to devaluation converging to a zero variation was the task at hand. Once this result was achieved - it was hoped - the economy would be entirely de-indexed.

Lopes (p. 517; 544) argued that the government should signal a policy of gradual devaluation with a firmly held purpose, so as to reduce anxiety in markets with the risk of overshooting the exchange rate increase (measured as the dollar value in terms of the domestic currency). This was a view Lopes and Franco shared. In a paper sent out on 9 June 1997, Franco reinforces the argument that gradual corrections "are not inflationary", but “discrete corrections" are very much so. (p. 550). This is inkling of Franco's shift towards the rational expectations hypothesis. He asserts that under low inflation, firms set prices à la Sargent-Lucas, that is, they will only adjust prices if they can discern a real shock from a nominal one. ${ }^{202}$ Hence, Franco (p. 551) suggests that the "productivity gains" that had been reaped be used to back the gradual devaluation, preventing the pass-through from devaluation to inflation. But why should the exchange rate be assigned the role of a transmission channel of these productivity gains to inflation? It would be naïve, he claims (p. 552) to expect that such gains would be reflected in lower prices; in "a normal capitalist economy" productivity gains result from the need "to reduce costs and restore profit margins". Therefore these gains are allocated in production reengineering, and in increases of wages and profit margins. Hence these productivity increases have to be discounted via the exchange rate, which

\footnotetext{
202 On a handwritten added note, Franco (p. 551) goes even further in stating that he does not claim that the economy has entirely undergone de-indexation, and that, by this, agents now can fully distinguish real from nominal quantities. However, he believes it is very costly to discern them when inflation is too low. This is due, he argues, to a greater variance of prices with respect to the average price level under low inflation, due perhaps to higher proportional flexibility in prices.
} 
reduces the cost in terms of foreign currencies, enhancing competitiveness of exports without breeding any inflationary spurts.

The papers indicate that the re-indexation scare was present all along the years that followed disinflation but now one level of abstraction higher than during the synchronization phase. The plan aimed to dismantle the widely encompassing system of indexation. As we have seen above, such a propagation mechanism had taken over the inflation trends and was believed to have turned inflation into a fully self-feeding process, hence its "inertial" quality. Taming inflation required breaking the inflationary memory. This task implied substituting a new mindset (low inflation) for a degenerate one infected with "bad recollections". To achieve this outcome, the economic team had to create a system of forward-looking incentives that preclude the old adaptive habits of price- and wage- setters. This is much like preventing the return of viral infection after a radiation shock, by means of injecting the viral gene into the body in a controlled way, so the body will form natural protective mechanisms against eventual viral advances. And as such, it may or may not work, for the viruses are prone to mutation. The question is always: was the shock effective in killing the virus? As regards indexation, the answer is a resounding "no". Because of that, gradualism was the politically viable option. An all-out de-indexation movement would leave agents free to form their expectations whichever way they saw fit. Not eliminating index-linking practices in government-enforced rulings and in the legal structure at large signified, arguably, setting the country back some three decades (1960s), in terms of its monetary institutional framework, an aspect noted by Simonsen (1995) shortly after the plan was launched. The stress test came in January 1999, when the exchange rate overshot in a large devaluation.

As for policy guidelines, economists have to muse over the vague notion that managing the spread of indexing practices hinges on keeping inflation within controlled boundaries. But without knowing, in greater detail, how such an institution spreads informally ${ }^{203}$, this is hardly a solid ground to stand on. After being severely hit by a currency crisis in early 1999, Brazil opted to adopt inflation targeting, a system which is believed to fulfill the purpose of keeping inflation within reasonable limits.

\footnotetext{
${ }^{203}$ Franco (1986, p. 24) noted in the outset of his theoretical rationalization of inflationary inertia that: "It is difficult to account for the spread of informal indexation since it implies dealing with elusive and non-observable instances of human behavior such as 'awareness' of inflation or 'money-illusion'. It is though, a very important part of the process of adaptation of an economy to an inflationary process (...)”.
} 


\subsection{Inflation Inertia and Inflation Targeting in post-disinflation Brazil}

After several speculative attacks on a few countries' domestic currencies beginning in 1995 with the Tequila Crisis, Brazil was hit in a moment of high vulnerability in its external accounts. With a current account deficit ranging over $4 \%$ of the GDP, it was an easy prey to capital flights. When the latter were triggered, the exchange rate soared under the terrible pressure of events, thus relieving the interest rate from its supporting role to the ongoing policy regime. Prices rose sharply but indexation did not pick up. A slowly decreasing return was then triggered and inflation converged to its $6 \%$ average along the two terms of President Cardoso (1994-2002). To make matters even more sensitive, at this juncture, the economic team had lost most of its more senior specialists; so new blood was brought in. Armínio Fraga took up the position as President of the Central Bank and, under the pressure of the exchange rate hike, managed to match Brazil's monetary institutions with the novelties available in the international literature on monetary policy theory, namely: inflation targeting.

We have seen that indexation has outlived disinflation and was partially "lifesupported" by government measures and the provisional measures that eventual became attached to the permanent legal structure. On one side, after 20 years since its enactment, the Real plan has proved successful in maintaining a 12-month minimum interval for wage and contract renegotiations. On the other, little was added to our knowledge of how this institution spontaneously reproduced itself that we had not learned up to the mid-1990s.

Economists have, in fact, learned how to attack it in very sophisticated forms and with a powerful set of policy weaponry. All of these instruments came out of the observed correlation between the level of persistent inflation and the rise in indexing practices - and eventually the increase in the frequency of adjustments. However, beyond this statistical regularity, the "edge of economics", as it stands today, has little to teach on how it emerges, reproduces itself and resists treatment. Given the policy orientation that motivated theoretical efforts in the 1970s and 1980s, the topic gradually lost its academic appeal. But how has inflation inertia been understood nowadays in Brazil ${ }^{204}$

\footnotetext{
${ }^{204}$ Much empirical work has been devoted to accounting for inflationary persistence and inertia. Figueiredo e Marques (2009) show the existence of inertia in Brazil and detect a long-memory phenomenon embedded in the data-generating process. Tejada e Portugal (2001), Campêlo e Cribari-Neto (2003), Cribari-Neto e Cassiano (2005) e Araújo e Santos (2004) follow the same lines, and attempt to provide quantitative evidence on the effects - both temporary and permanent - of inflationary (or deflationary) shocks on the long run inflation trends in Brazil. Fasolo e Portugal (2004) formulate a nonlinear Phillips curve to the Brazilian economy and conclude in favor of a high persistence of inflation between 1990 and 2002, which is explained by an autonomous inertial component to price behavior.
} 
In its Inflation Report (Banco Central do Brasil 2011), the Brazilian Central Bank decomposes the Broad Consumer Price Index (IPCA, in Portuguese) - calculated by the Brazilian Institute of Geography and Statistics (IBGE) and main indicator for the inflation targeting regime - four large components, namely: (1) exchange rate variation; (2) inflationary inertia; (3) expectations; and (4) State-controlled (or administered) prices. In what concerns inertia, the methodology of calculation infers persistence from a combination of past-inflation adjustment coefficient and the "excess inflation over target, transmitted from the previous year's last quarter to the current year". (Banco Central do Brasil, 2011, p. 99). Freitas, Minella e Riella (2002, p. 10) provide the formula to obtain inertia.

$$
I_{t}^{g}=\left(\boldsymbol{\pi}_{t-\mathbf{1}}-\boldsymbol{\pi}_{\boldsymbol{t}-\mathbf{1}}^{\boldsymbol{T}}\right) \cdot C_{\text {inertia }} \cdot W_{\text {group }}
$$

$I_{t}^{g}$ denotes the effects of previous year's last quarter inflation over current year's first quarter index, estimated for a group $g$ of goods pertaining to the index basket; $\boldsymbol{\pi}_{\boldsymbol{t}-\mathbf{1}}$ and $\boldsymbol{\pi}_{\boldsymbol{t}-\mathbf{1}}^{\boldsymbol{T}}$ represent, respectively, observed inflation and target inflation in $t-1$.; $W_{\text {group }}$ is the weight of the group of goods (freely-adjusting prices or State-controlled) on IPCA (the headline consumer price index); and $C_{\text {inertia }}$ represents the coefficient of adjustment to previous quarter inflation rate, whose methodology is omitted by the Central Bank. The total effect of inertia is thus obtained by the combined product of inertia present in all groups of goods.

This current usage of the term inertia is tied to a generation of models known of as the New Neoclassical Synthesis ${ }^{205}$ (Goodfriend \& King, 1997), now fully incorporated into mainstream economics and has already reached undergraduate-level textbooks (Carlin \& Soskice, 2006, chapters $3 \& 5$ ). These models seem to take inertia as a given property of the system and justify their presence on the basis of technical problems in the price index measurement procedure or the hypotheses that a zero inflation goal may keep the economy too close to a deflation trap or that it may turn the labor market less flexible, among others. These justifications are definitely due, but still do not account for the building process of inertia. Such a measure of inertia is simply a statistical carry over between two quarters. ${ }^{206}$

\footnotetext{
${ }^{205}$ Our goal is not to present a detailed account of the inflation-targeting framework or the more general traits of the emerging consensus on monetary policy, which can be found in Goodfriend \& King (1997; 2004). but rather to point out that its application to policy decisions may have unintended effects (ARESTIS \& SAWYER, 2003) when it comes to an economy with deeply-rooted conflict-infused inflationary memory, such as Brazil. For instance, Bogdanski et al. (2001) discuss its application and point out its shortcomings and the challenges the Inflation Targeting framework faces. Therefore, one cannot say such theoretical apparatus has been naïvely put to work by monetary authorities in Brazil.
}

${ }^{206}$ Moreover, it leaves unaddressed the issue that the very estimation of a target is likely to generate a passthrough of inflationary memory accumulated in previous periods (some type of inflation prefixing), thereby 
Another illustration of the dilution of the inertial inflation paradigm we have hitherto tried to substantiate: we recall that Franco (1986, p. 73-74) had measured inertia as a simple autoregressive parameter born out of a simple least-square regression with inflation rates in the following equation, highly reminiscent of Simonsen's feedback model: $\pi_{t}=a+b \pi_{t-1}+$ $u_{t}$. This view is highly consistent with the idea of inertia as mere time series property of data, as Barbosa (2004) sees it, when he reinterprets the history of inflation inertia on monetarist terms. And that is the whole point we have been trying to make: that the inertial component could be represented as an autoregressive component was not new and neither was it neglected by the neo-structuralist economists; it was what caused inertia in chronic inflations to differ from those in moderate ones. Again, we draw on Simonsen to give the final touch on our portrait. When asked if the available macroeconomic theories in mid-1990s offer proper diagnostics and solutions to control inflation, he responds: "I think so. The Brazilian inflation is now well understood. It is not a problem of diagnosis, now it is a matter of action". One of the interviewers replies: "We have then gone back to old, classic inflation". Simonsen: "Agreed" (interview to Biderman, Cozac \& Rego 1996, p. 202). What is nowadays the basic macroeconomic framework and how does it explain inflation inertia?

In modern macroeconomics, inflation inertia is distinguished from inflation persistence. Inertia refers to the delayed and gradual response of inflation to shocks, while inflation persistence refers to prolonged deviations of inflation from steady state following shocks. In short, inertia refers to time elapsed between some perturbation or shock and the response of variables; persistence, in its turn, alludes to the speed of return by the variable to some equilibrium path or state. Both of them thus adopt the underlying premise regarding the existence of a stable path or trajectory (see Fuhrer 2006, 2008, 2010).

In general, the economy modeled consists of a continuum of measure one for each group of agents, namely, households, firms, financial intermediaries and a government. Optimality and other equilibrium conditions for each of these groups of agents are clearly and mandatorily presented. Models from this lineage are built on individualistic premises encompassed by discount rates and intertemporal utility functions of optimizing agents. As a

setting a floor to inflation expectations rendering prices downwardly rigid. This was noted by Franco (2005, p. 283, note 40) in his analysis of the Brazilian long struggle against inflation, but also by Bernanke and Mishkin (1997, p. 18) on a broader perspective of the Inflation Targeting framework for monetary policy. If this is correct, the current consensus on monetary policy is likely to impose higher costs to disinflation and stabilization measures when applied to different institutional schemes (Segura-Ubiergo, 2012). That seems to be so for the Brazilian case (Tombini \& Alves, 2006). Such costs however are hardly subject to generalizations and may differ among countries, according to historical and institutional specificities (Taylor, 1988). 
result, inflation inertia in these models is mainly ascribed to price setting assumptions of rational, forward-looking optimization. A popular approach to introducing inflation inertia into rational expectations models is the 'hybrid' NKPC, introduced by Clarida et al. (1999) and Galí and Gertler (1999). This combines a rational forward-looking element with some dependence on lagged inflation.

A similar role is played by index linking of contracts to past inflation in the work of Christiano et al. (2005). ${ }^{207}$ However, backward-looking expectations are perceived as a second-best theoretical premise - and can be deemed "arbitrary". The supposed lack of robust justification is attributed to the assumption that agents draw information from past occurrences, rather than learn from them in order to infer future developments based on presently available information. Nonetheless, the majority of the orthodox branch of the profession seems to hold views similar to Galí et al. (2005), with the understanding that backward-looking price setting behavior is quantitatively modest but nevertheless statistically significant. Still, it is the one that best generates high intrinsic inflation inertia. Notwithstanding the results attained by this model class, they still fall short of fully explaining the behavior of inflation inertia, beyond a few periods after a shock. A quote by Duarte (2011, p. 392) is revealing of this shortcoming:

To use Frisch's (1933) terminology, the basic new Keynesian model has little persistency in its propagation mechanism beyond that assumed for the impulse (exogenous shock). Even when one makes its propagation mechanism more persistent, (...) it is clear that this model does not reproduce those stylized facts that macroeconomists believe are present in the data: the impulse response functions are not hump-shaped, the peak of the IRF of both inflation and output occur at the instant when the shock occurs-instead of inflation peaking later than output after not responding immediately for a short period following the shock - and they tend to return to zero faster than what is observed in the data.

Economists are thus compelled to "reverse engineer and add features to it", such as habit persistence, adjustment costs to investments, capital utilization, as well as the already conventional price and wage stickiness. Heymann \& Leijonhufvud (1995, p. 31) have reflected on this problem of explaining inertia and found that rationalizing on backwardlooking behavior is an elusive task if it is couched on optimizing behavior. It is more easily done based on common sense: durable economic relationships require an easy arrangement that reduces the costs of frequently negotiating contracts and prices, if inflation is constantly

\footnotetext{
${ }^{207}$ A survey of recent studies on inertia can be found in Julliard et al. (2008).
} 
above zero. Adjusting nominal values in predetermined intervals according to a CPI measures mitigates the costs of negotiation, but also renders the adjustment of wages and intervals more mechanic. This approach demands a "satisficing" approach that is reputed, within modern macroeconomics, to lack rigor, just as it was thought of the inertial inflation paradigm when it was framed in a specific concept of rationality that precluded a real-world phenomenon such as inertia to be imprecisely, but nonetheless, explained.

To wrap up our discussion, this transition from the neo-structuralist inertial inflation model to the New Keynesian closes the long historical process of conceptual change about inflation inertia. This process has been marked by an institutional and structural strip-down process whereby several sociological and historical features partly accounting for the selfreplicating pattern of price rises gradually collapsed into a more individualistic and mechanistic approach that tried to explain inflation by means of constrained optimizing behavior.

The Brazilian chapter of this history has proved quite rich to an intellectual-historical account, given the variety of models and conceptualizations this real-world phenomenon has inspired. Our aim was to cut through many details of this history in order to unearth one specific narrative line that allowed us to observe the transformation in the way Brazilian economists understood inflation inertia. Instrumental to the unraveling of our plot was the methodological flexibility displayed by the economists at PUC-Rio and by one of the most important economists of the second-half of the twentieth-century in Brazil, Mario Henrique Simonsen. With the former the early structuralist inflation theory was revived and technically updated and, with the latter, it was diluted into the more general setting of mainstream economics. 


\section{Concluding Remarks}

The idea for this thesis sprung from the simple observation that, 21 years after stabilization, Brazil has still endured difficulties in taming inflation. Despite the country's success in keeping price rises under control, the phenomenon seems to breathe a life of its very own. It has been, in fact, compared to a giant dragon that erodes the purchasing power of money by blurting fire through its nostrils. For a Republic as young as Brazil, it is painfully amusing to find meaning in such a $20^{\text {th }}$ century mythology, whose timely pedagogy has arisen in both a $200 \%$ rate of inflation of early 1980 s and $6 \%$ inflation rates in early 2010 s.

In light of these general observations, we wondered, at first, if anything had gone wrong with the Real plan, and have come to question its countrywide celebrated success. After all, the plan pursued the goal of zero inflation, which as we saw, is a concept whose meaning has evolved to stabilize around a mean-rate of inflation in the 1-2\% range. Even under this more complacent connotation, such goal has eluded our country's best efforts: $8 \%$ is the average rate we have mustered to achieve thus far, since the enactment of the plan. This is, however, no small accomplishment, especially when we recall the three-digit inflation rates that beset the Brazilian population in the fifteen years prior to disinflation.

Nevertheless, Brazilians can hardly avoid thinking about inflation. Fourteen price indices are calculated on a monthly basis, with 29 publications within any given month of the year, including Saturdays and Sundays. An "inflationary bias" has become, in our opinion, completely ingrained in the country's collective memory, to use Kindleberger's (1985) unorthodox hypothesis about unobservable forces behind the engines of History. Given the obvious difficulties in grasping the subject within such undefined scope, we steered towards how Brazilians have reasoned about the problem. Having become (un)comfortably used to it, Brazilian economists have always had much to say about inflation and how to live with it as peacefully as it is institutionally and socially possible.

We tried to approach the problems in many ways. We started with the suspicion that something had changed, in the aftermath of stabilization; the way Brazilian economists understood the concept of inflation inertia, when compared to their previous dwellings on the matter in the 1980s (Chapter 7). As we delved deeper into their published papers and reported recollections of those times, we devised a much broader and lengthier strand of reasoning on the long-lived problem of rigidity in inflation patterns, the experience of which revealed a far 
greater geographical diversity than we had anticipated, appearing in many countries with differing ranges of indexation schemes among them (Chapter 1).

However, the voluminous amount of academic material related, in various degrees of proximity, to the problem of inertia gradually imposed constraints to the scope of our analysis. The range of our investigations seemed to expand spontaneously, as academic contemplations on the matter vividly ramified in several directions, under the influence of various contributions coming, sometimes, from unexpected sources. For instance, the connection between advances in operations research and the development of the saw-tooth pattern of nominal incomes under constant non-zero inflation proved quite striking; even more so if we considered it was a rather unorthodox economist, Nicholas Kaldor, who introduced it into the debates on stabilization and growth in Latin America (Chapter 2). The ties between these apparently disconnected fields of research opened up an exciting avenue for future exploratory endeavors into the history of economics in the 1950s, the establishment of mathematical economics and the reactions it invited from various country-specific segments of the economics profession, a point touched upon in Chapter 3 with the bridging contributions by Julio Olivera, Mario Henrique Simonsen and an interesting input by Nicholas Georgescu-Roegen.

It is unfortunate that easily and remotely available historical documentation has been hitherto insufficient to substantiate this interesting hypothesis, the further investigation of which will reveal, we believe, important channels promoting the international diffusion of economic ideas. This latter aspect was tackled throughout our entire narrative in punctuated fashion, and received a much closer assessment on Chapter 4, when we were able to find suggestive similarities between the modeling and reasoning formats put forth by a varied group of neo-Keynesian economists working at MIT, Yale and Harvard - such as Robert Gordon, James Tobin, Arthur Okun, Rudiger Dornbusch, Lance Taylor, among others - and the ones expressed by some of the self-declared heterodox economists engaged in academic debates on inflation, at first, and then as economists in charge of Brazilian stabilization plans in the 1980 s.

These findings narrowed even further our narrative's scope. We decided then to focus one sub-group of the heterodox camp: the neo-structuralist economists at PUC-Rio. Their intellectual trajectories indicated an interesting heterogeneity in terms of methodological claims, of the relative significance ascribed to the numerous determinants of inflation inertia, of modeling and communication strategies - or rhetoric, if it pleases the reader (Chapter 5). 
Notwithstanding this variance within the sample, a more distanced analysis suggested that the group seemed to share a gradual shift toward a more eclectic view of inflation. It was as though they were waving a white flag at previously questioned orthodox-monetarist claims. In this regard, it seemed to us quite well-suited to label this process an ecumenical turn, an expression we borrowed from Boianovsky's (2012) assessment of Celso Furtado's endeavor into policymaking in the 1960s. Our findings, presented in Chapter 6, only allow us to conclude that this second-generation structuralist transformation reflected more of a shift of emphasis than a discontinuity in these economists' intellectual trajectories.

This seemingly parsimonious conclusion reflects a difficulty we faced in gathering historical documentation that could undergird the claims we aimed at making. Contributing to the history of Brazilian economic thought faces daunting challenges, forcing the student of this field to rely on little more than oral communications through interviews or on autobiographical revisions of one's contributions, beyond the usual published works by scholars and information extracted from news media. As is commonly held by intellectual historians, one's perceptions regarding one's past are likely to change with the passage of time. Emphasis moves around and, as a result, the material context of the past gradually succumbs to conclusions reached only later. To use one of Arida's ([1983] 1996) terms, the "multi-textuality of the historical context" collapses into a rationalized and linear view of past events. We tried to avoid, to the best of our effort, the common temptation bedeviling intellectual historians of reading too much into seminal developments of fractions and vague statements of what later came to constitute a full coherent theory.

Our work contributes to the literature in, at least, three ways. First, we pointed out the unexplained change in how Brazilian economists understood the concept of inflation inertia and tied it to a long and wide network of theoretical developments at the international level, highlighting the cross-fertilizations between economics and the mathematics and engineering disciplines. Second, by systematically undertaking the close reading of inflation inertia models in a wider time span than the analyses available did, we stress the analytical dimension with one eye on the intelectuall context of the profession (the rise of mechanical models and the debunking of "sociological" appraisals of inflation) and another on the policyrelated contentions. The available intellectual historical accounts of this period, in most part, emphasize the policy orientation of these theoretical developments in Brazil and, by doing so, understress important connections to intellectual history of the economics discipline and the complex dynamics behind the international diffusion of ideas. 
Third, our work provides evidence of original Brazilian contributions to the understanding of chronically inflationary processes. It speaks to the importance of exercises in the historical reconstitution of economic thought. In this case, we showed how ideas seem to flourish and then fall out of favor, according to changing circumstances and to the balance of power among nations in the real world. This perception enhances the light upon the maxim that all theories are right on their own - if they uphold inernal consistency -, but every so often they turn out to be irrelevant. Therefore, a theory's relevance is both time-dependent and state-contigent.

The history of the concept of inflation inertia reveals that the Brazilian contribution to the general corpus of the economics profession at large is greater than intellectual historians outside Latin America have acknowledged and more modest than some participants in the stabilization debates have once believed. In general, this reflects the limited impact the problem of chronic inflations had on the international academic economics; this latter is frequently - if not constantly - dominated by the academic and policy agendas of developed economies. The reason behind the foundation of CEPAL in 1948 was to attenuate this intellectual dominance from the north. It aimed at opening up space for theoretical considerations of matters reputed endemic to the region; hence it framed a set of problems typically endured only by underdeveloped economies about which the anglo-saxon theory provided little insight.

This Latin American episode in the history of economic thought is inkling of the complexity that involves the transmission of knowledge among (and within) academic networks at the international level. It also speaks to the diversity of the subject of economics and stresses the need to moderate the application of rigorously- and abstractly-built theories to real-world circumstances with the knowledge of bottom-up features of real economic structures. In the end, the implicit message of the rise and decline of the "inertial inflation paradigm" is that history, in all its dimensions, must not be assumed away. 


\section{References}

AKERLOFF, George A. (1969) Relative Wages and the Rate of Inflation. The Quarterly Journal of Economics, Vol. 83, No. 3 (August), pp. 353-374.

. (1980) A theory of social custom, of which unemployment may be one consequence.

The Quarterly Journal of Economics, Vol. 94, n. 3 (June), p. 749-755.

; YELLEN, Janet L.(1985b). The theory of near-rationality and small menu costs with continued shocks. University of California, Berkeley.

ANPEC (1978) Painel sobre conjuntura econômica brasileira e inflação. Estudos Econômicos, v. 8, n.1 p. 153-157.

ARAÚJO, Eurilton; SANTOS, Tatiana Teles. A dinâmica da Inflação Brasileira após o Plano Real In: Insper Working Paper, WPE 054, IBMEC: São Paulo, 2004, p. 1-32.

ARESTIS, P.; SAWYER, M. Inflation Targeting: A Critical Appraisal. Working Paper, The Levy Economics Institute of Bard College, September, 2003.

ARIDA, Pérsio (1981) Reajuste salarial e inflação: uma sugestão de política econômica. IX Encontro Anual de Economia, vol. 4 (ANPEC - Brasília), p. 1485-1514. n.2, Agosto.

. (1982a) Reajuste salarial e inflação. Pesquisa e Planejamento Econômico, v. 12,

. (1982b) Austeridade, Autotelia e Autotomia. Texto para Discussão TD-36, PUC-RJ. September.

. (org.). (1983a). Dívida externa, recessão e ajuste estrutural: o Brasil diante da crise. $3^{\text {a }}$. Ed. Rio de Janeiro: Paz e Terra.

. (1983b) Neutralizar a inflação: uma ideia promissora. Economia e Perspectiva (Boletim do Conselho Regional de Economia de São Paulo), jul. 1983.

. (1991) Comments on Cardoso (1991) In: M. Bruno, S. Fisher, E. Helpman, and N. Liviatan with L. Meridor, eds., Lessons of Economic Stabilization and Its Aftermath, MIT Press, Cambridge, Massachusetts, p. 143-177.

. (1992) Essays on Brazilian stabilization programs. PhD Thesis, MIT. Mimeo.

. ([1983] 1996) A História do Pensamento Econômico como Teoria e

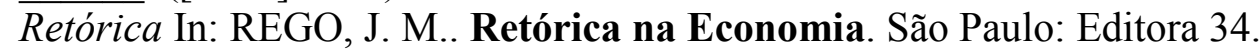

; RESENDE, André. (1985) Inflação Inercial e reforma monetária. In: Inflação Zero

- Brasil, Argentina e Israel, Pérsio Arida e A. Lara-Resende (org), 9-36. Rio de Janeiro: Paz e Terra.

ARNDT, Heinz Wolfgang (1985). The origins of structuralism. World Development, 13.2, pages $151-159$.

ARROW, K. (2002) The genesis of "optimal inventory policy” Operations Research INFORMS, Vol. 50, No. 1, January-February 2002, pp. 1-2

; HARRIS, Theodore; MARSCHAK, Jacob (1950) Optimal inventory policy. Cowles Commission Paper, New Series, n. 44.

. HARRIS, Theodore; SCARF, Herbert. Studies in the mathematical theory of inventory and production .Stanford: Stanford University Press. 
AUJAC, Henri (1950) Inflation as the Monetary Consequence of the Behaviour of Social Groups: A Working Hypothesis. International Economic Papers No. 4 (originally published in French in Economie Appliquée, April/June 1950).

AZARIADIS, Costas (1975) Implicit Contracts and Underemployment Equilibria. The Journal of Political Economy, Vol. 83, No. 6 (Dec., 1975), pp. 1183-1202.

BACHA, E. (1979). Notas sobre inflação e crescimento: um texto didático. Textos para discussão 3, Department of Economics: PUC-Rio.

(1982a). Introdução à macroeconomia: uma perspectiva brasileira. Rio de Janeiro, Campus, 1982. $204 \mathrm{p}$.

(1982b) Resenha bibliográfica 2: Economic stabilization in developing countries.

Pesquisa e Planejamento Econômico, Rio de Janeiro, 12(2), agosto, p. 633-636.

(1983) Por uma política econômica positiva In: Arida, P. Dívida Externa, recessão e Ajuste Estrutural: O Brasil diante da Crise. Rio de Janeiro: Paz e Terra, p.171-180.

(1988) Moeda, inércia e conflito: reflexões sobre políticas de estabilização no

Brasil. Pesquisa e Planejamento Econômico. Vol.18 N. 1, p. 1 a 16, abril.

(1994) O fisco e a inflação: uma interpretação do caso brasileiro. Revista de

Economia Política. Vol.14 N. 1, p. 5 a 17, janeiro-março.

(1998a). O Plano Real: uma avaliação In: MERCADANTE, Aloizio. O Brasil pós-

Real: a política econômica em debate. Campinas, SP: UNICAMP. IE, 1998, p. 11-70.

(1998b). Memória acadêmica. Economia Aplicada, v. 2, n. , p. 197-210.

(2003) Reflexões Pós-Cepalinas sobre Inflação e Crise Externa. Revista de

Economia Política, vol. 23, no 3 (91), julho-setembro, p. 143-150.

; TAYLOR, Lance. (1977). Brazilian income distribution in the 1960's: 'facts', model results and the controversy In: TAYLOR, Lance (1977) Models of growth and distribution in Brazil. Cambridge, Mass.

; LOPES, F. L. (1983) Inflation, growth and wage policy: in search of a Brazilian paradigm. Journal of Development Economics, v. 13 n. 1-2, p. 1-20.

BACKHOUSE, Roger E; BOIANOVSKY, Mauro (2013) Transforming modern macroeconomics: exploring disequilibrium microfoundations: 1956-2003. New York: Cambridge University Press.

BAER, W.; KERSTENETZKY, I. (1964) Inflation and Growth in Latin America. Homewood, Ill.: Irwin.

. (1967). The Inflation Controversy in Latin America: A Survey. Latin American

Research Review, Vol. 2, No. 2 (Spring), pp. 3-25.

BALL, Laurence (1991) The Genesis of Inflation and the Costs of Disinflation. Journal of Money, Credit and Banking, Blackwell Publishing, vol. 23(3), pages 439-52, August.

; CECCHETTI, Stephen G (1988) Imperfect Information and Staggered Price

Setting. American Economic Review, American Economic Association, vol. 78(5), December, p. 999-1018.

; ROMER, David (1989a) The Equilibrium and Optimal Timing of Price Changes.

Review of Economic Studies, Vol. 56 (2), No. 186, (April),pp. 179-198, 
; ROMER, David (1989b) Are Prices Too Sticky? The Quarterly Journal of

Economics, Vol. 104, Issue 3, (August 1989), p. 507-524.

; ROMER, David (1990) Real Rigidities and the Non-Neutrality of Money. Review of Economic Studies, Vol. 57, No. 2, p. 183-203, (April 1990).

BANCO CENTRAL DO BRASIL. Relatório de Inflação. Brasília, v. 14, nº 2, jun. 2012, p. $1-143$.

Relatório de Inflação. Brasília, v. 13, nº 1, mar. 2011, p. 1-151.

BARBOSA, Fernando de Holanda (1979) Curva de Phillips e o modelo de realimentação: será Friedman um neo-estruturalista? - IPEA - Texto para Discussão Interna - n. 05, julho, $16 \mathrm{pp}$.

. (1980) Correção monetária e realimentação inflacionária. Pesquisa e

Planejamento econômico. Rio de Janeiro, 8(3): p. 757-780, dezembro.

. (1983), A Inflação Brasileira no Pós-Guerra: Monetarismo versus Estruturalismo, Rio de Janeiro: IPEA/INPES.

. (1997). A contribuição acadêmica de Mário Henrique Simonsen, Revista de

Econometria, 17(1), 115-130.

. (2004) Inflação: inércia e déficit público, Ensaios Econômicos, FGV, no. 533.

Globo.

. \& SIMONSEN, M.H. (1989) Plano cruzado: inércia x inépcia. Rio de Janeiro:

BARBOSA-FILHO, Nelson (2008) Inflation Targeting in Brazil: 1999-2006. International

Review of Applied Economics, v. 22, n. 2, p. 187-200.

BARRO, Robert J. (1976) Rational expectations and the role of monetary policy. Journal of Monetary Economics, 2, p. 1-32.

BASTOS, Carlos Pinkusfeld Monteiro (2001) Inflação e estabilização. In: Fiori, J. \& Medeiros, C. (eds.). Polarização mundial e crescimento. Petrópolis: Vozes.

. (2002) Price stabilization in Brazil: a classical interpretation for an indexed nominal

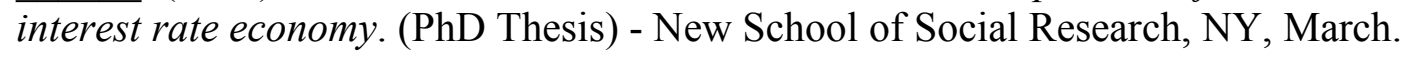

; MELlo NETO, Mario Rubens. (2008) Moeda, Inércia, Conflito, o Fisco e a Inflação: Teoria e Retórica dos Economistas da PUC-RJ. UFRJ -Textos para Discusso 229. Online. Available at: http://www.uff.br/econ/.

BAUMOL, William T. (1967) Macroeconomics of unbalanced growth: the anatomy of urban crisis. The American Economic Review, v. 57, n. 3 (Jun.), p. 415-426.

(1952) The Transactions Demand for Cash: An Inventory Theoretic Ap-proach.

Quarterly Journal of Economics 66 (November 1952), 545-56.

., TOBIN, James (1989) The Optimal Cash Balance Proposition: Maurice Allais.

Journal of Economic Literature, Vol. 27, No. 3 (September), pp. 1160-1162.

BENASSI, Corrado; CHIRCO, Alessandra; COLOMBO, Caterina (1994). The New Keynesian Economics. Cambridge, USA: Blackwell.

BERNANKE, Ben E.; MISHKIN, Frederic S. (1997). Inflation Targeting: A New Framework for Monetary Policy? Journal of Economic Perspectives, American Economic Association, vol. 11(2), pages 97-116, Spring. 
BEVILAQUA, A.; MESQUITA, M.; MINELLA, A. Brazil: taming inflation expectations. Brasília, DF: Banco Central do Brasil, jan. 2007. (Working Paper Series, n. 129). Disponível em: <http://www.bcb.gov.br>.

BIDERMAN, C.; COZAC , L.F.; REGO, J. M.(1996) Conversas com economistas brasileiros. São Paulo: Editora 34.

BIER, A. G., PAULANI, L. \& MESSENBERG, R. (1987). O Heterodoxo e o pós-Moderno: $o$ Cruzado em conflito. Rio de Janeiro: Paz e Terra.

BLANCHARD, Olivier J. (1983) Inflexible Relative Prices and Price Level Inertia, NBER Working Papers 1147, National Bureau of Economic Research, Inc.

(1982a) The Anatomy of Double Digit Inflation in the 1970s In: Inflation: Causes and Effects, edited by Robert E. Hall, pp. 261-282. Chicago: University of Chicago Press, 1982.

. (1982b). Core Inflation by Otto Eckstein: Review. Journal of Political Economy, Vol. 90, No. 6 (Dec., 1982), pp. 1306-1309.

BOGDANSGI, J., TOMBINI, A.A. and WERLANG, S.R. (2000) Implementing Inflation Targeting in Brazil In: Working Papers Series, Banco Central do Brasil, July-2000, pp. 129.

BOIANOVSKY, Mauro (2010). A View from the Tropics: Celso Furtado and the Theory of Economic Development in the 1950s. History of Political Economy, 42:2, Duke University Press, 2012, p. 221-266.

. (2012), Celso Furtado and the Structuralist-Monetarist Debate on Economic Stabilization in Latin America. History of Political Economy, 44:2, Duke University Press, 2012, p. 277-330.

BRAUN, Anne Romanis (1976) Indexation of Wages and Salaries in Developed Economies. Staff Papers (International Monetary Fund), Vol. 23, No. 1 (March), pp. 226-271.

BRECHLING, Frank (1968) The Trade-Off between Inflation and Unemployment, Journal of Political Economy, Vol. 76, No. 4, Part 2: Issues in Monetary Research, 1967 (Jul. - Aug.), pp. 712-737.

BRESSER PEREIRA, L.C. (1989) Da crise fiscal à redução da dívida In: L.C. BresserPereira, (org.) Dívida Externa: Crise e Soluções, São Paulo: Brasiliense.

(1991a) Economic crisis in Latin America: Washington consensus or fical crisis approach? University of Chicago, Department of Political Science, East-South Systems transformation Project, Working Paper 6, January.

. (1991b) Populismo e política econômica no Brasil. In: Bresser Pereira (ORG.).

Populismo econômico: ortodoxia, desenvolvimentismo e populismo na América Latina. São Paulo: Nobel, 1991, p. 107-122.

. (2010) A inflação inercial descoberta. Revista de Economia Contemporânea, 14 (1), janeiro: 167-192.

; NAKANO, Yoshiaki. (1984). Fatores aceleradores, mantenedores e sancionadores

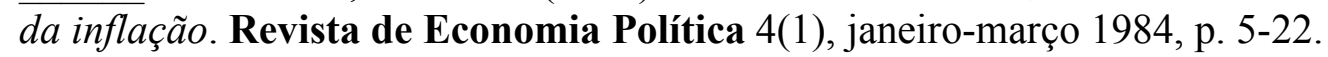

BRONFENBRENNER, Martin; HOLZMAN, Franklyn (1963). Survey of inflation theories. The American Economic Review, Vol. 53, No. 4 (September), pp. 593-66. 
BRUNO, Michael (1993). Crisis, stabilization, and economic reform: therapy by consensus. Oxford and New York: Clarendon Press.

BRUNO, M.; DI TELLA, G.; DORNBUSCH, R.; FISCHER, S. (1988) Inflation

Stabilization: The Experience of Israel, Argentina, Brazil, Bolivia, and Mexico. MIT Press.

BRUNO, M.; FISCHER, S.; HELPMAN, E.; LIVIATAN, N. (1991) Lessons of economic stabilization and its aftermath. Cambridge, Mass.: MIT Press .

; EASTERLY, William (1996). Inflation and growth: in search of a stable relationship. Review, Federal Reserve Bank of St. Louis, issue May, p. 139-146.

CABELLO, Andrea Felippe (2014) Mário Henrique Simonsen e a construção do conceito de inflação inercial. Revista de Economia Política, vol . 34, no 2 (135), abril-junho, p . 317326.

CAGAN, Phillip (1956). The Monetary Dynamics of Hyperinflation. In Friedman, Milton (ed.). Studies in the Quantity Theory of Money. Chicago: University of Chicago Press.

CALVO, Guillermo A. (1978). On the Time Consistency of Optimal Policy in a Monetary Economy. Econometrica. Vol. 46, No. 6 (November), p. 1411-1428.

(1983). Staggered prices in a utility-maximizing framework. Journal of Monetary

Economics, 12 (November), p. 383-398

; Celasun, O., Kumhof, M., (2001). A theory of rational inflationary inertia. In:

Aghion, P., Frydman, R., Stiglitz, J., Woodford, M. (Eds.), Knowledge, Information and Expectations in Modern Macroeconomics: In Honor of Edmund S. Phelps. Princeton University Press, Princeton.

CAMARGO, José Márcio.(1983) Do milagre à crise: a economia brasileira nos anos oitenta. In: Arida, P. Dívida Externa, recessão e Ajuste Estrutural: O Brasil diante da Crise. Rio de Janeiro: Paz e Terra, p. 181-188.

CAMPÊLO, A. K.; CRIBARI-NETO, F. Inflation inertia and 'inliers': the case of Brazil. Revista Brasileira de Economia, v. 57, n.4, p. 713-719, 2003.

CAPLIN, Andrew S.; SPULBER, Daniel F. (1987). Menu costs and the neutrality of Money. Quarterly Journal of Economics 102 (November), p. 703-725.

CAMPOS, Roberto de Oliveira (1962) Two views on inflation in Latin America In: Latin American issues: essays and comments (edited by Albert O. Hirschman). New York: The Twentieth Century Fund, p. 69-79.

CANAVESE, Alfredo J. (1982). The structuralist explanation in the theory of inflation. World Development, Elsevier, vol. 10(7), pp. 523-529, July.

CARDOSO, Eliana (1979) Inflation, growth and the real exchange rate: essays on economic history in Brazil. Unpublished manuscript - Ph.D Thesis. Cambridge, Massachusets, MIT.

. (1980a) Oferta de Alimentos e Inflação. Pesquisa e Planejamento Econômico, v. 10, n.1, p. 46-69, abril, 1980.

. (1980b) Teoria estruturalistas da inflação: um comentário. Pesquisa e

Planejamento Econômico, v.10, n.1, abril, p. 333-340.

. ([1980] 1981a) Food supply and inflation. Journal of Development Economics,

Volume 8, Issue 3, June 1981, Pages 269-284. 
. (1981b) Celso Furtado Revisited: The Postwar Years. Economic Development and

Cultural Change, Vol. 30, No. 1 (Oct.1), pp. 117-128.

. (1981c). Uma Equação para a Demanda de Moeda no Brasil. Pesquisa e

Planejamento Econômico, v. 11, p. 617-636.

. (1983) Indexação e acomodação monetária: um teste do processo inflacionário

brasileiro. Revista Brasileira de Economia, v. 37, n. 1, p. 3-12.

. (1988) Comments on Part IV In: Bruno, M., Di Tella, G., Dornbusch R., Fischer, S.

Inflation stabilization: the experience of Israel, Argentina, Brazil, Bolivia and Mexico.

Cambridge-M: MIT Press, p. 287-294.

. (1991) From Inertia to Mega Inflation: Brazil in the 1980s In: M. Bruno, S. Fisher,

E. Helpman, and N. Liviatan with L. Meridor, eds., Lessons of Economic Stabilization and Its Aftermath, MIT Press, Cambridge, Massachusetts, p. 143-177.

; HELWEGE, Ann (1995). Latin America's Economy: Diversity, Trends, and

Conflicts. MIT Press.

CARLIN, Wendy; SOSKICE, David. (1990) Macroeconomics and the Wage Bargain: A Modern Approach to Employment, Inflation, and the Exchange Rate. Oxford University Press. Press.

. (2006) Macroeconomics: Imperfections, Institutions, and Policies. Oxford University

CARVALHO, Fernando J. Cardim. Reforma monetária, indexação generalizada e o plano de estabilização In: Revista de Economia Política, v. 14, n. 2(54), abril-junho/1994, p. 108-113.

CARVALHO, André Roncaglia (2014) A persistência da indexação no Brasil pós-Real.

Revista de Economia Política, vol . 34, no 2 (135), abril-junho, p. 266-283.

CHENERY, Hollis (1975). The Structuralist Approach to Development Policy. The American Economic Review, v. LXV, n. 2, pp. 310-316.

Press.

. (1979) Structural change and development policy. New York: Oxford University

CHRISTIANO, L.; EICHENBAUM, M.; EVANS, C. Nominal rigidities and the dynamic effects of a shock to monetary policy In: Journal of Political Economy, 113, p.1-45, 2005.

CLARIDA, R., GALÍ, J. and GERTLER, M. (1999). The Science of Monetary Policy: A New Keynesian Perspective, Journal of Economic Literature, 37(4), 1661-1707.

CONTADOR, Cláudio R. (1974). Crescimento econômico e o combate à inflação. Revista Brasileira de Economia, v. 31, n. 1, p. 131-168.

. (1977) O efeito realimentador da correção monetária. Pesquisa e Planejamento econômico. Rio de Janeiro, 7(3): p. 663-680, dezembro.

CRAVEN, Carolyn (1994) A transformation problem: monetarism to structuralism in the Economic Commission for Latin America. History of Political Economy, 26.1: 1-19.

CRIBARI-NETO, F.; CASSIANO, K. Uma análise da dinâmica inflacionária brasileira. Revista Brasileira de Economia, v.59, n. 4, p. 535-566, 2005.

CUNHA, Alexandre Barros (2001) What is Behind the Brazilian Stabilization? Revista

Brasileira de Economia, v. 55, n. 1, p. 133-146.

CUNHA, Patrícia Helena F.. (2006). A estabilização em dois registros. Estudos Econômicos (São Paulo), 36(2), 383-402. 
CUNHA, L.R.C; LEOPOLDI, M.A.; RAPOSO, E. (2013) Dionísio Dias Carneiro, um humanista cético: uma história de formação de jovens economistas. Editora LTC.

DANBY, Colin (2005) Noyola's institutional approach to inflation. Journal of the History of Economic Thought,Volume 27 / Issue 02 / June, pp 161-178.

DAY, A.C.L. (1952) Review of $A$ Study in the Theory of Inflation by Bent Hansen. The Economic Journal Vol. 62, No. 247 (September), p. 609-611.

DE VROEY, Michel (2012). Dead or Alive? The Ebbs and Flows of Keynesianism over the History of Macroeconomics In: T. Cate (ed.), The General Theory: Seventy-five years later, Edward Elgar, pp. 77-102.

DORNBUSCH, Rudiger (1976a) Expectations and Exchange Rate Dynamics. Journal of Political Economy, Vol. 84, No. 6 (Dec., 1976), pp. 1161-1176

(1976b) Exchange rate expectations and monetary policy. Journal of International Economics 6(3), p. 231-244. . (1980) Open economy macroeconomics. Basic Books, New York. ; CLINE, William. (1997) Brazil's Incomplete Stabilization and Reform. Brookings Papers on Economic Activity, Vol. 1997, No. 1, p. 367-404. ; EDWARDS, Sebastian (1989) Macroeconomic Populism in Latin America. NBER Working Paper No. 2986 (Also Reprint No. r1543) - Issued in May, 66p.

; EDWARDS, Sebastian (1990) Macroeconomic Populism. Journal of Development Economics, Vol. 32, pp. 247-277.

; EDWARDS, Sebastian (1992) Macroeconomic Populism in Latin America. Chicago: University of Chicago Press.

; SIMONSEN, Mario Henrique. (1983) Inflation, debt and indexation. Cambridge, Massachussets: MIT Press.

\& SIMONSEN, M.H. (1988) Inflation stabilization: the role of incomes policy and of monetization In: DORNBUSCH, R. Exchange rates and inflation. Cambridge-MA: MIT Press. p. 439-465.

DUARTE, Pedro Garcia. (2010). Not Going Away? Microfoundations in the Making of a New Consensus in Macroeconomics. Department of Economics, FEA-USP - Working Paper, $\mathrm{N}^{\mathrm{o}}$ 2011-02.

(2011). Recent developments in macroeconomics: the DSGE approach to business cycles in perspective. In: John B. Davis; D. Wade Hands. (Org.). The Elgar companion to recent economic methodology. 1 ed. Cheltenham, UK: Edward Elgar,, v. 1, p. 375-403.

DUESENBERRY, James S. (1948) Income - Consumption Relations and Their Implications In: Lloyd Metzler et al., Income, Employment and Public Policy, New York: W.W.Norton \& Company, Inc.

DUESENBERRY, James S. (1949) Income, Saving and the Theory of Consumption Behavior, Cambridge, Mass.: Harvard University Press, 1949.

DUESENBERRY, James (1950) The Mechanics of Inflation. The Review of Economics and Statistics, Vol. 32, No. 2 (May), p. 144-149.

DUTT, A. \& JAMESON, K. (1992) New Directions in Development Economics, Hants (U.K.): Edward Elgar. 
; ROS, Jaime (2003). Development economics and structuralist macroeconomics:

essays in honor of Lance Taylor. Northhampton, MA: Edward Elgar.

ECKSTEIN, Otto (1982) Core Infation. Englewood Cliffs, N.J.: Prentice-Hall, Inc..

EDWARDS, S. (1995). Crisis and reform in Latin America: from despair to hope. Oxford University Press.

ENTHOVEN, Alain (1956) Monetary disequilibria and the dynamics of inflation. The Economic Journal, June.

FASOLO, A. M.; PORTUGAL M. S. Imperfect rationality and inflationary inertia: a new estimation of the Phillips Curve for Brazil. Estudos Econômicos, 34(4): 2004.

FEIWEL, G. (1975) “Kalecki and Keynes”, De Economist, 123 (2): 164-197.

FELIX, David. (1962) An alternative view of the "monetarist"- "structuralist" controversy In: Latin American issues: essays and comments (edited by Albert O. Hirschman). New York: The Twentieth Century Fund, p. 81-93.

FGV. (1974). Ensaios econômicos. Escola de Pós-graduação em Economia - Fundação Getúlio Vargas. Rio de Janeiro: Ed. Expressão e Cultura, 1974, 206p.

FIGUEIREDO, Erik Alencar, MARQUES, André M.. Inflação Inercial como um Processo de Longa Memória: Análise a partir de um Modelo Arfima-Figarch In: Estudos Econômicos, São Paulo, v. 39, n. 2, abril-junho de 2009, p. 437-458.

FISCHER, Stanley. Wage indexation and macroeconomic stability In: Journal of Monetary Economics, 1977.

. (1981a) Indexing and Inflation. NBER Working Paper Series, No. 610, 35 pp.

. (1981b). Relative shocks, relative price variability and inflation. Brookings Papers on Economic Activity, p. 381-431.

. (1986) Indexing, Inflation and Economic Policy. Cambridge, MA: MIT Press.

. (1997) Financial system soundness. Finance \& Development. International

Monetary Fund, vol 34, n.1, March, p. 14-16.

FISHLOW, Albert (1974). Indexing Brazilian style: inflation without tears? Brookings Papers on Economic Activity, pp. 261-282.

FIUZA, Guilherme. 3000 Dias no bunker: um plano na cabeça e um país na mão. Rio de Janeiro: Editora Record, 2010.

FONSECA, Pedro Cesar Dutra. As origens e as vertentes formadoras do pensamento cepalino. Revista Brasileira de Economia, 54 (3), Rio de Janeiro, jul-sept/2000, p. 333-358.

Forder, James. (2010) "Economists on Samuelson and Solow on the Phillips Curve," University of Oxford, Department of Economics, Economics Series Working Papers: 516.

FRAGA NETO, Armínio. Indexation and inflation in Brazil. Textos para discussão - PUCRJ, n. 96, 1985.

FRANCO, G. H. B. (1986) Aspects of the Economics of Hyperinflation: Theoretical Issues and Historical Studies of Four European Hyperinflations, Ph.D. diss.. Harvard University. . (1989) Aspects of the Economics of Hyperinflation: Theoretical Issues and Historical

$\overline{\text { Studies }}$ of Four European Hyperinflations. Weblink: http://www.econ.pucrio.br/gfranco/Ch5.PDF. Acess on 16/03/2013. 
. (1992) Cursos de Economia. Rio de Janeiro: ANPEC.

. (1995) O Plano Real e outros ensaios, Editora Francisco Alves, Rio de Janeiro.

.(2005) Auge e declínio do inflacionismo no Brasil In: Giambiagi, Fabio, André

Villela, Lavinia Barros de Castro e Jennifer Hermann, Economia Brasileira Contemporânea (1945-2004). Elsevier Editora, 2005.

FREITAS, P.S., MINELLA, A., RIELLA, G. Metodologia de cálculo da inércia inflacionária e dos efeitos do choque dos preços administrados. Notas Técnicas do Banco Central do Brasil, Brasília, n. 22, jul-2002, p. 1-14.

FRIEDMAN, Milton. (1963) Inflation: Causes and Consequences. New York: Asia Publishing House.

. (1968) The Role of Monetary Policy. American Economic Review 58: 1-17.

(1974) Monetary correction. In: Essays on inflation and indexation. American Enterprise Institute. p. 25-61.

FRISCH, Helmut (1977) Inflation Theory 1963-1975: A "Second Generation" Survey. Journal of Economic Literature, Vol. 15, No. 4 (December), pp. 1289-1317.

FUHRER, Jeffrey C. (2000) Habit Formation in Consumption and Its Implications for Monetary-Policy Models. American Economic Review, 90(3): 367-390.

. (2006) Intrinsic and inherited inflation persistence. International Journal of Central Banking 2(3): 49-86.

.(2008) Special issue comment on optimal price setting and inflation inertia in a rational expectations model. Journal of Economic Dynamics and Control 32: 2536-2542.

. (2010) Inflation persistence In: Benjamin M. Friedman \& Michael Woodford (ed.), (2010) Handbook of Monetary Economics, Handbook of Monetary Economics, Elsevier, edition 1, volume 3, number 3, January, chapter 9, p. 423-486.

; MOORE, George (1995) Inflation persistence. The Quarterly Journal of Economics, 110 (1): 127-159.

FURTADO, Celso ([1952] 1954). Capital Formation and Economic Development. Translated by J. Cairncross. International Economic Papers 4:124-44.

. (1954). A economia brasileira. Rio: A Noite.

. ([1959] 1963). The Economic Growth of Brazil: A Survey from Colonial to Modern

Times. Translated by R. Aguiar and E. Drysdale. Berkeley: University of California Press.

. ([1962] 1965). Diagnosis of the Brazilian Crisis. Translated by S. Macedo. Berkeley: University of California Press.

. (1976) Economic Development of Latin America: Historical Background and Contemporary Problems, Volume 8, Cambridge Latin American Studies, Cambridge University Press.

. (1985) A Fantasia Organizada. Rio de Janeiro: Editora Paz e Terra.

GABARINO, J.W. (1962) Wage policy and long-term contracts. Brookings Institution, Washington, D.C.

GALLARDO, Julio Lopez; MANSILLA, Ricardo (2007) The Latin American Theory of Inflation and Beyond In: Caldentey, Esteban Perez \& Vernengo, Matias (ed.) Ideas, Policies and Economic Development in the Americas. Taylor \& Francis Group, p. 81-97. 
GEORGESCU-ROEGEN, Nicholas (1968). O Estrangulamento - Inflação Estrutural e o Crescimento Econômico. Revista Brasileira de Economia, v. 22, n. 1, p. 5-14.

. (1970). O impasse da inflação estrutural e o desenvolvimento equilibrado. Revista Brasileira de Economia, v. 26, n. 3, p. 109-146. (Also published in Economies et Societés, PARIS, Cahiers de l'I.S.M.E.A., tome IV, n. 3, p. 557-605, mars 1970, under the title Structural Inflation-lock and Balanced Growth).

GIERSCH, Herbert (1974). Index clauses and the fight against inflation. In: Essays on inflation and indexation. American Enterprise Institute. p. 1-23.

GOODFRIEND, Marvin (2004). Monetary policy in the new neoclassical synthesis: a primer. Economic Quarterly, Federal Reserve Bank of Richmond, issue Sum, pages 21-45.

. (2007). How the World Achieved Consensus on Monetary Policy. Journal of Economic Perspectives, 21(4): 47-68.

; KING, R. (1997) The New Neoclassical Synthesis and the Role of Monetary Policy. In Bernanke, B., Rotemberg, J. (eds.), NBER Macroeconomics Annual 1997. Cambridge: MIT Press, págs. 231-283.

GORDON, Robert J. (1971) Steady Inflation: an exaggerated menace In: The 1971 Midyear Review of the Economy, Hearings before the Joint Economic Committee, 92 Cong. 1 sess.

. (1975), Alternative responses of policy to external supply shocks, Brookings Papers on Economic Activity 6, no. 1, $183-206$

. (1976) Recent developments in the theory of inflation and unemployment. Journal of Monetary Economics, Volume 2 (2), April, p. 185-219.

GRAY, Jo Anna. Wage indexation: a macroeconomic approach In: Journal of Monetary Economics (2), 1976.

GRUNWALD, Joseph (1962). The structuralist school on price stabilization and economic development: the Chilean case. In: Latin American issues: essays and comments (edited by Albert O. Hirschman). New York: The Twentieth Century Fund, p. 95-123.

GUDIN, Eugênio. (1965) Princípios de economia monetária. $1^{\text {o }}$. volume. $5^{\mathrm{a}}$. Edição. Rio de Janeiro.

GUDIN, Eugênio. (1962) Inflation in Latin America In: Inflation, edited by D. C. Hague, 342-58. London: Macmillan.

HABERLER, Gottfried (1974) Inflation as a worldwide phenomenon an overview Weltwirtschaftliches Archiv, June, Volume 110 (2), p. 179-193

HAGGER, A. J. (1961) Bent Hansen's inflation theory. Bulletin of Economic Research, 13(2), p. 95-13.

. (1977) Inflation: theory and policy. NY: MacMillan.

HANES, Christopher (2010) The rise and fall of the sliding scale, or why wages are no longer indexed to product prices. Explorations in Economic History 47, p 49-67.

HANSEN, Bent (1951). A Study in the theory of inflation. Library of Economics, Section II, No. 4, Allen \& Unwin, London.

HARBERGER, Arnold C.(1978) A Primer on Inflation. Journal of Money, Credit and Banking, 10(4), pp. 505-21. 
HARRIS, Seymour E. (1949) In Theory and Recent History. The Review of Economics and Statistics, Vol. 31, No. 3 (Aug., 1949), pp. 200-210.

HEYMANN, Daniel \& LEIJONHUFVUD, Axel (1995). High Inflation. NY: Oxford University Press.

HICKS, John R. (1974). The Crisis in Keynesian Economics. Oxford: Basil Blackwell.

HIRSCHMAN, A. (1958). The strategy of economic development. New Haven and London: Yale University Press.

. (1962) Latin American issues: essays and comments. New York: The Twentieth

Century Fund.

HOLZMAN, Franklyn D. (1950) Income Determination in Open Inflation. The Review of Economics and Statistics, Vol. 32, No. 2 (May, 1950), pp. 150-158.

(1959) Creeping Inflation. The Review of Economics and Statistics, Vol. 41, No. 3 (Aug., 1959), pp. 324-329.

. (1960) Inflation: Cost-Push and Demand-Pull. The American Economic Review, Vol. 50, No. 1 (Mar., 1960), pp. 20-42.

HUMPHREY, Thomas M. (1975) The Persistence of Inflation. Annual Report. Richmond: Federal Reserve Bank of Richmond.

. (1976). Some current controversies in the theory of inflation. Economic Review, Federal Reserve Bank of Richmond, issue Jul, pages 17-24.

. (1997) Fisher and Wicksell on the Quantity Theory. FRB Richmond Economic Quarterly, Vol. 83, No. 4, Fall, p. 71-90.

JOVANOVIC, Boyan (1982). Inflation and Welfare in the Steady State. Journal of Political Economy 90 (3): 561-577.

JULLIARD, Michael ; KAMENIKB, Ondra; KUMHOFC, Michael (2008). Optimal price setting and inflation inertia in a rational expectations model. Journal of Economic Dynamics \& Control, 32 (2008) 2584-2621.

KAFKA, Alexandre (1974) Indexing for inflation in Brazil In: Essays on inflation and indexation. Washington, D.C.: American Entreprise Institute for Public Policy Research, p. 87-98.

KALDOR, N. (1957a) ‘A Model of Economic Growth’, Economic Journal 67(268):591-624. (1957b). Características do desenvolvimento econômico. Revista Brasileira de Economia, March (Also published in Ensayos sobre desarrollo econômico, CEMLA, 1962) . (1957c) "Inflação e desenvolvimento econômico", Revista Brasileira de Economia, 11 (1), August. p. 55-82. . (1957d) "La inflación chilena y la estructura de la producción”, Panorama Económico, 180, November.

. (1959) Economic Growth and the Problem of Inflation. Economica, New Series, Vol. 26, No. 103 (Aug., 1959), pp. 212-226.

. ([1956] 1959). Economic problems of Chile, ECLA, mimeo; also in El Trimestre Economico, April-June 1959.

KALECKI, Michal (1941a) What is inflation? In: Bulletin of the Oxford Institute of Statistics. Vol. 3, n. 8, June $7^{\text {th }}$. 
. (1941b) Inflation, wages and rationing In: The Banker, October.

. (1943) Studies in Economic Dynamics. London: George Allen and Unwin.

. (1954a) Theory of Economic Dynamics. London: George Allen and Unwin.

. (1954b) El problema del financiamento del desarollo económico. EI Trimestre

Económico. Vol. 21, no. 84(4), Octubre-Diciembre, p. 381-401.

. (1971) Selected essays on the dynamics of the capitalista economy: 1933-1970.

London: Cambridge University Press.

. (1956) Teoría de la dinámica económica: Ensayo sobre los movimientos cíclicos y a largo plazo de la economía capitalista. Traducción de Felipe Pazos y Víctor L. Urquidi.

Mexico: Fondo de Cultura Económica.

KANDIR, Antônio (1989) A dinâmica da inflação. São Paulo, Nobel. 180p.

KEYNES, J.M. [1923 (1963)] Essays in Persuasion. New York: W. W. Norton \& Company, Inc.

. [1936 (1964)] The General theory of employment interest and money.

. (1940) How to pay for the war: a radical plan for the Chancellor of the Exchequer.

London: MACMILLAN AND CO., LIMITED.

KINDLEBERGER, Charles (1985). Keynesianism vs. Monetarism and other essays in financial history. London: George Allen \& Unwin.

KING, John. (2009) Nicholas Kaldor Great Thinkers in Economics Series (organized by A.P. Thirlwall). Hampshire, UK: Palgrave \& Macmillan.

KOOPMANS, Tjalling (1942) The Dynamics of Inflation. The Review of Economics and Statistics, Vol. 24, No. 2 (May), p. 53-65.

LAIDLER, David and PARKIN, Michael (1975) Inflation: A Survey. The Economic Journal, Vol. 85, No. 340 (December), pp. 741-809.

LEESON, Robert (1997). The eclipse of the goal of zero inflation. History of Political Economy, 29:3, p. 445-496.

LEFORT, F; SCHMIDT-HEBBEL, K. (2002): Indexation, inflation and monetary policy: an overview In: F Lefort and K Schmidt-Hebbel (eds), Indexation, inflation and monetary policy, Central Bank of Chile.

LEITÃO, Miriam. A saga brasileira: a longa luta de um povo por sua moeda. Rio de Janeiro: Editora Record, 2011.

LEMGRUBER, Antonio Carlos Braga (1977) Ensaios sobre moeda e inflação na RBE.

Revista Brasileira de Economia, v. 31, n. 4, p. 632-556.

. (1978). Uma adaptação do approach monetário do balanço de pagamentos. Revista

Brasileira de Economia, v. 32, n. 1, p. 227-254.

LERNER, Abba (1967) Employment Theory and Employment Policy. American Economic Review 57.2 (May): 1-18.

LIPSEY, Richard G. (1960) The Relation between Unemployment and the Rate of Change of Money Wage Rates in the United Kingdom, 1862-1957: A Further Analysis. Economica, New Series, Vol. 27, No. 105 (February), p. 1-31. 
. (1981) The Understanding and Control of Inflation: Is There a Crisis in MacroEconomics? The Canadian Journal of Economics / Revue Canadienne d'Economique, Vol. 14, No. 4 (Nov., 1981), pp. 545-576.

LITTLE, I. M. D., (1982) Economic Development: Theory, Policy and international Relations. New York: Basic Books.

LOPES, F. L.(1979). Teoria e política da inflação brasileira: uma revisão crítica da literatura. In: SAYAD, João (org.), Resenhas de economia brasileira, São Paulo: Saraiva, 1979.

. (1982) Inflação e nível de atividade no Brasil: um estudo econométrico. Texto para discussão n. 33 , Departamento de Economia, PUC, Rio de Janeiro. (publicado em Pesquisa e Planejamento Econômico v. 12, n. 3, p. 639-670.

.(1984a) Só um choque heterodoxo pode derrubar a inflação. Economia em

Perspectiva (Boletim do Conselho Regional de Economia de São Paulo), August. dezembro.

.(1984b) Inflação inercial, hiperinflação e desinflação. Revista da Anpec, n. 7,

.(1985) Inflação inercial, hiperinflação e desinflação: notas e conjecturas. Revista de Economia Política, v. 5, n. 2, p. 135-151.

. (1986). O Choque Heterodoxo. Rio de Janeiro: Campus.

. (1989). O desafio da hiperinflação. Rio de Janeiro: Campus.

; WILLIAMSON, John. ([1978] 1980) A teoria da indexação consistente. Estudos Econômicos. Rio de Janeiro, 10(3): 61-69, setembro-dezembro.

LOUREIRO, Maria Rita. (2009) Economists in the Brazilian government: from developmentalist state to neoliberal policies In: MONTECINOS,Veronica \& MARKOFF, John. Economists in the Americas. Massachussets: Edward Elgar, pp. 100-141.

MAIA, A.; CRIBARI NETO, F. Dinâmica inflacionária brasileira: resultados de autoregressão quantílica. Revista Brasileira de Economia, v. 60, n. 2, p. 153-165, 2006.

MANKIW, N.G. (1985) Small menu costs and large business cycles: a macroeconomic modelo f monopoly. Quarterly Journal of Economics 100 (May), p. 529-539.

; ROMER, David (org.) (1991a) New Keynesian Economics, vol. 1, Imperfect Competition and Sticky Prices. Cambridge, MA: MIT Press.

; ROMER, David (org.) (1991b) New Keynesian Economics, vol. 2, Coordination Failures and Real Rigidities. Cambridge, MA: MIT Press.

MANTEGA, Guido; REGO, José Marcio (1999) Conversas com Economistas Brasileiros II. São Paulo: Editore 34.

McCLOSKEY, D.N. (1983) The Rhetoric of Economics. Journal of Economic Literature, vol XXI. p. 173-174.

McNELLIS, Paul (1986) Indexing as an instrument for stabilization policy: a survey of theoretical developments and international experience during the past decade. The Helen Kellogg Institute for International Studies, Working Paper n. 75 (August), 56 pp.

McNELLIS, Paul (1988) Indexation and Stabilization: Theory and Experience. The World Bank Research Observer, Vol. 3, No. 2 (Jul., 1988), pp. 157-169. 
MEHRLING, Perry (1990) The evolution of macroeconomics: the origins of Post Walrasian macroeconomics In: COLANDER, D. Beyond Microfoundations. Cambridge University Press, p. 71-86.

METZLER, Lloyd A. (1941) The Nature and Stability of Inventory Cycles. The Review of Economics and Statistics, Vol. 23, No. 3 (Aug., 1941), pp. 113-129.

MIROWSKI, Phillip (1989). More Heat than Light: Economics as Social Physics, Physics as Nature's Economics Cambridge University Press.

MIROWSKI, Phillip (2002) Machine Dreams: Economics becomes a Cyborg Science, Cambridge: Cambridge University Press.

MODIANO, E. (1983a) A dinâmica de salários e preços na economia brasileira: 1966-1981. Pesquisa e Planejamento Econômico, v. 15, n. 1, p. 39-68, 1983.

. (1983b). Choques esternos e preços internos: dificuldades da política de ajuste : In: Arida, P. Dívida Externa, recessão e Ajuste Estrutural: O Brasil diante da Crise. Rio de Janeiro: Paz e Terra, p. 139-153.

. (1985) Salários, preços e cambio: os multiplicadores dos choques numa economia

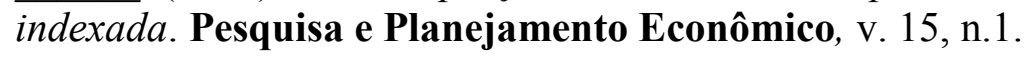

. (1988a) Inflação: inércia e conflito. São Paulo: Campus.

. (1988b) The Cruzado first attempt: the Brazilian stabilization program of february 1986 In: Bruno, M.; Di Tella,G.; Dornbusch, R.; Fischer, S. (1988) Inflation Stabilization: The Experience of Israel, Argentina, Brazil, Bolivia, and Mexico. MIT Press, p. 215-258. MODIGLIANI, Franco (1977) The Monetarist Controversy or, Should We Forsake Stabilization Policies? American Economic Review, American Economic Association, vol. 67(2), pages 1-19, March.

. ([1977] 1986) The debate over stabilization policy. Cambridge, UK: Cambridge University Press.

.; PADOA-SCHIOPPA, Tommaso (1977). La politica economica in una economia con salari indicizzati al 100\% piu, Moneta e Credito, Economia cCvile, vol. 30(117), pages $3-53$.

MOLLO, M. L., SAAD FILHO, Alfredo. Reconhecimento social da moeda: observações sobre a inflação e a estabilização de preços no Brasil In: Revista de Economia Política, v. 21, n.2 (82), abril-junho/2001, p. 24-42.

MORAES, Roberto Camp (1990) Teorias estruturalistas da inflação. Análise Econômica, Ano 8, n.2, Novembro, p. 11-38.

MORGAN, Mary S. (1991) The History of Econometric Ideas. Cambridge University Press. . (2012) The world in the model: how economists work and think. Cambridge University Press, $435 \mathrm{pp}$.

; MORRISON, Margaret (1999) Models as mediators: perspectives on natural and social sciences. Cambridge, UK: Cambridge University Press.

MYRDAL, G. (1957) Economic Theory and Underdeveloped Regions. London: Duckworth. 
NORDHAUS, William D., HOUTHAKKER, Hendrik S. and SACHS, Jeffrey D. (1980) Oil and Economic Performance in Industrial. Brookings Papers on Economic Activity, Vol. 1980, No. 2, pp. 341-399.

NOYOLA, J.F. (1955a) Review of Furtado 1954. Revista Brasileira de Economia, 1, p.19195.

. (1955b) Notas Bibliográficas (Review) de Celso Furtado: A Economia Brasileira: contribuição à análise de seu desenvolvimento. El Trimestre Económico, v. 22, n. 85-88, p. 137-142.

(1956a) El desarrollo economico y la inflacion en Mexico y otros paises

Latinoamericanos. Investigación Económica. 16: 603-48.

(1956b) La evolución del pensamento económico en el último cuarto de sigo y su influencia en la América Latina. El Trimestre Económico. v. 23, n. 3, Julio-Septiembre, p. 269-283.

OECD, 1984. Economic Surveys, France 1983-1984. Paris.

OKUN, Arthur M. (1973) Upward mobility in a high-pressure economy. Brookings Papers on Economic Activity, n. 1, p. 235-252.

. (1975) Inflation: its mechanics and welfare costs. Brookings Papers on Economic Activity, n. 2, p. 351-390.

; (1981) Prices and Quantities: A Macroeconomic Analysis. Washington,D .C.: The Brookings Institution.

; PERRY, George L. (1978) Curing chronic inflation. Washington, D.C.: The Brookings Institution.

OLIVERA, J.H. (1960). La teoria no monetaria de la inflación. El Trimestre Económico. 27: $616-28$.

\section{Economic}

(1964). On structural inflation and Latin-American 'structuralism'. Oxford

Papers 16: 321-32. $\overline{261-66 .}$

(1967a). Aspectos dinámicos de la inflación estrutural. Desarrollo Económico. 7:

(1967b) Money, prices and fiscal lags: a note on the dynamics of inflation, Banca Nazionale del Lavora, Quarterly Review, No. 88 (September).

PAGE, S. A. B.; TROLLOPE, S. (1974). An international survey of indexing and its effects. National Institute Economic Review, number 70, November.

PALLEY, Thomas (2008) The Relative Income Theory of Consumption: A Synthetic KeynesDuesenberry-Friedman Model, Working Paper N. 170 - Political Economy Research Institute (PERI) - University of Massachusetts Amherst, April.

PALMA, J. Gabriel; MARCEL, Mario (1989) Kaldor on the 'discrete charm' of the Chilean bourgeoisie. Cambridge Journal of Economics, 13, p. 245-272.

PARKIN, Vincent (1991). Chronic Inflation in an Industrializing Economy: The Brazilian Experience. Cambridge University Press, May.

PASINETTI, L. (1962), Rate of profit and Income Distribution in Relation to the Rate of Economic Growth, Review of Economic Studies, XXIX (4), October, 267-279. 
PASTORE, Affonso Celso (1969). Inflação e política monetária no Brasil. Revista Brasileira de Economia, v. 23, n. 1, p. 92-123.

PAULANI, Leda M. (1997) Teoria da inflação inercial: um episódio singular na história da ciência econômica no Brasil? In: LOUREIRO, M.R. 50 anos de ciência econômica no Brasil (1946-1996): pensamento, instituições, depoimentos. Petrópolis-RJ: Ed. Vozes, p. 159-179.

PAZOS, F. (1949) Inflation and exchange instability in Latin America, The American Economic Review, 39 (3), Papers and Proceedings: 396-405 253. . (1953) Economic development and financial stability, IMF Staff Papers, 3, (2): 228. (1963) Notas para un Estudio de la Espiral Inflacionaria. El Trimestre Económico, 30. (Also published in FMI-BID-CEMLA, Processo Inflacionario y el caso de America Latina, 1969. Biblioteca Financiera, CEMLA).

. (1969) Medidas para detener la inflación crónica en América Latina, México: Edicones CEMLA.

. (1972) Chronic Inflation in Latin America, New York: Praeger Publishers.

PERRY, George L. (1980) Inflation in Theory and Practice. Brookings Papers Econ. Activity, no. 1, pp. 207-41.

PHELPS, Edmund S. (1967) Phillips Curves, Expectations of Inflation and Optimal Unemployment over Time. Economica, New Series, Vol. 34, No. 135, (Aug., 1967), pp. 254281.

PHELPS, Edmund S.; TAYLOR, John B. (1977) Stabilizing Powers of Monetary Policy under Rational Expectations. Journal of Political Economy, Vol. 85, No. 1 (Feb., 1977), pp. 163-190.

PHILLIPS, A. W. (1950) Mechanical Models in Economic Dynamics. Economica, New Series, Vol. 17, No. 67 (Aug., 1950), p. 283-305.

. (1958) The Relation between Unemployment and the Rate of Change of Money Wage Rates in the United Kingdom, 1861-1957. Economica, New Series, Vol. 25, No. 100 (Nov., 1958), pp. 283-299.

PITCHFORD, J.D. (1957) Cost and Demand Elements in the Inflationary Process. The Review of Economic Studies, Vol. 24, No. 2 (Feb., 1957), pp. 139-148.

POLAK, J. J. (1957) Monetary Analysis of Income Formation and Payments Problems, IMF Staff Papers, 6, issue 1, p. 1-50.

PRADO, Maria Clara do. A real história do Real: a radiografia da moeda que mudou o Brasil. Rio de Janeiro: Editora Record, 2005.

PURVIS, Douglas D. (1982) James Tobin's Contributions to Economics. The Scandinavian Journal of Economics, Vol. 84, No. 1, pp. 61-88.

RADCLIFFE, et al. (1960) Committee on the Working of the Monetary System: Minutes of Evidence. London: HMSO.

RAMALHO, Valdir.(2003) Simonsen: pioneiro da visão inercial da inflação In: Revista Brasileira de economia, 57(1), Rio de Janeiro: janeiro-março/2003, p. 223-238. . (2000) As raízes conceituais do inercialismo. Análise Econômica, 18(33):101-119. 
RANGEL, I. M.(1963) A inflação brasileira. Rio de Janeiro: Tempo Brasileiro. p. $5-25$.

. (1985) Recessão, inflação e dívida externa. Revista de Economia Política, v. 5, n. 3,

RBE (1957) Mesa-Redonda da Associação Econômica Internacional - Agosto de 1957.

Revista Brasileira de Economia, v. 11, n.1, Rio de Janeiro. Available online (downloaded on 11/12/2014): http://bibliotecadigital.fgv.br/ojs/index.php/rbe/issue/view/11-1.

REDDAWAY, W.B. (1997) The changing significance of inflation In: Harcourt, G. \& Riach, P. A. (eds) (1997) The Second edition of the General Theory, Vol. 2, p. 28-40.

REDER, M. W. (1948) The Theoretical Problems of a National Wage-Price Policy. The Canadian Journal of Economics and Political Science / Revue canadienne d'Economique et de Science politique, Vol. 14, No. 1 (Feb., 1948), pp. 46-61.

. (1952) The Theory of Union Wage Policy. The Review of Economics and Statistics, Vol. 34, No. 1 (Feb., 1952), pp. 34-45.

REGO, J. M. R. (Org.). (1986) Inflação Inercial, Teorias sobre Inflação e o Plano Cruzado. 1. ed. São Paulo: Editora Paz e Terra.

. (org.) (1988) A aceleração recente da inflação: a teoria da inflação inercial reexaminada. 1a. ed., v. 1, São Paulo: Editora Bienal.

RESENDE, A. (1979) Incompatibilidade distributiva e inflação estrutural. Texto para discussão n.1, Departamento de Economia, PUC, Rio de Janeiro. (publicado em Estudos Econômicos v. 11, n. 3, p. 133-150, 1981)

. (1982). A política brasileira de estabilização 1963/69. Pesquisa e Planejamento Econômico, vol.12, no.3, p. 757a 806, dezembro.

.(1984) A moeda indexada: uma proposta para eliminar a inflação inercial. Gazeta Mercantil, p. 26-28, September.

. (1985) A moeda indexada: uma proposta para eliminar a inflação inercial. Revista de Economia Política, v. 5, n.2, p. 130-134, 1985.

RESENDE, André Lara ([1989] 1994) From chronic inflation to hyperinflation. Revista Brasileira de Economia, v. 48, n. 4, p. 577-586.

.; LOPES, F. L. ([1979] 1981) Sobre as causas da recente aceleração inflacionária. Texto para discussão n. 6, Departamento de Economia, PUC, Rio de Janeiro. (publicado em Pesquisa e Planejamento Econômico v. 11, n. 3, p.509-616, 1981)

; ARIDA, P. (1985) Inertial inflation and monetary reform. In: WILLIAMSON, JOHN (Org.). Inflation and Indexation: Argentina, Brazil and Israel. Cambridge: MIT Press, 1985. Originally presented at a Conference held in Washington, November.

ROBINSON, Joan (1956) The Accumulation of Capital. London: Macmillan \& Co. Ltd.

ROMER, David (1986). A Simple General Equilibrium Version of the Baumol-Tobin Model. Quarterly Journal of Economics 101 (4): 663-686.

ROS, J. (1984) Propiedades analiticas del modelo in J. Ros (ed.), MODEM: un modelo macroeconómico de la economía mexicana . CIDE; Mexico City.

. (1988) On Inertia, Social Conflict, and the Structuralist Analysis of Inflation.

Helsinki: WIDER. 
(2000). Development theory and the economics of growth. Ann Arbor, MI:

University of Michigan Press.

ROWTHORN, Robert (1977) Conflict, inflation and money. Cambridge Journal of Economics, v.1, n.3, p. 215-239.

SACHS, Jeffrey D. (1979), "Wages, Profit, and Macroeconomic Adjustment: A Comparative Study," Brookings Papers on Economic Activity, 2: 1979, 269-319.

SAMUELSON, P. A. \& SOLOW, R. M. (1960) Analytical aspects of anti-inflation policy. American Economic Review 50 (2): 177-194

SARDENBERG, C. A. (1987). Aventura e agonia: nos bastidores do cruzado. Sao Paulo.Companhia das Letras.

SARGENT, Thomas J. (1982) The Ends of Four Big Inflations. NBER Chapters, in: Inflation: Causes and Effects, pages 41-98 National Bureau of Economic Research, Inc.

SCHULTZE, Charles L. (1959) Recent inflation in the United States, Study Paper No. 1 for the Joint Economic Committee of Congress, Washington, 1959.

SCHULTZE, Charles L. (1981) Some Macro Foundations for Micro Theory. Brookings

Papers Econ. Activity, no. 2, pp. 521-76.

SEERS, Dudley.(1962) A Theory of Inflation and Growth in Under-Developed Economies Based on the Experience of Latin America. Oxford Economic Papers, New Series, Vol. 14, No. 2 (June), pp. 173-195.

SEGURA-UBIERGO, Alex (2012). The Puzzle of Brazil's High Interest Rates. No. 12-62. International Monetary Fund.

SERRANO, F. (1986), Inflação Inercial e Desindexação Neutra In: J.M. Rego (ed.), Inflação Inercial: Teorias sobre Inflação e o Plano Cruzado, Rio de Janeiro: Paz e Terra. .(2010) O conflito distributivo e a teoria da inflação inercial In: Revista de Economia Contemporânea, Rio de Janeiro, v. 14, n. 2, p. 395-421, may/aug.

SHESHINSKI, Eytan \& WEISS, Yoram (1977). Inflation and costs of price adjustment. Review od Economic Studies, v. 54, p. 287-303.

; WEISS, Yoram (1983). Optimum pricing policy under stochastic inflation. Review of Economic Studies, v. 50, p. 513-529.

SILVA, Adroaldo Moura da (1981) Inflação: reflexões à margem da experiência brasileira. Revista de Economia Política. São Paulo: Ed. 34. - 1(3), p. 57-81.

SIMKIN, C.G.F. (1952) Notes on the Theory of Inflation, The Review of Economic Studies, Vol. 20, No. 2 (1952 - 1953), pp. 143-151

SIMONSEN, M.H.(1964) A experiência inflacionária no Brasil. Estudo IPES/GB. . (1970a) Novos aspectos da inflação brasileira. Estudo ANPES, n. 19, 1970.

Simonsen, M. H. (1970b). Inflação: Gradualismo x Tratamento de Choque. Apec, Rio de Janeiro.

. (1974) A nova economia brasileira. Rio de Janeiro: José Olympio.

. (1980) A teoria da inflação e a controvérsia sobre a indexação. Estudos

Econômicos. Rio de Janeiro, 10(2): 5-55, maio-agosto.

. (1983a) Dinâmica macroeconômica. São Paulo: McGraw Hill do Brasil. 
. (1983b) Price stabilization and income policies: Theory and the Brazilian case study. In Dornbusch, Rudiger \& Simonsen, M. H., editor, Inflation, Debt and Indexation. MIT Press, Cambridge.

. (1984) Desindexação e reforma monetária. Conjuntura Econômica, V. 38, n. 11, Novembro. Rio de Janeiro: Fundação Getúlio Vargas, p. 101-105.

. (1985), Contratos salariais justapostos e política anti-inflacionária, Revista de Econometria, 5(2), 5-32.

. (1986), Rational Expectations, Income Policies and Game Theory, Anais do XIV Encontro Nacional de Economia, ANPEC.

. (1988a) Price stabilization and incomes policy: theory and the Brazilian case study In: Bruno, M., Di Tella, G., Dornbusch R., Fischer, S. Inflation stabilization: the experience of Israel, Argentina, Brazil, Bolivia and Mexico. Cambridge-M: MIT Press, p. 259-286.

. (1988b), Rational expectations, game theory and inflationary inertia, In:

ANDERSON, P.W., ARROW, K.J. e PINES, D. (orgs.), The Economy as an Evolving Complex System, Vol.5, Santa Fe: Santa Fe Institute.

. (1989) Inércia inflacionária e inflação inercial In: Simonsen \& Barbosa (1989), p. 354.

. (1995) 30 anos de indexação. Rio de Janeiro: Editora FGV.

; CAMPOS, Roberto Oliveira. (1975) Formas criativas de desenvolvimento. Rio de Janeiro: APEC Editora.

; BARBOSA, F.H. (1989) Plano Cruzado: Inércia vs. Inépcia. Rio de Janeiro: Globo.

SINGER, Paul. (1988) Inflação e mercado como sistemas alternativos de regulação In:

Estudos Avançados (USP), vol.2 no.3, p. 77-87.

SLITOR, Richard E. (1978) Tax-based incomes policy: concept and rationale. Proceedings of the Annual Conference on Taxation Held under the Auspices of the National Tax Association-Tax Institute of America, Vol. 71, p. 67-73.

SMITHIES Arthur (1942) Process Analysis and Equilibrium Analysis. Econometrica, Vol. 10, No. 1 (Jan., 1942), pp. 26-38.

. (1957) The Control of Inflation. The Review of Economics and Statistics, Vol. 39, No. 3 (Aug., 1957), pp. 272-283

SNOWDEN, Nicholas (2011) Inflationary price stability and the Great Crash: an early analysis reconsidered. Cambridge Journal of Economics 2011, 35, 921-936

SOLOW, Robert (1986) Unemployment: Getting the Questions Right. Economica, New Series, Vol. 53, No. 210, Supplement: Unemployment, pp. S23-S34.

SUNKEL, Osvaldo (1958) La inflación chilena: un enfoque heterodoxo. El Trimestre Económico.

SZMRECSÁNYI, Tamás; COELHO, Francisco da Silva (org.) (2007) Ensaios de História do Pensamento Econômico no Brasil Contemporâneo. São Paulo: Atlas

TAVARES, M. C. e BELLUZZO, L. G. ([1984] 1986) Uma reflexão sobre a natureza da inflação contemporânea. Revista do Instituto de Economia Industrial, UFRJ, dezembro de 
1984. Republished in: REGO, J. M., org. (1986) Inflação Inercial, Teorias sobre Inflação e o Plano Cruzado. Rio de Janeiro, Paz e Terra.

TAYLOR, John B. (1979) Staggered Wage Setting in a Macro Model. The American Economic Review. Vol. 69, No. 2, Papers and Proceedings of the Ninety-First Annual Meeting of the American Economic Association (May, 1979), pp. 108-113. . (1980) Aggregate Dynamics and Staggered Contracts. Journal of Political Economy, Vol. 88, No. 1 (Feb., 1980), pp. 1-23.

. (1981) Stabilization, Accommodation, and Monetary Rules. The American

Economic Review, Vol. 71, No. 2, Papers and Proceedings of the Ninety-Third Annual Meeting of the American Economic Association (May, 1981), pp. 145-149.

TAYLOR, Lance (1974). Short-term policy in open semi-industrialized economies: the narrow limits of the possible. Journal of Development Economics Volume 1, Issue 2, September 1974, Pages 85-104.

. (1979) Macro Models for Developing Countries. New York: McGraw-Hill.

(1983) Structuralist macroeconomics. New York: Basic Books.

(1988) Varieties of stabilization experience: towards sensible macroeconomis in the third world. Oxford, Clarendon Press.

. (1989) Stabilization and growth in developing countries: a structuralist approach. (Fundamentals of pure and applied economics, volume 29) Economic development studies section. Chur, Switzerland: Harwood Publishers.

. Reconstructing macroeconomics: structuralist proposals and critiques of the mainstream. Harvard University Press, 2004.

; BACHA, Edmar (1976). The unequalizing spiral: a first growth model for Belindia. Quarterly Journal of Economics, 90 (2), may, p. 197-218.

; BACHA, Edmar, CARDOSO, Eliana, LYSY, Frank (1980) Models of Growth and Distribution for Brazil. New York: Oxford University Press, 355p.

TEJADA, C.; PORTUGAL, M. (2001) Credibilidade e inércia inflacionária no Brasil: 19861998. Estudos Econômicos, v. 31, n. 3, july-september, p. 459-494.

TOBIN, James (1956) The Interest-Elasticity of Transactions Demand for Cash. Review of Economics and Statistics ,38 (August), 241-47.

(1961) Money, Capital, and Other Stores of Value. The American Economic Review, Vol. 51, No. 2, Papers and Proceedings of the Seventy-Third Annual Meeting of the American Economic Association (May, 1961), pp. 26-37Published

. (1970) The Wage-Price Mechanism : Overview of the Conference In: The

Econometrics of Price Determination. Conference sponsored by Board of Governors of the Federal Reserve System and Social Science Research Council. Washington, D. C., October 30-31.

. (1980a). Stabilization Policy Ten Years After. Brookings Papers on Economic

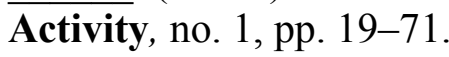

. (1980b) The Monetarist Counter-Revolution Today-An Appraisal.The Economic Journal, Vol. 91, No. 361 (Mar., 1981), pp. 29-42 
. (1981) Diagnosing inflation: a taxonomy. In: FLANDERS, M. \& RAZIN, Assaf (orgs.). Development in an Inflationary World. New York: Academic Press, pp. 19-30.

; ROSS, Leonard. (1971) Living with Inflation. New York Review of Books, Vol. 16

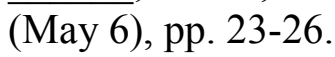

TOMBINI, A. S.; ALVES, S. A. L.(2006) The recent Brazilian disinflation process and costs. Central Bank of Brasil, June, (Working Paper Series, n. 109).

TOYE, John (1987). Varieties of Stabilization Experience: A Comment, Brighton: Institute of Development Studies, University of Sussex.

TURVEY, Ralph (1949) Period Analysis and Inflation. Economica, New Series, Vol. 16, No. 63 (Aug., 1949), pp. 218-227.

TURVEY, Ralph (1951) Some Aspects of the Theory of Inflation in a Closed Economy. The Economic Journal, Vol. 61, No. 243 (Sep., 1951), pp. 531-543

VALOR ECONÔMICO (2012) Indexação ainda afeta 38\% da inflação. Reportagem de 06/07/2012. Online. Disponível em: http://www.valor.com.br/brasil/2740704/indexacaoainda-afeta-38-da-inflacao\#ixzz228MjwydB. Access on July 7th 2012.

VIANNA, Pedro Jorge Ramos. (1984) Inflação vs. indexação: uma contribuição ao tema. Fortaleza, FIEC/IEL.

VERA, Leonardo. (2005). Can recession feed inflation? a conflicting claims framework. Review of Political Economy, Volume 17, Number 4, 1-19, October.

VERA, Leonardo. (2013a) A note on the Pazos-Simonsen mechanism and Kaldor's early research on Latin American inflation. Brazilian Journal of Political Economy, vol. 33, $\mathrm{n}^{\circ} 2$ (131), pp. 260-280, April-June.

VERA, Leonardo (2013b) Inflación estructural redux. Banco Central de la Republica Argentina Ensayos Económicos 69 , Diciembre, p. 37-99.

Weintraub, E. Roy (1991). Stabilizing Dynamics: Historical Perspectives on Modern Economics. Cambridge: Cambridge University Press.

. (1999) How should we write the history of twentieth-century economics? Oxford Review of Economic Policy, vol. 14, n.4, p. 139-152.

(2002) How Economics Became a Mathematical Science. Durham, NC/London: Duke University Press.

WERLANG, Sérgio Ribeiro da Costa (1998) Simonsen, inflação, expectativas racionais e os pós-keynesianos. Revista Brasileira de Economia, v. 52, Edição Especial, p. 161-166.

WILES, Peter (1973). Cost Inflation and the State of Economic Theory. The Economic Journal, Vol. 83, No. 330 (June), pp. 377-398.

WHITIN, Thomson M. (1952) Inventory Control in Theory and Practice. Quarterly Journal of Economics, n. 66 (November), 502-21.

WHITIN,Thomson M. (1953) Theory of Inventory Management. Princeton, NJ: Princeton University Press.

WOODFORD, Michael (2003) Interest and Prices: Foundations of a Theory of Monetary Policy. Princeton: Princeton University Press.

- (2009) Convergence in Macroeconomics: Elements of the New Synthesis. American

Economic Journal: Macroeconomics, 1(1): 267-79. 